\title{
Preliminary Design and Economic Investigations of Diffuser Augmented Wind Turbines (DAWT)
}

\section{Final Report}

\author{
K. M. Foreman
}

Research Department Grumman Aerospace Corporation Bethpage, New York 11714

December 1981

Performance Period: May 15, 1979 to March 31, 1980

Prepared Under Subcontract No. XH-9-8073-1

Solar Energy Research Institute

A Division of Midwest Research Institute

1617 Cole Boulevard

Golden, Colorado 80401

Prepared for the

U.S. Department of Energy

Contract No. EG-77-C-01-4042

Technical Monitor: Richard Mitchell 


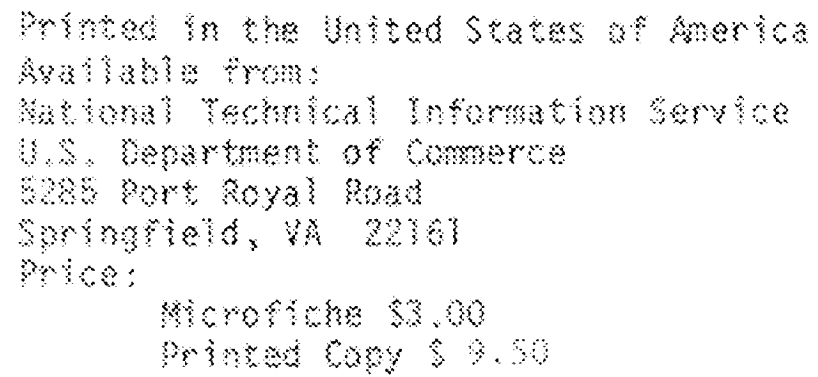

\section{Mone}

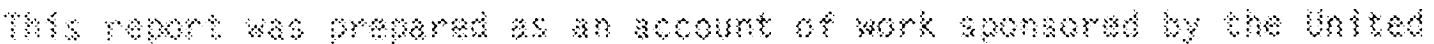

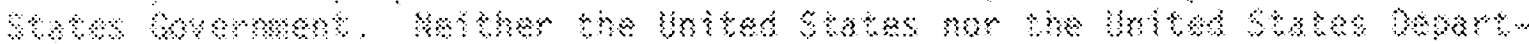

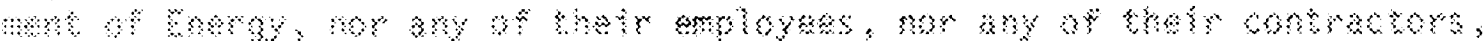

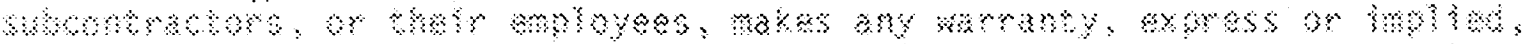

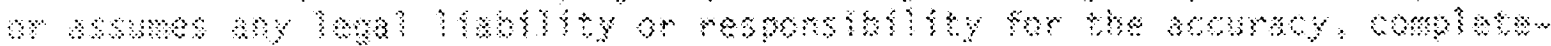

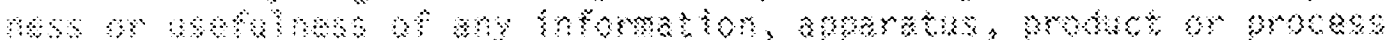

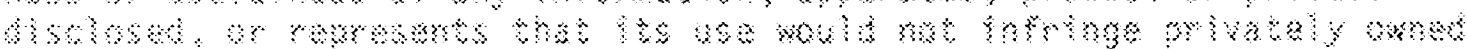
miss. 


\section{FOREWORD}

The Solar Energy Research Institute (SERI), a Division of the Midwest Research Institute, has been authorized by the U.S. Department of Energy to provide technical management services for the Wind Energy Innovative Systems (WEIS) program. The focus of the WEIS program is to assess the technical and economic feasibility of innovative concepts and systems. A large number of these concepts have potential merit. Therefore, a critical examination of their technical and economic attributes will provide guidance and direction for future WEIS efforts.

This report summarizes work prepared by Grumman Aerospace Corporation, Bethpage, New York for SERI, Golden, Colorado under Subcontract XH-9-8073-1. The SERI Technical Monitor was Mr. Richard Mitchell.

The objective of this research effort was to establish by preliminary design and manufacturing trade-off studies the economic feasibility of the Diffuser Augmented Wind Turbine (DAWT) concept. The results suggest that fiberglass reinforced plastics construction of the diffuser could lead to attractive and competitive cost of electrical generation for the small (5-200 kW) rated output wind energy conversion system range. 


\section{PREFACE}

This investigation was supported by the Solar Energy Research Institute under Subcontract XH-9-8073-1. The author thanks Dr. Irwin Vas, SERI, for his support and guidance. In a work of such diversity and detail as is evidenced by this report, no one individual could originate all the factual material. While the author bears sole responsibility for the presentation and conclusions derived from these facts, he accords recognition for the special help and contributions of Conroy Betts, Ed Brazill, Bruce Collemer, Norman Flinn, Dr. Barry Gilbert, Paul Henton, Gordon Hudson, Walt Ivanoff, Dr. Leslie Karafiath, Dr. Richard Oman, and David J. Seymour. Finally, we acknowledge and thank William Golchas for the preparation of illustrations and tabTes and Lee Lucas and Judy Simins for typing the manuscript. 
SUMMARY

The Diffuser Augmented Wind Turbine (DAWT) is an innovative approach under investigation since 1975. Its goal is to improve the life cycle economics of wind energy conversion. Through the use of a unique compact diffuser, the volumetric flow processed by the turbine is much greater than conventional rotors of the same diameter and more natural wind power is converted at the same free wind speed. However, the diffuser structure is an economic burden that potentially can offset the technical performance gains of the concept. To prevent this from occuring, careful attention must be accorded the design and manufacturing approaches of the diffuser and its supporting structure to assure low enough costs to retain attractive overall system prospects.

This report covers work conducted under SERI Contract XH-9-8073-1 to explore system engineering design alternatives and to determine preliminary cost and energy output of cost effective DAWTs.

For each of three DAWT physical sizes, three materials of construction approaches were taken within the scope of a preliminary design effort as shown by the schematic procedure of Fig. 1. Diffuser structures made of aluminum, fiberglass-reinforced plastics sandwich (FRP) and ferrocement were designed to common criteria by three teams, each of which were specialists in their particular medium. In addition, each team developed a production approach and a production costing estimate with about $10-15 \%$ accuracy. Extrapolations of these design point costs to other diffuser design configurations and expansion area ratios were developed based on costing rules recommended by the study teams.



Figure 1. DIFFUSER COSTING PROCEDURE 
The conclusions of this preliminary engineering study are that the best overall design approach for the DAWT's diffuser is of a hybrid, fiberglass sandwich skin mounted on an aluminum frame. (Ferrocement also is a viable approach but is 1 imited by current technology to diffuser sizes under $12.2 \mathrm{~m}$ $(40 \mathrm{ft})$ maximum diameter).

A production approach for cost effective DAWT systems in the 5-150 kW rating range would be to fabricate transportable subassemblies at production centers within marketing regions of $300-400 \mathrm{~km}$ (185-250 mile) radii.

These factory-built major components are then to be shipped to installation sites for final assembly and erection onto pre-prepared foundations of reinforced concrete. Typical locations for appropriate production centers are Wichita, Kansas, and Oklahoma City, Oklahoma. Our cost estimates presented here reflect the regional labor and material indices of these candidate production centers during 1979.

Using performance measured during prior wind tunnel test phases in which DAWT models having an $.46 \mathrm{~m}$ ( $18 \mathrm{in.}$ ) diameter turbine were investigated, three rating sizes of DAWTs with rotor diameters of $2.7,6.9$, and $11 \mathrm{~m}(9,22.5$ and $36 \mathrm{ft}$ ) have been established for candidate point designs. The rotor has been assumed to use a low cost, untapered, untwisted, extruded aluminum blade design as incorporated in a present conventional wind turbine unit.

Each of the three rotor diameters have been rated on the basis of a realistic assessment of generator and gear box availability at lowest cost and highest reliability compatible with rating wind speeds and annual distribution spectra of wind speed. As shown by Table 1, this results in ratings between 11 and $150 \mathrm{~kW}$; the potentially available wind energy is computed from an assumed Rayleigh distribution of wind speed occurrence, installation site annual average wind speed $(\bar{V})$ of $25.7 \mathrm{~km} / \mathrm{h}(16 \mathrm{mph})$, cut-in speed of $9.7 \mathrm{~km} / \mathrm{h}$ $(6.0 \mathrm{mph})$, and cut-out speed of $64.3 \mathrm{~km} / \mathrm{h}(40 \mathrm{mph})$. Representative possible installed selling prices (within 10 - 15\% accuracy) for the representative three DAWT power ratings in limited production lots of approximately 100 to 500/yr are in 1979 dollars:
a) $11 \mathrm{~kW}-\$ 18,000$ to $\$ 20,000$
b) $60 \mathrm{~kW}-\$ 65,000$ to $\$ 70,000$
c) $150 \mathrm{~kW}-\$ 140,000$ to $\$ 150,000$

Table 1 DAWT RATING \& ROTOR SIZE MODELS

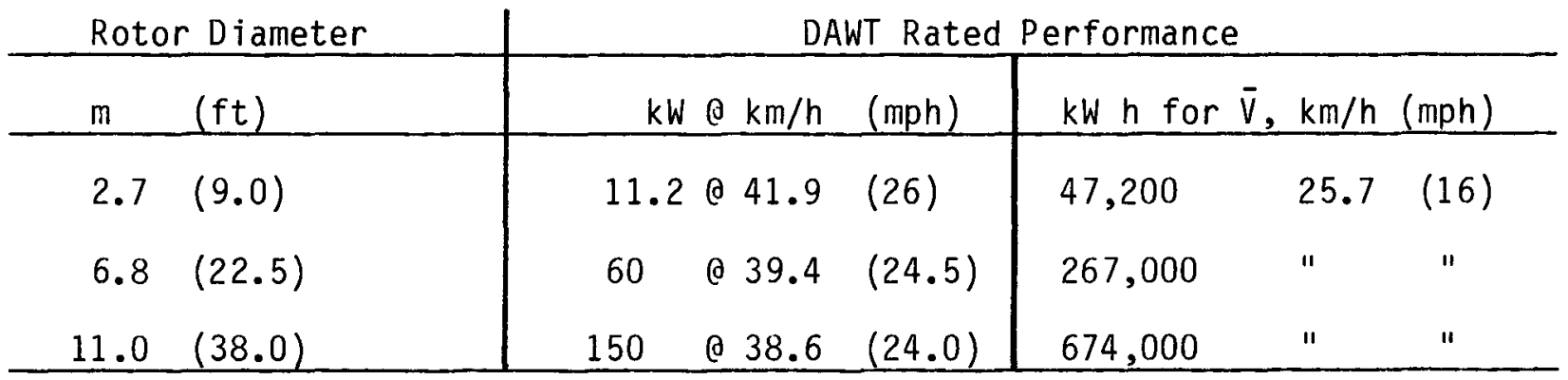


Using the DoE calculation method, the busbar cost of electricity (COE) generated by these DAWTs is between about 2.0 and 6 cents per $\mathrm{kW} \mathrm{h}$ in the 150 $\mathrm{kW}$ rating range and between about 4 and 10 cents per $\mathrm{kW} h$ in the $11 \mathrm{~kW}$ rating range for typical end users of these power units and sites with annual average wind speeds of 16 to $12 \mathrm{mph}(25.7$ and $19.3 \mathrm{~km} / \mathrm{h})$ respectively.

These DAWT COE estimates in 1979 dollars are compared to goals established by the DoE in 1978. Without accounting for inflationary effects between the 1978 and 1979 dollars, or tax incentives, commercial end users of the DAWT would incur lower COE expenses than the DoE goals for limited production conditions at virtually all ratings up to $200 \mathrm{~kW}$. For farmer applications, the DAWT provides lower COE at all ratings greater than about $40 \mathrm{~kW}$. With more refined rotor design for negligible cost increments, the DAWT's COE has the potential of extending the superiority over the DoE 1978 goals for all power ratings. The differences between DAWT and DoE cost trends provide margin to devise marketing and pricing strategies to stimulate manufacturing investment and accomodate changing market conditions. Therefore, the DAWT appears to provide the potential for broader market penetration than possible with planned improvements or refinements of conventional wind turbine systems.

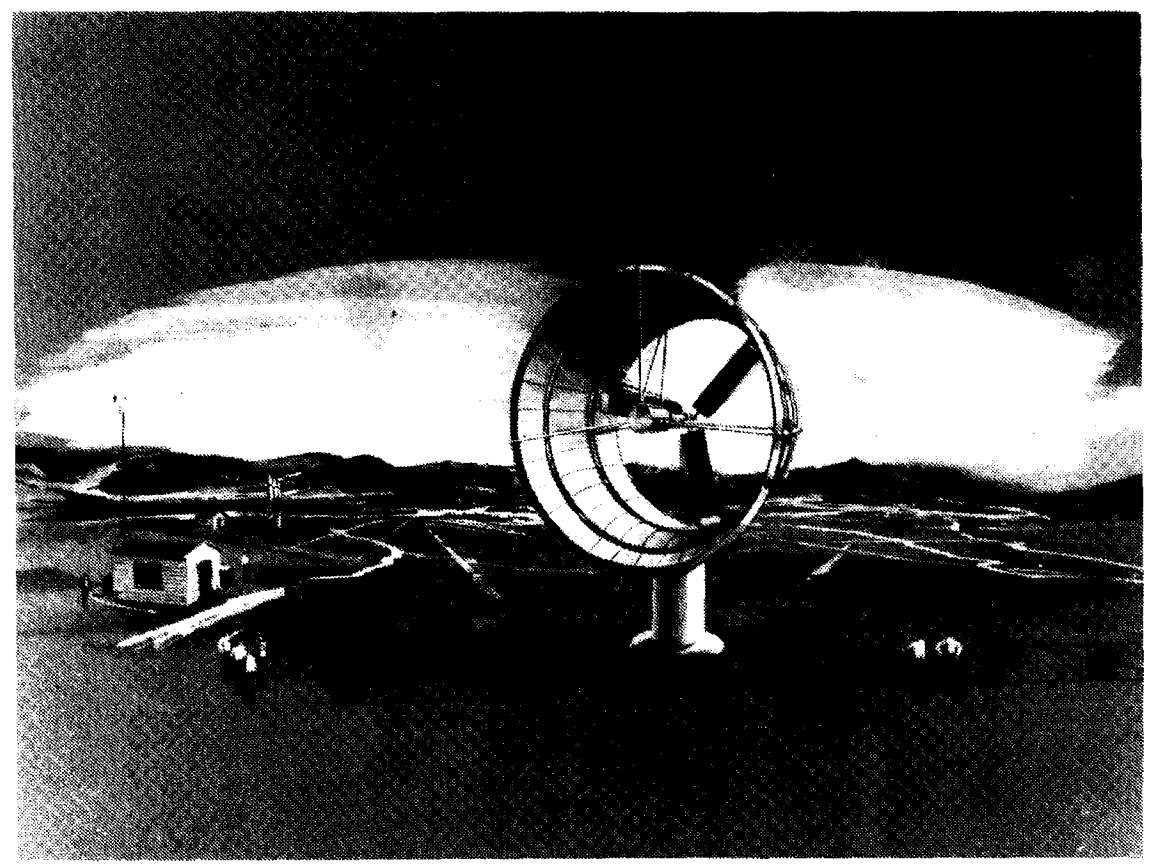

Conceptual Installation of Two DAWTs with a $5.5 \mathrm{~m}$ (18 ft) Diameter Turbine 
TABLE OF CONTENTS

Page

Foreword ........................ . . . .

Summary. . . . . . . . . . . . . . . . . . . . . vii

Table of Contents........................ xi

List of figures...................... xiji

List of Tables...................... $x v$

Nomenclature List. ................... xvi

1.0 Introduction ........................ 1

2.0 DAWT Design. . . . . . . . . . . . . . . . 3

2.1 Sizing and Rating ................. . . 3

2.2 Descriptions. . . . . . . . . . . . . . . 11

2.3 Loads and Design Criteria . . . . . . . . . . 12

2.3.1 Aluminum Construction. ........... 12

2.3.2 Ferrocement Construction ............ 18

2.3.3 Fiberglass Reinforced Plastics (FRP) Construction. . . 22

2.3.4 Foundation Design.............. 26

2.4 Weight Estimate ................ 28

2.5 Turbine Design. . . . . . . . . . . . . 32

2.6 Ice and Snow Loads. . . . . . . . . . . . . 36

3.0 Manufacturing Approach and Costing ............. 39

3.1 Application Scenario. . . . . . . . . . . . 39

3.2 Manufacturing Considerations. . . . . . . . . 42

3.2.1 Ferrocement. ................. 43

3.2.2 Fiberglass Reinforced Plastics (FRP) ........ 44

3.2.3 All Aluminum Design. ............ 47

3.3 Costing ............................ 51

3.3.1 General Assumptions. ............ 51

3.3.2 Labor Rates................. 53

3.3.3 Production Quantity Effects........... 53

3.3.4 Cost/Pricing Analysis............. 54

3.3.5 Price Per Pound. ............. 60

4.0 Busbar Cost of Electricity . . . . . . . . . . . . 65

4.1 Wind Energy Potential . . . . . . . . . . 67 
TABLE OF CONTENTS (continued)

Page

4.2 Annual Charge Factor. . . . . . . . . . 68

4.3 Operations and Maintenance. . . . . . . . . 68

4.4 Salvage Value ........................... 68

4.5 Busbar Cost of Energy ............... 71

4.6 Comparison to DoE Goals . . . . . . . . . . 72

5.0 Summary and Recommendations. . . . . . . . . . . 77

5.1 Summary ................... 77

5.2 Atmospheric Testing Model ............. 78

5.3 Recommendations ................... 79

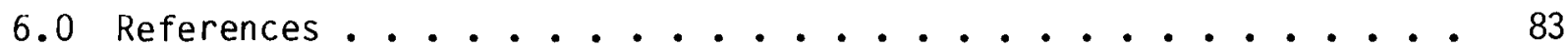

Appendix A - Ferrocement Diffuser Study . . . . . . . . . . . A-1

Appendix B - Preliminary Stress Analysis. . . . . . . . . . B-1

Appendix C - Investigation of FRP DAWTS . . . . . . . . . . C-1

Appendix D - Details of Foundations for DAWTs . . . . . . . . . D-1 
LIST OF FIGURES

Page

2-1 Diffuser Costing Procedure . . . . . . . . . . . . 4

2-2 Basic Factors Affecting DAWT Evaluation. . . . . . . . . 5

2-3 Theoretical Peak DAWT Augmentation Ratio vs Diffuser Area Ratio. . 7

2-4 Relative Cost (Based on Diffuser Surface Area) of Different DAWT

Diffuser Designs .................. 8

2-5 Theoretical Variation of DAWT Utility Index with Diffuser Area

Ratio..................... 10

2-6 Comparison of Basic Lines of Baseline and Dump Diffuser Designs. • 13

2-7 Estimated Axial Variation of Basel ine DAWT Internal Static Pressure ................... 15

2-8 DAWT Static Pressure Profile for Maximum Design Loading. . . . . 16

2-9 DAWT Static Pressure Profile for Maximum Design Loading

(Cylindrical Section). . . . . . . . . . . . . 17

2-10 Structural Hinge at Base of Column for Diffuser Erection . . . . 19

2-11 Typical Final Assembly and Erection of Diffuser. . . . . . . 20

2-12 Typical DAWT Design in Aluminum. . . . . . . . . . . . 21

2-13 Typical Ferrocement Design . . . . . . . . . . . 23

2-14 Typical Fiberglass Reinforced Plastics Sandwich Construction with End Grain Balsa Wood Core. . . . . . . . . . . . 24

2-15 Typical FRP Panel Joint Construction . . . . . . . . . 25

2-16 Relative DAWT Characteristics for Three Construction Approaches. . 30

2-17 Typical DAWT Turbine Assembly for $22.5 \mathrm{ft}$. Rotor Diameter. . . • 35

2-18 Typical Theoretical Performance for DAWT . . . . . . . . . 37

3-1 Casting Ferrocement Segments for DAWT Structure. . . . . . . 45

3-2 Shipping and Erection of DAWT Structure Made of Ferrocement. . . 46

3-3 Typical Truck Shipment Arrangement . . . . . . . . . . . 48 


\section{LIST OF FIGURES (continued)}

Page

4-1 1979 DAWT Projected COE Estimates vs. 1978 DoE Goals (Limited Production, Commercial User) . . . . . . . . . . 75

4-2 1979 DAWT Projected COE Estimates vs. 1978 DoE Goals (Limited Production, Farmer User) . . . . . . . . . . . . 75 


\section{LIST OF TABLES}

$\underline{\text { Page }}$

2-1 Three DAWT Study Models. . . . . . . . . . . . 6

2-2 Baseline Diffuser Dimensions .................... 9

2-3 Summary of Wind Loads and Moments on Baseline DAWT . . . . . . 14

2-4 Weight Comparison of 3 DAWT Sizes. . . . . . . . . . . 29

2-5 Weight Comparison of 3 DAWT sizes.............. 33

3-1 Representative 1979 Regional Construction Cost Indices . . . . 40

3-2 General Contractor Financial Assumptions . . . . . . . . 52

3-3 Estimated Cost Analysis - DAWT - Baseline Diffuser, Al l-Aluminum Structure.................... 55

3-4 Estimated Cost Analysis - DAWT - Baseline Diffuser FRP Panels and Aluminum Structure .............. 56

3-5 Estimated Cost Analysis - DAWT - Baseline Diffuser Ferrocement Diffuser Construction. ............. 57

3-6 FRP/Aluminum DAWT Baseline Design Subsystem Cost Breakdown . . . 59

3-7 FRP/Aluminum DAWT Baseline Design Unit Fixed Production Costs. . . 59

3-8 Projections of Estimated Cost - DAWT - for Two Diffuser Designs. - 61

3-9 Relative Selling Price of DAWTs with $45^{\circ}$ Versus $30^{\circ}$ Half Angles. . 62

3-10 Estimated Market Price per Pound of DAWTs. . . . . . . . . 63

4-1 Projections of Cost of Electricity for DAWT (45 $\mathrm{Half}$ Angle) . . 66

4-2 Operations and Maintenance Cost Estimates. . . . . . . . 69

4-3 Reduction of COE from Scrap Aluminum Salvage Recovery (after 30 Years)...................... . . 72

4-4 Summary Net COE for 3 DAWT Rated Output Units. . . . . . . . 73

5-1 Estimate of Production Labor and Purchased Parts for One DAWT 9 Proof-of-Concept System for Atmospheric Testing. . . . . . . 81

5-2 Estimate of Billing Cost of Fabrication for One DAWT 9. . . . 81 


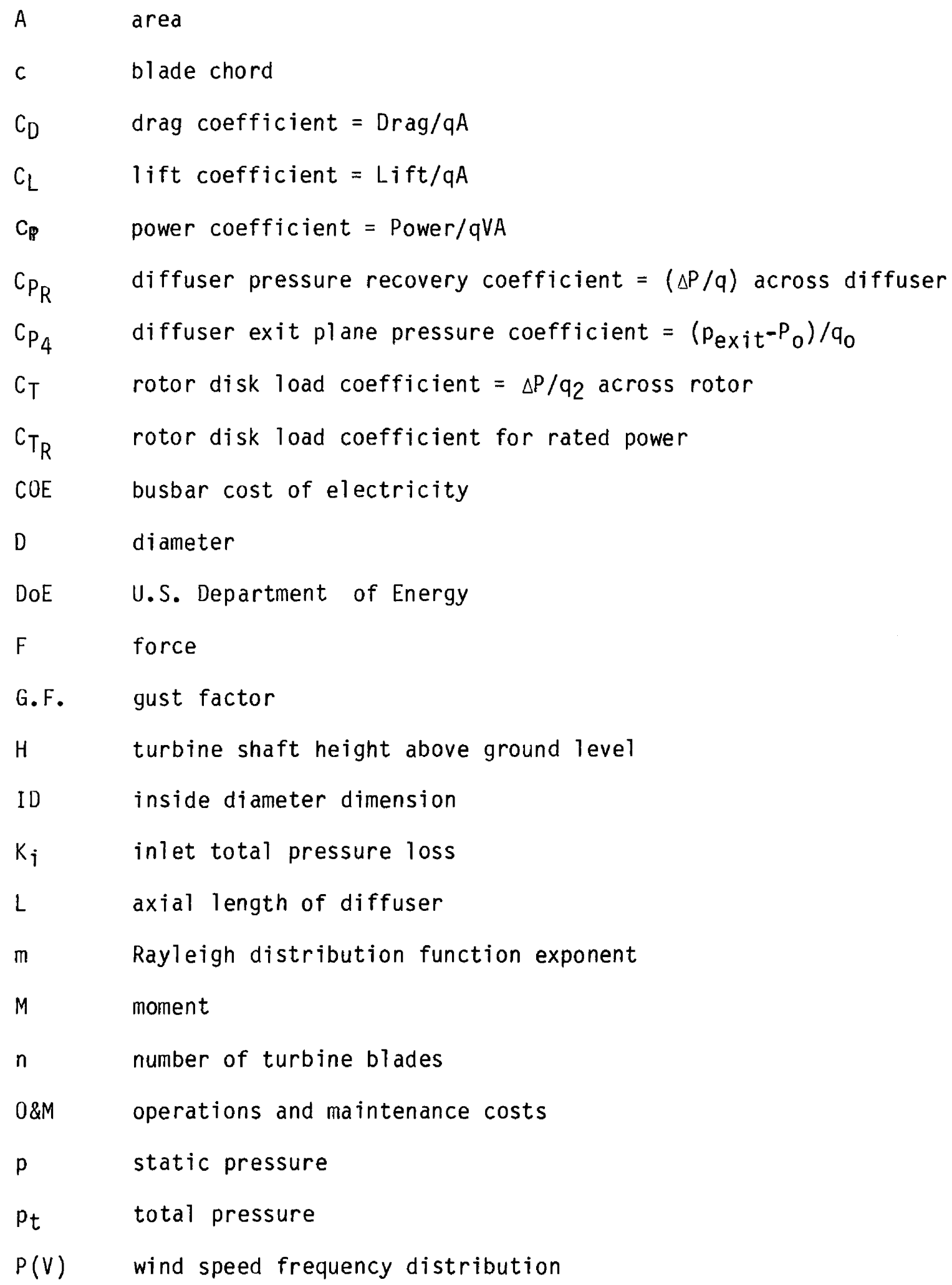




\section{NOMENCLATURE LIST (continued)}

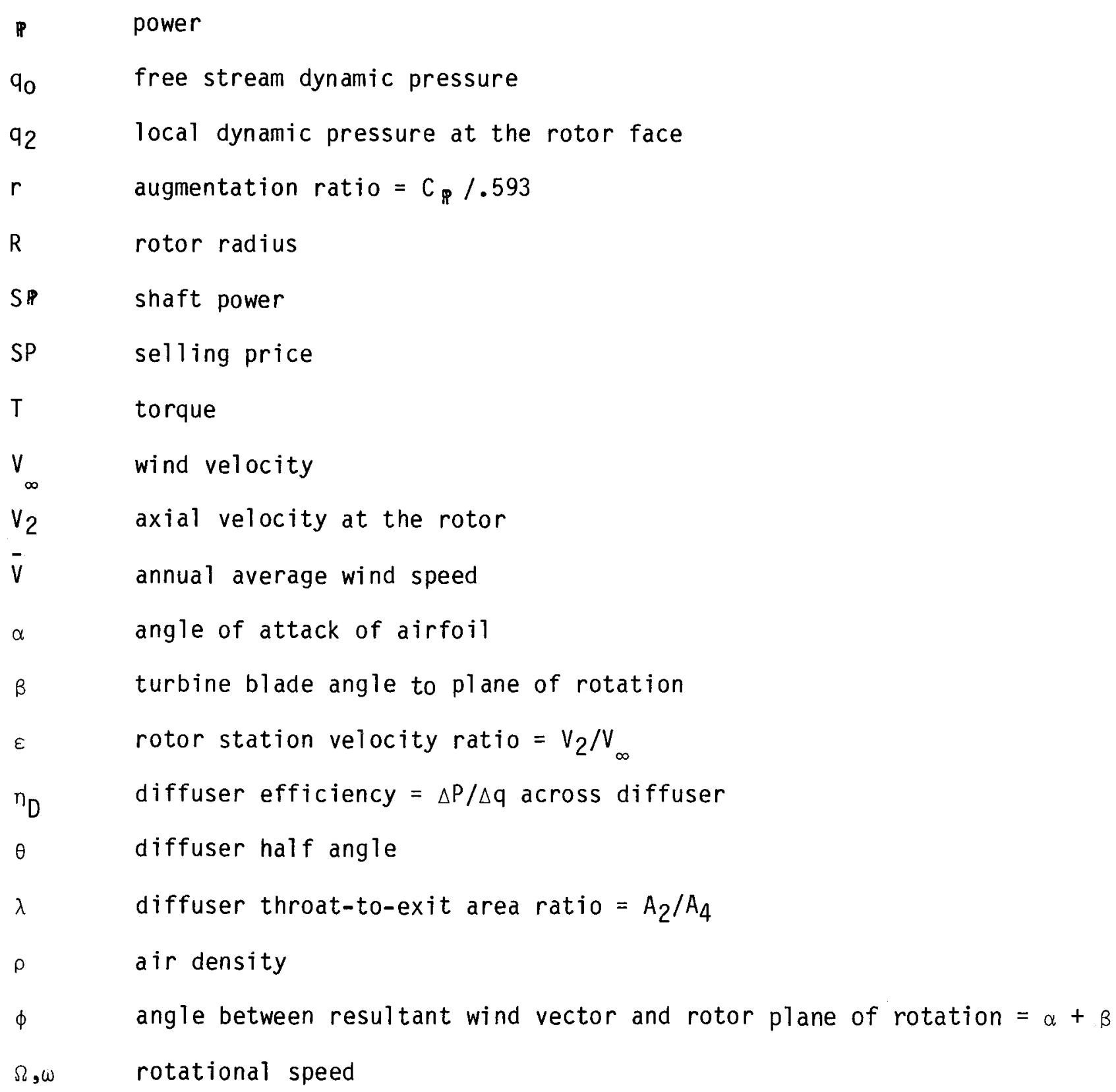


SECTION 1.0

INTRODUCTION

This report summarizes the work conducted under SERI Contract XH9-8073-1 to examine system engineering design alternatives and determine costs and energy output for the diffuser augmented wind turbine (DAWT) innovative wind energy conversion (WEC) concept. The wind energy innovative systems (WEIS) program, managed by the Solar Energy Research Institute (SERI) on behalf of the U.S. Deptartment of Energy ( $D O E)$, has the goal of making the wind form of solar energy a more attractive and cost effective resource than conventional WEC approaches, and competitive with alternative means of energy production.

The DAWT concept originated in 1973 in its present modern form. Earlier analyses and development (Ref. 1,2,3) had not considered overcoming the economic penalty of the diffuser although a valuable perspective had been obtained later through tests regarding possible performance and operational features (Ref. $4,5,6,6 a$ ).

Our break with the traditional DAWT diffuser designs was in recognizing and discovering means of creating very compact diffusers that would be inherently low cost but of high aerodynamic performance. The fluid mechanical challenge was confronted, starting in 1975 under a U.S. ERDA contract. Subsequently, the experimental investigation progressed through a multi-stage process involving three research test facilities, and was supported by fluid dynamic analyses and estimates of costs. Sufficient data was obtained to prove the feasibility of the concept, and that the demonstrable augmentation of power is of considerable magnitude (Ref. 7). Forecasts of performance resulting from improvements in DAWT design beyond the model configurations investigated predict up to 10 times the annual energy attainable by conventional bare turbines.

In Ref. 7 the various issues affecting the design, manufacturing, and economics of DAWT were discussed. The present investigation addresses these issues and presents estimates of the cost of energy produced by DAWT systems in the 5 to $150 \mathrm{~kW}$ power rating range. In Section 2.0, the DAWT system concept is reviewed and designs are described for three candidate construction materials. In Section 3.0, the manufacturing approaches and cost estimates are presented. The busbar costs of electricity are computed in Section 4.0, and compared with DoE cost goals published in 1978 (Ref. 8). Finally, recommendations for a DAWT field investigation model are made in Section 5.0, as well as for a scope of work for continued development of the DAWT concept.

Specific design studies for two non-metallic candidate materials are described in Appendices $A$ and $B$. A preliminary stress analysis of the aluminum fabricated DAWT is given in Appendix C. Details of three foundation designs are given in Appendix $D$. 
SECTION 2.0

DAWT DESIGN

\subsection{SIZING AND RATING}

It was the intent of this reported effort to provide wide value to DAWT assessment. Therefore the initial task of this SERI contract required selection of three system sizes (i.e., rotor diameters). For each selection, point designs were conducted in each of three candidate materials of construction. From these nine designs and the resulting trend of cost sensitivity models for various other diffuser configurations, we have been able to generate diffuser cost trend estimates as graphically depicted by Fig. 2-1.

The limiting rotor size that actually was selected was a consequence of the wind turbine design philosophy assumed for this investigation. This assumption was that the blades be untwisted, and of constant chord and constant sectional contour to take advantage of the low cost aluminum extrusion fabrication technique.* With the presently available aluminum extrusion press capacity, the longest cantilevered span blade considered practical is $5.5 \mathrm{~m}$ (18 $\mathrm{ft}$ ); thus, the maximum rotor diameter considered for this study is $11 \mathrm{~m}(36 \mathrm{ft})$. Because of the centerbody dimension needed to enclose other components of the wind turbine, such as electrical generator, transmission gear box, etc., the shortest span blade considered practical is $1.35 \mathrm{~m}(4.5 \mathrm{ft})$, for a rotor diameter of $2.7 \mathrm{~m}(9 \mathrm{ft})$. A third rotor size, to make trend analysis possible, was selected at the mid-range of the rotor diameter limits or $6.9 \mathrm{~m}(22.5 \mathrm{ft})$.

As indicated by the interactive elements schematic, shown by Fig. 2-2, the performance evaluation of DAWT systems in terms of electrical energy cost requires a determination of annual energy production among other factors. This value of generated output potential requires consideration of the power rating for each of the three DAWT rotor sizes. Realistic ratings depend on the natural characteristics of the projected installation site such as wind velocity duration profiles and mean wind power potential. They also depend, in the specific case of the DAWT, on the diffuser's economically appropriate augmentation ratio, and the generator and power transmission machinery available. Although DoE has made attempts to standardize or reference wind turbine ratings to a free wind speed of $8.94 \mathrm{~m} / \mathrm{s}(20 \mathrm{mph})$, the liberties taken by commercial developers and producers of conventional wind turbines in rating their machines at other wind speeds is obvious to the serious worker in this field. Therefore, it seems grossly unfair to assign a fixed and arbitrary rating wind speed to the DAWT which does not serve at least another functional purpose. One useful and meaningful such purpose is linking the rating to the commercially available, standard generators. Although electrical generators represent a minority cost element of an entire DAWT, the cost advantages and especially reliability of a mature production generator better justifies a

\footnotetext{
*These design assumptions lead to conservative DAWT performance. Therefore, the ratings and economics considered here do not represent the ultimate potential of the DAWT concept.
} 




Figure 2-1. DIFFUSER COSTING PROCEDURE 




Figure 2-2. BASIC FACTORS AFFECTING DAWT EVALUATION 
rating pattern that accomodates the available hardware rather than an arbitrary wind speed value. Of even greater significance to the consumer than power rating is the annual energy ( $k W h$ ) potentially available from a wind energy conversion system; analytical studies of the sensitivity of annual energy to rating wind speed indicate increased total energy output as the rated wind speed is increased, if energy demand is not a constraint. In Table 1 , we provide the ratings for the three DAWT study models based on the assumed diffuser augmentation ratio attainable, and the and the most cost-effective standard generator compatible with the rotor size. For comparison, we also provide the rating that would have resulted from consideration of an arbitrary $8.94 \mathrm{~m} / \mathrm{s}(20 \mathrm{mph})$ rating wind speed. For a Rayleigh windspeed distribution the total annual energy available with both power rating methods is given for a site with an annual average wind speed of $7.15 \mathrm{~m} / \mathrm{s}(16 \mathrm{mph})$.

Table 2-1. THREE DAWT STUDY MODELS*

\begin{tabular}{|c|c|c|c|c|c|c|}
\hline \multirow{3}{*}{$\begin{array}{c}\text { Rotor } \\
\text { Diam. } \\
\text { m }\end{array}$} & \multirow{3}{*}{$(f t)$} & \multirow{3}{*}{$\begin{array}{l}\text { Assumed } \\
\text { Diffuser } \\
\text { Augment. } \\
\text { Ratio, } \\
\text { r }\end{array}$} & \multicolumn{4}{|c|}{ DAWT Rated Performance } \\
\hline & & & \multicolumn{2}{|c|}{$\begin{array}{c}\text { Stand. Generator } \\
\text { Method }\end{array}$} & \multicolumn{2}{|c|}{$\begin{array}{l}20 \mathrm{MPH} \text { Std. Wind Speed } \\
\text { Method }\end{array}$} \\
\hline & & & $\begin{array}{l}\text { Power } \\
\mathrm{kW} \quad 0 \mathrm{MPH}\end{array}$ & $\begin{array}{c}\text { Energyt } \\
\text { kWh }\end{array}$ & $\begin{array}{l}\text { Power } \\
\text { kW }\end{array}$ & $\begin{array}{c}\text { Energyt } \\
\text { kWh }\end{array}$ \\
\hline 2.7 & (9) & 5.5 & 11.2026 & 47,200 & 5.2 & 27,150 \\
\hline 6.8 & $(22.5)$ & 5.5 & (a) 24.5 & 267,000 & 32.3 & 168,600 \\
\hline 11 & (36) & 5.5 & (d) 24 & 674,000 & 82.5 & 430,650 \\
\hline
\end{tabular}

$t$ at $\nabla=16 \mathrm{mph}$ measured at $9.1 \mathrm{~m}(30 \mathrm{ft})$ height

The assigned DAWT augmentation ratio has been developed, as suggested by Fig. 2-2, from the interplay of benefit and cost of different diffuser configurations, exit-to-entrance cross-sectional area ratios, and aerodynamic performance. The theoretical trends of aerodynamic performance to area ratio trends are shown by Fig. 2-3. The greater the area ratio of the diffuser, the higher the augmentation ratio. These theoretical performance curves have been modified to show the strong (about 25\%) downturn in performance at area ratios less than about 2.25 in accord with our experimental observations.*

The relative cost-to-diffuser area ratio trend curves are presented by Fig. 2-4. Here, lower costs are a direct result of smaller diffuser surface areas in accord with manufacturing estimator's recommendations. As Fig. 2-4 shows, there is generally decreasing cost (and surface area) with lowered area ratios as well as certain other geometric and diffuser shape influences.

\footnotetext{
*Note earlier footnote in Subsection 2.1 regarding the rotor design philosophy; use of this bare turbine design gives ratings, below, which are not representative of the ultimate DAWT potential.

** Unreported proprietary data of Grumman Aerospace Corporation.
} 


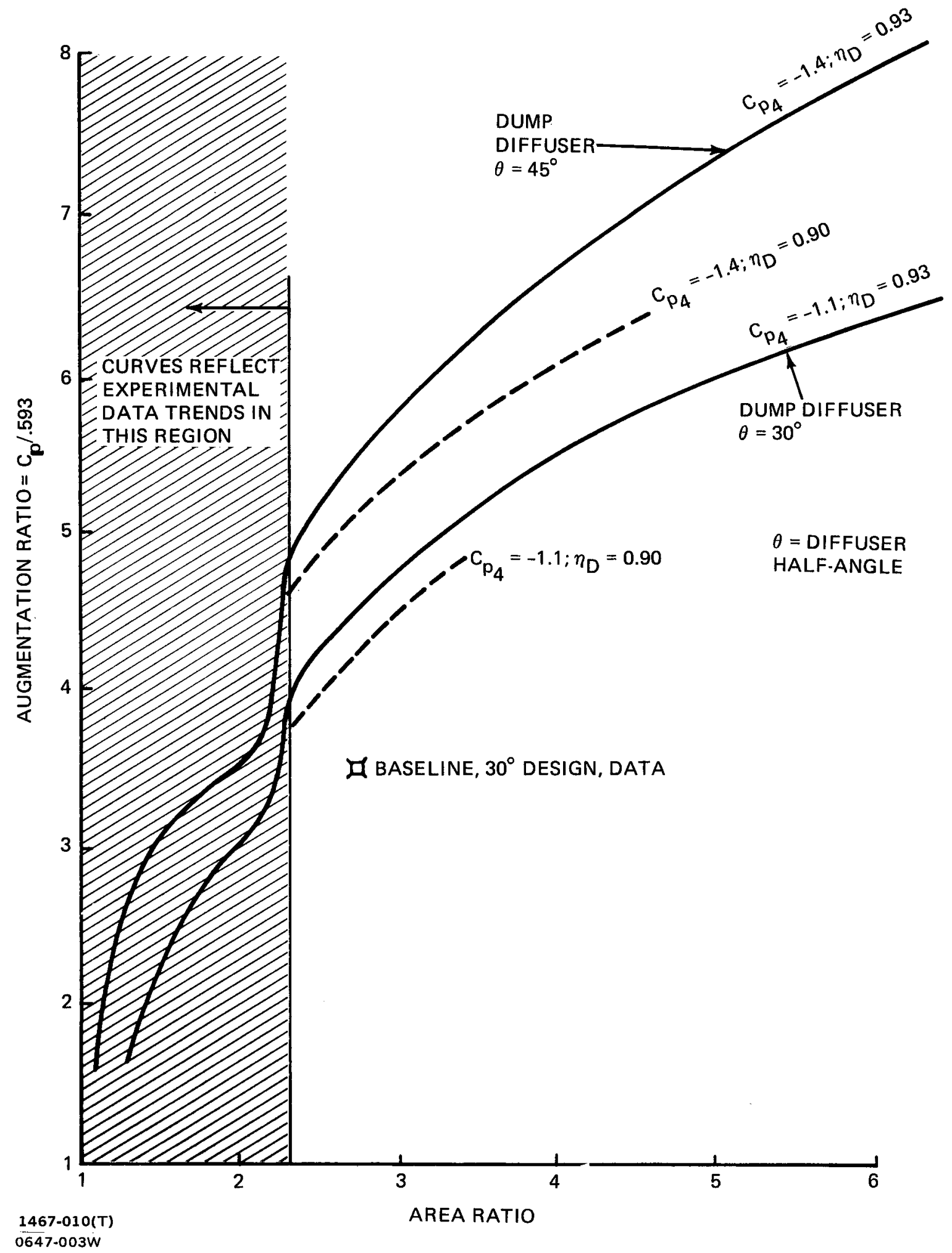

Figure 2-3. THEORETICAL PEAK DAWT AUGMENTATION RATIO VS DIFFUSER AREA RATIO. DATA POINT IS PEAK VALUE FOR $30^{\circ}$ HALF.ANGLE BASELINE CONFIGURATION MODELS IN WIND TUNNEL INVESTIGATION. SHADED REGION IS TREND SUGGESTED BY GRUMMAN PROPRIETARY DATA NOT REPORTED OTHERWISE. 


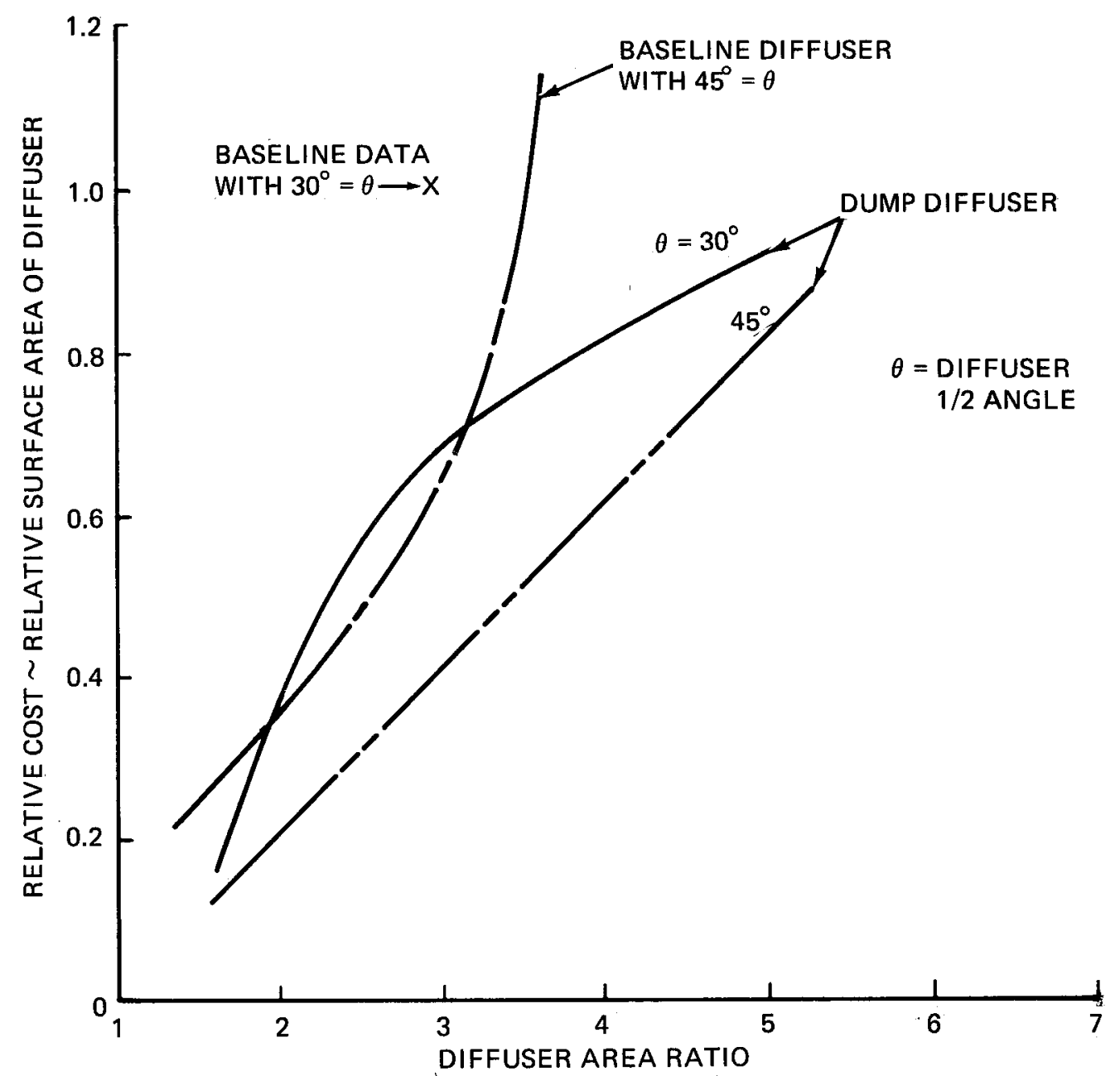

1467-011(T)

4270-004W

Figure 2-4. RELATIVE COST (BASED ON DIFFUSER SURFACE AREA) OF DIFFERENT DAWT DIFFUSER DESIGNS WITH AREA RATIO VARIATION 
Combining the trends of Fig. 2-3 and 2-4 results in Fig. 2-5 which offers a measure of benefit-to-cost that tends to reach a maximum at an area ratio of about 2.25. However, because long term operation probably is more reliable at a design point somewhat removed from a potentially rapidly changing dynamic performance condition, we have rather arbitrarily assumed the diffuser area ratio in this study to be 2.75 , although 2.50 probably also would be satisfactory. The fine adjustment of this diffuser sizing parameter can be reasonably deferred until a later date. It is sufficient, at this point, only to draw attention to the conservative impact on cost estimates of the 2.75 area ratio used in this report; lower area ratios are possible and should improve the economic prospects of the DAWT.

It is indicated by Fig. 2-1 that several diffuser configurations have been assessed in this report. However, only the 2.75 area ratio, baseline diffuser with 30 degree half angle has been made the subject of intensive point design effort for each of the three rotor sizes selected. Table 2-2 gives the major dimensions of the baseline diffuser configuration for these three point designs.

Table 2-2. BASELINE DIFFUSER DIMENSIONS

\begin{tabular}{|c|c|c|c|c|}
\hline \multirow[b]{2}{*}{ Rotor Diam m (ft) } & \multicolumn{4}{|c|}{ Baseline Diffuser Dimensions $m(\mathrm{ft})$ for $30^{\circ}$ Half-Angle } \\
\hline & Inlet Diam & Exit Diam & Axial & Length \\
\hline $2.7(9)$ & $3.0 \quad(10)$ & $4.6 \quad(15)$ & 2.0 & $(6.5)$ \\
\hline $6.8(22.5)$ & $7.6 \quad(25)$ & $(37.5)$ & 4.3 & $(14.0)$ \\
\hline $11.0(36)$ & $12.2(40)$ & 18.3 & 6.6 & $(21.5)$ \\
\hline
\end{tabular}

The height above ground level of the turbine axis has been assumed to be $3.0 \mathrm{~m}$ $(10 \mathrm{ft})$ plus half the diffuser exit diameter. This exit diameter clearance is considered adequate to permit full rotation into the prevailing wind direction without hazard to personnel or conventional vehicles. It is also adequate to prevent animals or children from climbing into the diffuser cone without further safeguards, such as an $2.4 \mathrm{~m}(8 \mathrm{ft})$ high chain link perimeter fence, being necessary. This ground clearance also is adequate for most usual snowfalls in the U.S. in open fields, and to allow the diffuser to escape the most erosive effects of storm-driven sand and particulates.* For the three rotor diameters investigated the ground clearance assumption gives a hub height between $5.3 \mathrm{~m}(17.5 \mathrm{ft})$ to $12.2 \mathrm{~m}(40 \mathrm{ft})$ and the usual $9.1 \mathrm{~m}(30 \mathrm{ft})$

* Although no direct evidence is available for DAWT installations, it is believed that the small sized aerosol particulates capable of rising in strong winds above about $1.5 \mathrm{~m}(\sim 5 \mathrm{ft})$ will not cause severe erostion. 


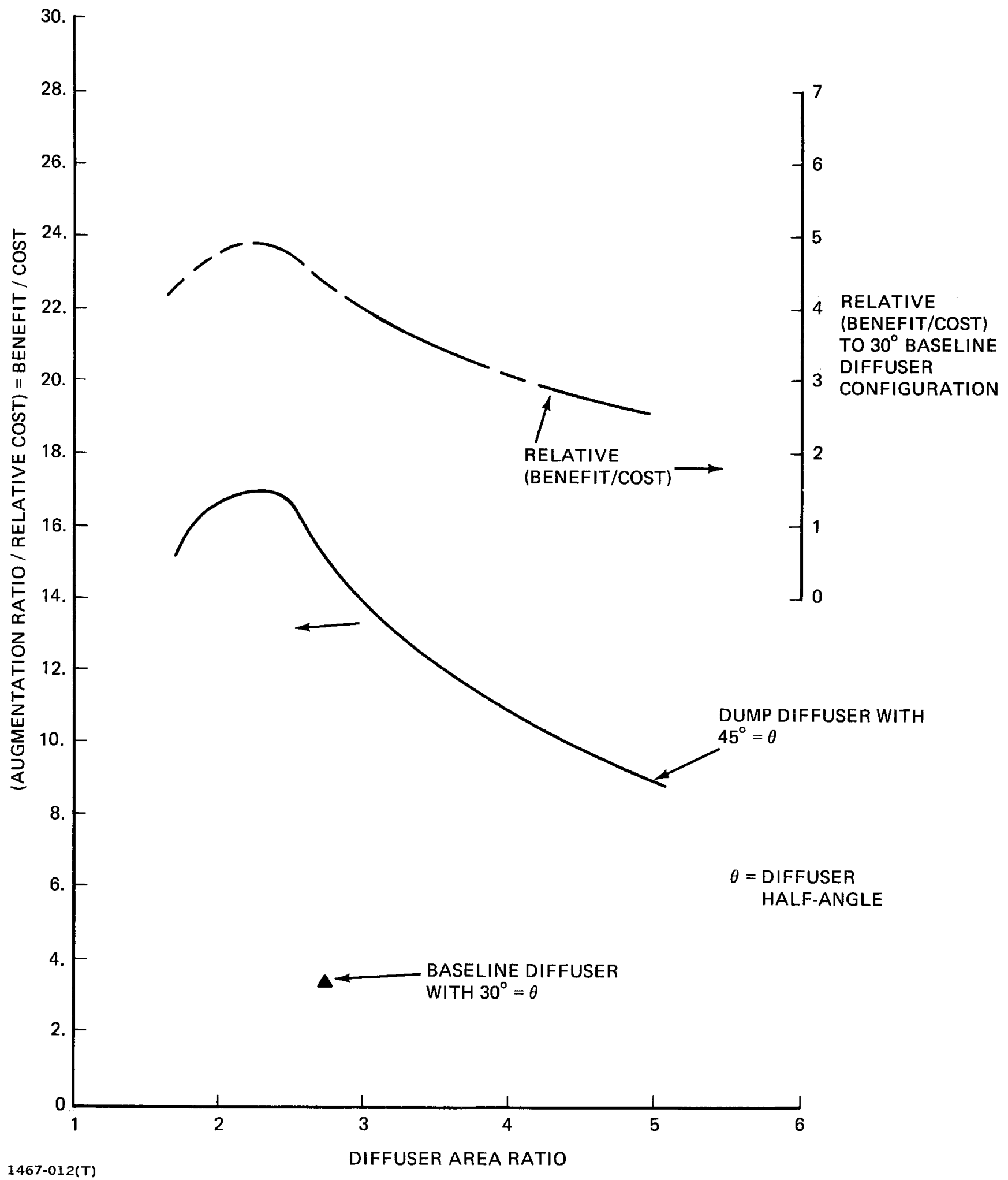

4270-005W

Figure 2-5. THEORETICAL VARIATION OF DAWT UTILITY INDEX WITH DIFFUSER AREA RATIO. DATA POINT SHOWN IS FROM WIND TUNNEL RESULTS FOR $30^{\circ}$ HALF-ANGLE BASELINE DIFFUSER MODELS, AND ANALYTICAL COST ESTIMATES. 
altitude wind statistical measurements for geographic locations may be applied directly for energy computations with negligible error. *

\subsection{BASELINE DIFFUSER DESCRIPTION}

The focus of the engineering point designs has been the baseline diffuser configuration, comprising three components whose features are described as follows :

- A cylindrical duct, $0.91 \mathrm{~m}$ ( $3 \mathrm{ft}$ ) long encloses the rotor and its inside diameter (ID) is greater than the rotor diameter creating a gap of $3 \%$ of the rotor radius.

- The second diffuser element consists of a divergent section, concentric and downstream of the cylindrical duct. The upstream end of this element is cylindrically shaped with an inside diameter greater than the rotor diameter by $5.5 \%$. The wall of this component proceeds downstream, through a curved transition section of increasing diameter to a $30^{\circ}$ half angle conical frustrum and

- A third coaxial (downstream) divergent element that continues the $30^{\circ}$ half angle frustrum to the final downstream exit diameter, producing an overall expansion area ratio of 2.75 . The upstream end of the third component coincides with the axial location of the downstream end of the second component but the former has a greater ID, creating an annular gap between the two components equal to 0.8 percent of the local diameter. The total axial length of the two conical components for a 2.75 overall area ratio is $50 \%$ of the inlet diameter; the upstream conical element alone has about a 30\% length-to-inlet diameter ratio. The expansion area ratio of the upstream conical element is 1.83 .

Variations on the baseline diffuser geometry, called sensitivity models, also were established. These were designed initially to yield costing rules, by means of a few point design estimates, for other diffuser area ratios, diffuser expansion half angles and shape configurations. However, because the production cost estimators held the view that diffuser cost is predominantly controlled by the surface area of each design, a more general investigation was conducted, using geometric relationships, leading to the relative costs shown by Fig. 2-4, referenced to the $30^{\circ}$ half angle, 2.75 area ratio, baseline configuration. In these relative cost studies the cylindrical housing around the rotor remains unchanged.

The dump diffuser shape retains the same upstream conical diffuser component as the baseline but reduces the axial length of the downstream conical section to about $10 \%$ of the inlet diameter. The total expansion area ratio is achieved by a radially outward projecting collar at the downstream end of the

\footnotetext{
*Wind tunnel investigations of DAWT models in simulated Earth boundary layer velocity gradients exhibit slightly improved power coefficients compared to uniform flow conditions (Ref. 5). In the absence of more detailed evidence, the correction for hub height is neglected in this present preliminary study, as a simplifying assumption.
} 
shortened conical element. * Figure 2-6 compares the basic lines of the baseline and dump diffuser designs for a 2.75 overall area ratio and a $30^{\circ}$ half angle.

\subsection{LOADS AND DESIGN CRITERIA}

The three sizes of baseline DAWTs have been designed to survive without permanent deformation a projected maximum loading due to a steady state sea level wind speed of $53.6 \mathrm{~m} / \mathrm{s}(120 \mathrm{mph})$ and an applied wind gust factor of 1.21. The gust factor used is that recommended in Ref. 9 and results in a maximum dynamic pressure of $53.7 \mathrm{psf}(2563 \mathrm{~Pa})$. Based on wind tunnel model investigations the frontal view drag coefficient $C_{D f}$ has been determined as 1.1 ; the side view drag coefficient, $C_{D}$, has been measured as 0.80 (Ref. 7). Table 2-3 presents the maximum arag forces computed for each of the DAWT study designs, and the resulting ground level moments for the hub height, $H$, that assures a $3.05 \mathrm{~m}(10 \mathrm{ft})$ ground clearance for the diffuser exit plane. The indicated total weight in Table 2-3 is an approximate preliminary estimate. The condition for maximum wind load does not coincide with an operational, power generating condition. For purposes of design the DAWT ceases operation at or less than $33.5 \mathrm{~m} / \mathrm{s}(75 \mathrm{mph})$. The estimated variation of internal static pressure within the diffuser is presented by Fig. 2-7 for the maximum operational wind speed.

The external static pressure loading on the diffuser varies with circumferential angle from the stagnation point of the mean wind flow direction. Figures 2-8 and 2-9 show this angular variation based on the experimental model data reported in Ref. 7.

\subsubsection{Aluminum Construction}

A preliminary stress analysis of the complete DAWT aluminum structure is given in Appendix C. The structural design of the aluminum and FRP versions of the DAWT compares favorably to the criteria used to design the Sears Tower, the world's tallest $442 \mathrm{~m}$ (1450 ft) office building (Ref. 10). In the Sears Tower project a 1.8 safety factor was applied to the extreme wind load condition expected with a statistical recurrence of over 10,000 years. The design wind pressure at the top of the Sears Tower was $62.5 \mathrm{psf}$ (2993 Pa) (Ref. 10). The DAWT, with a maximum structural element at about $21.3 \mathrm{~m}(70 \mathrm{ft})$ has been designed for a uniform maximum wind pressure of $53.7 \mathrm{psf}(2563 \mathrm{~Pa})$. The required DAWT 1 ifetime of 30 years contrasts to the statistically expected recurrence of DAWT maximum wind pressure in excess of 120 years (Ref. 9). The allowable design stress of $22,000 \mathrm{psi}(151,690 \mathrm{kPa})$ used for the DAWT aluminum structure was the same value used on the Lunar Module and is well under the ASTM specified yield strength of about $40,000 \mathrm{psi}(275,800 \mathrm{kPa})$ for 5083 aluminum alloy. A study of Appendix $C$ reveals that positive margins of safety (at times quite large) exist for all conditions of the analyses. For the level of costing accuracy assumed for this contract, a more detailed design and analysis beyond that presented in Appendix $C$ was considered unwarranted.

\footnotetext{
* At the station of sudden cross sectional change, the flow is thought of as "dumped" into the relatively. low pressure region immediately downstream of the collar. This sudden, radially expanded, flow change gives this diffuser configuration its name.
} 




4270-006W

Figure 2-6. COMPARISON OF BASIC LINES OF BASELINE AND DUMP DIFFUSER DESIGNS 
Table 2-3. SUMMARY OF WIND LOADS AND MOMENTS ON BASELINE DAWT (1 $\mathrm{FT}=0.3048 \mathrm{~m}$ )

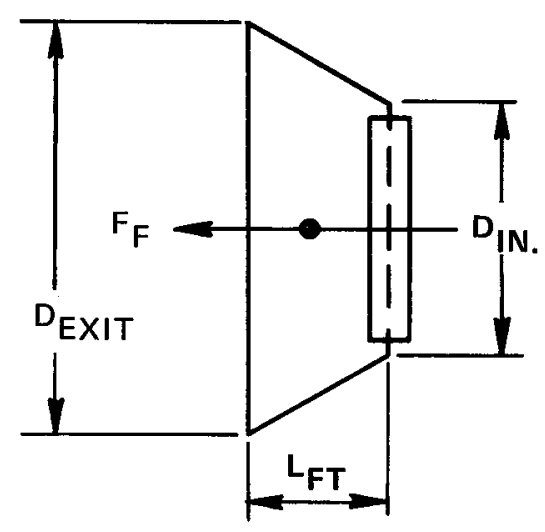

RONTAL DRAG FORCE

WIND $=120$ M.P.H. $(53.6 \mathrm{~m} / \mathrm{s})$

$(X(G . F .=1.21)=145 \mathrm{MPH}=64.9 \mathrm{~m} / \mathrm{s})$

\begin{tabular}{|c|c|c|c|c|c|c|c|c|}
\hline \multirow[b]{2}{*}{ DESIGN } & \multirow[b]{2}{*}{$\mathrm{L}_{\mathbf{F T}}$} & \multirow[b]{2}{*}{$D_{\text {EXIT }}{ }^{\mathrm{T} T}$} & \multirow[b]{2}{*}{$\mathrm{D}_{\text {IN. }}{ }^{\mathrm{FT}}$} & \multicolumn{2}{|c|}{ PROJECTED AREA, $\mathrm{FT}^{2}$} & \multirow{2}{*}{$\begin{array}{l}\text { ESTIMATED } \\
\text { TOTAL WEIGHT } \\
\text { (PRELIMINARY) } \\
\text { LBS }\end{array}$} & \multirow[b]{2}{*}{$F_{F}$, LBS } & \multirow[b]{2}{*}{$\mathrm{F}_{\mathbf{S}}$, LBS } \\
\hline & & & & FRONT & SIDE & & & \\
\hline 1 & 6.5 & 15 & 10 & 98.2 & 62.5 & 2,570 & 5,779 & 2,675 \\
\hline 2 & 14.0 & 37.5 & 25 & 613.6 & 390.6 & 14,750 & 36,110 & $.16,718$ \\
\hline 3 & 21.5 & 60 & 40 & 1570.8 & 1000 & 52,500 & 92,442 & 42,800 \\
\hline
\end{tabular}

(1 LB $=0.454$ KG)

\begin{tabular}{|c||l|l|c|}
\hline DESIGN & H $_{\text {FT }}$ & M $_{\mathbf{S}}$, LBS-FT & $\mathbf{M}_{\mathbf{S}}$, LBS-FT \\
\hline 1 & 17.5 & 101,135 & 46,815 \\
\hline 2 & 28.75 & $1,038,163$ & 480,643 \\
\hline 3 & 40 & $3,697,664$ & $1,712,000$ \\
\hline
\end{tabular}

0647-22W

1467-013(T)

( 1 LB. - FT $=0.138 \mathrm{~m}-\mathrm{K} \overline{\mathrm{G}}$ )
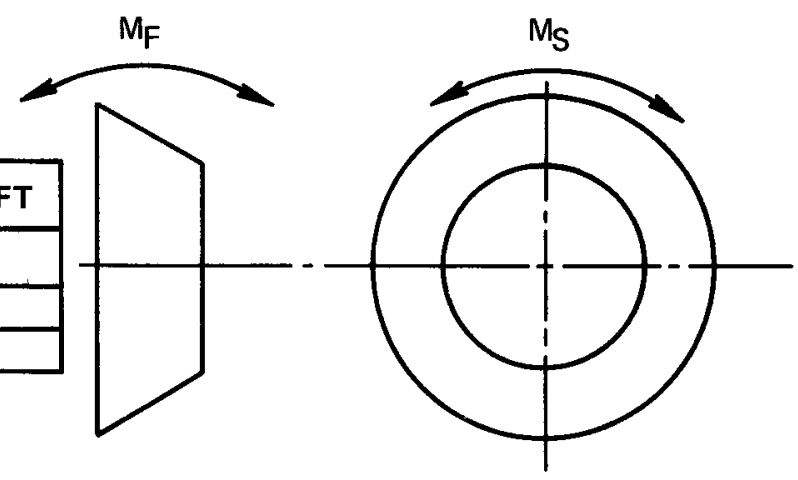




PRESSURE AT L/2 $=-0.475$ PSI

AVERAGE PRESSURE BETWEEN O AND L/2

$=-0.6125 \mathrm{PSI}$

AVERAGE PRESSURE BETWEEN L/2 AND L

$=\underline{-0.3375 \text { PSI }}$

4270-007W

1467-014(T)

Figure 2-7. ESTIMATED AXIAL VARIATION OF BASELINE DAWT INTERNAL STATIC PRESSURE FOR $\mathrm{V}_{\infty}=75 \mathrm{MPH}(33.5 \mathrm{~m} / \mathrm{s})(1 \mathrm{PSI}=6.895 \mathrm{kPa})$ 


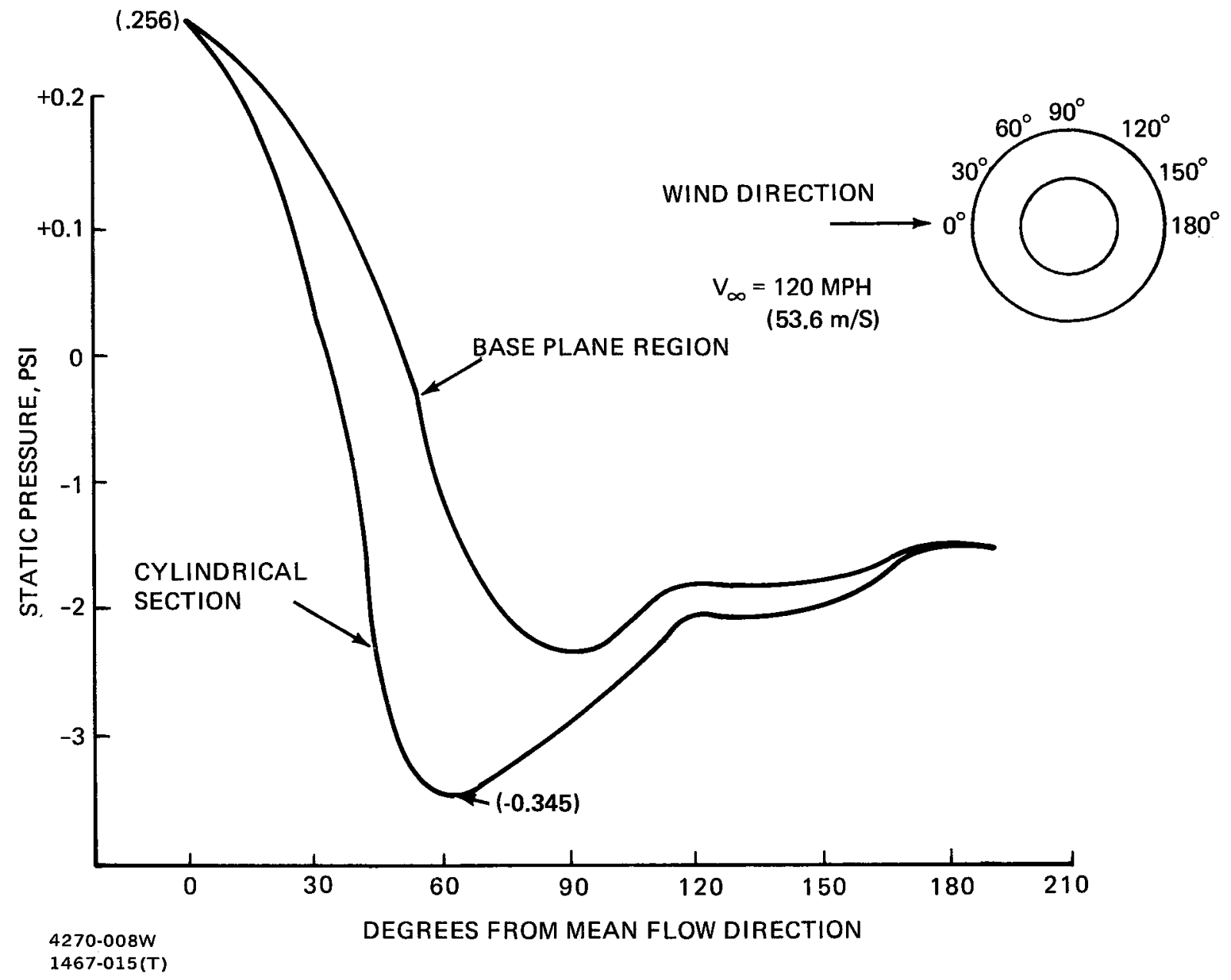

Figure 2-8. DAWT STATIC PRESSURE PROFILE FOR MAXIMUM DESIGN LOADING $(1 \mathrm{PSI}=6.895 \mathrm{kPa})$ 




Figure 2-9. DAWT STATIC PRESSURE PROFILE FOR MAXIMUM DESIGN LOADING (CYLINDRICAL SECTION) (1PSI $=6.895 \mathrm{kPa})$ 
The structural design approach, including safety factors, for the ferrocement version of DAWT has been dictated by the allowable stress and design standards for ferrocement vessels established by the Norwegian Shipping Board (Det

Norske Veritas Rutles). These standards are considered the most authoritative for this construction material, and in our consultant's/subcontractor's (David J. Seymour) opinion impose more severe design requirements than any non-maritime environment application for the same external loading criteria assumed for DAWT.

The DAWT design approach presented in this report is that of a stressed skin conical shell with external longitudinal stiffening members at segment attachment locations which also transfer the loads to fore and aft circumferential rings. The centerbody nacelle is suspended by three sets of staggered $\mathrm{N}$ shaped struts attached to the circumferential rings at three equi-spaced locations. The preferred mounting of the aluminum and FRP diffuser designs is by means of an aluminum cantilevered cylindrical column anchored to a belowground concrete foundation. Each DAWT (rotor) size has had an individual foundation designed for average mid-continent soil conditions; column attachment to the foundation is by bolts to a steel collar anachored into the foundation. A structural hinge and lock at the bottom of the column allows erection after ground level assembly and check out as shown by Figs. 2-10 and $2-11$.

The DAWT concept has an insensitivity of performance for minor transient directional changes of the wind, within about plus or minus $15^{\circ}$ off-axis (Ref. $6,6 a)$. For major changes of wind direction, associated with, for example, weather frontal movement, there is a need for the DAWT to have freedom to yaw in the horizontal plane. Such motion is provided by a lubricated journal-type bearing near the upper end of the column. The bearing is located as high as possible on the column and still permit clearance of the diffuser's longerons. In this way the overturning moment acting on the bearing is minimized. The bearing design approach taken has been to construct two tapered steel rims, rotating relative to each other and separated by a packed grease lubricant. The steel rims are chrominum electroplated over a base plated nickel substrate to protect the steel from corrosion. An outer circumferential clamp helps to retain the lubricant, and mechanically align and fix the two parts of the column support.

A typical DAWT configuration, constructed of aluminum, and containing the features described above, is shown by Fig. 2-12. It is determined in Appendix $C$ that the journal bearing pressure for the maximum DAWT operational condition $(33.5 \mathrm{~m} / \mathrm{s}(75 \mathrm{mph})$ ) varies with rotor diameter size from $1189 \mathrm{ps} i$ (8198 $\mathrm{kPa})$ for the $2.7 \mathrm{~m}(9 \mathrm{ft})$ diameter rotor to $2541 \mathrm{psi}(17520 \mathrm{kPa})$ for the $11 \mathrm{~m}$ (36 $\mathrm{ft}$ ) diameter rotor; these pressures are $1 \mathrm{l}$ in comparison to usual journal bearing design criteria of $7000 \mathrm{psi}(48,265 \mathrm{kPa})$.

\subsubsection{Ferrocement Construction}

The ferrocement version of the DAWT introduces other features because of the unique characteristics of this constructional material. Details of the ferrocement design study including structural analysis are presented in Appendix A. This study was conducted for Grumman by David J. Seymour, Ltd, an organization with considerable ferrocement boat design and construction experience. However, ferrocement appears inappropriate to the $11 \mathrm{~m}(36 \mathrm{ft})$ rotor diameter point design because the state of current knowledge and 


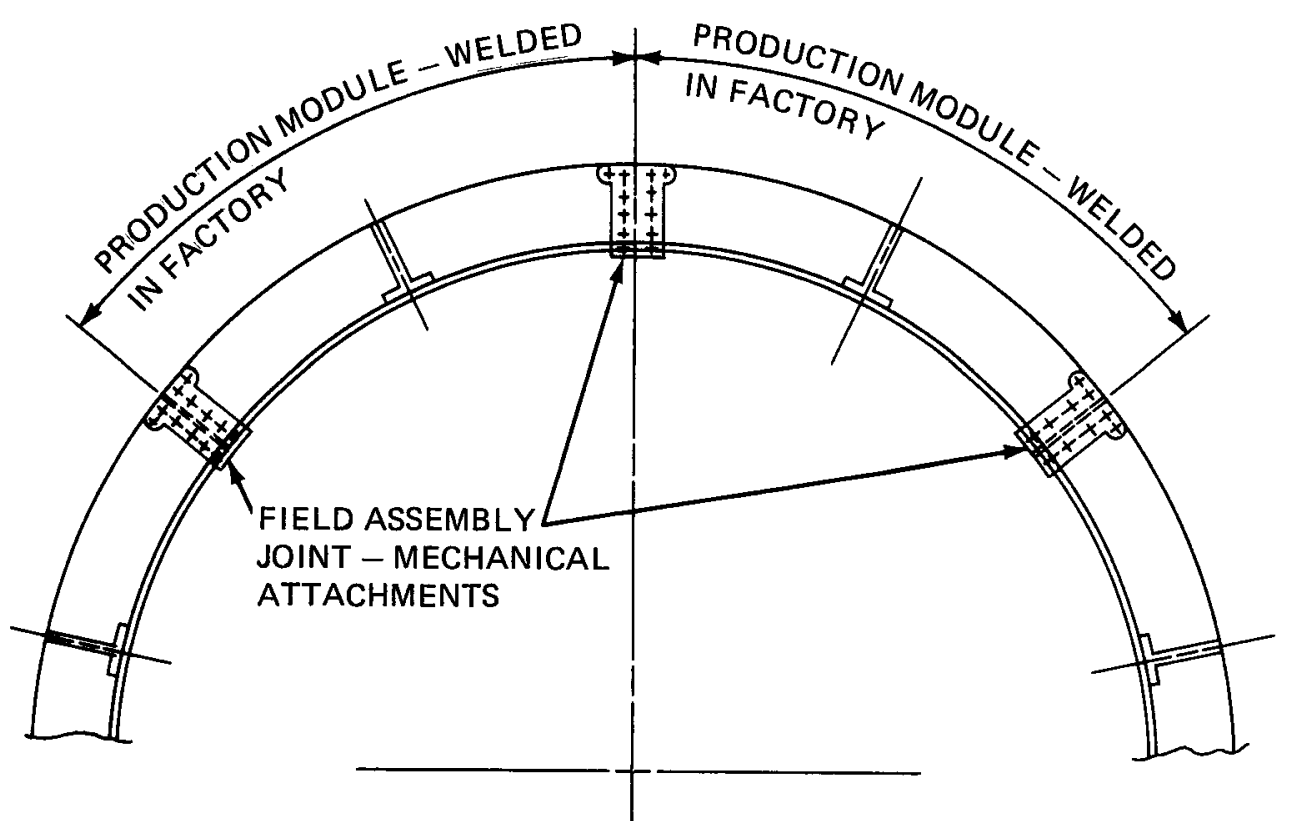

FIELD ASSEMBLY OF FACTORY

WELDED MODULES USING

MECHANICAL ATTACHMENTS

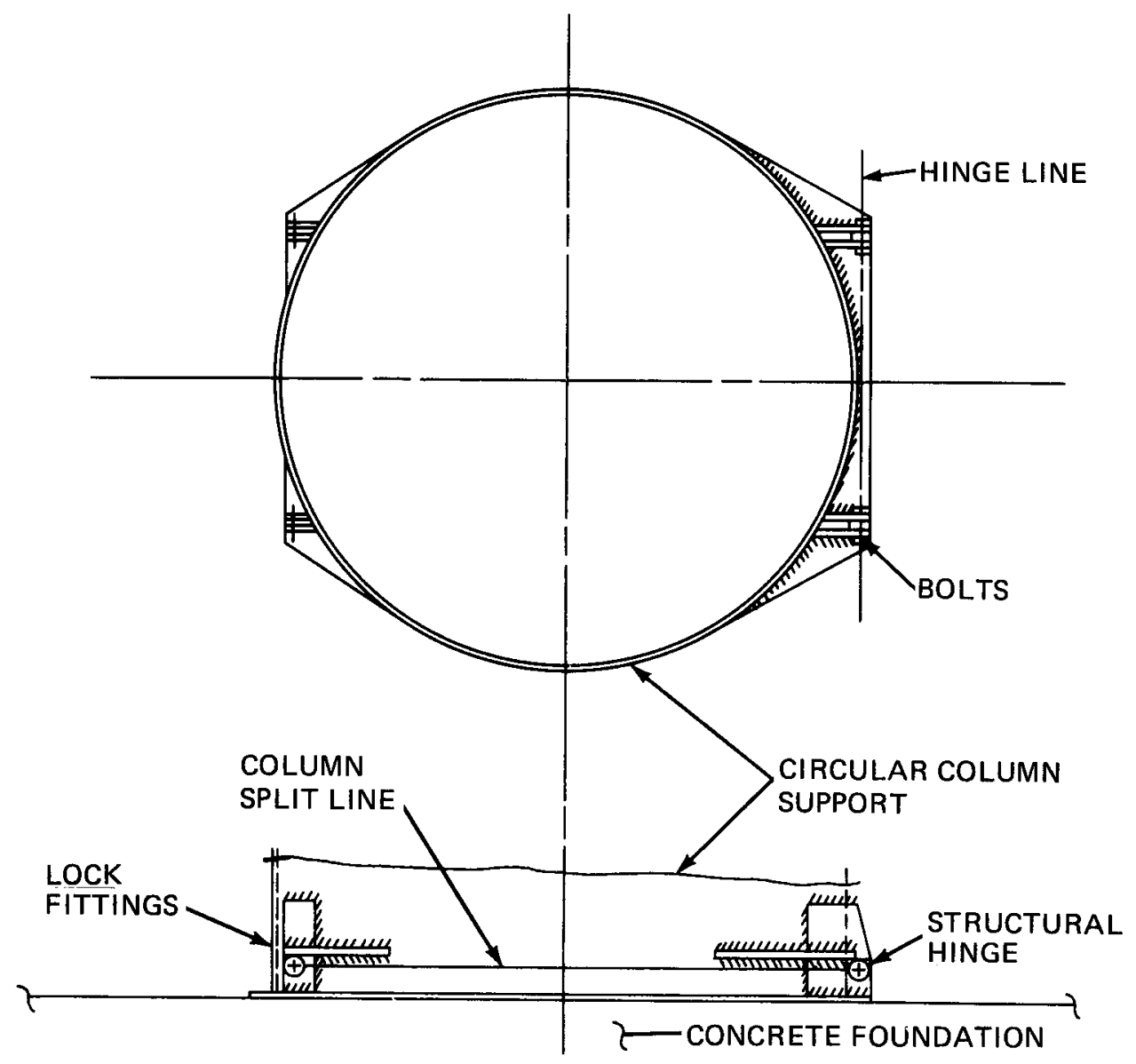

4270-010W

Figure 2-10. STRUCTURAL HINGE AT BASE OF COLUMN FOR DIFFUSER ERECTION 


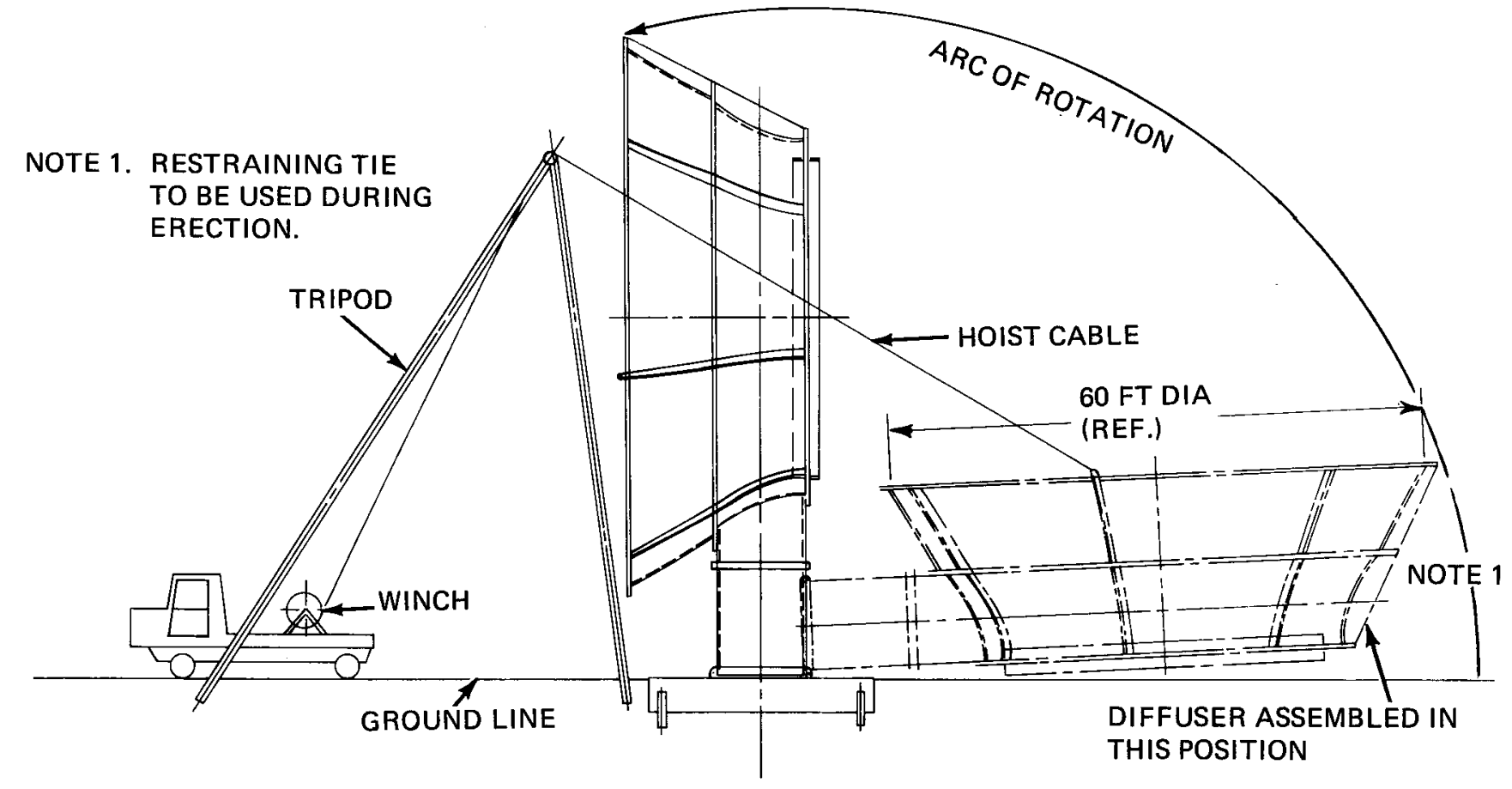

Figure 2-11. TYPICAL FINAL ASSEMBLY AND ERECTION OF DIFFUSER 
NOTE: UNSPECIFIED DIMENSIONS ARE IN INCHES.

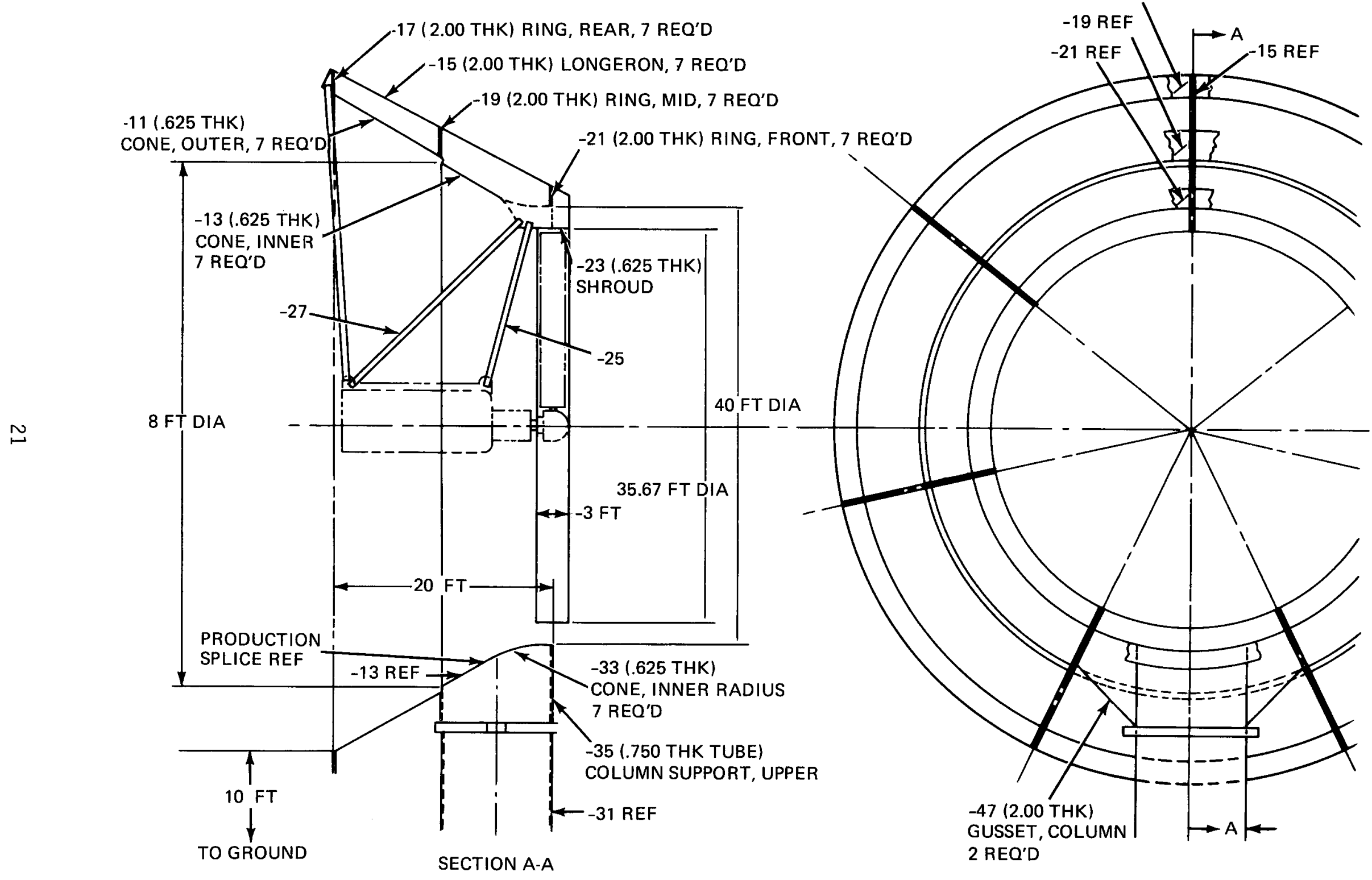

Figure 2-12. TYPICAL DAWT DESIGN IN ALUMINUM (NUMBERS AFTER DASHES IN DRAWING REFER TO COMPONENT PART NUMBERS) 
experience has not extended to such large sizes; our subcontractor, $\mathrm{Mr}$. Seymour, has recommended a modified approach using prestressed concrete and

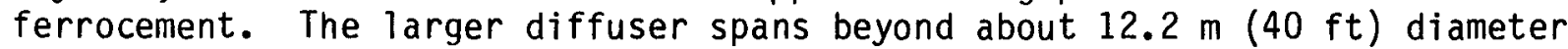
are expected to produce cracking of the mortar in the pure ferrocement design, because of untenably high tensile stresses; the hybrid alternative appears a feasible solution but requires further investigations which Mr. Seymour also describes and proposes in Appendix A.

For the smaller rotor sizes suitable for ferrocement the design is a stressed skin, of high rigidity, composed of layers of wire mesh and rods covered by a layer of mortar. Longitudinal reinforcement ribs of ferrocement construction and section attachment flanges aid the load transfer to the ground support. In the general arrangement shown by Fig. 2-13 a single vertical post support and several roller casters allow the DAWT to rotate in yaw. This design is an alternative to the single column, journal bearing configuration described for the all-aluminum version. Either diffuser support design is practical and interchangeable, although this ferrocement version in Fig. 2-13 is not specifically shown for the single column mounting.

\subsubsection{Fiberglass Reinforced Plastics (FRP) Construction}

Another approach to DAWT construction introduces a sandwich material (typified in Fig. 2-14) consisting of a core of end grain balsa wood encased by FRP layers of moderate thickness 0.32 to $0.48 \mathrm{~cm}(1 / 8$ to $3 / 16 \mathrm{in}$.). Assisting us in this design effort has been Pearson Yachts, a major designer and producer of commercial FRP sail boats, and the Baltek Corp., commercial suppliers of balsa wood.

The diffuser skin thicknesses have been computed by a Baltek computer program for critical buckling pressure on truncated cones. These design calculations are based on NASA SP 8019 and MIL Handbook ANC 23 recommendations for isotropic sandwich shells with a 1.8 safety factor. Material properties and details of the computer calculations are presented in Appendix B. The FRP/balsa sandwich panels are fastened to an aluminum skeleton consisting of upstream and downstream flanges and interconnecting, axial longerons. The $0.91 \mathrm{~m}$ ( $3 \mathrm{ft}$ ) long cylindrical shroud surrounding the rotor also is made of FRP around a $0.95 \mathrm{~cm}$ ( $3 / 8 \mathrm{in}$.) thick balsa core. This shroud is attached by aluminum supports to the longerons; plywood inserts in the FRP shroud allow fastening to the aluminum supports. The centerbody housing the generator, gearbox, and turbine controls is suspended from the end flanges by staggered- $\mathrm{N}$ strut arrays at three locations $120^{\circ}$ circumferentially apart.

The longitudinal FRP panels are connected to form diffuser sectors by means of riveted overlap joints as shown by Fig. 2-15. A silicone type sealant is applied along the joint to dampen inter-panel vibrations, exclude moisture, and provide some flexure-resistant adhesion.

Each diffuser size requires a different optimum thickness of end grain balsa wood core to assure that the FRP skin layer carries the loads effectively and that the structure is rigid. Thicker FRP skins are stronger structurally and need thinner balsa cores but impose penalties in overall weight and cost. The density of FRP as used by Pearson Yachts is $1602 \mathrm{~kg} / \mathrm{m}^{3}$ (about $100 \mathrm{lb} / \mathrm{ft}^{3^{3}}$ ) whereas the end grain balsa supplied by Baltek has a density of 136 to 144 $\mathrm{kg} / \mathrm{m}^{3}\left(8.5\right.$ to $\left.9 \mathrm{lb} / \mathrm{ft}^{3}\right)$. Although two FRP skin thickness options are 

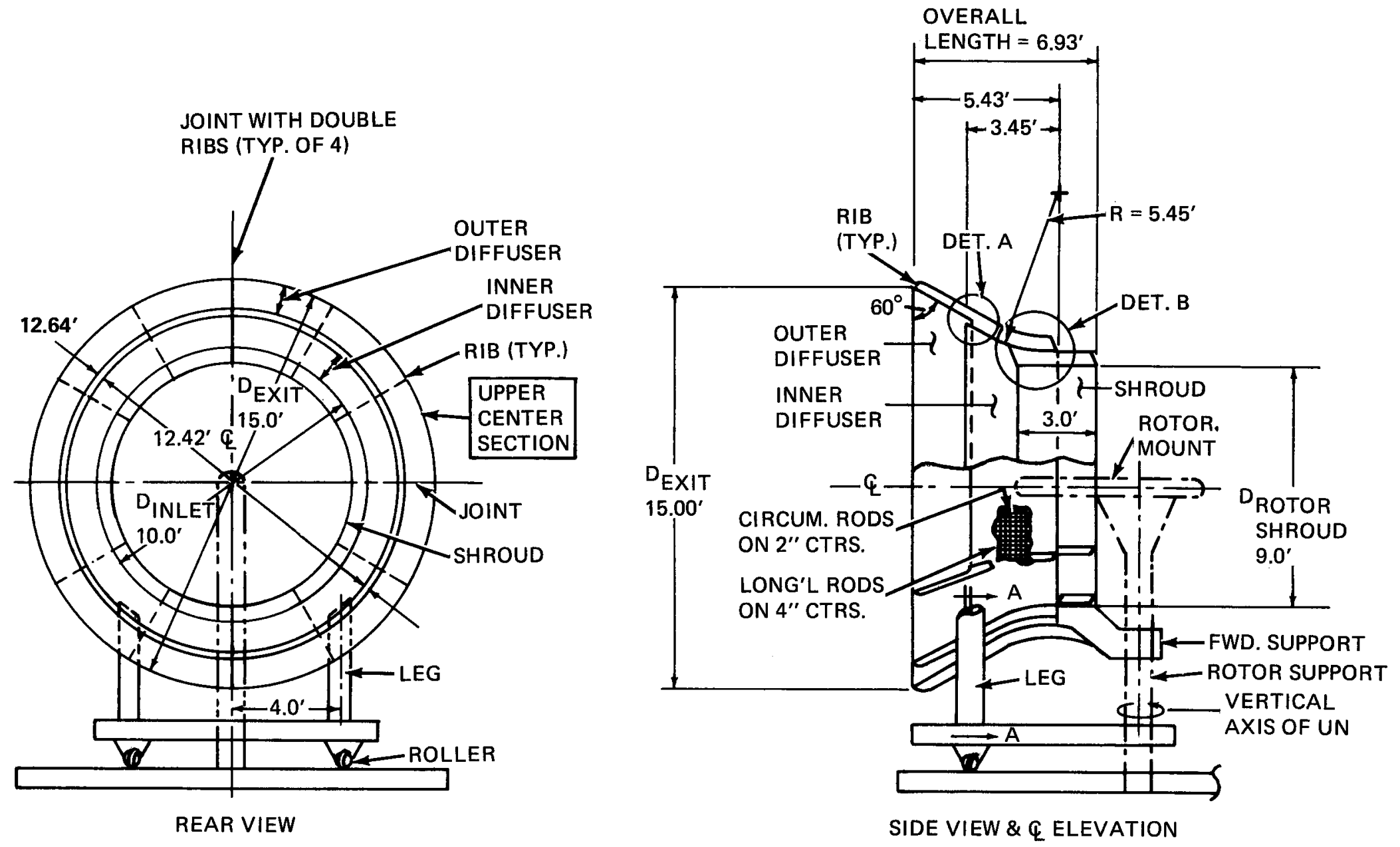

4270-013W

Figure 2-13. TYPICAL FERROCEMENT DESIGN 


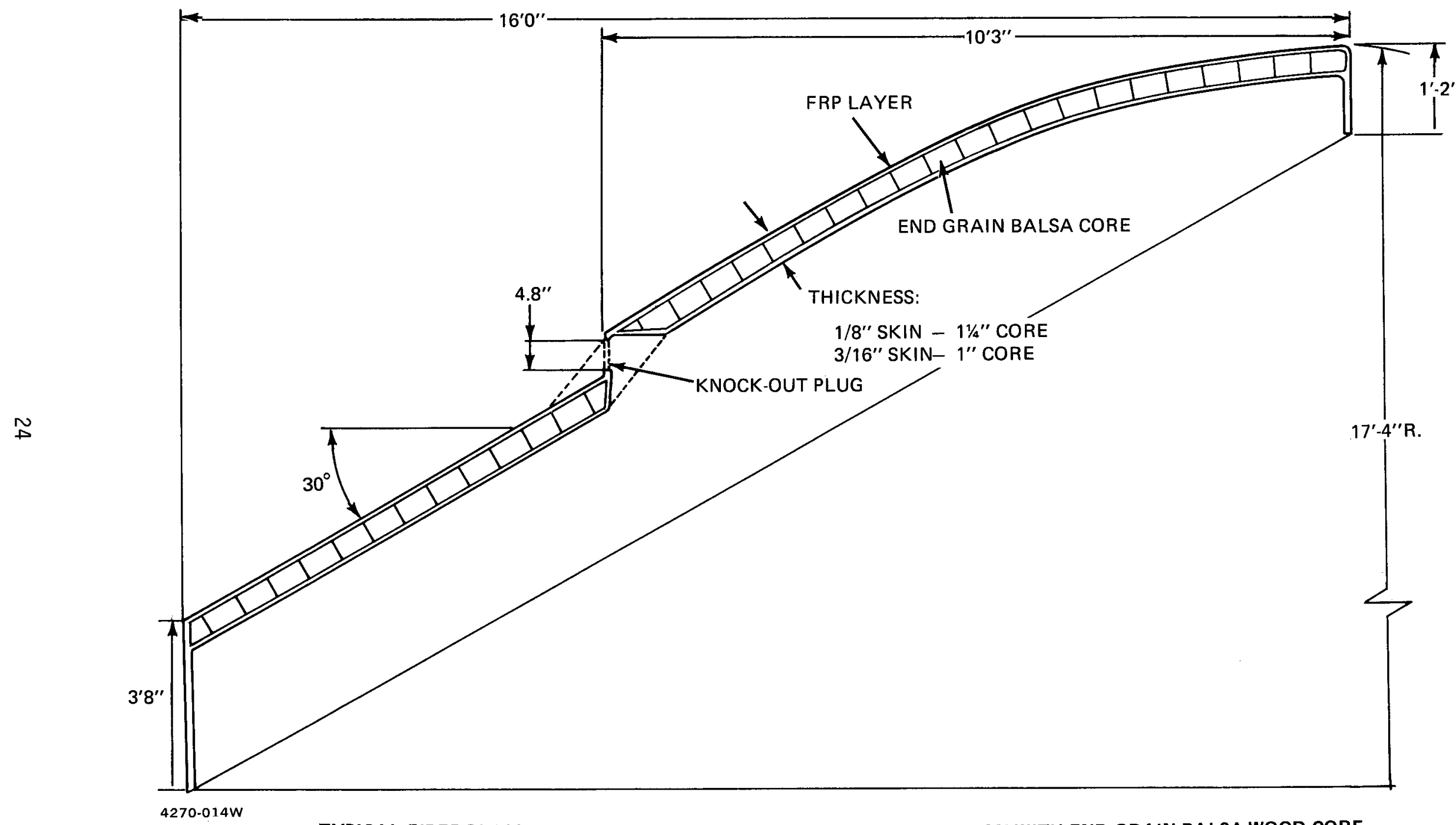

Figure 2-14. TYPICAL FIBERGLASS REINFORCED PLASTICS SANDWICH CONSTRUCTION WITH END GRAIN BALSA WOOD CORE 


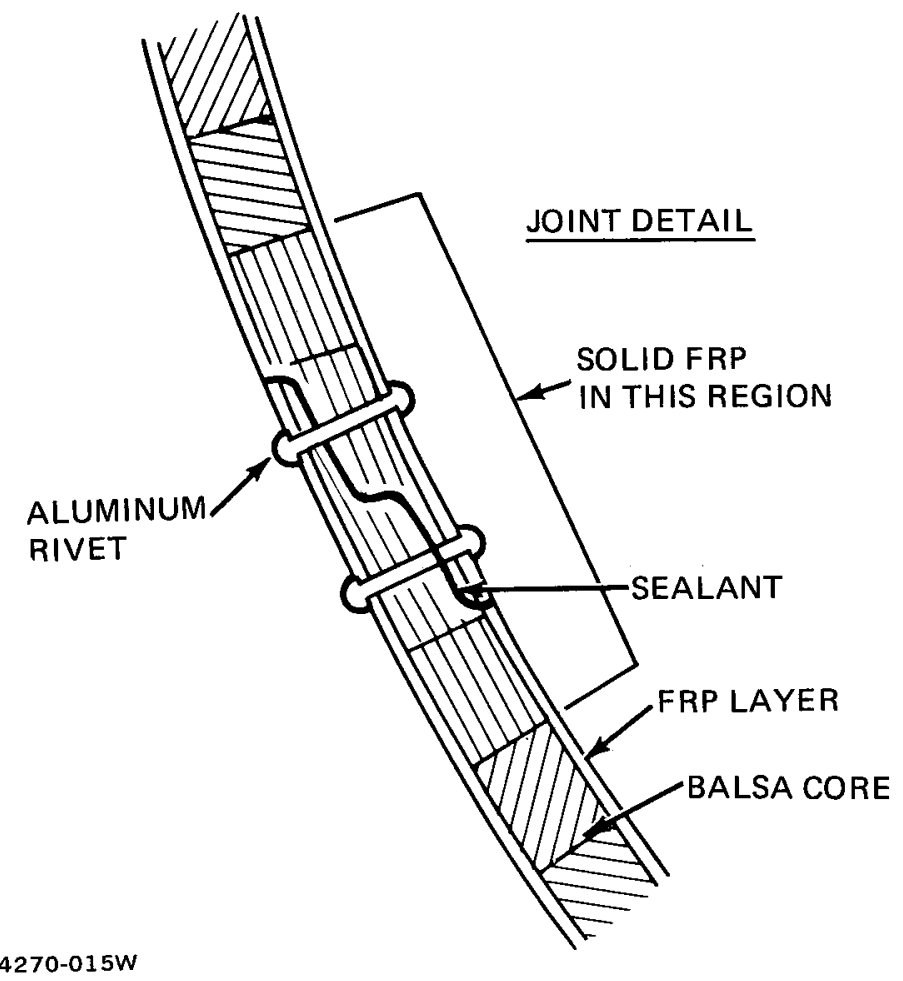

Figure 2-15. TYPICAL FRP PANEL JOINT CONSTRUCTION 
discussed in Appendix $B$, we have used the thicker one $(0.48 \mathrm{~cm}(3 / 16$ in.)) for the 6.9 and $11.0 \mathrm{~m}(22.5$ and $36 \mathrm{ft})$ turbine diameter designs, and the $0.32 \mathrm{~cm}$ $(1 / 8 \mathrm{in.})$ skin thickness for the $2.7 \mathrm{~m}(9 \mathrm{ft})$ rotor diameter design.

In order to prevent moisture from reaching the balsa core, Pearson's engineering department has found from experience that it is desirable to bring upper and lower FRP skins together in a sealed joint shown by Fig. 2-14; the larger the length of the joint, the better the probability that integrity of the seal will be maintained. This feature favors the dump diffuser configuration shape for FRP construction. Although an aluminum plate attachment flange is still essential, the longer FRP flange of the dump design provides a shorter, stronger, more rigid diffuser structure, for a given area ratio, than a baseline design geometry.

To facilitate highway shipping, no dimension of the FRP panels may exceed $3.7 \mathrm{~m}(12 \mathrm{ft})$. As a result the diffuser for the $11.0 \mathrm{~m}(36 \mathrm{ft})$ diameter rotor consists of 16 FRP panel segments and that for the $6.9 \mathrm{~m}(22.5 \mathrm{ft})$ diameter rotor has 10 segments. The $2.7 \mathrm{~m}(9 \mathrm{ft})$ diameter rotor need only have its diffuser made in two halves. As shown in Appendix $B$, the FRP segments may be nested on a truck trailer so that more than one complete DAWT set can be transported at a time.

The cylindrical column support, with aloft journal bearing for yaw movement, is equally suitable for the FRP panelled diffuser as for the completely aluminum-made diffuser.

The wall slots necessary to make the compact diffuser practical are facilitated in the FRP panel by localized knock-out plugs as indicated in Fig. 2-14. These plugs are created at a jog in the diffuser wall during the lay-up manufacturing process by omitting the balsa cone and forming a thin web of FRP alone along a portion of the panel's arc width. This web is then cut out and removed after the panel is cured. Sections of the jogged wall adjacent to the slot webs are built up to the full design thickness, including balsa core, to bridge the fore and aft parts of the panel.

\subsubsection{Foundation Design}

This study included consideration of foundation requirements. The single column support has been chosen for all diffuser material designs because it presents the least restrictions to field operational possibilities. For example, an alternative support approach that superficially appears attractive, provides multi-element supports in the nature of caster wheels, attached to the bottom rear end of the diffuser, and a front pivotal post. The wheels roll along a hardened ground level walkway as the diffuser yaws in response to free wind changes. However, the wheels could become immobilized by moderate snowfalls, blowing sand, rocks or debris, or freezing rain during low wind speed conditions.

But with the yaw bearing located high on a vertical column support, only the upper section of the column need rotate. The stationary bottom column section is attached to a subsurface foundation. The size and depth of the foundation depends on the maximum vertical and horizontal forces imposed by the wind on the diffuser as well as the DAWT weight and soil conditions. Therefore, each 
DAWT size has to be analyzed individually for an optimum foundation design; we have created three such designs.

The $9 \mathrm{ft}$ rotor diameter DAWT foundation is controlled by the overturning moment of the maximum wind. For a $30^{\circ}$ soil friction angle, the passive pressures of the soil on the side of the footing resist the wind moment. An unequal ground pressure distribution at the base of the footing also helps to resist overturning. As a result of this analysis the smallest size DAWT requires a poured concrete foundation of about $3.6 \mathrm{~m}(12 \mathrm{ft})$ depth and $1.8 \mathrm{~m}$ $(6 \mathrm{ft})$ in diameter. This is the simplest type of footing where soil conditions permits easy excavation.

The middle-sized DAWT, with a $6.9 \mathrm{~m}(22.5 \mathrm{ft})$ diameter turbine, requires a somewhat different foundation design to resist the wind forces and moments. For this size, a large diameter, shallow depth reinforced concrete slab is required. The shift in distribution of soil pressures overcomes the overturning moments. Steel rod reinforcement is needed to resist the shear loads in the large concrete slab. The slab diameter is established by the criterion that negative (tensile) ground pressures are not permitted. This basic type of foundation is appropriate for almost any soil condition but the reinforcement and large slab diameter approach becomes less attractive economically where piles may be used instead. For the $6.9 \mathrm{~m}(22.5 \mathrm{ft})$ rotor DAWT, a reinforced concrete slab of $1.5 \mathrm{~m}(5 \mathrm{ft})$ depth and $8.5 \mathrm{~m}(28 \mathrm{ft})$ diameter is found to be needed.

The largest size DAWT, with a $11 \mathrm{~m}(36 \mathrm{ft})$ diameter turbine, has peak wind forces and overturning moments which are best resisted by a foundation consisting of timber piles and a reinforced concrete pile cap. The downward and upward forces on the piles resist the wind induced overturning moment. The highest pile force is at the position furthest from the foundation center in the prevailing wind direction. The pile forces are symmetrical in proportion to their distance from an axis perpendicular to the wind direction. The weight of the DAWT and the pile cap is equally distributed among the piles. Timber is an economical pile material with good uplift capacity under most dry soil conditions. A local high ground water level at any given installation site would require the piles to be specially treated to prevent rot.

For the $36 \mathrm{ft}$ diameter rotor DAWT, a $1.2 \mathrm{~m}(4 \mathrm{ft})$ deep reinforced concrete pile cap of $7.6 \mathrm{~m}(25 \mathrm{ft})$ diameter would be poured over a circular array of twenty tapered piles of $0.3 \mathrm{~m}$ (12 in.) nominal diameter by $9.1 \mathrm{~m}(30 \mathrm{ft})$ long treated timber.

In all foundation designs a steel base plate and collar is anchored to the top of the concrete to receive the aluminum cylindrical pedestal for the DAWT. To facilitate final assembly and erection of the DAWT at a site, the bottom of the aluminum column features a structural hinge (see Fig. 2-10) to rotate the entire DAWT assembly from ground level to a vertical position as shown by Fig. 2-11. Lock fittings at the base keep the support column in this operational position until DAWT maintenance requires a return to the ground.

Details of the three foundation designs and costs are presented in Appendix D. 


\subsection{WEIGHT ESTIMATE}

From the preliminary stress analyses accompanying each point design for the different material approaches the DAWT weight estimates shown by Table 2-4 have been generated. These data are for a baseline diffuser configuration with $30^{\circ}$ half-angle and a 2.75 area ratio. For a rotor diameter increase by a factor up to 4 , the trends of component and system weight increase with turbine diameter increase are shown by Fig. 2-16 (sheet 1). Relative to the smallest rotor diameter $(2.7 \mathrm{~m}(9 \mathrm{ft})$ ) studied, the ferrocement diffuser approach produces the lowest rate of weight increase with rotor size growth. The use of FRP panels, instead of aluminum skin, for the diffuser yields a slower rate of increase of total above ground system weight with increase of rotor diameter above $6.9 \mathrm{~m}(22.5 \mathrm{ft})$. Below $6.9 \mathrm{~m}$, the relative change of total above ground system weight with rotor size appears insensitive to the material used for the diffuser. The turbine assembly weight increases slowly with rotor size change. Because the wind power conversion potential increases with the second power of rotor diameter change, the ratio of DAWT weight-topower changes much slower than the weight alone (see sheet 2 of Fig. 2-16). For ferrocement construction of the diffuser the relative weight/power ratio is almost constant as rotor size increases, as shown in Fig. 2-16 (sheet 2). While the FRP panelled diffuser approach produces about $30 \%$ greater relative weight-to-power ratios with a $400 \%$ growth in rotor diameter, it is less than half the comparable ratio increase for the all-aluminum construction.

For the FRP panel/aluminum frame diffuser design approach, the weight of the fiberglass fraction varies from almost $60 \%$ of the total, for the smallest DAWT studied, to about $42 \%$ for the $11 \mathrm{~m}$ (36 ft) turbine diameter design. This diminishing FRP fraction trend points out the more rapid growth with DAWT size of the ring and longeron structural frame requirements to absorb wind loads.

In this total system weight analysis, the basic design of the support column and yaw bearing is assumed unchanged for all material approaches except the ferrocement version. For the latter, a $10 \%$ increase in material thickness is assumed to accommodate the much heavier diffuser weight.* While the predominant material of the support component is aluminum, between 26 and $32 \%$ by weight is steel; this material is principally used in the yaw bearing plates and positioning clamp. As DAWT size increase, the weight fraction of steel in the support subsystem slowly increases to absorb the increased diffuser weight and wind loading.

The weight of the DAWT foundation is not well correlated to DAWT size because foundation designs are not geometrically similar. Each footing situation is predicated more on a cost optimized solution from among several options rather than on a single geometrically scaled approach. The use of timber pilings for the $11 \mathrm{~m}$ (36 ft) DAWT size, with a rather shallow concrete cap is actually lighter in weight than the deeper concrete cylinder foundation for the $6.9 \mathrm{~m}$ $(22.5 \mathrm{ft})$ DAWT. However, the heavier type foundation is estimated to cost less than a pile supported foundation for the intermediate sized DAWT; these foundation design cost relations reverse for the largest sized DAWT.

\footnotetext{
*This simplifying assumption for ferrocement does not affect the general conclusions of this report. SERI reviewers caution that a more rigorous stress analysis is needed to assure that positive safety factors exist.
} 
Table 2-4. WEIGHT COMPARISON OF 3 DAWT SIZES WITH DIFFERENT DIFFUSER CONSTRUCTION MATERIALS (BASELINE, $30^{\circ}$, DIFFUSER CONFIGURATION, 2.75 AREA RATIO) (ALL WEIGHTS IN POUNDS)

\begin{tabular}{|c|c|c|c|c|c|c|c|c|c|}
\hline \multirow{2}{*}{ 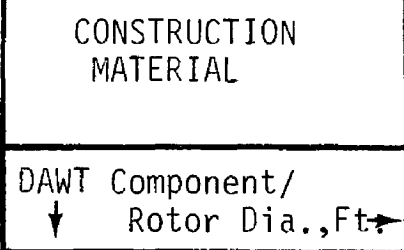 } & \multicolumn{3}{|c|}{ ALL ALUMINIMM } & \multicolumn{3}{|c|}{ FRP PANELS/ALUM. FRAME } & \multicolumn{2}{|c|}{ FERRO CEMENT DIFFUSER } & \multirow[t]{2}{*}{ REMARKS } \\
\hline & 9 & 22.5 & 36 & 9 & 22.5 & 36 & 9 & 22.5 & \\
\hline Diffuser & 940 & 9,320 & 40,530 & $\begin{array}{r}1,405 \\
\text { Note } 1\end{array}$ & $\begin{array}{l}12,730 \\
\text { Note } 2\end{array}$ & $\begin{array}{c}37,900 \\
\text { Note } 3\end{array}$ & 5,400 & 37,600 & $\begin{array}{r}\text { Note } 1-59.8 \% \text { FRP } \\
2-46.7 \% \text { FRP } \\
3-42.4 \% \text { FRP } \\
\text { Balance Aluminum }\end{array}$ \\
\hline $\begin{array}{l}\text { Yaw } \\
\text { Bearing } \\
\text { and Support } \\
\text { Pedestal }\end{array}$ & $\begin{array}{r}595 \\
\text { Note } 4\end{array}$ & $\begin{array}{r}5,340 \\
\text { Note } 5\end{array}$ & $\begin{array}{l}19,310 \\
\text { Note } 6\end{array}$ & $\begin{array}{r}595 \\
\text { Note } 4\end{array}$ & $\begin{array}{r}5,340 \\
\text { Note } 5\end{array}$ & $\begin{array}{l}19,310 \\
\text { Note } 6\end{array}$ & $\begin{array}{r}655 \\
\\
\text { Notes } \\
\quad 4,8\end{array}$ & $\begin{array}{c}5,900 \\
\text { Notes } \\
5,8\end{array}$ & $\begin{array}{l}\text { Note } 4-25.6 \% \text { St } 1 . \\
5-29.9 \% \text { St } 1 . \\
6-32.4 \% \text { St } 1 . \\
\text { Balance Aluminum } \\
\text { Note } 8-110 \% \text { of } \\
\text { FRP and Alum. } \\
\text { Versions }\end{array}$ \\
\hline $\begin{array}{l}\text { Turbine and } \\
\text { Centerbody }\end{array}$ & 975 & 3,275 & 6,650 & 975 & 3,275 & 6,650 & 975 & 3,275 & Various Materials \\
\hline Total Above Ground & 2,510 & 17,935 & 66,490 & 2,975 & 21,345 & 63,860 & 7,030 & 46,775 & \\
\hline Foundation & 42,150 & 400,500 & $\begin{array}{l}256,000 \\
\text { Note } 7\end{array}$ & 42,150 & 400,500 & $\begin{array}{l}256,000 \\
\text { Note } 7\end{array}$ & 42,150 & 400,500 & $\begin{array}{l}\text { Concrete with St1. } \\
\text { reinforcements and } \\
\text { flanges. } \\
\text { Note } 7 \text { - does not } \\
\text { include about } \\
40,000 \text { lbs. of } \\
\text { timber pilings }\end{array}$ \\
\hline
\end{tabular}




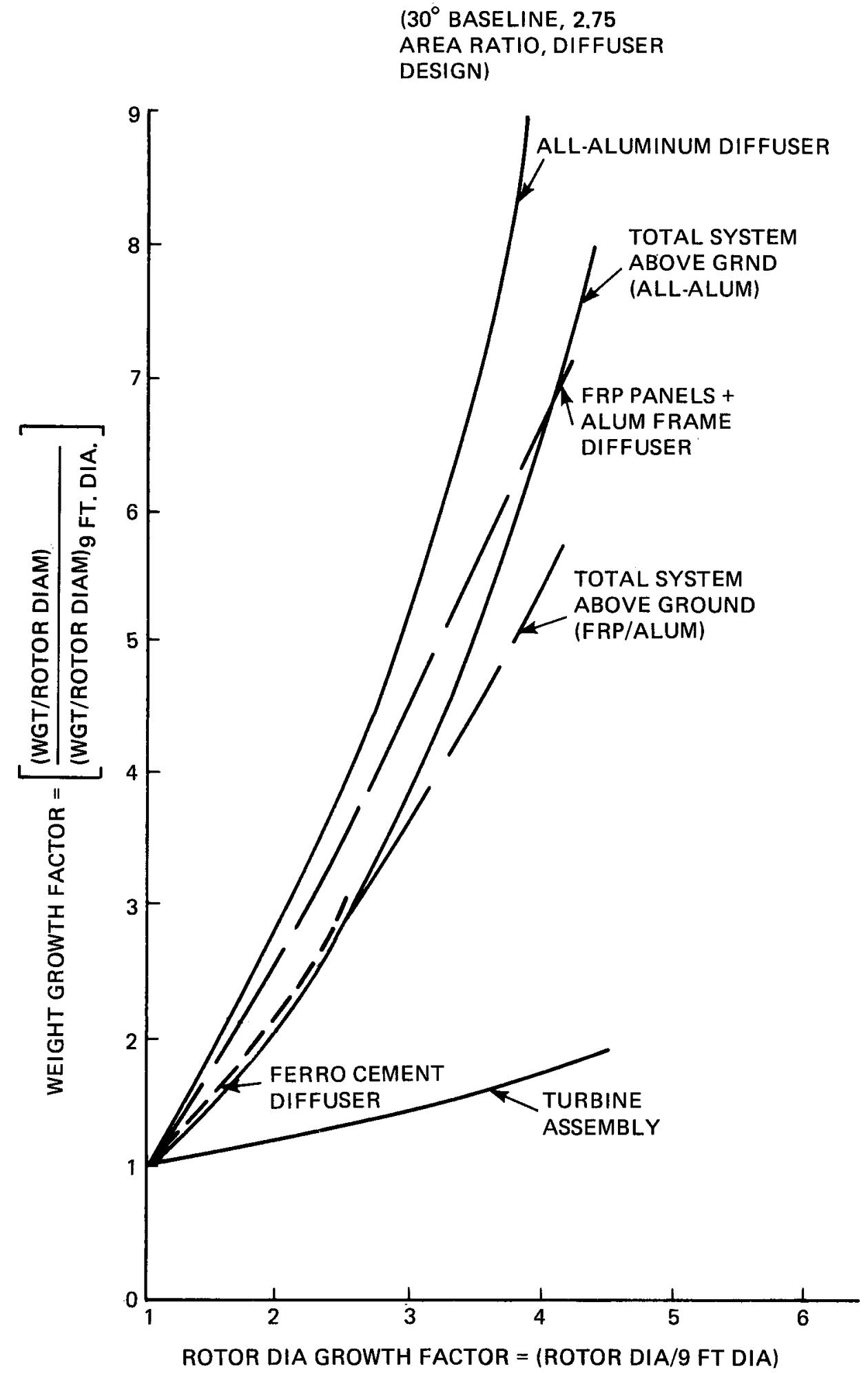

a) WEIGHT VARIATION WITH ROTOR SIZE APPROACHES (SHEET 1 OF 2) 


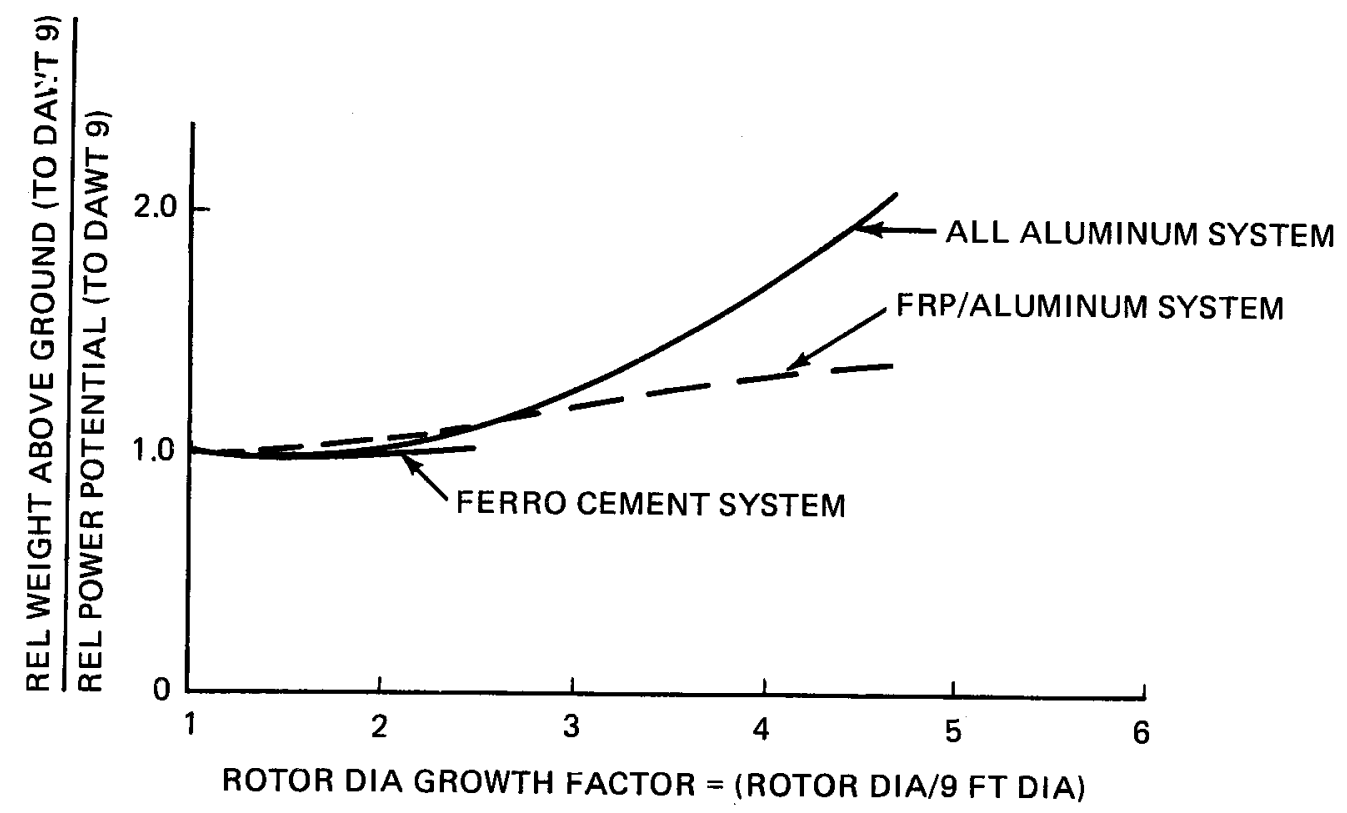

b) WEIGHT-TO-POWER RATIO VARIATION WITH ROTOR SIZE (REL TO DAWT WITH 9 FT DIA ROTOR)

0647-017W 1467-018(T)

Figure 2-16. RELATIVE DAWT CHARACTERISTICS FOR THREE CONSTRUCTION APPROACHES (SHEET 2 OF 2) 
It is concluded from this design study that the widely assumed (e.g., Ref. 10a) preliminary estimates of weight growth to the third power of relative characteristic (e.g., rotor) dimension $\left(W \approx D^{3}\right)$, and weight-to-power ratio growth directly with characteristic dimensions $[(W / \mathbb{P}) \approx D]$ lead to incorrect conclusions. Within the DAWT system sizes studied here, there is very evident economies of scale of materials utilization with geometrically larger unit sizes and with different constructional materials. These data do not invalidate, however, the general assumption that at some critical size further geometric scaling up will lead to extraordinary increases in weight (and weight/power ratio) because other and new design considerations will have to be introduced to assure integrity and reliability.

Table 2-5 lists our weight estimates for two diffuser configurations that are different from the $30^{\circ}$ baseline shape used for the point designs. These new values are lower than those in Table 2-4 and were obtained from the geometric relations that characterize the diffuser shape change. Component elements that primarily are affected are the diffuser skin area and the longeron length.

Increasing the baseline half angle from 30 to $45^{\circ}$ results in a $29 \%$ reduction in slant length of the diffuser, and in the skin and longeron weight. This effect is included in the diffuser component weight estimates, for allaluminum construction of DAWT weights in Table 2-5. For the dump diffuser with $45^{\circ}$ half angle, the diffuser skin and longeron component weights are $51.8 \%$ of their counterparts in the baseline - $30^{\circ}$ design. ${ }^{\star}$ On an overall consideration for a constant 2.75 diffuser area ratio, the weight of the improved configuration DAWT (i.e., $45^{\circ}$ half angle, dump diffuser) for above ground equipment is about $75-80 \%$ of the baseline configuration for which the point designs were made.

In contrast to Betz' approximate theory (Ref. 10a) that relates the increase of weight/power ratio directly with rotor diameter, a 0.36 power law exponent (i.e., D.36) is a better approximation to trend the $30^{\circ}$ baseline al1-aluminum point designs over a $4: 1$ range of rotor diameter change. Furthermore, for the FRP panelled, $45^{\circ}$ dump diffuser configuration the exponent reduces to 0.29 over the same range of rotor diameter change. Because it was possible to make only two ferrocement point designs (see Subsection 2.3.2), and over a much narrower range of rotor sizes, we do not attempt to establish more generalized scaling relationships for this material.

\subsection{TURBINE DESIGN}

Preliminary designs were developed by Grumman Energy Systems (GES) for rotor diameters of $2.7,6.9$ and $11 \mathrm{~m}(9,22.5$, and $36 \mathrm{ft})$ based on the $8 \mathrm{kWWTG}$ $(10 \mathrm{~m}(33 \mathrm{ft})$ rotor diameter) GES design sponsored by the DoE Rocky Flats Wind Systems Program.

\footnotetext{
*In the "dump" diffuser design, the height of the exit plane flange increases the ring depth. But the principal load carrying elements of the C-shaped exit ring are its end legs. Lengthening the connecting radial web, then, leads to relatively small increases in the total ring weight. For simplicity, this small weight increment has been neglected here. But the small expected overall weight growth should result in an incremental cost that likewise is small and within the accuracy of this preliminary estimate.
} 
Table 2-5. WEIGHT COMPARISON OF 3 DAWT SIZES

WITH DIFFERENT DIFFUSER CONSTRUCTION MATERIALS

(IMPROVED, $45^{\circ}$, DUMP DIFFUSER CONFIGURATION, 2.75 AREA RATIO) (ALL WEIGHT IN POUNDS)

\begin{tabular}{|c|c|c|c|c|c|c|c|c|c|}
\hline $\begin{array}{l}\text { CONSTRUCTION } \\
\text { MATERIAL } \\
\text { (configuration) } \\
\end{array}$ & \multicolumn{3}{|c|}{$\begin{array}{c}\text { ALL ALUMINUM } \\
\left(45^{\circ} \text { Baseline DAWT }\right)\end{array}$} & \multicolumn{5}{|c|}{$\begin{array}{c}\text { FRP PANELS/ALUM. FRAME FERRO CEMENT DIFFUSER } \\
\begin{array}{c|c}\left(45^{\circ} \text { DUmp DAWT }\right) & \left(45^{\circ} \text { Dump DAWT }\right) \\
\end{array}\end{array}$} & \multirow[t]{2}{*}{ REMARKS } \\
\hline $\begin{array}{l}\text { DAWT Components/ } \\
\downarrow \quad \text { Rotor Dia.,Ft. } \neq\end{array}$ & 9 & 22.5 & 36 & 9 & 22.5 & 36 & 9 & 22.5 & \\
\hline Diffuser & 815 & 7,835 & 32,880 & $\begin{array}{l}900 \\
\text { Note } 1\end{array}$ & $\begin{array}{r}8,240 \\
\text { Note } 2\end{array}$ & $\begin{array}{l}24,530 \\
\text { Note } 3\end{array}$ & 2,800 & 19,480 & $\begin{aligned} \text { Note } 1-48.3 \% \text { FRP } \\
2-37.4 \% \text { FRP } \\
3-33.1 \% \text { FRP } \\
\text { Balance Aluminum }\end{aligned}$ \\
\hline $\begin{array}{l}\text { Yaw Bearing } \\
\text { and } \\
\text { Support } \\
\text { Pedestal }\end{array}$ & $\begin{array}{c}595 \\
\text { Note } 4\end{array}$ & $\begin{array}{r}5,340 \\
\text { Note } 5\end{array}$ & $\begin{array}{l}19,310 \\
\text { Note } 6\end{array}$ & $\begin{array}{l}595 \\
\text { Note } 4\end{array}$ & $\begin{array}{r}5,340 \\
\text { Note } 5\end{array}$ & $\begin{array}{l}19,310 \\
\text { Note } 6\end{array}$ & $\begin{array}{l}655 \\
\text { Notes } \\
4,7\end{array}$ & $\begin{array}{c}5,900 \\
\text { Notes } \\
5,7\end{array}$ & $\begin{array}{l}\text { Note } 4-25.6 \% \text { St1. } \\
5-29.9 \% \text { St } 1 . \\
6-32.4 \% \text { St1. } \\
\text { Balance Aluminum } \\
\text { Note } 7-110 \% \text { of FRP } \\
\text { and Alum. Versions }\end{array}$ \\
\hline $\begin{array}{l}\text { Turbine and } \\
\text { Centerbody }\end{array}$ & 975 & 3,275 & 6,650 & 975 & 3,275 & 6,650 & 975 & 3,275 & Various Materials \\
\hline $\begin{array}{l}\text { Total Above } \\
\text { Ground Weight }\end{array}$ & 2,385 & 16,450 & 58,840 & 2,470 & 16,855 & 50,490 & 4,430 & 28,655 & \\
\hline Foundation & \multicolumn{9}{|c|}{ Same as Baseline Diffuser Construction Materials (See Table 4) } \\
\hline $\begin{array}{l}\% \text { of } 30^{0} \\
\text { Baseline Config. } \\
\text { Weight (see } \\
\text { Table } 4 \text { ) }\end{array}$ & 95 & 91.7 & 88.5 & 83 & 79 & 79 & 73 & 74 & \\
\hline
\end{tabular}

$1467-021(T)$ 
The wind turbine consists of three untwisted, constant chord blades, of $10 \%$ tip solidity and fabricated from 6061-T6 aluminum extrusions. The blade cross sections are typically of a modified NACA 4418 airfoil (Ref. 10b) shape with chord lengths of $30.5,76$, and $114 \mathrm{~cm}(12,30$, and $45 \mathrm{in}$.) for rotor diameters of $2.7,6.9$, and $11 \mathrm{~m}(9,22.5$, and $36 \mathrm{ft})$ respectively. For the largest rotor diameter the blade section chord exceeds the current extrusion press capacity of $91 \mathrm{~cm}$ (36 in.). Consequently, for this chord size only, the blade trailing section is a separate extrusion that is spanwise seam welded to the front torsion box section extrusion along the top and bottom surfaces. This latter design approach adds somewhat to the blade fabrication cost but avoids the development and capital costs of a new, larger capacity extrusion press for limited production runs.

The central spar box of the aluminum blade extrusion is attached by two cadmium plated, high strength bolts to stainless steel blade stubs fastened to the low speed drive shaft as shown by Fig. 2-17. The step up in drive shaft rotational speed to the induction generator is achieved by a commercial double helical steel gearbox with a gear ratio, typically, of 15:1. Both Dodge Manufacturing Co. and Browning Manufacturing Division (of Emerson Electric Co) gear boxes for Class I service have been selected; the latter company's product line is applied only to the lowest output ratings of the DAWT. Up to $30 \mathrm{~kW}(40 \mathrm{hp})$ generator rating, Dayton drip proof, three phase induction motors $(240 \mathrm{~V}, 60 \mathrm{~Hz}, 1800 \mathrm{rpm})$ are specified as typical generators. Typical larger generator sizes have been selected from the Westinghouse, 240/480 V, 60 $\mathrm{Hz}, 1800 \mathrm{rpm}$, product line of induction motors.

Active pitch control of the blades is employed to start up the turbine at the low wind speed end of the operating regime. It is also used to feather the turbine blades for wind speeds above $40 \mathrm{mph}$. The control activates a primary and secondary electromechanical actuator which alters the blade pitch by push-pull rods. A programmable micro-processor is on board for the turbine control logic.

The DAWT in stand-alone status, is assumed connected electrically to a stand-by diesel-electric powered grid. In the event of grid power loss, the turbine has a permanent magnet generator driven off the high speed shaft for emergency pitch-change actuator operation.

The primary motor drive for the actuator has a design lifetime of $10^{6} \mathrm{in}$. of travel. Because of the randomness of the natural wind it is impossible to specify the time needed before replacement of the drive is necessary. All other components are designed for very long lifetime (i.e., 20 - 30 years) low maintenance operation.

The generator, gear box, transmission coupling, and accessories are mounted onto a rigid bed plate fabricated of Cor-Ten steel plate and channel. The cylindrical enclosure which forms the turbine centerbody is made of aluminum. Access doors in the enclosure permit maintenance and servicing.

The centerbody is concentrically mounted within the diffuser by means of three sets of struts attached to the diffuser primary structure (i.e, rings and longerons). The blades are located at the upstream end of the centerbody and the mid chord position of the blades coincide with the center of the

cylindrical shroud. The 3\% R clearance between the blade tip and shroud ID is designed to suppress blade end flow losses and still allow for blade radial growth because of centrifugal loading. 




Figure 2-17. TYPICAL DAWT TURBINE ASSEMBLY FOR 22.5 FT ROTOR DIAMETER 
There is no yaw control directly provided to the turbine because the response to major wind change is supplied by the yaw control for the entire DAWT unit; minor wind directional changes for $\pm 15^{\circ}$ off-axis variations need not be followed at all because of the inherent insensitivity of the DAWT concept's performance to such changes (Ref 6a).

Augmented output of the DAWT's turbine is linked to requirements and characteristics of the diffuser. For a given diffuser geometry, from a theoretical standpoint the maximum augmentation tends to require low turbine loading coefficient $C_{T}$, values as shown by Fig. 2-18. However, for high diffuser efficiencies, $n_{D}$, (i.e., greater than $85 \%$ ) the rate of performance fall off is relatively less for higher $C_{T}$ values than for values less than optimum, typified by the curves of Fig. 2-18.

Turbine cut-in normally occurs at high tip speed ratios, $R_{\omega} / V_{2}$, typically around 12. As the free wind speed increases, tip speed ratio decreases for constant rotational speed, $\omega$. As a result, the power coefficient, $C_{\mathbb{P}}$, increases until a rated value is attained at a tip speed ratio of about 5 .

Further increase in wind speed reduces the tip speed ratio below 5 and causes the turbine power coefficient and turbine efficiency to fall off. The decrease in $C_{\mathbb{P}}$ has the effect of offsetting somewhat the increasingly available natural wind power. This tendency toward aerodynamic self limitation of shaft power may not eliminate, however, the need for a shaft-mounted brake or a turbine control to feather the blades at very high wind speeds or for special situations like maintenance periods.

The characteristics of the diffuser do not upset this normally inverse relation of $C$ and available wind power at high wind speeds. However, the enhanced quantity of air flow processed by the DAWT results in a higher local air speed at the upstream face of the DAWT's turbine than for an equal diameter bare turbine exposed to the same free wind conditions.

\subsection{ICE AND SNOW LOADS}

Although specific provisions for snow and ice loads were not made in the current DAWT designs, some discussion is warranted. In response to our requests to SERI for this type of load criteria information, we were advised that none were available during our design phase. Because the static structure of the DAWT is designed with ample safety margin for the very high wind condition, we believe it is inherently structurally safe for static loads equivalent to $2.54 \mathrm{~cm}$ ( 1 in.) thickness of ice. Without actual field tests we are unable to realistically assess the effect of ice or snow on DAWT

operation; several possible remedies are available such as electrical heating of leading edges and the use of ohmic and frictional heating from the electric generator and gear box. It might be noted that the DAWT may provide greater protection than for bare turbines from ice cast off from the blades to the ground. 


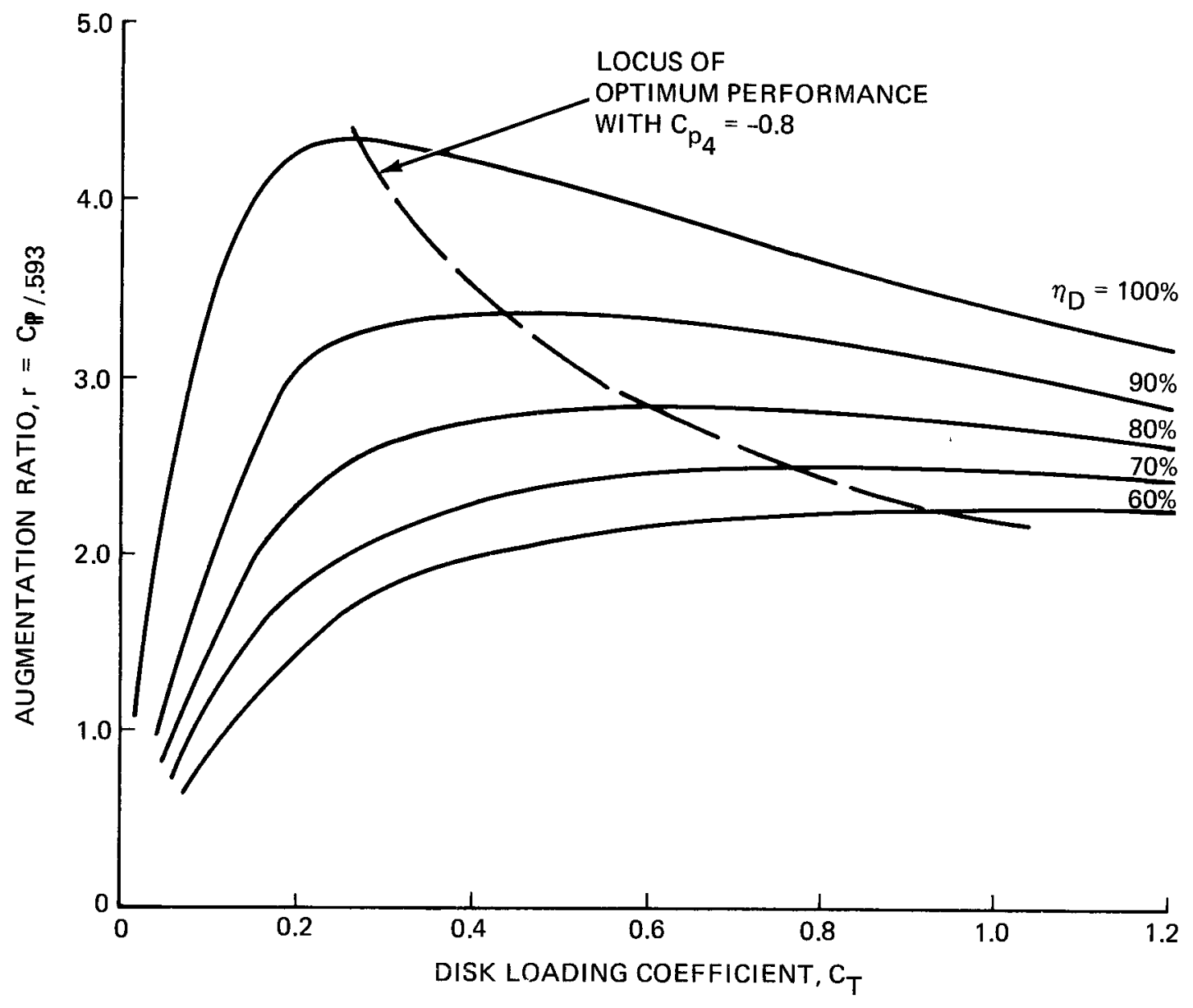

0647-018W

Figure 2-18. TYPICAL THEORETICAL PERFORMANCE FOR DAWT $\left(A_{4} / A_{2}=2.78\right.$ and $\left.C_{p_{4}}=-0.8\right)$ 
SECTION 3.0

MANUFACTURING APPROACH AND COSTING

In this section we develop the cost estimates for the three different size DAWT point designs in each of the three materials investigated. A prerequisite to the financial estimate is an assumed model for the production approach.

Primarily because the candidate major marketing areas for wind generators are regionally segregated (e.g., high plains, Pacific Northwest, Southern Appalachians, Northeast and Texas Gulf Coast) and long distance shipping of large components is very costly, it was assumed early in the project that DAWT production centers would be established within candidate marketing areas.

Another element that would influence production center selection is the regional cost index of labor and materials and possible inducements of local economic development commissions such as business tax concessions, low interest loans, plant availability, and labor training programs. In this investigation we apnlied regional wind power potential and regional cost index criteria in establishing a manufacturing approach scenario, al though the reputation of regional labor force skills also shaded our decisions.

Table 3-1 presents construction project cost indices for labor and materials for 11 selected metropolitan areas within top candidate wind marketing regions (Ref. 11).

\subsection{APPLICATION SCENARIO}

For this study, a typical business scenario to accommodate an annual production rate of 100 units is a production center in the Wichita, Kansas metropolitan area. This industrial center with a population of over 250,000 already has a significant private airplane manufacturing base and a labor and management resource pool knowledgeable in the metal trades and relatively low in labor costs. It is also located in one of the highest wind power potentia] regions. Throughout this area the electrical needs are supplied by several private utilities and electrical generating cooperatives such as Central Kansas Electrical Cooperative, Sumner-Cowley Electric Cooperative and Central Telephone and Utilities Corp (CT\&U). Crisscrossing this part of Kansas are transmission lines of the power and distribution companies, thereby, providing an existing grid for connection to wind power arrays. In addition to large centralized steam turbine plants, these Kansas utilities typically maintain smaller (1 - $15 \mathrm{MW})$ generators driven by diesel engines or gas turbines for line voltage boosting and to meet local peak loads. These smaller production facilities provide opportunities for wind energy applications as petroleum fuel savers. During 1973, CT\&U generated 4, $506,000 \mathrm{~kW}$ hours from these small power installations (Ref. 12). The diesel and gas turbine generating installations had an asset value of about $\$ 6,311,000$, used $\$ 180,861$ in fuel and had an operations and maintenance (0\&M) cost of $\$ 157,541$ (Ref. 12). Using a typical utilities annual charge factor of 0.18 , the production cost of diesel and gas turbine generated electricity in 1973 was $\$ 0.0242 \mathrm{~kW} \mathrm{~h}$ for capital cost, 
Table 3-1. REPRESENTATIVE 1979 REgIONAL CONSTRUCTION COST INDICES (Ref. 11)

\begin{tabular}{|c|c|c|c|}
\hline \multirow[b]{2}{*}{ Metropolitan Area } & \multicolumn{3}{|c|}{ Indices* } \\
\hline & Labor & Material & Total \\
\hline Charlotte, NC & 71 & 98 & 83.5 \\
\hline Roanoke, VA & 74 & 100 & 86 \\
\hline Lubbock, TX & 79 & 100 & 89 \\
\hline Dallas, TX & 86 & 96 & 90 \\
\hline Portland, MA & 81 & 103 & 91 \\
\hline Jacksonville, FL & 84 & 101 & 92 \\
\hline Wichita, KA & 91 & 99 & 94 \\
\hline OKlahoma City, OK & 89 & 101 & 94.5 \\
\hline Binghamton, NY & 91 & 99.5 & 95 \\
\hline Billings, MT & 90 & 102 & 96 \\
\hline Providence, RI & 95 & 101 & 97 \\
\hline Denver, Co & 97 & 103 & 100 \\
\hline St. Louis, MO & 103 & 99 & 101 \\
\hline Portland, OR & 109 & 98.5 & 104 \\
\hline New York, NY & 113 & 100 & 107 \\
\hline
\end{tabular}

\footnotetext{
*Index of 100 is based on the average of conditions in 30 major U.S. and Canadian cities as of July 1,1978 . Material index base $(=100)$ represents average of 100 construction project materials and their typical relative quantities. Labor index base $(=100)$ represents average of 30 labor categories with typical construction project weighting but not relative productivity between categories or cities.
} 
$\$ 0.039 / \mathrm{kW} \mathrm{h}$ fuel cost, and $\$ 0.034$ in $0 \& M$, for a total cost of $\$ 0.315 / \mathrm{kW} \mathrm{h.}$ *

Therefore, it is not surprising that CT\&U used this equipment at only $9.65 \%$ of its total installed energy production capacity. As will be seen in Section 4.0 , the projected cost of energy of substitute wind energy generating installation will be considerably less than CT\&U's marginal cost of production from its oil burning equipment.

Our assumed typical DAWT array installation site is located in Harper County in south central Kansas. The governmental seat of this 801 sq mile county, the city of Harper, is about 44 miles $(73 \mathrm{~km})$ southwest of Wichita and is linked by the Atchison, Topeka and Santa Fe rajlroad and three primary nighways. Harper County had a population of 8319 in 1973 (13) and the land is almost entirely used for agriculture and composed primarily of deep loam and sandy loam, an important consideration for designing DAWT foundations. The city of Harper is strategically placed, about midway between CT\&U's $25 \mathrm{MW}$ electric generation installation at Pratt and its $40 \mathrm{MW} p l$ ant at wellington in adjacent Pratt and Sumner Counties, respectively (Ref. 14).

In order to minimize costs of labor and equipment modification to prepare DAWT sites and foundations and to assemble and electrically connect to the utility's transmission line, we assume a 10 by 10 array of 100-150 kW rated DAWTs. The array is located just north of the Harper City limits in Township 6 and adjacent to an E-W running complex of private and REA power transmission and distribution lines. The DAWTs can be spaced between 0.2 and 0.5 miles (or more) apart and will "farm" the wind in a $4-25 \mathrm{sq}$ mile area on a noninterfering basis with the original crop or grazing use of the 1 and. The required dedicated land area surrounding the 100 DAWT foundations is a total of about $0.2 \%$ of a square mile, or a little more than one acre.

This Harper County model is not an isolated case in the high plains states. Literally hundreds of such opportunitites exist within the rural area bounded by the low labor cost, metropolitan area industrial centers of Dallas, Oklahoma City, and Wichita.

* SERI reviewers hold that DAWT should compete with conventional WECS and not diesel and gas turbine generating installations for peak load. However, DAWT's competitiveness with conventional WECS is automatically gaged by its comparison to DoE goals shown by Fig. 4-1 and 4-2. (To date, these goals have yet to be demonstrated by actual conventional WECS.) Hard operational cost data exists for diesel and gas turbines and the trend is upward as fuel cost escalates beyond the 1973 example year. Renewable energy sources like WECS and DAWT must be shown to compete with, and attractively displace, the non-renewable petroleum-fueled energy converters.

${ }^{\star \star}$ SERI reviewers comment that WECS cannot substitute for peakload capacity credit without energy storage provisions. The issue of capacity credit is a current institutional barrier and is beyond the scope of the present investigation. However, there are numerous contemporary reports and analyses that treat the viability of wind energy systems as fuel savers without energy storage, and without the need for capacity credit considerations. 
Furthermore, the 100 units described above at the Harper County location, only "farm" a maximum of about $3 \%$ of the county land area. Therefore the potential exists for 25 or 30 more such arrays, for a total of about 3000 units in the 100 - $150 \mathrm{~kW}$ rating class in this one Kansas county alone. This market would absorb 30 years of production at the assumed 100 annual rate, or 6 years at a yearly average rate of 500 units; at the higher production rate the average unit cost would be approximately $80 \%$ of the $100 /$ year rate, assuming an overall $90 \%$ learning curve experience (Ref. 14a) for the variable production costs and a prorata distribution for the fixed production costs.

\subsection{MANUFACTURING CONSIDERATIONS}

Because of the DAWT's fundamental requirements for a foundation and for standing apart from other structures, it has two manufacturing aspects. Part of the fabrication cycle is in a controlled manufacturing environment just like the conventional consumer product industry. A second part of the cycle occurs at the final installation site in an environment encountered by the building and public works construction industry. The permissible size and weight limits of conventional shipping modes establishes the boundary between the factory and field portions of a complete DAWT manufacturing cycle. Except in details, the field portion contains the same basic steps regardless of what material the DAWT diffuser is made; land at the site must be prepared, a foundation made, the DAWT components assembled, the assembly erected onto the foundation, and the generator unit hooked up and checked out.

These individual steps in the field may be separated by many months because of such factors as the need for the poured concrete to cure to maximum strength, and seasonal constraints on outdoor work.

In multiple unit arrays such as described above, the opportunity to pursue just one step at a time, e.g., land preparation, offers a field situation in which economies of scale of operations through efficient mobilization of manpower and machines and learning curve benefits, can lead to a lowered per unit cost as opposed to a single isolated installation. However, the foundation cost estimate included in Appendix $D$ has not assumed any economic benefit of multi-unit arrays, and therefore must be considered a conservative estimate in the context of our application scenario; a 90 - 95\% learning curve cost trend could reasonably be expected (Ref. 14a) which could lower the average per unit cost to between 59 and $77 \%$ respectively on an uninterrupted total lot of 100 .

The portion of the fabrication cycle accomplished in a controlled factory environment is next considered. In this situation, the particular needs of each of three constructional materials are addressed. However, certain elements and concerns are common to all materials.

For example, it is tacitly assumed that engineering design and development testing had been completed in a previous phase and the design lines of the commercialized model are frozen. Thus, tooling, processes, and material specifications will not change during a production run. It is assumed further that facilities exist which are accessible to road, rail or water shipping modes and that DAWT sub assemblies are produced to the largest size, weight and complexity compatible with these shipping modes. 
The availability, skills, and cost of the local labor force are assumed compatible with the production requirements of the materials of construction and DAWT size, and the cost estimates generated here. If skills presently are not available, it is assumed that labor pool training will precede employment and its costs be deferred by local or federal government grants or tax incentives except where of a minor nature. The precedent for such job training programs is widespread as deliberate government policy for socio-economic purposes.

It is assumed also that basic materials are available in the sizes, quantities, and to the specifications required, and at the average cost index associated with the regions such as listed in Table 3-1.

Because each construction technique has unique problems and production requirements, we break down the discussion of manufacturing approach by the diffuser material used.

\subsubsection{Ferrocement}

In Section 2.0 it was concluded that only the small and intermediate sized diffuser could be designed in ferrocement with any confidence because of the present state of knowledge and experience. The David J. Seymour organization indicates that indoor production facilities in former warehouses and even barns could be used to satisfy the batch lot manufacturing requirements of the diffuser structure. The marketing region would be serviced by this production center until market saturation would be achieved. This market centered manufacturing approach has the effect of reducing product transportation costs, of minimizing plant investment* and greatly involving local labor and locally rented heavy equipment, although for the relatively short term (i.e., less than 10 years.)

The latter aspect of duration could take advantage of a locally low cost, but perhaps less dedicated or less productive labor pool than provisions for long term commitment. On the other hand ferrocement fabrication requires relatively unskilled labor, for the most part, so investment in training should not be great. The critical human element problem to the short term, market located production center concept is the small cadre of production leadmen and on-site managers. Major relocation of these essential employees every few years may be viewed as psychologically disruptive, but it is a common construction industry practice. A possible solution, which also provides a response to the question of on-going service (i.e., repairs and spare parts) for units already installed in the consumer market, is offered by a network of these short term, local satellite production centers, in rented facilities, but supervised and supported by a state or regional operations and service center of longer term (e.g., 30 years) presence. This headquarters

* SERI reviewers maintain that only dedicated production facilities should be considered for DAWT in order to provide a comparison with conventional WECS. Such arbitrary constraints on strictly business decisions appear unwarranted. The entrepreneur in a free competitive society always has the freedom to meet the needs of the market place in the best way he sees fit - a usual and practical concept in contemporary U.S. business. 
can serve as the supply warehouse for small size, easily shipped components such as turbine blades, generators, gear boxes, and standard hardware and tools that are needed at new field installations as well as for replacement parts of already-installed units.

The local production centers probably will require adjunct concrete batch plants to make the desired mortar-mix if economical arrangements cannot otherwise be concluded with local, pre-existing concrete suppliers. Steam curing equipment permits more efficient use of molds by reducing to about 2 days the time for obtaining full cement strength from the usual 28 days. This equipment requires a fresh water supply and source of heat energy.

As illustrated in Fig. 3-1, molds for batch production quantities of 100 or more sets of DAWT components are made of steel and can be dismantled and reused elsewhere. These molds are sized to produce diffuser segments that are within the dimension and weight restrictions of highway shipment. Figure 3-2 shows typical shipping orientations. A set of the cast segments for one diffuser is assembled together at the installation site by bolting their flanges, at ground level. The complete assembly is then lifted onto the prepared foundation by a mobile crane, rented locally, as shown in Fig. 3-2. Large arrays of DAWTs promote high efficiency use of the special crane equipment and help to reduce the rental charge per unit installation.

For a single or small number of ferrocement diffusers the casting mold can be made of ferrocement. The advantage lies primarily in lower cost (about half that of the steel mold) and quicker availability because of the el iminated machining of a steel mold.

\subsubsection{Fiberglass Reinforced Plastics (FRP)}

As noted in Section 2.0, FRP construction is proposed and was considered, only to the making of the diffuser skin panels; the so-called FRP design is really a hybrid FRP/aluminum construction, where the aluminum-fabricated components are intercnangeable with the all-aluminum constructed diffuser assembly.

Pearson Yachts has estimated that a plant floor space of $35,000 \mathrm{sq} f t$, a staff of 102 people, and factory equiprient expenditures of just under $\$ 200,000$ are needed to manufacture simultaneously 100 sets of DAWT panel components per year in each of the three sizes studied. Full details are presented in Appendix C. The flow of work is from the mold department to a trim and sanding operation, and then shipping. A considerable reduction in floor space (to $6500 \mathrm{sq} \mathrm{ft}$ ) and personnel (to 60 ) is needed for a single production line of only the largest size $(11 \mathrm{~m}(36 \mathrm{ft})$ rotor diameter) DAWT. FRP panels for the smallest size DAWT $(2.7 \mathrm{~m}(9 \mathrm{ft})$ rotor diameter) can be produced in a very modest, $400 \mathrm{sq} \mathrm{ft}$, plant with but six workers at the 100 assembly/year rate. The production requirements are assumed to grow linearly with production rate. However, in the opinion of the Pearson organization, annual production rates above 300 units for the larger size DAWT models would require an excessively large single facility and labor force for the hand layup production process commonly used in the FRP industry. Solutions to problems raised by these higher production rate schedules are to geographically disperse plants within market areas and to use a resin transfer, or resin injection molding, process. The latter is a relatively new method of shorter fabrication cycle time, requires a lower level of labor skill, and is less labor intensive. 


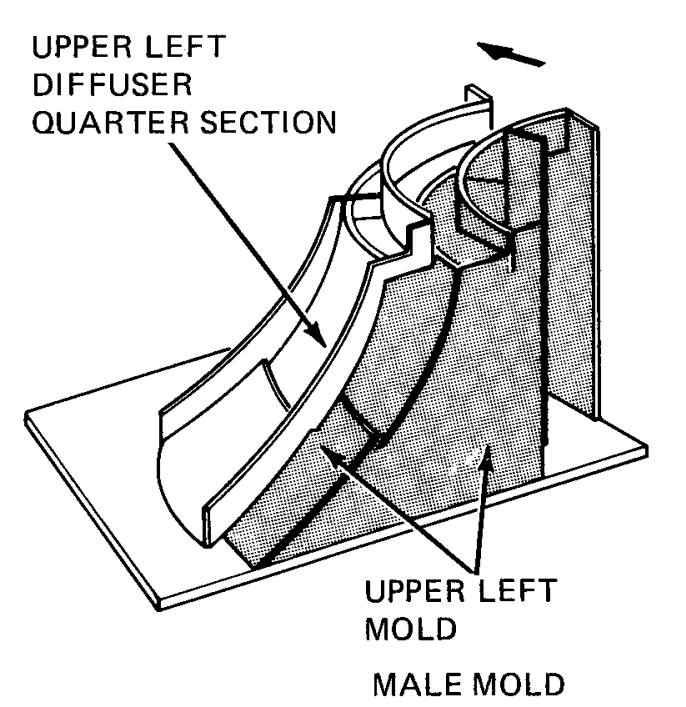

ज

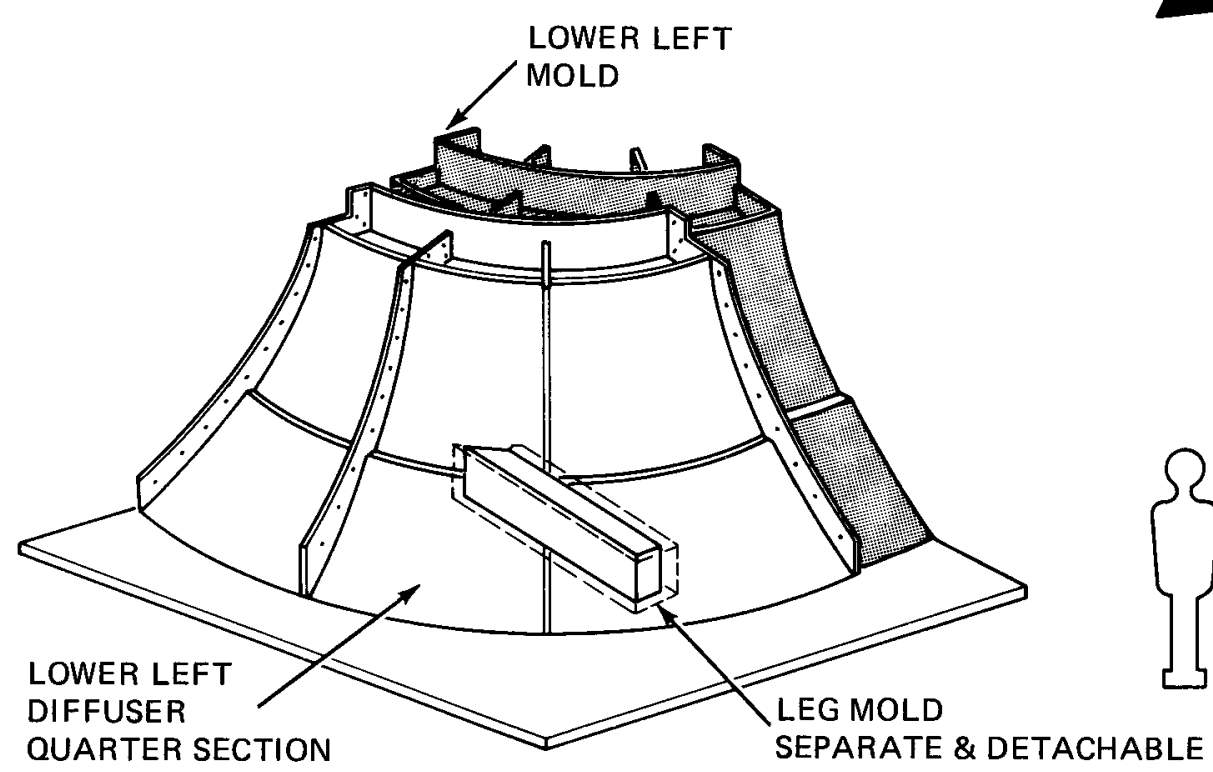

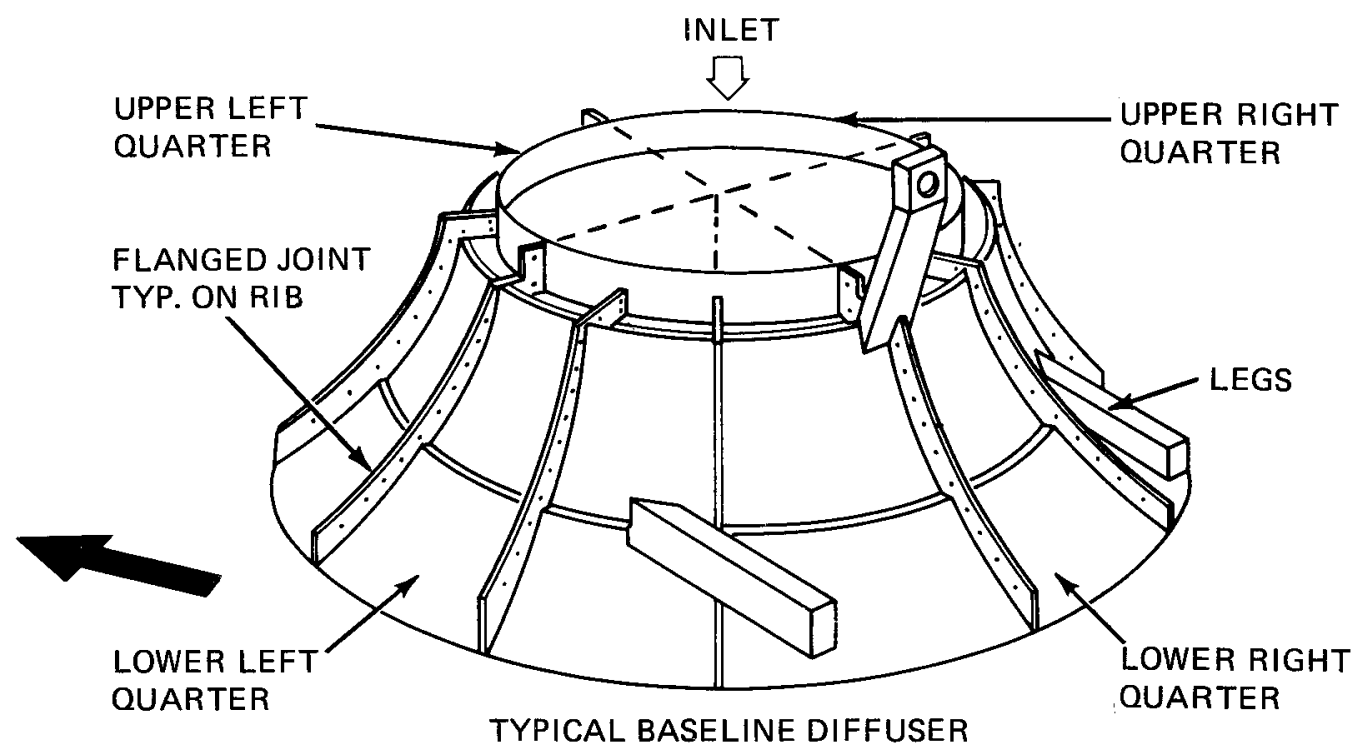

COMPLETED UNIT, FOUR QUARTERS ASSEMBLED.
0647-23W

Figure 3-1. CASTING FERROCEMENT SEGMENTS FOR DAWT STRUCTURE

PORTABLE MOLD

PIECE BETWEEN SECTION IN
WAY OF RIB

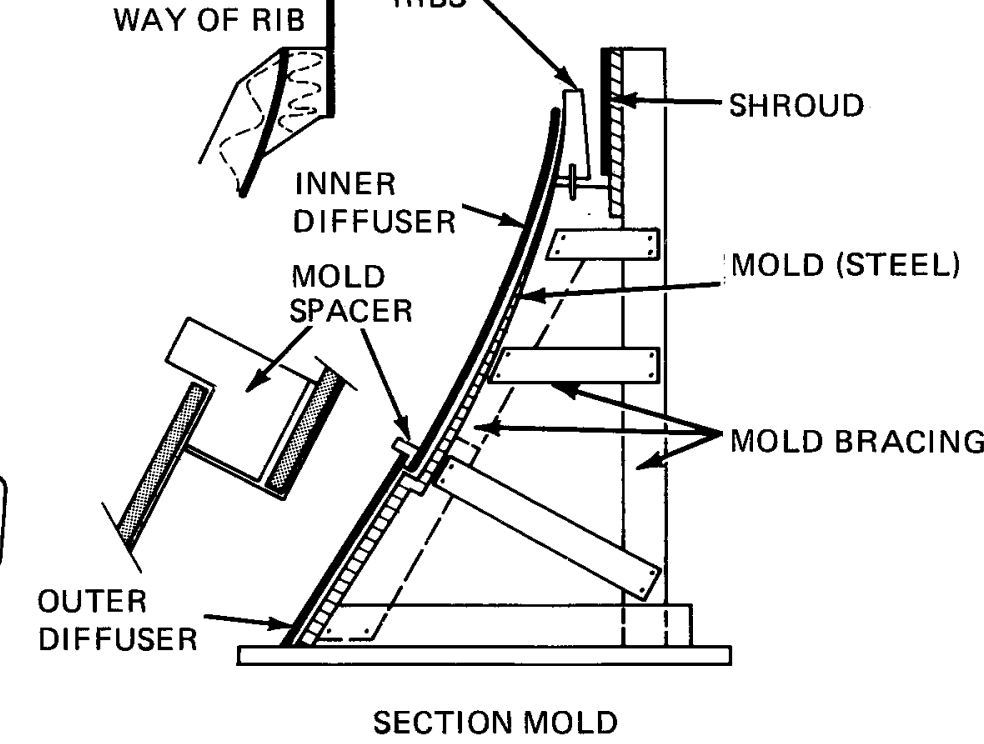

RIBS 


The FRP panels can be shipped to the site on flat bed trailer trucks, as well as rail freight cars or freighters. Within standard truck transport 1 imits, as many as 9 complete sets of $2.7 \mathrm{~m}(9 \mathrm{ft})$ diameter rotor DAWT panels to a limit of eleven-sixteenths of a full set of $11 \mathrm{~m}(36 \mathrm{ft})$ diameter rotor DAWT panels can be loaded on each standard flat bed trailer (see Fig. 3-1a, b, and c).

The components of this hybrid assembly that are made of aluminum or steel are to be separately supplied from geographically dispersed plants optimized by floor space to accomodate production machinery, market size, and available labor resources.

The major FRP tooling investment is the construction of a plywood master plug. The many production molds needed to sustain the targeted production rate are made by hand layed-up FRP molds using tooling quality resins and heavy duty, protecting surface coatings to ensure long life. For single prototypes, the FRP is applied by hand over a formica covered plywood mold. However, PVC foam is used as the core instead of end-grain balsa because it is easier to shape. The result is that the tooling for the prototype is of low cost and can easily be changed to reflect design improvements arising from development test stage inputs.

\subsubsection{All-Aluminum Design}

The manufacturing approach for the DAWT structure constructed entirely of aluminum (except for the yaw bearing) was developed at Grumman Aerospace. The production and tooling breakdown analysis was made according to aerospace industry manufacturing methods labor categories, but to commercial fabrication standards. Inspection was included in accordance with commercial practices.

Estimates of production manhours cover fabrication within the production center facility as well as metal forming component assembly, alignment and erection at the site. (Foundation and site preparation work was not included within this part of the estimate; see Appendix D.) The assumed machinery available for metal forming and processing has not been 1 imited by Grumman's current capabilities but is within known standard fabrication methods. This does create somewhat of a problem for making the largest size DAWT investigated because the compound curvature of the front diffuser section requires heavy duty rolling equipment that for the foreseeable future is otherwise fully committed within the U.S.. Therefore, dedicated machinery to assure availability for DAWT production would have to be separately acquired. In addition to the large pre-production investment required for machinery, a dedicated plant would have to be built, which would restrict the flexibility of serving several geographically dispersed market regions to within the restrictions of commercial shipping modes. There are no such machinery open capacity problems for the other two DAWT sizes examined. The diffuser skin for each of the two smaller sized DAWT's is to be made of 7 segments. The diffuser skin of the $11 \mathrm{~m}(36 \mathrm{ft})$ rotor diameter DAWT is to be made of 11 segments. 
$8^{\prime}-0^{\prime \prime}$ WIDE LOAD

11,000 LB LOAD

9 COMPLETE SETS

(18 SECTIONS)

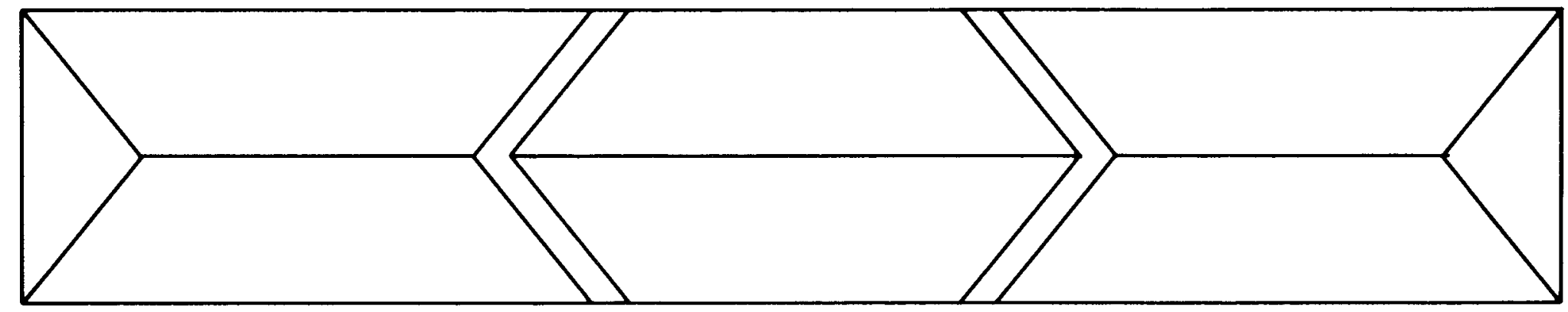

PLAN VIEW

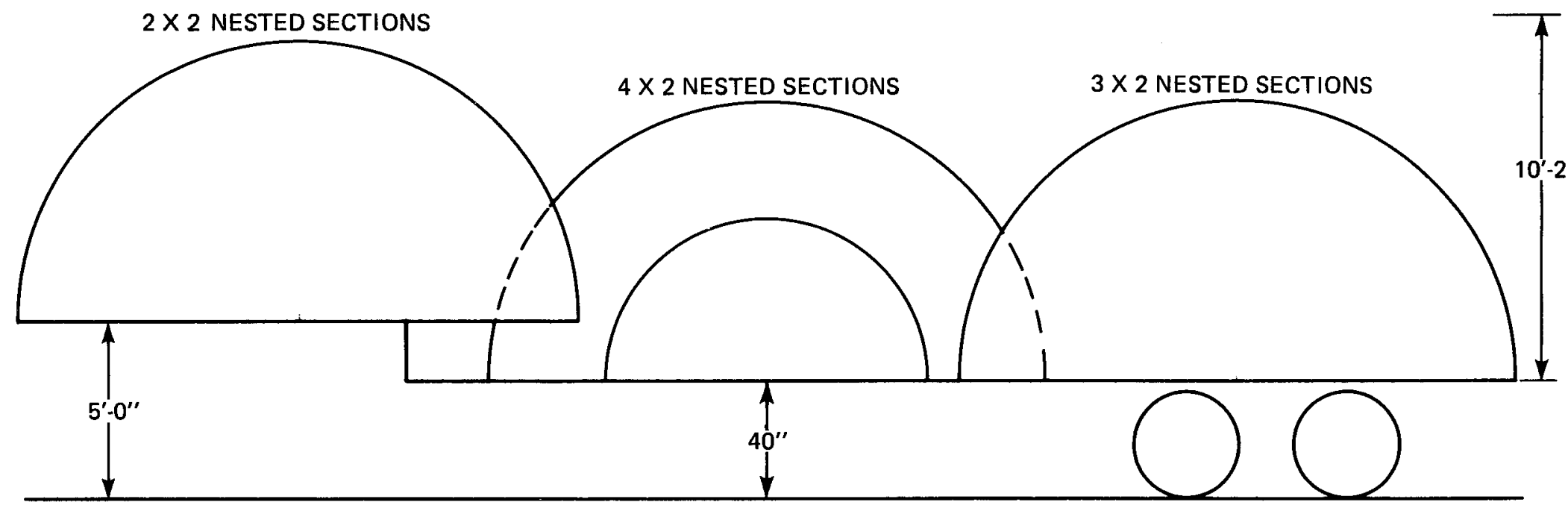

SIDE VIEW

$0647 \cdot 19 W$

Figure 3-3. TYPICAL TRUCK SHIPMENT ARRANGEMENT

a) FRP Panels for DAWT with 9 Ft Rotor Diameter 
10'-0" WIDE LOAD

7300 LB LOAD

1 COMPLETE SET

(11 SECTIONS)

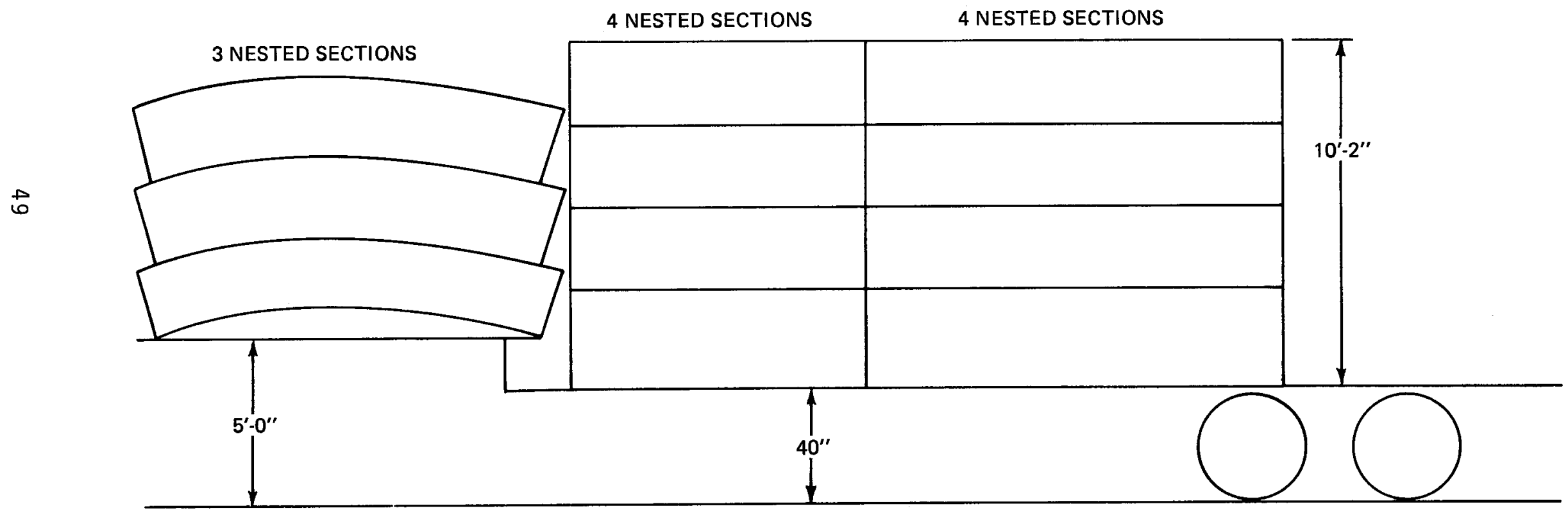

0647-20W

Figure 3-3. TYPICAL TRUCK SHIPMENT ARRANGEMENT

b) FRP Panels for DAWT with $22.5 \mathrm{Ft}$ Rotor Diameter 
12'-0" WIDE LOAD

11000 LB LOAD

11 SECTIONS

$(16$ SECTION $=1$ SET $)$

5 NESTED SECTIONS

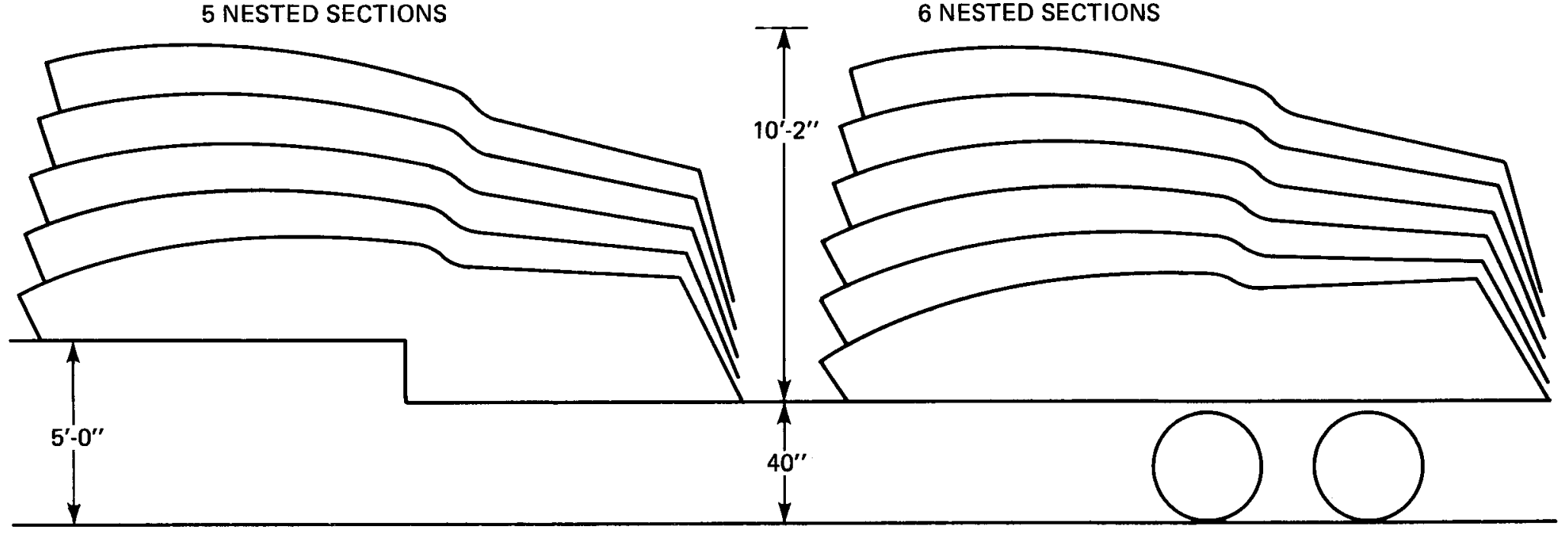

$0647-21 W$

Figure 3-3. TYPICAL TRUCK SHIPMENT ARRANGEMENT

c) FRP Panels for DAWT with $36 \mathrm{Ft}$ Rotor Diameter 


\subsection{COSTING}

\subsubsection{General Assumptions}

DAWT installations involve a substantial effort at the field site. Therefore, in estimating costs the practices of general contractors (Ref. 11) seem most appropriate. As recommended in Ref. 11, an overhead (indirect) rate of $20 \%$ of direct labor plus direct materials ( $D L+D M)$ is applied for components fabricated at the production centers, and $21 \%$ of $D L+D M$ is applied to field operations. Table 3-2 presents a breakdown of the average overhead rates excerpted from Ref. 11. Prevailing general and administrative (G\&A) expenses for general contractors plus an average net pretax profit of $5 \%$, Ref. 11 , adds $15 \%$ to the gross unit cost to generate a possible and viable unit selling price. A more extended discussion of the price-making process in the cases of individual projects, different consumer product types and basic commodities is beyond the scope of this study and the reader is referred to appropriate literature such as Ref. 15. Some of the appropriate and possible price making strategies for the relatively new wind energy conversion system market are:

- Market penetration pricing

- Loss leader pricing

- Price skimming

- Early recovery of investment cost

- Target return pricing

- Target rate of return pricing and for government stimulated competition

- Sealed bid pricing

- Going rate pricing.

A conventional cost breakdown format is followed here with consideration of variable and fixed production costs, indirect costs, and $G \& A$ and profit provisions all directed towards a unit selling price for a complete installation. Costs are estimated for major subcomponents, for each of three DAWT sizes, and in each of the three construction materials.

Fixed and tooling costs are prorated over production rates of 100, 200, and 500 units in a direct ratio to quantity basis.

Labor hours and raw material costs have been obtained from primary cost estimating sources.

- Aluminum and steel fabricated parts were analyzed by the Grumman Aerospace estimating department.

- Foundation and site preparation was costed within the Grumman Aerospace Research Dept. using construction industry typical data presented in Ref. 11. 
Table 3-2. GENERAL CONTRACTOR FINANCIAL ASSUMPTIONS (Ref. 11)




- FRP-made components were analyzed and estimated by the Pearson Yacht organization.

- Ferrocement made diffusers were estimated by the David J. Seymour, Ltd. organization.

- Wind turbine generator assemblies were estimated by the staff of Grumman Energy Systems Corporation.

\subsubsection{Labor Rates}

Labor cost rates per hour used were computed as averages of typical mixes of labor categories for DAWT factory production and tooling operations in Grumman's Stuart, Florida plant during 1979. The Stuart labor market is typical of a labor (1979) regional cost index of $90 \%$ closely comparable to that of Wichita and OKlahoma City. Labor involved in field operations was rounded off at a premium rate of about $10 \%$ above factory 1 abor. The base rate for variable production labor is taken at $\$ 6.90 / \mathrm{h}$ in the factory (production center) and $\$ 7.50 / \mathrm{h}$ for field operations; the base rate for fixed production expense (principally tooling and fixture making) is taken at $\$ 9 / \mathrm{h}$ in the factory (production center) and $\$ 10 / \mathrm{h}$ for field site operations. For the ferrocement constructed diffuser we have used the direct dollar billing cost estimates of David J. Seymour, Ltd. Their billing rate includes both direct and indirect production costs and is averaged at a straight $\$ 15 / \mathrm{h}$ rate for all labor categories.

\subsubsection{Production Quantity Effects}

Volume production of the same unit results in reduced average direct cost because of improved labor productivity through the learning experience, and quantity discounts for large purchase lots of materials. Although the learning experience factor is more usually associated with a factory environment of repeated operations, it also applies to physically separated field operations such as site preparations, foundation laying, and assembly and erection; this benefit is especially experienced where the different sites are not too distant and in the same topographic and geologic region (Ref. 14a).

From the information and analys is supplied by David J. Seymour, Ltd., the volume production of 100 complete assemblies should benefit by an approximate 95\% learning curve for labor involved in mold handling, mesh lay-up and mortaring. A quantity purchase discount of about $30 \%$ in the material cost, particularly the wire mesh, is considered likely. As a result, the combined effects of labor and material cost reductions lowers the looth unit cost to about 78\% of the prototype. The average direct production cost for the 100 units would be about $81 \%$ of the prototype. In addition, the production mold cost can be charged against the entire 100 unit lot which lowers the per unit cost for the molds and tooling. Although no further cost benefit has been assumed in labor or materials for production quantities of 200 or 500 (perhaps an unfair assumption) we have taken the added benefit in unit cost reduction for the mold and tooling expense by these larger lot sizes. For ferrocement construction, there does not appear to be a production volume dependency on DAWT size within the $\pm 10 \%$ accuracy in estimating and the size range considered. 
Estimates of volume of production economies for the FRP panels do appear to exhibit a physical size dependency, according to Pearson Yachts. For the 100 unit lot size the estimated DAWT unit variable cost of production is equivalent to an overal1 $91 \%$ learning curve trend for the $2.7 \mathrm{~m}(9 \mathrm{ft}$ ) rotor diameter size; a $96 \%$ curve for the $6.8 \mathrm{~m}(22.5 \mathrm{ft})$ rotor diameter size, and a $98 \%$ curve for the $11 \mathrm{~m}(36 \mathrm{ft})$ diameter rotor size DAWT. These trends provided by Pearson Yachts result in approximate average variable costs for 100 unit lots of $62 \%, 80 \%$, and $88 \%$, respectively for the three sizes, compared to first unit costs. If the estimated volume cost reduction trends are assumed extendable to 200 and 500 lot sizes, we obtain corresponding average costs of $57 \%, 77 \%$, and $86 \%$ for the 200 set quantity and $51 \%, 73 \%$, and $84 \%$ for the 500 set quantity. For purposes of this study, we have frozen the learning curve trend at the 100th set quantity value. However, unit fixed production cost arising from mold fabrication cost has been distributed over the 100 , 200, or 500 unit production lot sizes considered here.

The direct production labor hours for aluminum and steel components al so have been assigned a reduction trend with lot size according to information supplied by Grumman manufacturing estimators. A secondary dependency with item size as well as manufacturing operation has been estimated. On an overall basis, the direct labor hours for producing the $2.7,6.8$, and $11 \mathrm{~m}$ (9, 22.5 , and $36 \mathrm{ft}$ ) rotor diameter DAWT's are estimated to follow a $86 \%$, $90 \%$, and $88 \%$ learning curve trend, respectively, and to be extendable to the 500 set lot size.

Learning curve trends for sheet metal forming, metal machining, and installation site assembly are estimated at $80 \%, 85 \%$, and $95 \%$ respectively.

Overall cost estimates for the wind turbine generator, WTG, follow an approximate $80 \%$ learning trend for 100 unit lot sizes (suggested by Grumman Energy Systems estimators). For production lot sizes greater than 100 , we have not assumed a further production index benefit for the WTG subsystem, although this may be unduly conservative.

\subsubsection{Cost/Pricing Analysis}

With the assumptions and procedures already described, the analyses of estimated cost and selling price for DAWT's presented in Tables 7, 8, and 9 have been developed. Within the $\pm 10 \%$ accuracy associated with these estimates it appears that the units with ferrocement diffusers are the least expensive and those with a diffuser made entirely of aluminum are the most expensive. However, the fine details of the comparative evaluation are more virtual than real because any significant change in the assumed manufacturing process, or material thickness could alter greatly the relative rankings of the construction methods. If one generalizes which construction approach is the most versatile and the least capital intensive then the hybrid FRP/ Aluminum approach appears the best. The ferrocement approach is 1 imited to DAWT's with rotors under $7.6 \mathrm{~m}(25 \mathrm{ft})$ in diameter. The all-aluminum approach appears to require large capacity metal forming machinery to accommodate the upper range of DAWT sizes. If sufficient open capacity cannot be reserved under subcontract, production requirements have to be met by dedicated plant. and equipment obtained through pre-production investment of considerable magnitude. FRP tooling and molds are of 10 w enough investment magnitude to present no major impediment. 
Table 3-3. Estimated Cost Analysis - DAWT - Baseline Diffur AllAluminum Structure, $30^{\circ} \mathrm{Half}$ Diffuser, All-Aluminum

\begin{tabular}{|c|c|c|c|c|c|c|c|c|c|c|c|c|c|c|c|c|c|c|c|c|c|}
\hline & \multicolumn{2}{|c|}{ DAWT STRUCTURE } & \multirow{2}{*}{\begin{tabular}{|l|} 
FOUNDAT'N \\
(FLD SITE) \\
\end{tabular}} & \multirow{2}{*}{$\begin{array}{c}\text { ROTOR } \\
\text { ASY } \\
\text { (FACT'Y MADE) } \\
\text { FCT }\end{array}$} & \multirow{2}{*}{\multicolumn{3}{|c|}{ TOTALS }} & \multicolumn{2}{|c|}{ DAWT STRUCTURE } & \multirow{2}{*}{\begin{tabular}{|l} 
FOUNDAT'N \\
(FLD SITE) \\
\end{tabular}} & \multirow{2}{*}{\begin{tabular}{|c|}
$\begin{array}{c}\text { ROTOR } \\
\text { ASSY }\end{array}$ \\
(FACT'Y MADE) \\
\end{tabular}} & \multirow{2}{*}{\multicolumn{3}{|c|}{ TOTALS }} & \multicolumn{2}{|c|}{ DAWT STRUCTURE } & \multirow{2}{*}{\begin{tabular}{|l} 
FOUNDAT'N \\
(FLD SITE) \\
\end{tabular}} & \multirow{2}{*}{ 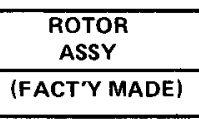 } & \multirow{2}{*}{\multicolumn{3}{|c|}{ TOTALS }} \\
\hline & (FACT'Y MADE) & \begin{tabular}{|l|} 
(FIELD MADE) \\
\end{tabular} & & & & & & \begin{tabular}{|l} 
(FACT'Y MADE) \\
\end{tabular} & \begin{tabular}{|l|} 
(FIELD MADE) \\
\end{tabular} & & & & & & \begin{tabular}{|l} 
(FACT'Y MADE) \\
\end{tabular} & \begin{tabular}{|l} 
(FIELD MADE) \\
\end{tabular} & & & & & \\
\hline \multirow{3}{*}{ 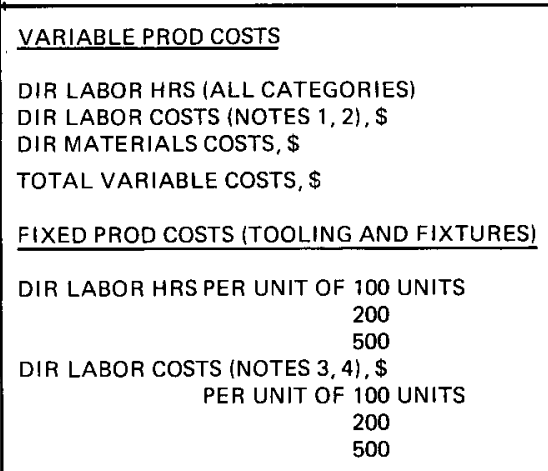 } & $\begin{array}{r}961 \\
6631 \\
49682\end{array}$ & $\begin{array}{r}4332 \\
32490\end{array}$ & & $\begin{array}{r}460 \\
3174 \\
16151 \\
\end{array}$ & $\begin{array}{r}5753 \\
42295 \\
658383\end{array}$ & & & $\begin{array}{r}390 \\
2961 \\
15995\end{array}$ & $\begin{array}{r}1456 \\
10920\end{array}$ & & $\begin{array}{r}400 \\
2760 \\
9725 \\
\end{array}$ & \multirow[b]{3}{*}{$\begin{array}{r}725 \\
363 \\
145 \\
6697 \\
3353 \\
1339\end{array}$} & & & $\begin{array}{r}208 \\
1435 \\
1653 \\
\end{array}$ & $\begin{array}{l}778 \\
5835\end{array}$ & & $\begin{array}{r}340 \\
2346 \\
3757\end{array}$ & \multirow[b]{3}{*}{ 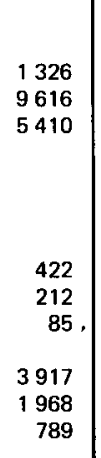 } & & \\
\hline & 56313 & 32490 & 24000 & 19325 & 132128 & & & 17886 & 10920 & 16000 & 12485 & & & & 3088 & 5835 & 2000 & 6103 & & & \\
\hline & $\begin{array}{r}985 \\
493 \\
197 \\
8865 \\
4437 \\
1773\end{array}$ & $\begin{array}{r}731 \\
366 \\
146 \\
7310 \\
3660 \\
1460\end{array}$ & & & $\begin{array}{r}1716 \\
859 \\
343 \\
16175 \\
8097 \\
3233\end{array}$ & & & $\begin{array}{r}553 \\
277 \\
111 \\
4977 \\
2493 \\
999\end{array}$ & $\begin{array}{r}172 \\
86 \\
34 \\
1720 \\
860 \\
340\end{array}$ & & & & & & $\begin{array}{r}303 \\
152 \\
61 \\
2727 \\
2368 \\
549\end{array}$ & $\begin{array}{r}119 \\
60 \\
24 \\
1190 \\
600 \\
240\end{array}$ & & & & & \\
\hline $\begin{array}{c}\text { TOTAL DIR PROD COSTS, } \\
\text { PER UNIT OF } 100 \text { UNITS } \\
200 \\
500 \\
500 \\
\text { INDIR PROD COSTS, } \$ \text { INOTES } 5,66 \\
\text { PER UNIT OF F } \\
2000 \text { UNITS } \\
500\end{array}$ & $\begin{array}{l}65178 \\
60750 \\
58086 \\
\\
13036 \\
12150 \\
11617\end{array}$ & $\begin{array}{l}39800 \\
36150 \\
33950 \\
\\
8358 \\
7592 \\
7130\end{array}$ & $\begin{array}{l}24000 \\
24000 \\
24000 \\
5040 \\
5040 \\
5040 \\
5040\end{array}$ & $\begin{array}{l}19325 \\
19325 \\
19325 \\
3865 \\
3865 \\
3865\end{array}$ & & $\begin{array}{l}148303 \\
14025 \\
135361 \\
30299 \\
282947 \\
22652 \\
27652\end{array}$ & & $\begin{array}{l}22863 \\
20379 \\
18885 \\
4573 \\
4076 \\
3777\end{array}$ & $\begin{array}{l}12640 \\
11780 \\
11260 \\
2654 \\
2474 \\
2365\end{array}$ & $\begin{array}{l}16000 \\
16000 \\
16000 \\
\\
3360 \\
3360 \\
3360\end{array}$ & $\begin{array}{l}12485 \\
12485 \\
12485 \\
2497 \\
2447 \\
2497 \\
2497\end{array}$ & & $\begin{array}{l}63988 \\
60644 \\
58630 \\
13084 \\
12407 \\
11999\end{array}$ & & $\begin{array}{r}5815 \\
4456 \\
3637 \\
\\
1163 \\
891 \\
727\end{array}$ & $\begin{array}{l}7025 \\
6435 \\
6075 \\
\\
1475 \\
1351 \\
1276\end{array}$ & $\begin{array}{l}2000 \\
2000 \\
2000 \\
\\
420 \\
420 \\
420\end{array}$ & $\begin{array}{l}6103 \\
6 \quad 103 \\
6103 \\
\\
1221 \\
1221 \\
1221\end{array}$ & & \begin{tabular}{|l}
20943 \\
18994 \\
17815 \\
4279 \\
3833 \\
3644
\end{tabular} & \\
\hline 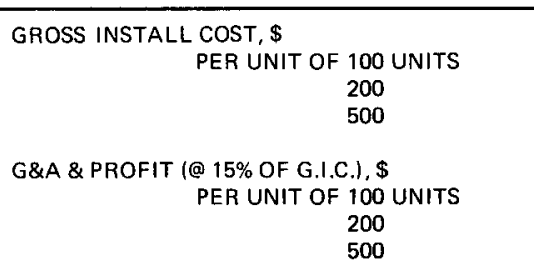 & & & & & & & $\begin{array}{l}178602 \\
16872 \\
163013 \\
26790 \\
22531 \\
24452 \\
24452\end{array}$ & & & & & & & $\begin{array}{l}77072 \\
73051 \\
70629 \\
\\
11561 \\
10558 \\
10594\end{array}$ & & & & & & & $\mid$\begin{tabular}{|l}
252222 \\
22287 \\
21459 \\
\\
\\
3783 \\
3432 \\
3219 \\
3219
\end{tabular} \\
\hline $\begin{array}{l}\text { SELLING PRICE, S } \\
\text { PER UNIT OF } 100 \text { UNITS } \\
\begin{array}{cc}200 \\
0647-033 \mathrm{~W}\end{array} \\
500\end{array}$ & & & & & & & $\begin{array}{l}205392 \\
1924203 \\
187465\end{array}$ & & & & & & & $\begin{array}{l}88633 \\
84009 \\
81223\end{array}$ & & & & & & & $\begin{array}{l}29005 \\
26309 \\
24678\end{array}$ \\
\hline
\end{tabular}

1. AVG FACTORY LABOR RATE $=\$ 6.90 / \mathrm{HR}$



AVG F XED LABOR RATE (FEED) = S10.001HR
INDIRECT FACTOR (FACTORY) $20 \%$ OF DL\&DM

INDIRECT FACTOR FFELD) =21\% OF DL\&DM
ALL COSTS IN 1979 DOLLARS 
Table 3-4. Estimated Cost Analysis - DAWT - Baseline Diffuser, FRP Panels \& Aluminum
$30^{\circ}$ Half-Angle, 2.75 Area Ratio

\begin{tabular}{|c|c|c|c|c|c|c|c|c|c|c|c|c|c|c|c|c|c|c|c|c|c|}
\hline & \begin{tabular}{|l|} 
DIFFUSERS \\
|FACTORYY|
\end{tabular} & $\begin{array}{l}\text { STRUCT } \\
\text { IFFELD) }\end{array}$ & \begin{tabular}{|c|c|} 
FRP \\
PANELS \\
(FACTORY) \\
\end{tabular} & \begin{tabular}{|l} 
DIFFUSER \\
(FACTORY
\end{tabular} & $\begin{array}{l}\text { SUPPORT) } \\
\text { |FIELDI }\end{array}$ & $\frac{\text { FoUNDAT'N }}{\text { (FIELD) }}$ & \begin{tabular}{|l|} 
AOTOR \\
ASYY \\
(FACTORY) \\
\end{tabular} & \begin{tabular}{|l|} 
DIFFUSER \\
(FACTORY) \\
\end{tabular} & $\begin{array}{l}\text { STRUCT. } \\
\text { (FIELD) } \\
\end{array}$ & $\begin{array}{c}\text { FAP } \\
\text { PAAELS } \\
\text { (FACTORY) } \\
\end{array}$ & \begin{tabular}{|c|} 
DIFFUSER \\
(FACTORYY)
\end{tabular} & \begin{tabular}{|l|l|l|l} 
SUPPORT \\
(FIELD)
\end{tabular} & \begin{tabular}{|l} 
FOUNDAT'N \\
(FIELD) \\
\end{tabular} & \begin{tabular}{|l|l|} 
ASOTY \\
AFACTORY) \\
(F)
\end{tabular} & \begin{tabular}{|l} 
DIFFUSER \\
|FACTORYYI
\end{tabular} & $\begin{array}{l}\text { STRUCT. } \\
\text { (FIELD) }\end{array}$ & $\begin{array}{c}\text { FAP } \\
\begin{array}{c}\text { FANELS } \\
\text { (FACTORY) }\end{array} \\
\end{array}$ & \begin{tabular}{|l|} 
DIFFUSER \\
(FACTORYY)
\end{tabular} & $\frac{\text { SUPPORT }}{\mid \text { (FIELD) }}$ & $\begin{array}{c}\frac{\text { FOUNDAT'N }}{\text { (FIELDI }} \\
\end{array}$ &  \\
\hline 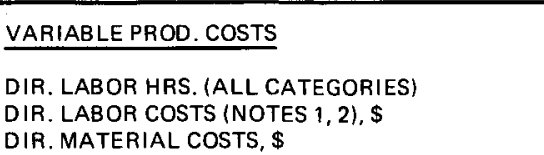 & $\begin{array}{r}788 \\
5437 \\
34724\end{array}$ & \begin{tabular}{|c|}
3041 \\
22808
\end{tabular} & $\begin{array}{rl}1 & 152 \\
7949 \\
13995\end{array}$ & $\begin{aligned} 157 \\
1083 \\
7220\end{aligned}$ & $\begin{array}{r}164 \\
1230\end{array}$ & & $\begin{array}{r}460 \\
3174 \\
16151\end{array}$ & $\begin{array}{l}185 \\
1277 \\
8244\end{array}$ & $\begin{array}{r}718 \\
5385\end{array}$ & $\begin{array}{r}550 \\
3588 \\
4453\end{array}$ & $\begin{array}{r}96 \\
662 \\
2780\end{array}$ & $\begin{array}{l}100 \\
750\end{array}$ & & $\begin{array}{r}400 \\
2760 \\
9725\end{array}$ & $\begin{array}{l}115 \\
794 \\
965\end{array}$ & $\begin{array}{r}455 \\
3413\end{array}$ & $\begin{array}{l}112 \\
773 \\
648\end{array}$ & $\begin{array}{l}40 \\
276 \\
390\end{array}$ & $\begin{array}{r}42 \\
315\end{array}$ & & $\begin{array}{r}\begin{array}{r}330 \\
2346 \\
3357\end{array} \\
3575\end{array}$ \\
\hline 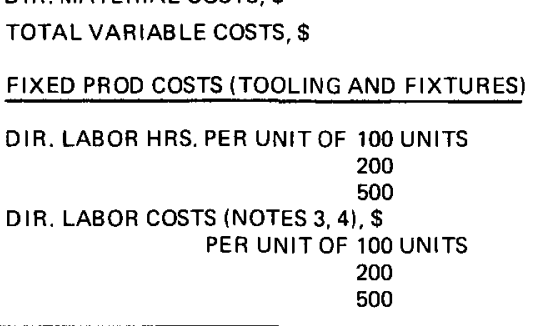 & $\begin{array}{r}40161 \\
\\
907 \\
454 \\
181 \\
8163 \\
4086 \\
1629\end{array}$ & $\begin{array}{r}22808 \\
\\
317 \\
159 \\
63 \\
3170 \\
150 \\
630 \\
630\end{array}$ & $\begin{array}{l}(\text { NOTE } 7) \\
3070 \\
3070 \\
3070\end{array}$ & $\begin{array}{r}8303 \\
96 \\
98 \\
48 \\
19 \\
864 \\
432 \\
171\end{array}$ & \begin{tabular}{|r|}
1230 \\
\\
33 \\
17 \\
7 \\
330 \\
170 \\
70
\end{tabular} & 24000 & 19325 & $\begin{array}{r}9521 \\
\\
268 \\
134 \\
54 \\
2412 \\
1206 \\
486\end{array}$ & $\begin{array}{r}5385 \\
\\
92 \\
46 \\
19 \\
920 \\
460 \\
190\end{array}$ & $\begin{array}{c}\text { (NOTE } 7) \\
1579 \\
1579 \\
1579\end{array}$ & $\begin{array}{r}3442 \\
\\
55 \\
28 \\
11 \\
495 \\
252 \\
99\end{array}$ & $\begin{array}{r}750 \\
\\
24 \\
12 \\
5 \\
240 \\
120 \\
50\end{array}$ & 16000 & 12485 & $\begin{array}{r}1759 \\
\\
163 \\
82 \\
33 \\
143 \\
1467 \\
738 \\
297\end{array}$ & $\begin{array}{r}3413 \\
\\
68 \\
34 \\
14 \\
680 \\
340 \\
140\end{array}$ & $\begin{array}{c}\text { (NOTE } 7) \\
436 \\
436 \\
436\end{array}$ & $\begin{array}{r}666 \\
\\
28 \\
14 \\
6 \\
252 \\
126 \\
54\end{array}$ & $\begin{array}{r}315 \\
\\
13 \\
7 \\
3 \\
130 \\
70 \\
30\end{array}$ & 2000 & 6103 \\
\hline $\begin{array}{c}\text { TOTAL DIR. PROD COSTS S } \\
\text { PER UNIT OF } 100 \text { UNITS } \\
200 \\
500 \\
500 \\
\text { INDIRECT PROD. COSTS, SINOTES } 5,61 \\
\text { PER UNIT OF } \\
2000 \text { UNITS } \\
500 \\
500\end{array}$ & 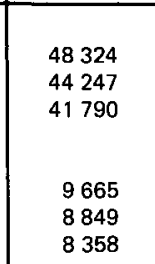 & $\begin{array}{l}25978 \\
24398 \\
23338 \\
5425 \\
5124 \\
4922\end{array}$ & $\begin{array}{l}25014 \\
25014 \\
25014 \\
5000 \\
5000 \\
5000\end{array}$ & $\begin{array}{l}9167 \\
8735 \\
8474 \\
1833 \\
1747 \\
1695\end{array}$ & $\begin{array}{l}1560 \\
1400 \\
1300 \\
328 \\
294 \\
273\end{array}$ & $\begin{array}{l}24000 \\
240000 \\
24000 \\
5040 \\
5040 \\
5040\end{array}$ & $\begin{array}{l}19325 \\
19325 \\
19225 \\
\\
3865 \\
3865 \\
3865\end{array}$ & $\begin{array}{l}11933 \\
10727 \\
10007 \\
2387 \\
2145 \\
2000\end{array}$ & $\begin{array}{l}6305 \\
5845 \\
5575 \\
1324 \\
1327 \\
1227 \\
1171\end{array}$ & $\begin{array}{l}9620 \\
9620 \\
9620 \\
\\
1924 \\
1924 \\
1924\end{array}$ & $\begin{array}{r}3927 \\
3694 \\
3541 \\
787 \\
739 \\
708\end{array}$ & $\begin{array}{l}990 \\
870 \\
800 \\
\\
208 \\
183 \\
168\end{array}$ & $\begin{array}{l}16000 \\
16000 \\
16000 \\
\\
3360 \\
3360 \\
3360\end{array}$ & $\begin{array}{l}12485 \\
12485 \\
12485 \\
2497 \\
2497 \\
2497 \\
2497\end{array}$ & $\begin{array}{r}3226 \\
2497 \\
2056 \\
\begin{array}{r}645 \\
499 \\
411\end{array}\end{array}$ & $\begin{array}{r}4093 \\
3753 \\
3553 \\
860 \\
878 \\
746\end{array}$ & $\begin{array}{r}1857 \\
1857 \\
1857 \\
\\
371 \\
371 \\
371\end{array}$ & $\begin{array}{l}918 \\
792 \\
720 \\
\\
\\
184 \\
158 \\
144\end{array}$ & $\begin{array}{r}445 \\
335 \\
345 \\
\\
93 \\
81 \\
72\end{array}$ & $\begin{array}{l}2000 \\
2000 \\
2000 \\
\\
420 \\
420 \\
420\end{array}$ & $\begin{array}{l}6103 \\
6103 \\
6103 \\
\\
1221 \\
1221 \\
1221\end{array}$ \\
\hline 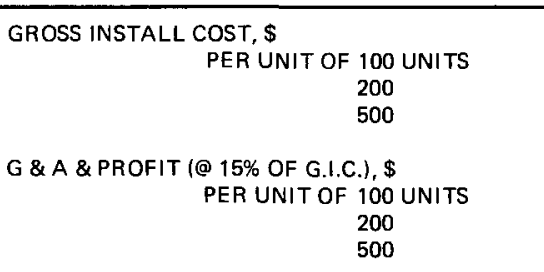 & & & & & & & \begin{tabular}{|l} 
TOTALS \\
1945554 \\
177038 \\
172494 \\
\\
27683 \\
26556 \\
25874
\end{tabular} & & & & & & & $\begin{aligned} \text { TOTALS } \\
73757 \\
71316 \\
69856 \\
\\
11064 \\
10697 \\
10479\end{aligned}$ & & & & & & & \begin{tabular}{r|} 
TOTALS \\
22436 \\
20925 \\
20019 \\
\\
3365 \\
3139 \\
3003
\end{tabular} \\
\hline  & & & & & & & $\begin{array}{l}\begin{array}{l}212237 \\
203594 \\
198368\end{array} \\
{ }_{1983}\end{array}$ & & & & & & & $\begin{array}{l}84821 \\
82013 \\
80335\end{array}$ & & & & & & & $\begin{array}{l}25801 \\
24064 \\
23022\end{array}$ \\
\hline
\end{tabular}

1. AVG. FACTORY LABOR RATE $=\$ 6.90 /$ HR.
2 AVG. FIELD LABOR RATE $=\$ 7.50 / H R$.

3. AVG. FIXED LABOR RATE (FACTORY) $=59.00 /$ H.
4. AVG. FIXED LABOR RATE (FIELD) $=\$ 10.00 / 4$.

(4)

7. MOLD COSTS VAAY DIRECTLY WITH PRODUCTION RATE 


\begin{tabular}{|c|c|c|c|c|c|c|c|c|c|c|c|c|}
\hline & \begin{tabular}{|c|} 
DIFFUSER \\
ASSY \\
(FACT'Y \& FLD)
\end{tabular} & $\begin{array}{l}\text { DIFFUSER S } \\
\text { (FACTORY) }\end{array}$ & $\begin{array}{l}\text { UPPORT } \\
\text { (FIELD) }\end{array}$ & $\begin{array}{c}\text { FOUNDAT'N } \\
\text { (FIELD) }\end{array}$ & $\begin{array}{c}\text { ROTOR } \\
\text { ASSY } \\
\text { (FACTORY) }\end{array}$ & TOTALS & $\begin{array}{c}\text { DIFFUSER } \\
\text { ASSY } \\
\text { (FACT'Y \& FLD) }\end{array}$ & $\begin{array}{l}\text { DIFFUSER S } \\
\text { (FACTORY) }\end{array}$ & $\begin{array}{l}\text { UPPORT } \\
\text { (FIELD) }\end{array}$ & $\begin{array}{l}\text { FOUNDAT'N } \\
\text { (FIELD) }\end{array}$ & \begin{tabular}{|c|} 
ROTOR \\
ASSY \\
(FACTORY)
\end{tabular} & TOTALS \\
\hline $\begin{array}{l}\text { VARIABLE PROD COSTS, } \$ \text { (LABOR } \\
\text { AND MATERIALS) }\end{array}$ & $\begin{array}{l}33000 \\
\text { (NOTE 1) }\end{array}$ & 3442 & 750 & 16000 & 12485 & 65677 & $\begin{array}{l}6100 \\
\text { (NOTE 1) }\end{array}$ & 666 & 315 & 2000 & 6103 & 15184 \\
\hline $\begin{array}{l}\text { FIXED PROD COSTS (TOOLING } \\
\text { AND MOLDS), \$ } \\
\begin{array}{r}\text { PER UNIT OF } 100 \text { UNITS } \\
200 \\
500\end{array}\end{array}$ & $\begin{array}{l}840 \\
420 \\
168\end{array}$ & $\begin{array}{l}495 \\
252 \\
100\end{array}$ & $\begin{array}{r}240 \\
120 \\
50\end{array}$ & & & & $\begin{array}{r}120 \\
60 \\
24\end{array}$ & $\begin{array}{r}252 \\
126 \\
50\end{array}$ & $\begin{array}{r}130 \\
70 \\
26\end{array}$ & & & \\
\hline $\begin{array}{c}\text { TOTAL DIRECT PROD COSTS, } \\
\text { PER UNIT OF } 100 \text { UNITS } \\
200 \\
500\end{array}$ & $\begin{array}{l}\text { (NOTE 1) } \\
33840 \\
33420 \\
33168\end{array}$ & $\begin{array}{l}3937 \\
3694 \\
3542\end{array}$ & $\begin{array}{l}990 \\
670 \\
800\end{array}$ & $\begin{array}{l}16000 \\
16000 \\
16000\end{array}$ & $\begin{array}{l}12485 \\
12485 \\
12485\end{array}$ & $\begin{array}{l}\text { (NOTE 1) } \\
67252 \\
66269 \\
65995\end{array}$ & $\begin{array}{l}\text { (NOTE 1) } \\
6220 \\
6160 \\
6124\end{array}$ & $\begin{array}{l}918 \\
792 \\
716\end{array}$ & $\begin{array}{l}445 \\
385 \\
341\end{array}$ & $\begin{array}{l}2000 \\
2000 \\
2000\end{array}$ & $\begin{array}{l}6103 \\
6103 \\
6103\end{array}$ & \begin{tabular}{|c} 
(NOTE 1) \\
15686 \\
15440 \\
15284
\end{tabular} \\
\hline $\begin{array}{c}\text { INDIRECT PROD COSTS, \$ } \\
\text { PER UNIT OF } 100 \text { UNITS } \\
200 \\
500\end{array}$ & & $\begin{array}{l}787 \\
739 \\
708\end{array}$ & $\begin{array}{l}208 \\
183 \\
168\end{array}$ & $\begin{array}{l}3360 \\
3360 \\
3360\end{array}$ & $\begin{array}{l}2497 \\
2497 \\
2497\end{array}$ & $\begin{array}{l}6852 \\
6779 \\
6733\end{array}$ & & $\begin{array}{r}184 \\
158 \\
37\end{array}$ & $\begin{array}{l}89 \\
81 \\
18\end{array}$ & $\begin{array}{l}420 \\
420 \\
420\end{array}$ & $\begin{array}{l}1221 \\
1221 \\
1221\end{array}$ & $\begin{array}{l}1914 \\
1880 \\
1696\end{array}$ \\
\hline $\begin{array}{c}\text { GROSS INSTALL COST, } \$ \\
\text { PER UNIT OF } 100 \text { UNITS } \\
200 \\
500\end{array}$ & & & & & & $\begin{array}{l}74104 \\
73048 \\
72728\end{array}$ & & & & & & $\begin{array}{l}17600 \\
17320 \\
16980\end{array}$ \\
\hline $\begin{array}{c}\text { G\&A \& PROFIT (@ 15\% OF G.I.C.) } \$ \\
\text { PER UNIT OF } 100 \text { UNITS } \\
200 \\
500\end{array}$ & & & & & & $\begin{array}{l}11116 \\
10957 \\
10910\end{array}$ & & & & & & $\begin{array}{l}2640 \\
2598 \\
2547\end{array}$ \\
\hline $\begin{array}{c}\text { SELLING PRICE, \$ } \\
\text { PER UNIT OF } 100 \text { UNITS } \\
200 \\
500\end{array}$ & & & & & & $\begin{array}{l}85220 \\
84005 \\
83638\end{array}$ & & & & & & $\begin{array}{l}20240 \\
19918 \\
19527\end{array}$ \\
\hline
\end{tabular}

NOTES

1. FERROCEMENT DIFFUSER COST INCLUDES DIRECT AND INDIRECT EXPENSES.

1. COSTS OF DIFFUSER SUPPORT, FOUNDATION AND ROTOR ASSY ARE SAME

AS FOR ALL-ALUMINUM CONSTRUCTED DAWT.

3. ALL COSTS IN 1979 DOLLARS

$\underset{1467-024(\mathrm{~T})}{0.031 \mathrm{~T}}$ 
For the FRP/aluminum DAWT, the average breakdown of the gross installation cost by major subsystem is given in Table 3-6. From this analysis it is evident that there is a DAWT size dependency on the relative cost of the rotor and the diffusers; the percentage cost of the turbine assembly diminishes with size, and the diffuser relative cost increases with size. The support pedestal relative cost remains almost constant with size and the foundation cost displays no fixed trend with size. The latter point probably is a result of the lack of geometric similarity of the designs and more influenced by the specific needs and features of each anchorage. Within the DAWT size range investigated, there is not yet an indication that the relative costs of the two major subsystems have reached an asymptote.

The selling price, SP for DAWT's with variation in turbine sizes between 2.7 and $11 \mathrm{~m}$ (9 and $36 \mathrm{ft}$ ) in diameter, $\mathrm{D}$, is approximately given by a SP $\mathrm{D}^{1.50}$ proportionality. The selling price-to-rated power ratio is proportional to $\mathrm{SP} / \mathrm{D}^{2}$, or approximately (SP/Power) $\approx \mathrm{D}^{-.50}$. This relationship points to more economical investments in wind power as the DAWT unit sizes increase in geometrically similar designs. This scenario does not account for the possibility of more economical diffuser design approaches in very large sizes, to bypass the shipping size and weight restrictions on component production. One such alternative, not currently examined, but actively employed in recent major construction projects, is the use of architectural fabrics (Ref. 16). In this approach, tension surfaces (made of coated fabrics) are made to survive for 30 to 50 years, and conform to desired shapes with the help of a metal framework structure. The fabrics are shipped in pre-cut bolt form and assembled under precalculated tension loads, to the skeleton framework. The investment of tooling and factory machinery is eliminated, and the lighter weight material yields a lower overall weight growth with size. It is our recommendation that architectural fabrics be investigated for very large DAWTs as a possible means to decrease the capital cost growth with size of the diffuser subsystem of the DAWT.

The fixed production costs of the FRP/aluminum DAWT version, involving only the tooling and fixture labor, are listed in Table 3-7 as a function of production lot size and DAWT size. The list shows the expected reduction in unit share of total tooling cost with production lot size. The reduction is somewhat less than linearly proportional to lot size because the mold cost for FRP-made component is practically invariant with annual production run. The required time for FRP lay-up fabrication and curing ties up each mold for about 2 - 3 days, so only about 100 - 150 components can be produced per year from each mold; annual production rates of greater number would require more molds, and prolonged production over several years also would necessitate mold replacement after between one to two years. It is revealing that the smallest DAWT size unit involves the largest percentage of gross cost in the fixed cost category. For this unit, improved production processes and tool design holds the potential of perhaps a one-third reduction in production fixed costs, representing a $2-5 \%$ reduction in gross installation cost (and selling price).

Major cost (and selling price) reductions from the estimates in Tables $3-3$ through 3-5 could be obtained by using a diffuser with a greater included angle, for example, $90^{\circ}$, than the $60^{\circ}$ considered here in our point designs. On the basis of small scale model testing (Ref. 5, 6) and theoretical grounds (Ref. 7,17 ) better aerodynamic performance is to be expected for a $45^{\circ}$ half 
Table 3-6. FRP/ALUMINUM DAWT BASELINE DESIGN SUBSYSTEM COST BREAKDOWN

\begin{tabular}{c|c|c|c}
\hline \multirow{2}{*}{ Subsystem } & \multicolumn{3}{|c}{ Average \% of Gross Installation Cost } \\
\cline { 2 - 3 } & \multicolumn{3}{|c}{ Rotor Diameter, Ft } \\
\cline { 2 - 4 } & 36 & 22.5 & 9 \\
\hline 1. Diffuser (Overal1) & 64 & 45 & 48 \\
\hline a. FRP Parts & 17 & 15 & 9.5 \\
\hline D. Metal Parts & 47 & 30 & 38.5 \\
\hline 2. DAWT Support & 7 & 8 & 7 \\
\hline 3. Turbine Assembly & 13 & 20 & 34 \\
\hline 4. Foundation & 16 & 27 & 11 \\
\hline
\end{tabular}

Table 3-7. FRP/ALUMINUM DAWT BASELINE DESIGN UNIT FIXED PRODUCTION COSTS (DIRECT AND INDIRECT)

\begin{tabular}{c|c|c|c}
\hline \multirow{2}{*}{ Production Lot Size } & \multicolumn{3}{|c}{$\%$ of Gross Installation Cost } \\
\cline { 2 - 4 } & \multicolumn{3}{|c|}{ Rotor Diameter, Ft } \\
\hline & 36 & 22.5 & 9 \\
\hline 100 & & & \\
\hline 200 & 10.2 & 9.2 & 15.9 \\
\hline 500 & 6.3 & 6.1 & 9.8 \\
\hline
\end{tabular}


angle than $30^{\circ}$ half angle. With the influence on internal boundary layer flow created by tangential slot injection, a full flowing diffuser continues to be anticipated with the $45^{\circ}$ half angle. The geometric relationships leading to lower relative costs, for the same overall area ratio, have previously been calculated (see Fig. 2-4) for the alternative $45^{\circ}$ half angle and dump diffuser configurations. The net result of these very reasonable considerations is the projected estimated cost and selling price listed in Table 3-8. Two materials of construction and three turbine sizes are involved in these projections. The shortened axial length of the diffuser obtained with a $45^{\circ}$ half angle, for the constant 2.75 area ratio, is further accentuated by the employment of the dump diffuser configuration for a FRP/aluminum construction approach. The diameter of the diffuser support pedestal (column) also will be affected by the axially shortened $45^{\circ}$ dump diffuser design. Therefore, the relative cost factor has been applied to two diffuser related subsystems of the DAWT but excluded from the rotor assembly and foundation subsystems in Table 3-8. The net effect, at the 100 unit production lot run level is to lower the required unit selling price to between $69-81 \%$ of the point designs (baseline $30^{\circ}$ half angle) for FRP/aluminum hybrid construction, and $79-84 \%$ for the all-aluminum construction approach (see Table 3-9).

In the next section we will use these projected selling prices in computing the projected cost of electricity and comparing it against Department of Energy 1978 goals for different DAWT unit sizes. The $45^{\circ}$ half angle diffuser configuration projections are presented foremost because this design represents the best likely achievable commercial product based on the current analytical and experimental information available to us.

\subsubsection{Price Per Pound}

In the highly industrialized U.S. economy, there are a sufficiently large number and diversity of manufactured products to make possible an approximate generalization of selling price on the basis dollar per unit weight ratio for the three major groupings of products: a) precision, b) electromechanical, and c) functional. To provide data to those who wish to indulge in this preliminary estimating process, we present Table 3-10. In this tabulation, we have employed the above-ground weight data of Tables 2-4 and 2-5. We also use the selling price estimates of Tables $3-3,3-4,3-5$, and $3-8$ for 1 imited, 100 units/year, production rates. The concrete foundation has been excluded in each of these considerations because of its unrepresentative weight and cost relative to the above-ground equipment.

The above ground weights of the DAWT vary between about 2000 and 60,000 pounds for rotor diameters between about 2.7 and $11 \mathrm{~m}$ (9 and $36 \mathrm{ft})$. As shown in Table 3-10, the estimated price per pound (in 1979 dollars) ranges between about $\$ 2$ and $\$ 10$, with the smaller sized units being the more costly. Generally speaking, the indices for the limited production lot DAWT models are very comparable to the price per pound of standard mid-1970's vintage automobiles which are mature production items. 
Table 3-8. . PROJECTIONS OF ESTIMATED COST - DAWT - FOR TWO DIFFUSER DESIGNS, $45^{\circ}$ HALF-ANGLE, 2.75 AREA RATIO

\begin{tabular}{|c|c|c|c|c|c|c|}
\hline $\begin{array}{l}\text { ROTOR } \\
\text { DIA } \\
\text { (FT) }\end{array}$ & $\begin{array}{l}\text { MATERIAL OF } \\
\text { CONSTRUCTION }\end{array}$ & $\begin{array}{l}\text { TOTAL S.P. - } \\
30^{\circ} \text { BASELINE } \\
\text { DAWT, \$ }\end{array}$ & $\begin{array}{c}\text { DIFF ASSY } \\
\text { PORTION OF } \\
\text { DAWT S.P., } \\
30^{\circ} \text { BASELINE, } \\
\$\end{array}$ & $\begin{array}{c}\text { DIFF REL } \\
\text { COST: } \\
\left(\begin{array}{c}45^{\circ} \text { DESIGN } \\
30^{\circ} \text { BASELINE }\end{array}\right)\end{array}$ & $\begin{array}{c}\text { PROJECTED } \\
\text { S.P. } \mathbf{4 5}^{\circ} \\
\text { DIFF ASSY, } \\
\$\end{array}$ & $\begin{array}{l}\text { PROJECTED } \\
\text { S.P. - TOTAL } \\
\text { DAWT, } 45^{\circ} \\
\text { DIFF, \$ }\end{array}$ \\
\hline 36. & $\begin{array}{l}\text { ALL-ALUM - BAS } \\
\text { PER UNIT OF } \\
100 \text { UNITS } \\
200 \\
500\end{array}$ & $\begin{array}{l}\text { ELINE CONFIG } \\
205392 \\
194203 \\
187465\end{array}$ & $\begin{array}{l}145325 \\
134138 \\
127400\end{array}$ & $\begin{array}{l}.710 \\
.710 \\
.710 \\
.710\end{array}$ & $\begin{array}{r}103180 \\
95238 \\
90454\end{array}$ & $\begin{array}{l}163247 \\
155303 \\
150519\end{array}$ \\
\hline 36. & $\begin{array}{l}\text { FRP PANELS/ALU } \\
\text { PER UNIT OF } \\
100 \text { UNITS } \\
200 \\
500\end{array}$ & \begin{tabular}{|c|} 
M STRUCTURE \\
212237 \\
203594 \\
198368
\end{tabular} & $\begin{array}{c}\text {-DUMP. CONFIG } \\
137350 \\
129527 \\
124697\end{array}$ & $\begin{array}{l}.518 \\
.518 \\
.518 \\
.518\end{array}$ & $\begin{array}{l}71147 \\
67095 \\
64593\end{array}$ & $\begin{array}{l}146034 \\
141162 \\
138264\end{array}$ \\
\hline 22.5 & $\begin{array}{l}\text { ALL-ALUM - BAS } \\
\text { PER UNIT OF } \\
100 \text { UNITS } \\
200 \\
500\end{array}$ & $\begin{array}{l}\text { ELINE CONFIG } \\
\qquad 88633 \\
84009 \\
81223\end{array}$ & $\begin{array}{l}49140 \\
44515 \\
41730\end{array}$ & $\begin{array}{l}.710 \\
.710 \\
.710 \\
.710\end{array}$ & $\begin{array}{l}34889 \\
31605 \\
29628\end{array}$ & $\begin{array}{l}74382 \\
71099 \\
68233\end{array}$ \\
\hline 22.5 & $\begin{array}{l}\text { FRP PANELS/ALU } \\
\text { PER UNIT OF } \\
100 \text { UNITS } \\
200 \\
500\end{array}$ & \begin{tabular}{|c|} 
M STRUCTURE \\
84821 \\
82013 \\
80335
\end{tabular} & \begin{tabular}{|c|} 
DUMP. CONFIG \\
33493 \\
31488 \\
30297
\end{tabular} & $\begin{array}{l}.518 \\
\\
.518 \\
.518 \\
.518\end{array}$ & $\begin{array}{l}17349 \\
16311 \\
15694\end{array}$ & $\begin{array}{l}68677 \\
66836 \\
65732\end{array}$ \\
\hline 9. & $\begin{array}{l}\text { ALL-ALUM - BAS } \\
\text { PER UNIT OF } \\
100 \text { UNITS } \\
200 \\
500\end{array}$ & $\begin{array}{c}\text { ELINE CONFIG } \\
29005 \\
26309 \\
24678\end{array}$ & $\begin{array}{l}17800 \\
15103 \\
11715\end{array}$ & $\begin{array}{l}.710 \\
.710 \\
.710 \\
.710\end{array}$ & $\begin{array}{r}12638 \\
10723 \\
8318\end{array}$ & $\begin{array}{l}23843 \\
21929 \\
21281\end{array}$ \\
\hline 0647.029W & $\begin{array}{l}\text { FRP PANELS/ALU } \\
\text { PER UNIT OF } \\
100 \text { UNITS } \\
200 \\
500\end{array}$ & \begin{tabular}{|c} 
M STRUCTURE \\
25801 \\
24064 \\
23022
\end{tabular} & \begin{tabular}{|c|}
-DUMP. CONFIG \\
12710 \\
11230 \\
10343
\end{tabular} & $\begin{array}{l}.518 \\
.518 \\
.518 \\
.518\end{array}$ & $\begin{array}{l}6584 \\
5817 \\
5358\end{array}$ & $\begin{array}{l}19675 \\
18651 \\
18037\end{array}$ \\
\hline
\end{tabular}


Table 3-9. RELATIVE SELLING PRICE OF DAWTS WITH $45^{\circ}$ VERSUS $30^{\circ}$ HALF-ANGLES AND TWO MATERIALS OF CONSTRUCTION

\begin{tabular}{|c|c|c|c|}
\hline \multirow{2}{*}{$\begin{array}{c}\text { Material of } \\
\text { Construction }\end{array}$} & $\begin{array}{c}\text { (Based on 100 Unit Production Lot Run) } \\
\% \text { of } 30^{\circ} \text { Base line Design SP }\end{array}$ \\
\cline { 2 - 4 } & 36 & 22.5 & 9 \\
\hline All Aluminum & $79 \%$ & $84 \%$ & $82 \%$ \\
\hline $\begin{array}{c}\text { FRP/Aluminum } \\
\text { 1467-022(T) }\end{array}$ & $69 \%$ & $81 \%$ & $76 \%$ \\
\hline
\end{tabular}


Table 3-10. ESTIMATED MARKET PRICE PER POUND* OF DAWT'S (1979 DOLLARS)

\begin{tabular}{|c|c|c|c|c|c|c|}
\hline DAWT Configuration & \multicolumn{3}{|c|}{$\begin{array}{l}\text { Improved, } 45^{\circ} \text { Half-Angle, Dump } \\
\text { Diffuser, } 2.75 \text { Area Ratio } \\
\end{array}$} & \multicolumn{3}{|c|}{$\begin{array}{l}\text { Baseline, } 30^{\circ} \text { Half-Angle, Baseline } \\
\text { Diffuser, } 2.75 \text { Area Ratio }\end{array}$} \\
\hline Rotor Diameter; Ft. & 9 & 22.5 & 36 & 9 & 22.5 & 36 \\
\hline $\begin{array}{l}\text { Material of } \\
\text { Construction }\end{array}$ & \multicolumn{3}{|c|}{ Above Ground \$/Pound } & \multicolumn{3}{|c|}{ Above Ground \$/Pound } \\
\hline A11 Aluminum & 8.85 & 3.20 & 2.21 & 10.45 & 3.70 & 2.60 \\
\hline FRP Panels/Alum. Frame & 6.85 & 2.75 & 2.23 & 7.75 & 2.45 & 2.80 \\
\hline Ferro Cement & 3.15 & 1.55 & N.A. & 2.95 & 1.35 & N.A. \\
\hline
\end{tabular}

*Includes all above-ground components (e.g., diffuser, turbine assembly, support, etc.) $1467-023(T)$ 
SECTION 4.0

BUSBAR COST OF ELECTRICITY

The cost of electricity (COE) generated by DAWTs is computed in Table 4-1 by the standard DoE equation (Ref. 18):

$$
\mathrm{COE}=(\text { Capital Cost, \$) (Annual Fixed Charge, \%)/Annual Energy, } \mathrm{kW} \mathrm{h}
$$

In addition, the yearly operations and maintenance (0\&M) expenses, over the lifetime of the unit should be included to present a realistic commercial environment. We present 0\&M costs separately here in view of the greater uncertainty about its magnitude because of the lack of precedence and experience.

In Table 4-1 in addition to our recommended FRP/aluminum version of the DAWT, in three rotor sizes, we present the all-aluminum for comparison. As previously indicated in Section 3.0, we have not projected the COE for production lot sizes beyond 500 because of uncertainty of the appropriate scaling relation. There is the possibility, also, that very much larger quantities will require different manufacturing techniques for the FRP panels, which cannot be extrapolated from the data about the presently assumed manufacturing approach.

The largest size DAWT (11 m (36 ft) rotor diameter) has been analyzed for three output ratings, 150,100 and $82.5 \mathrm{~kW}$. While all employ the same rotor size and DAWT structure the first rated unit differs from the latter two by virtue only of a higher capacity generator and gear box. The price differential is only $\$ 3000$, or only a $2 \%$ price increase to yield a $50 \%$ increase in power rating. The $82.5 \mathrm{~kW}$ unit, rated at $20 \mathrm{mph}$, employs a $100 \mathrm{~kW}$ capacity generator and transmission gearbox and, therefore, sells at the same price as the $100 \mathrm{~kW}$ unit rated at $21 \mathrm{mph}$; the only difference is the $1 \mathrm{mph}$ wind speed change at which the rating is made. The data emphasizes the point previously made in Section 2.0 about the artificiality of "standardizing" the rating wind at $20 \mathrm{mph}$. The DAWTs with the two smaller rotor sizes 6.8 and 2.7 $\mathrm{m}$ (22.5 and $9 \mathrm{ft}$ ) in diameter are presented in two ratings, one for which the installed generator is capable of providing output and the other for comparing to a "standard" $20 \mathrm{mph}$ wind speed. As a result, the possible selling price of these smaller units does not vary between the installed capacity rating and the under-rated condition imposed by a $20 \mathrm{mph}$ wind speed.

The output performance (in $\mathrm{kW} h$ ) of each DAWT analyzed here is conservative because of the rotor design philosophy initially assumed. As was noted in the first section of this report, a more refined rotor blade design, incorporating, for example taper and twist, would be expected to increase the output by $50 \%$ or more, without any contemplated changes in diffuser configuration. Although the blade manufacturing costs would increase somewhat by these refinements, it should have a small impact on the total cost of the DAWT; one rough estimate is about a $3 \%$ overall cost increment. Thus the results of Fig. 2-15 must be viewed as merely indicative but not definitive regarding the ultimate economic prospects for the DAWT concept. 
Table 4-1. PROJECTIONS OF COST OF ELECTRICITY

FOR DAWT $\left(45^{\circ}\right.$ HALF ANGLE, 2.75 AREA RATIO)

\begin{tabular}{|c|c|c|c|c|c|c|c|c|c|c|c|c|c|c|c|c|}
\hline \multirow{2}{*}{$\begin{array}{l}\text { ROTOR } \\
\text { DIA } \\
\text { FT }\end{array}$} & \multirow[b]{2}{*}{ DAWT VERSION } & \multirow{2}{*}{$\begin{array}{l}\text { PROJECTED } \\
\text { UNIT SELL'G } \\
\text { PRICE, } 10^{3} \$\end{array}$} & \multirow{2}{*}{$\begin{array}{l}\text { PRODUCTION } \\
\text { LOT } \\
\text { SIZE }\end{array}$} & \multirow{2}{*}{$\begin{array}{l}\text { AUGMENT'N } \\
\text { RATIO }\end{array}$} & \multirow{2}{*}{$\begin{array}{l}\text { CUT-IN } \\
\text { WIND SPEED } \\
\text { MPH }\end{array}$} & \multirow{2}{*}{$\begin{array}{l}\text { RATED } \\
\text { POWER, } \\
\text { kW }\end{array}$} & \multirow{2}{*}{$\begin{array}{l}\text { RATED WIND } \\
\text { SPEED, } \\
\text { MPH }\end{array}$} & \multirow{2}{*}{\multicolumn{3}{|c|}{ 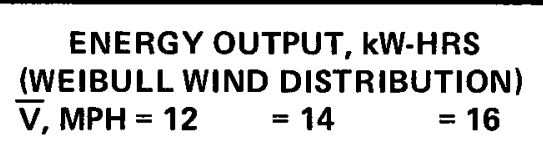 }} & \multicolumn{6}{|c|}{ BUSBAR COST OF ELECTRICITY (\$ $/ \mathrm{kW}$-HR) } \\
\hline & & & & & & & & & & & \multicolumn{3}{|c|}{$\begin{array}{l}\overline{\bar{V}}, \text { MPH }=12=14=16 \\
\text { ANNUAL CHARGE FACTOR }=.18\end{array}$} & \multicolumn{3}{|c|}{$\begin{array}{ccc}=12 & =14 & =16 \\
\text { ANNUAL CHARGE FACTOR } & =.10\end{array}$} \\
\hline 36 & $\begin{array}{l}\text { FRP PANELS/ALUM. STRUCTURE } \\
\text { DUMP DIFFUSER CONFIGURATION }\end{array}$ & $\begin{array}{l}149(1) \\
144(1) \\
141(1)\end{array}$ & $\begin{array}{l}100 \\
200 \\
500\end{array}$ & $\begin{array}{l}5.5 \\
5.5 \\
5.5\end{array}$ & $\begin{array}{l}6.0 \\
6.0 \\
6.0\end{array}$ & $\begin{array}{l}150 \\
150 \\
150\end{array}$ & $\begin{array}{l}24 \\
24 \\
24\end{array}$ & $\begin{array}{l}466600 \\
466600 \\
466600\end{array}$ & $\begin{array}{l}579795 \\
579795 \\
579795\end{array}$ & $\begin{array}{l}674185 \\
674185 \\
674185\end{array}$ & $\begin{array}{l}.058 \\
.056 \\
.054\end{array}$ & $\begin{array}{l}.047 \\
.045 \\
.043\end{array}$ & $\begin{array}{l}.040 \\
.038 \\
.036\end{array}$ & $\begin{array}{l}.032 \\
.031 \\
.030\end{array}$ & $\begin{array}{l}.026 \\
.025 \\
.024\end{array}$ & $\begin{array}{l}.022 \\
.021 \\
.020\end{array}$ \\
\hline & & $\begin{array}{l}146 \\
141 \\
138\end{array}$ & $\begin{array}{l}100 \\
200 \\
500\end{array}$ & $\begin{array}{l}5.5 \\
5.5 \\
5.5\end{array}$ & $\begin{array}{l}6.0 \\
6.0 \\
60\end{array}$ & $\begin{array}{l}100 \\
100 \\
100\end{array}$ & $\begin{array}{l}21 \\
21 \\
21\end{array}$ & $\begin{array}{l}367130 \\
367130 \\
367130\end{array}$ & $\begin{array}{l}446630 \\
446630 \\
446630\end{array}$ & $\begin{array}{l}499915 \\
499915 \\
499915\end{array}$ & $\begin{array}{l}.072 \\
.068 \\
068\end{array}$ & $\begin{array}{l}.058 \\
.054 \\
054\end{array}$ & $\begin{array}{l}.052 \\
.050 \\
049\end{array}$ & $\begin{array}{l}.040 \\
.038 \\
038\end{array}$ & $\begin{array}{l}.032 \\
.030 \\
030\end{array}$ & $\begin{array}{l}.029 \\
.028 \\
027\end{array}$ \\
\hline & & 146 & 100 & 5.5 & 6.0 & 82.5 & 20 & 314325 & 380325 & 430650 & .083 & .068 & .061 & .046 & .038 & .034 \\
\hline \multirow[t]{2}{*}{22.5} & $\begin{array}{l}\text { FRP PANELS/ALUM. STRUCTURE } \\
\text { DUMP DIFFUSER CONFIGURATION }\end{array}$ & $\begin{array}{l}69 \\
67 \\
66\end{array}$ & $\begin{array}{l}100 \\
200 \\
500\end{array}$ & $\begin{array}{l}5.5 \\
5.5 \\
5.5\end{array}$ & $\begin{array}{l}6.0 \\
6.0 \\
6.0\end{array}$ & $\begin{array}{l}60 \\
60 \\
60\end{array}$ & $\begin{array}{l}24.2 \\
24.2 \\
24.2\end{array}$ & $\begin{array}{l}185680 \\
185680 \\
185680\end{array}$ & $\begin{array}{l}230950 \\
230950 \\
230950\end{array}$ & $\begin{array}{l}267050 \\
267050 \\
267050\end{array}$ & $\begin{array}{l}.067 \\
.065 \\
.065\end{array}$ & $\begin{array}{l}.054 \\
.052 \\
.050\end{array}$ & $\begin{array}{l}.047 \\
.045 \\
.045\end{array}$ & $\begin{array}{l}.037 \\
.036 \\
.036\end{array}$ & $\begin{array}{l}.030 \\
.029 \\
.028\end{array}$ & $\begin{array}{l}.026 \\
.025 \\
.025\end{array}$ \\
\hline & & 69 & 100 & 5.5 & 6.0 & 32.3 & 20 & 123065 & 148905 & 168605 & .100 & .083 & .074 & .056 & .046 & .041 \\
\hline \multirow[t]{2}{*}{9} & $\begin{array}{l}\text { FRP PANELS/ALUM. STRUCTURE } \\
\text { DUMP DIFFUSER CONFIGURATION }\end{array}$ & $\begin{array}{l}20 \\
19 \\
18\end{array}$ & $\begin{array}{l}100 \\
200 \\
500\end{array}$ & $\begin{array}{l}5.5 \\
5.5 \\
5.5\end{array}$ & $\begin{array}{l}6.0 \\
6.0 \\
6.0\end{array}$ & $\begin{array}{l}11.2 \\
11.2 \\
11.2\end{array}$ & $\begin{array}{l}26 \\
26 \\
26\end{array}$ & $\begin{array}{l}32350 \\
32350 \\
32350\end{array}$ & $\begin{array}{l}40510 \\
40510 \\
40510\end{array}$ & $\begin{array}{l}47170 \\
47170 \\
47170\end{array}$ & $\begin{array}{l}.112 \\
.106 \\
.101\end{array}$ & $\begin{array}{l}.090 \\
.085 \\
.079\end{array}$ & $\begin{array}{l}.077 \\
.072 \\
.068\end{array}$ & $\begin{array}{l}.062 \\
.059 \\
.056\end{array}$ & $\begin{array}{l}.050 \\
.047 \\
.044\end{array}$ & $\begin{array}{l}.043 \\
.040 \\
.038\end{array}$ \\
\hline & & 20 & 100 & 5.5 & 6.0 & 5.2 & 20 & 19810 & 23970 & 27145 & .182 & .151 & .133 & 101 & .084 & .074 \\
\hline 36 & $\begin{array}{l}\text { ALL-ALUMINUM STRUCTURE } \\
\text { BASELINE DIFFUSER } \\
\text { CONFIGURATION }\end{array}$ & $\begin{array}{l}163 \\
155 \\
151\end{array}$ & $\begin{array}{l}100 \\
200 \\
500\end{array}$ & $\begin{array}{l}5.2 \\
5.2 \\
5.2\end{array}$ & $\begin{array}{l}6.0 \\
6.0 \\
6.0\end{array}$ & $\begin{array}{l}78 \\
78 \\
78\end{array}$ & $\begin{array}{l}20 \\
20 \\
20\end{array}$ & $\begin{array}{l}294840 \\
294840 \\
294840\end{array}$ & $\begin{array}{l}355680 \\
355680 \\
355680\end{array}$ & $\begin{array}{l}405600 \\
405600 \\
405600\end{array}$ & $\begin{array}{l}.101 \\
.094 \\
.092\end{array}$ & $\begin{array}{l}.083 \\
.079 \\
.077\end{array}$ & $\begin{array}{l}.072 \\
.068 \\
.068\end{array}$ & $\begin{array}{l}.056 \\
.052 \\
.051\end{array}$ & $\begin{array}{l}.046 \\
.044 \\
.043\end{array}$ & $\begin{array}{l}.040 \\
.038 \\
.038\end{array}$ \\
\hline 22.5 & $\begin{array}{l}\text { ALL-ALUMINUM STRUCTURE } \\
\text { BASELINE DIFFUSER } \\
\text { CONFIGURATION }\end{array}$ & $\begin{array}{l}74 \\
71 \\
68\end{array}$ & $\begin{array}{l}100 \\
200 \\
500\end{array}$ & $\begin{array}{l}5.2 \\
5.2 \\
5.2\end{array}$ & $\begin{array}{l}6.0 \\
6.0 \\
6.0\end{array}$ & $\begin{array}{l}30.6 \\
30.6 \\
30.6\end{array}$ & $\begin{array}{l}20 \\
20 \\
20\end{array}$ & $\begin{array}{l}115670 \\
115670 \\
115670\end{array}$ & $\begin{array}{l}139535 \\
139535 \\
139535\end{array}$ & $\begin{array}{l}159120 \\
159120 \\
159120\end{array}$ & $\begin{array}{l}.115 \\
.112 \\
.106\end{array}$ & $\begin{array}{l}.095 \\
.092 \\
.088\end{array}$ & $\begin{array}{l}.083 \\
.079 \\
.077\end{array}$ & $\begin{array}{l}.064 \\
.062 \\
.059\end{array}$ & $\begin{array}{l}.053 \\
.051 \\
.049\end{array}$ & $\begin{array}{l}.046 \\
.044 \\
.043\end{array}$ \\
\hline $\begin{array}{c}9 \\
0647-030 w\end{array}$ & $\begin{array}{l}\text { ALL-ALUMINUM STRUCTURE } \\
\text { BASELINE DIFFUSER } \\
\text { CONFIGURATION }\end{array}$ & $\begin{array}{l}24 \\
22 \\
21\end{array}$ & $\begin{array}{l}100 \\
200 \\
500\end{array}$ & $\begin{array}{l}5.2 \\
5.2 \\
5.2\end{array}$ & $\begin{array}{l}6.0 \\
6.0 \\
6.0\end{array}$ & $\begin{array}{l}4.9 \\
4.9 \\
4.9\end{array}$ & $\begin{array}{l}20 \\
20 \\
20\end{array}$ & $\begin{array}{l}18520 \\
18520 \\
18520\end{array}$ & $\begin{array}{l}22345 \\
22345 \\
22345\end{array}$ & $\begin{array}{l}25480 \\
25480 \\
25480\end{array}$ & $\begin{array}{l}.234 \\
.214 \\
.205\end{array}$ & $\begin{array}{l}.194 \\
.176 \\
.169\end{array}$ & $\begin{array}{l}.169 \\
.155 \\
.148\end{array}$ & $\begin{array}{l}.130 \\
.119 \\
.114\end{array}$ & $\begin{array}{l}.108 \\
.098 \\
.094\end{array}$ & $\begin{array}{l}.094 \\
.086 \\
.082\end{array}$ \\
\hline
\end{tabular}

(1) INCLUDES $\$ 3000$ DIFFERENTIAL FOR 150KW RATED GENERATOR AND 1467-025(T) 


\subsection{WIND ENERGY POTENTIAL}

The COE Table also differentiates between different sites and different types of users. Sites with annual average wind speeds of 12,14 , and $16 \mathrm{mph}$ are considered with regard to their annual energy potential for each DAWT rating. The wind speed occurrence distribution (i.e., probability) assumed for this energy computation is a special case of the Weibull equation known as the Rayleigh distribution (Ref. 19). This single parameter model has been recommended where the wind speed frequency distribution of a site is generally unknown but the long term mean wind speed is known and is greater than $10 \mathrm{mph}$ $(4.5 \mathrm{~m} / \mathrm{s})$ (Ref. 19).

The Rayleigh distribution function has the form

$P(V)=\frac{\pi}{2} \frac{V}{V^{2}} e^{-m}$

where: $m=\left(0.7854 v^{2} / \bar{v}^{2}\right)$

$P(V)=$ wind speed frequency distribution

$V \quad=$ wind speed

$\bar{V} \quad=$ long term mean wind speed.

Using the Rayleigh function, the number of hours per year, T, that the wind exceeds a value, $V$, can be computed as:

$$
\mathrm{T}=8766 \mathrm{e}^{-\mathrm{m}}
$$

Because the instantaneous power in the wind is proportional to $v^{3}$, the annual mean wind power is proportional to $\bar{V}^{3}$ rather than $(\bar{V})^{3}$. For the Rayleigh distribution (Ref. 19):

$$
\overline{v^{3}} \simeq 1.91(\nabla)^{3}
$$

and the potentially available mean wind power at a site or region is (Ref. 19)

$$
P_{A} \simeq 0.955 \rho \overline{V^{3}} \text {, watts } / m^{2}
$$

where: $\rho$ is air density in $\mathrm{kg} / \mathrm{m}^{3}$

and $\quad V$ is wind speed in $\mathrm{m} / \mathrm{s}$.

We have computerized the calculation of energy generated by the DAWT using the Rayleigh distribution, stated above, for specific values of the DAWT power rating, power rating wind speed, cut-in wind velocity and cut-out wind velocity. For the cut-out speed a value of $40 \mathrm{mph}(17.8 \mathrm{~m} / \mathrm{s})$ is used in Table 4-1 although we find that using a higher value, such as $75 \mathrm{mph}(33.4 \mathrm{~m} / \mathrm{s})$, produces only a negligibly larger annual energy.

It is also assumed in our application of wind statistics that the long term average wind speed has been measured at a height above the ground that is representative of the DAWT hub height. A typical meteorological measurement height is $9.1 \mathrm{~m}(30 \mathrm{ft})$; the hub of the three DAWTs investigated here are assumed to be at $6-13 \mathrm{~m}$ above the ground. Since the vertical profile of 
wind speed is sensitive to upwind terrain features as well as general atmospheric conditions (e.g., stratified, unstable, etc), no assumption is further made for hub height correction to the measured wind speed at $9.1 \mathrm{~m}$ (30 $f t)$.

\subsection{ANNUAL CHARGE FACTOR}

The annual charge factor appropriate to two classes of end users of DAWTs is given in Table 4-1 as 0.18 for use by utilities and large industrial corporations and 0.10 for farmers and REA cooperatives (Ref. 20, 21). Although a more comprehensive justification of these annual factors is beyond the scope of the present project, we believe it is useful to note that this factor includes allowances for cost of money, depreciation, return to investors, debt retirement, insurance, income and other taxes (Ref. 21). The factor varies with equipment type, regional site and service life of the equipment. Therefore any change in DAWT ownership conditions that affects the site location, service life, and acccounting or tax provisions will change the annual factor and the cost of energy over the lifetime of the unit. Federal or local government incentives through reduced taxes, co-insurance, low-cost loans, or equipment cost rapid write-offs would have an immediate and large influence, far beyond minor technological improvements or finely tuned site selection, in reducing the DAWT cost of energy to competitiveness with current conventional baseload energy generation. At the values of annual charge factor assumed in Table 4-1, the DAWT generates electrical energy that is cost competitive with current diesel and gas turbine powered generators and secondary fossil fuel power plants in which pollution abatement equipment cost is included (Ref. 20).

\subsection{OPERATIONS AND MAINTENANCE}

Estimates of the annual allowance for operations and maintenance of the 100 unit DAWT array over a 30-year lifetime are given in Table 4-2. These 0 \& $M$ estimates add about $\$ 0.001-\$ 0.003$ per $\mathrm{kW} \mathrm{h}$ to the COE given in Table 4-1 for the $150 \mathrm{~kW}-60 \mathrm{~kW}$ units, respectively. Because of the much 1 ower energy output level of the smaller machines, $30 \mathrm{~kW}$ or below, the $0 \& \mathrm{M}$ cost contribution to the busbar cost is between $2-6$ mills per $\mathrm{kW} \mathrm{h}$. For these small machines, however, the likely end-user is the individual farmer, consumer or small agricultural processing industry. In this case the operations cost can be considered negligible because it would be performed by the owner-user. This situation would lower the $0 \& M$ costs to between $1-3$ mills per $\mathrm{kW} \mathrm{h}$, and may become negligible if the owner-user performs the maintenance in contrast to a contracted service from a regional maintenance organization.

\subsection{SALVAGE VALUE}

Finally, the element of salvage value of the DAWT at the end of its 30-year design lifetime must be considered. At present (1979), scrap aluminum is purchased at a price of $\$ 0.30$ per pound by Reynolds Aluminum (Ref. 21); projections of what aluminum producers might be willing to pay for scrap in 30- years are speculative, but could be as high as $\$ 1.00 / 1 \mathrm{~b}$ in 1979 dollar 
Regular maintenance of the DAWT entails only an annual change of transmission lubricant and the lubrication of the journal bearing.

Case 1. For $60-150 \mathrm{~kW}$ Units

$$
\begin{aligned}
& \text { Estimated Annual Maintenance }=2 \text { days } \times 8 \mathrm{~h}=16 \mathrm{~h} \\
& 1979 \text { Hourly Labor Cost o } \$ 15 / \mathrm{h}=\$ 240 / \mathrm{yr} \\
& \text { Levelizing factor to account for escalation } \\
& \text { of labor rates over } 30 \text { year lifetime of unit } \times 2 \\
& \text { "Levelized" Labor Cost per Year = } \$ 480 / \mathrm{yr} \\
& \text { Estimated Annual Operations Cost per Unit } \\
& \text { of } 100 \text { Unit Array (Averaged over } 30 \text { years) }=\$ 150 / y r \\
& \text { Total } 0 \& M=\$ 630 / y r
\end{aligned}
$$

a) COE for $150 \mathrm{~kW}$ Rated Unit

$$
\frac{\text { Annual Total 0\&M Cost }}{\text { Average Annual Energy }}=\frac{\$ 630}{500,000 \mathrm{~kW} / \mathrm{h}}=\$ .0013 / \mathrm{kW} \mathrm{h}
$$

b) $\mathrm{COE}$ for $100 \mathrm{~kW}$ Rated Unit

$$
\frac{\text { Annual Total 0\&M Cost }}{\text { Average Annual Energy }}=\frac{\$ 630}{400,000 \mathrm{~kW} / \mathrm{h}}=\$ .0016 / \mathrm{kW} \mathrm{h}
$$

c) $\mathrm{COE}$ for $60 \mathrm{~kW}$ Rated Unit

$$
\frac{\text { Annual Total 0\&M Cost }}{\text { Average Annual Energy }}=\frac{\$ 630}{200,000 \mathrm{~kW} / \mathrm{h}}=\$ .0032 / \mathrm{kW} \mathrm{h}
$$

Case 2. For $10-30 \mathrm{~kW}$ Units

$$
\begin{aligned}
\text { Estimated Annual Maintenance - } 1 \text { Day } \times 4 \mathrm{~h} & =4 \mathrm{~h} \\
1979 \text { Hourly Labor Cost a } \$ 15 / \mathrm{h} & =\$ 60 / \mathrm{yr}
\end{aligned}
$$

\footnotetext{
*These 0 and $M$ estimates are consistent with the basic turbine design used in this investigation and were described in DoE Report RFP-3007 (Vol 1), Table V, page 9, March 1980. They are not to be considered as representative of other designs and general conventional wind turbine experience.
} 
Table 4-2. OPERATIONS AND MAINTENANCE COST ESTIMATES (continued)

Case 2. (continued)

$$
\begin{aligned}
\begin{array}{l}
\text { Levelizer Factor over } 30 \text { year } \\
\text { lifetime of unit }
\end{array} & =\frac{\times 2}{\text { "Levelized" Labor Cost }} \\
\text { Estimated Annual Operations Cost per Unit } & =\$ 120 / \mathrm{yr} \\
\text { (Averaged over } 30 \text { years) } & \$ 80 / \mathrm{yr} \\
\text { Total } 0 \& M & =\$ 200 / \mathrm{yr}
\end{aligned}
$$$$
\text { (Averaged over } 30 \text { years) }
$$

d) $\mathrm{COE}$ for $30 \mathrm{~kW}$ Rated Unit

$\frac{\text { Annual Total 0\&M Cost }}{\text { Average Annual Energy }}=\frac{\$ 200}{120,000 \mathrm{~kW} / \mathrm{h}}=\$ .0017 / \mathrm{kW} \mathrm{h}$

e) $\mathrm{COE}$ for $10 \mathrm{~kW}$ Rated Unit

$$
\frac{\text { Annual Total 0\&M Cost }}{\text { Average Annual Energy }}=\frac{\$ 200}{35,000 \mathrm{~kW} / \mathrm{h}}=\$ .0057 / \mathrm{kW} \mathrm{h}
$$


equivalents. * For the FRP/aluminum DAWT design approach recommended here, the scrap aluminum at a recycle net value of $\$ 0.30$ to $\$ 1.00 / 1 \mathrm{~b}$ in 1979 dollars would have a range of salvage worths, for the three DAWT sizes, of approximately:
DAWT Rotor Diam., $m(f t)$
2.7 (9)
$6.8(22.5)$
11. (36)
DAWT Aluminum Salvage Value (1979\$)
c $\$ 0.30 / 1$ b resale price
270
2070
6,360
a $\$ 1.00 / 1 b$ resale price
900
6900
21,200

The effect of salvage value is to reduce the net capital cost outlay depreciated over the 30-year lifetime of the unit. As a simplification, we treat salvage value as untaxed negative (or reduced) capital expenditure in the COE equation, then the effect is to reduce the energy cost of the unit. Table 4-3 presents the approximate average reduction in COE for the utility and the REA cooperative or farmer, applying the appropriate ACFs of $18 \%$ and $10 \%$, respectively, and the two possible bounds for scrap aluminum prices.

\subsection{BUSBAR COST OF ENERGY}

The calculation of net COE with consideration of basic installation cost, 0\&M costs, and projected salvage value is given by Table 4-4. The utility user is the most likely to employ the 60 to $150 \mathrm{~kW}$ DAWT units in arrays, with net busbar costs between about $\$ 0.03-\$ 0.06 / \mathrm{kW} \mathrm{h}$, for limited DAWT production. The REA Cooperative is the likely user for arrays of $60-150 \mathrm{~kW}$ units with net busbar costs between about $\$ 0.015$ and $\$ 0.035 / \mathrm{kW} \mathrm{h}$, for limited DAWT production. The individual farmer or consumer is the likely market for the 11 $\mathrm{kW}$ rated unit and in individual units produced from 1 imited production lots the net busbar cost of electricity is estimated between $\$ 0.04$ and $\$ 0.06 / \mathrm{kW} \mathrm{h}$. In view of the degree of uncertainty connected with $0 \& M$ as well as salvage amounts, one can approximately consider these items as offsetting each other.

\footnotetext{
${ }^{\star}$ Recycled aluminum currently provides a 95\% saving in energy needs over the conventional processing of ore to virgin aluminum. The aluminum industry has turned increasingly to recycling since 1973 in the face of greater consumption growth than in increased smeltering capacity. The pacing factor contributing to low smeltering growth has been the available supply of US electrical energy. With continuing restrictions presented by US energy costs and availability, it is likely that recycling will expand and that the price scrap aluminum will command will exceed by a considerable margin the normal long term inflationary rate of the general economy. However, advances in smeltering technology or pressures on a mature metals market (e.g., material substitution) may cap aluminum pricing in 20 to 40 years and affect the future need and affordable price paid for scrap by the industry. If scrap aluminum appreciates in value in excess of the long term inflation rate at a compound rate of just 2 to $4 \%$, then at the end of 30 years its present value would appear to be $\$ 0.54$ to $\$ 0.97 / 1 \mathrm{~b}$, respectively, in 1979 dollars.
} 
Table 4-3. REDUCTION OF COE FROM SCRAP ALUMINUM SALVAGE RECOVERY (AFTER 30 YEARS)

$\begin{array}{llll}\text { DAWT ROTOR DIA, m, (ft) } & 2.7(9) & 6.8(22.5) & 11.0(36) \\ \begin{array}{l}\text { Assumed Avg. Annual } \\ \text { Energy, kWh }\end{array} & 35,000 & 200,000 & 500,000\end{array}$

REDUCTION IN COE, \$/kW h $(1979 \$)$

Utility end-user

a $\$ 0.30 / 1$ b resale price $\quad 0.0014 \quad 0.0019 \quad 0.0023$

a $\$ 1.00 / 1 \mathrm{~b}$ resale price $0.0046 \quad 0.0062 \quad 0.0076$

Farmer end-user

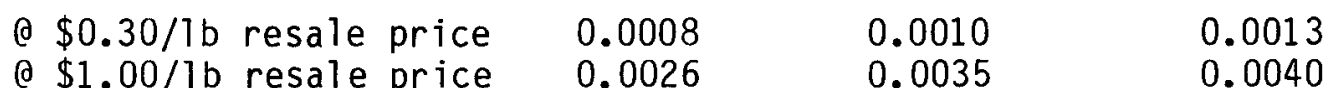

In Table 4-4, we have assumed $100 \%$ availability of the DAWT. For lesser availability because of machine or natural causes, the COE cited above will increase directly. Thus, for 95\% availability the REA cooperative would have busbar COE of $(\$ 0.015-0.035) / 0.095$, or $\$ 0.0158-0.0368 / \mathrm{kW} \mathrm{h}$. Arrays of DAWT's are likely to have higher availabilities than single, stand-alone, units, partly because of superior logistical support.

\subsection{COMPARISON TO DOE GOALS}

To provide a basis for evaluation, the data of Table 4-4 is plotted in Fig. 4-1 and 4-2 against the band of Department of Energy (DoE) goals established in 1978 (Ref. 8). The band for site annual average wind speeds between 12 and $16 \mathrm{mph}$ is presented as a continuous plot against output rating although the DoE Goals were for discrete 8,40 and $200 \mathrm{~kW}$ sized units. Limited production cost goals are used although in DoE terminology this refers to production runs of 1000's of units and the DAWT estimates are only for lot sizes of 100's. The $200 \mathrm{~kW}$ sized unit costs (Ref. 8) are for the third generation, Mod- $x$, paper design proposed by NASA in January 1979. DoE goals for this rating of unit are not differentiated by user; therefore in Fig. 4-2 we have projected the COE goal for farmer applications by use of the same ratio of farmer-to-commercial costs employed for the 8 to $40 \mathrm{~kW}$ ratings.

It is clear from Fig. 4-1 and 4-2 that the estimated DAWT busbar cost of energy in 1979 dollars is lower than the commercial and farmer application goals set in 1978, at all ratings between 40 and $200 \mathrm{~kW}$ and for all average wind sites. The differential between goal and estimate could represent the margin available for different pricing strategies by a manufacturer to support future product improvement, warranty and service provisions, or marketing concessions as well as the $\pm 10 \%$ accuracy associated with the present cost estimates. In the $20-40 \mathrm{~kW}$, for the rating range, commercial user the DAWT estimated $\mathrm{COE}$ is $5-18 \%$ lower than the DOE goal, without further accounting for the inflationary effect on the value of the dollar between the 1978 and 
Table 4-4. SUMMARY

NET COE FOR THREE DAWT RATED OUTPUT UNITS IN LIMITED PRODUCTION LOTS

DAWT Rotor Diam, m (ft)

$2.7(9)$

$6.8(22.5)$

11. $(36)$

Utility, Industrial, Commercial End-User

Rated Output, kW

11

60

150

Basic Installation

$+0 \& M$

$0.068-0.112$

0.0057

0.045-0.067

0.0032

0.036-0.058

Total COE, $\$ / \mathrm{kW} \mathrm{h}$

$0.074-0.118$

$0.048-0.070$

0.0013

- Avg. Salvage Value
c $\$ 0.30 / 1 b$
0.0014
0.0046
0.0019
0.0062
0.0023
c $\$ 1.00 / 1 \mathrm{~b}$

0.0046

$0.042-0.064$

$0.037-0.059$

Net COE, $\$ / \mathrm{kW} \mathrm{h}$
$0.073-0.117$
$0.046-0.068$
a $\$ 0.30 / 1 \mathrm{~b}$ resale
$0.069-0.113$
$0.035-0.057$
$0.029-0.051$

Farmer, Consumer, REA Cooperative End-User

Rated Output, kW

Basic Installation

$+0 \& M$

Total COE, $\$ / \mathrm{kW} \mathrm{h}$

- Avg. Salvage Value
c $\$ 0.30 / 1 \mathrm{~b}$
(a) $\$ 1.00 / 1 \mathrm{~b}$

Net COE, $\$ / \mathrm{kW} \mathrm{h}$

c $\$ 0.30 / 1 \mathrm{~b}$ resale

d \#1.00/1b resale
11

$0.038-0.062$

0.0057

$0.044-0.068$

0.0008

0.0026

0.0010

0.0035

0.0013

0.0040
150

$0.020-0.032$

0.0013

$0.021-0.033$

0.043-0.067

0.027-0.039

$0.041-0.065$

0.025-0.037

0.020-0.032

0.017-0.029 
1979 referenced years. * At higher power ratings (e.g., $150 \mathrm{~kW}$ ) the DAWT estimate is one-half the DoE goal for the commercial user.

For the farmer end user, the 1979 DAWT estimate (on average) is about equal to the DoE goal for the high site speed $(\bar{V}=16 \mathrm{mph})$ situation, and about 6 to $14 \%$ lower at the low site speed $(\bar{V}=12 \mathrm{mph})$ application. At this time, there appears to be a potential for broader market penetration, once this market is stimulated, by the DAWT than by improved conventional wind energy machines.

\footnotetext{
*In this regard, the US dollar lost $10 \%$ of its buying power in this one year interval. However, according to the US Bureau of Labor Statistics, the average cost of energy in the US had increased by $15 \%$. Thus, the energy cost goals would be expected to increase at a faster rate than the overall economic climate.
} 


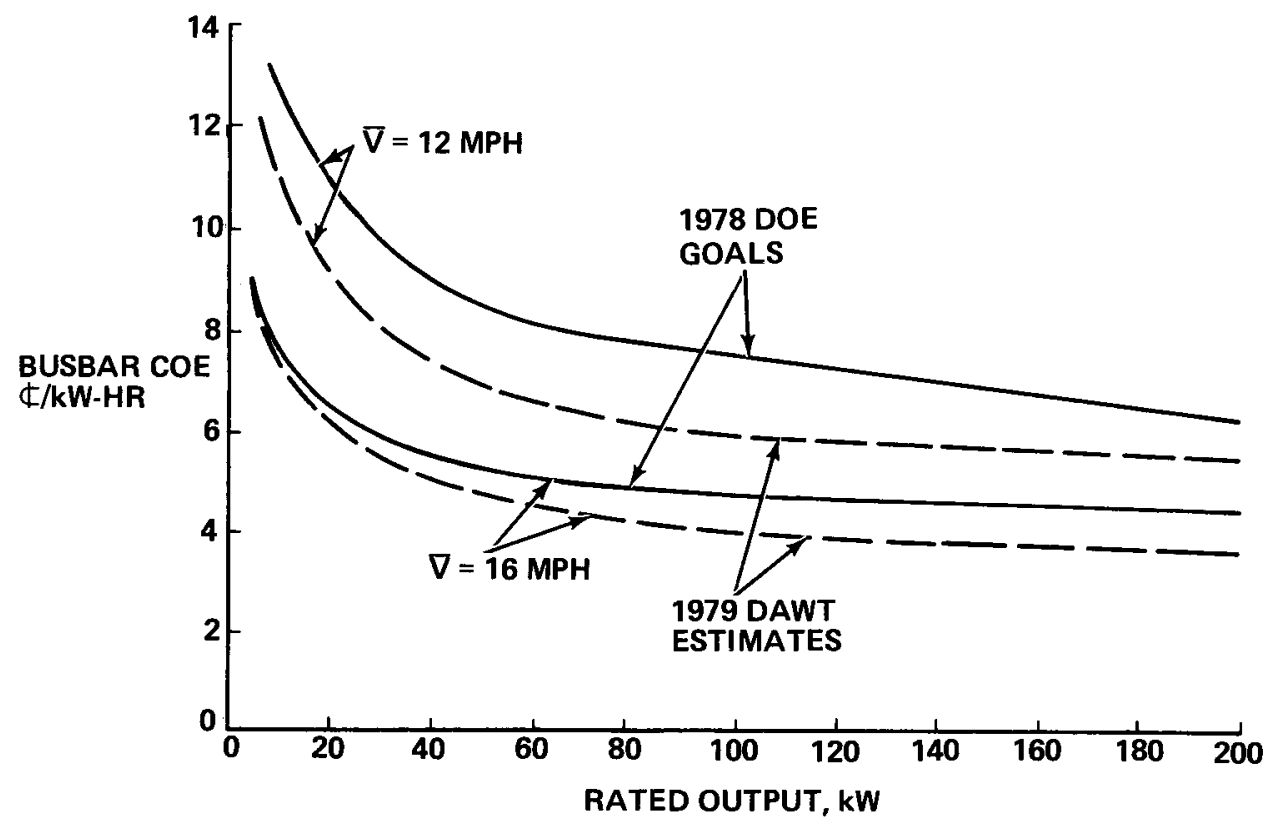

Figure 4-1. 1979 DAWT PROJECTED COE ESTIMATES VS 1978 DoE GOALS (Limited Production, Commercial User)

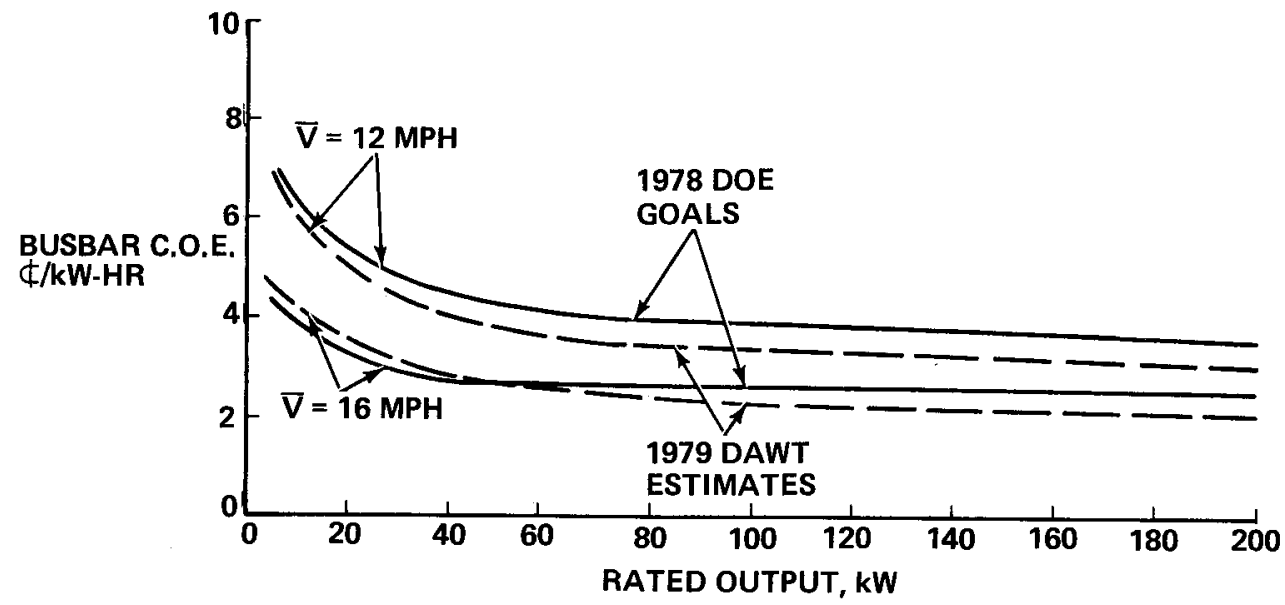

Figure 4-2. 1979 DAWT PROJECTED COE ESTIMATES VS 1978 DoE GOALS (Limited Production, Farmer User) 
SECTION 5.0

SUMMARY AND RECOMMENDATIONS

\subsection{SUMMARY}

In this report we have provided technical direction and a preliminary assessment for the DAWT approach to wind energy conversion in unit outputs up to $150 \mathrm{~kW}$. The results rather convincingly demonstrate the economic viability of the DAWT measured, for example, against the COE goals established by the Department of Energy in 1978. These conclusions require no more than existing design and manufacturing technology. Further economic benefits, leading to even better prospects, are likely with:

- Future refinements in product design and production approaches

- Economies of larger quantity production

- Speciar tax incentive situations, and

- Continuing cost escalation of non-renewable energy sources.

Some of these factors require detailed and individualized financial analyses beyond the current scope of investigation. 0ther factors can follow from actions taken by Government policy makers and planners as well as industrialists with their appreciation that the DAWT innovative concept is ready to emerge from the research phase to become a practical and commercial product.

The reason for these unabashed conclusions stems from the investigations of DAWT point designs with rotor diameters between 2.7 and $11 \mathrm{~m}$ (9 and $36 \mathrm{ft}$ ) and in three engineering materials. From design, manufacturing, and cost considerations, the preferred diffuser configuration is of hybrid construction with FRP panels supported by an aluminum frame. The most desirable diffuser shape is the three element, tangential wall slots design originated by Grumman Research.

The diffuser half-angle is $45^{\circ}$ and features an exit "dump" flange which creates an inlet to exit plane area ratio of 2.75 in an overall axial length of about $25 \%$ of the inlet radius dimension. All factory-made diffuser components have been sized to conform to standard shipping dimensions and weights. The turbine employs Grumman Windstream 33 rotor technology, which is an extruded aluminum, constant chord, untwisted blade approach; active blade pitch control; and an AC induction generator.

We have generated realistic preliminary estimates of production costs (within about $10 \%$ accuracy) because experienced cost estimators analyzed the engineering drawings of the point designs, and current (1979) published regional standard labor rate indices of the construction industry were used.

Limited production runs (i.e., 100 to 500 units per year) of factory built subassemblies, and subsequent, on-site, final assembly and erection within 300 - $400 \mathrm{~km}$ (185 - 250 miles) of regional production centers is the assumed manufacturing scenario. For commercial end users of 60 to $150 \mathrm{~kW}$ rated 
DAWTs, we estimate busbar COE between approximately $\$ 0.065$ - $\$ 0.035 / \mathrm{kw} \mathrm{h}$, respectively, dependent on production lot size and local annual average wind speed. These costs in 1979 dollars include provisions for operations and maintenance on an annualized basis over a 30-year lifetime. Because of different financial treatment and objectives of investment, the COE for farmers, homeowners, and REA Cooperatives is estimated at between $\$ 0.035$ $\$ 0.020 / \mathrm{kW} \mathrm{h}$ for the same rated units and site conditions.

At the $5-15 \mathrm{~kW}$ unit rating size end of DAWT systems the COE for farmers is estimated at $\$ 0.045-\$ 0.065 / \mathrm{kW} \mathrm{h}$, and for commercial end users at $\$ 0.070$ $\$ 0.115 / \mathrm{kW} \mathrm{h}$. No tax credit incentives have been considered in this COE determination; the salvage value of the aluminum components of the DAWT has been estimated and included in a manner to approximate conventional cost accounting practices affecting depreciation of capital investment.

Without considering special pricing strategies, we project possible selling prices (1979 dollars) for fully installed DAWTs as ranging from $\$ 141,000$ for very limited production of $150 \mathrm{~kW}$ units to $\$ 18,000$ for $11 \mathrm{~kW}$ rated DAWTs. Assuming the high side of an estimated $10 \%$ accuracy, the capital cost will vary from about $\$ 1.00 / \mathrm{W}$ for the $150 \mathrm{~kW}$ rated unit to $\$ 1.80 / \mathrm{W}$ for the $11 \mathrm{~kW}$ system. On an above-ground weight basis, the $60-150 \mathrm{~kW}$ DAWTs average about $\$ 2.50 / 1 b$ for 1 imited production which is comparable to mature production standard automobiles. The smallest sized, $11 \mathrm{~kW}$, DAWT unit analyzed costs about $\$ 7.00 / 1 \mathrm{~b}$ which is comparable to that of luxury/sports automobiles.

The trend of installed selling price of the DAWT per rated power varies approximately inversely as the square root of rotor diameter for the 2.7 to 11 $\mathrm{m}$ ( 9 to $36 \mathrm{ft}$ ) rotor diameter range. The two major DAWT components, the rotor-generator subassembly and the diffuser structure, comprise approximately 34 and $48 \%$, respectively, of the entire installed system cost for the $2.7 \mathrm{~m}$ ( 9 $\mathrm{ft})$ diameter rotor, $11 \mathrm{~kW}$ rated DAWT system. These relative amounts change to about $13 \%$ and $64 \%$, respectively, for the 1 argest, $11 \mathrm{~m}(36 \mathrm{ft}$ ) diameter rotor, $150 \mathrm{~kW}$ rated, DAWT system considered.

\subsection{ATMOSPHERIC TESTING MODEL}

Wind tunnel research (Ref. 6, 7) has been an essential first step to demonstrate feasibility and quantify the fluid dynamics effect of the DAWT concept. However, this controlled flow laboratory environment is not intended to duplicate the environmental rigors and random variations of the natural wind. Because the end goal of the DAWT project ultimately is to introduce widespread DAWT utilization, it seems prudent to conduct atmospheric testing to verify the total system integrity and, thus, assure product acceptance in the market place.

Atmospheric testing involves the structural as well as fluid-mechanical elements of the DAWT. Therefore, this final proof-of-concept model should be essentially a physical duplicate of the end item (i.e., a prototype).

We recognize the many DAWT size variations possible and justifiable on different grounds. On the basis of minimum cost to accomplish proof-ofconcept testing we propose a DAWT with the minimum practical rotor diameter of $2.7 \mathrm{~m}(9 \mathrm{ft})$ (i.e., DAWT 9 ) in accordance with design features shown by Fig. 3-8 and 3-10. 
This one-off production prototype is anticipated to be more costly to fabricate than the first of a regular production lot because the tooling will be more improvised to save production engineering costs but the full costs of jigs and fixtures will have to be absorbed by a single unit. In addition, there will be the usual high relative cost of a one-of-a kind item because of lack of prior experience.

The estimate for the DAWT 9 is presented in Table 5-1 in terms of labor hours and purchased parts or materials in the absence of an existing regional production center and uncertainty about the installation site location. This estimate assumes that all required engineering and drawings have been completed in a prior phase, and that the engineering liaison is sufficient in the ratio of $1: 25$ to production hours.

Assuming fabrication in three metropolitan areas, Denver, Houston, and New York, with standard metal trades costs of labor in 1979 (Ref. 11), the possible billing cost for making a proof-of-concept DAWT 9 can range between $\$ 335,500$ (Houston) and $\$ 415,000$ (New York), excluding engineering liaison and shipping as shown by Table 5-2 for the baseline, $30^{\circ}$ half-angle diffuser configuration. Over $70 \%$ of this cost (or between $\$ 250,000$ and $\$ 300,000$ ) is estimated to be associated with the tooling, $j$ igs and fixtures for this proof-of-concept model. A substantial savings of about $\$ 100,000$ is anticipated by planning to use a dump diffuser design with $45^{\circ}$ half-angle instead of the $30^{\circ}$ baseline configuration.

It is expected that the DAWT 9 would be subjected to atmospheric testing for at least two years during which time essentially all aspects of DAWT operation and performance could be characterized. No cost estimate is presented for this testing phase because of the different possibilities of its sponsorship and administration.

\subsection{RECOMMENDATIONS}

From the conclusions of this investigation we believe there is strong justification to proceed to:

1. Detail design of a hybrid (FRP panel-aluminum frame) version of the DAWT $9^{*}$ with dump flange, $45^{\circ}$ half-angle, 2.75 area ratio diffuser features.

2. Obtain multiple bids for the cost of manufacturing this hybrid version of a DAWT 9 model.

Upon completion of a wind tunnel investigation verifying the Performance expectations of a dump diffuser $45^{\circ}$ half-angle version of the currently available DAWT model with 18 in. turbine diameter (DAWT 1.5):

3. Proceed to construction of a proof-of-concept DAWT 9 for atmospheric testing at Rocky Flats or equivalent facilities.

\footnotetext{
*That is, a DAWT with a $2.7 \mathrm{~m}(9 \mathrm{ft})$ diameter turbine.
} 
4. Plan for two or more years of atmospheric testing of the DAWT 9. Prepare the test site foundation and support facilities including instrumentation for this protracted investigation.

In anticipation of further economic investigations of the DAWT concept directed toward large power rating systems:

5. Investigate the design problems and prospects for economical fabrication of DAWT diffusers constructed of architectural fabrics.

6. Investigate the material strength properties and design problems of a prestressed concrete/ferrocement version of a large size DAWT diffuser for use with a rotor of $50 \mathrm{ft}$, or greater, diameter. Conduct material testing in research laboratories to supply needed data. 
Table 5-1. ESTIMATE* OF PRODUCTION LABOR AND PURCHASED PARTS FOR ONE

DAWT 9 PROOF-OF-CONCEPT SYSTEM FOR ATMOSPHERIC TESTING

(Baseline, $30^{\circ}$ half-angle, 2.75 Area Ratio Diffuser Configuration)

Component

1. Aluminum Frame

Tooling

Direct Fabrication

2. Aluminum Pedestal

(including yaw bearing)

Tooling

Direct Fabrication
Labor Hours

9700

1200

1720

220
Purchased Parts or Mt ]s. (1979 \$)

3. FRP Diffuser Panels (Purchased parts)

Tooling (mold)

Panels (1/8 in. thick)

$$
\begin{array}{r}
\$ 5,000 \\
9,000
\end{array}
$$

Included in item 1

$$
\text { Panels (1/8 in. thick) }
$$

4. Rotor Assembly

Direct Fabrication $\quad 1700$

$$
\begin{array}{r}
\$ 14,000 \\
4,500
\end{array}
$$

5. Foundation (subcontracted)

$$
\begin{aligned}
& \text { Direct Fabrication } \\
& \text { (Includes site preparation) }
\end{aligned}
$$

$\$ 18,000$

6. Liaison Engineering

580

\begin{tabular}{|c|c|c|c|}
\hline & \multicolumn{3}{|c|}{ Metropolitan Area } \\
\hline & Denver & Houston & New York \\
\hline $\begin{array}{l}\text { Avg. Hourly Billing Rate } \\
\text { for Metal Workers } \\
\text { Total hours (from Table 19) } \\
\text { Total Labor Cost }\end{array}$ & $\begin{array}{r}\$ 19.60 \\
14,540 \\
\$ 285,000 \\
\end{array}$ & $\begin{array}{r}\$ 19.30 \\
14,540 \\
\$ 280,600 \\
\end{array}$ & $\begin{array}{r}\$ 24.40 \\
14,540 \\
\$ 355,000 \\
\end{array}$ \\
\hline $\begin{array}{l}\text { Materials \& Purchased Parts } \\
\text { (from Table 19) }\end{array}$ & $\$ 54,500$ & 54,500 & 54,500 \\
\hline Total Billing Cost & $\$ 339,500$ & 335,100 & 414,500 \\
\hline
\end{tabular}

$$
\begin{array}{lr}
\text { Totals: } \quad \begin{array}{r}
14540 \mathrm{~m}-\mathrm{hrs}, \text { shop } \\
580 \mathrm{~m}-\mathrm{hrs}, \text { eng'g }
\end{array}
\end{array}
$$

$\$ 54,500$

*Excludes instrumentation, electrical hook-up, travel and shipping costs to field site, special equipment rental, and spare parts.

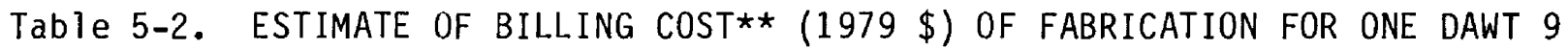
(Baseline, $30^{\circ}$ half-angle, 2.75 Area Ratio Diffuser Configuration)

**Excludes shipping, engineering liaison, productivity variations, etc. 
SECTION 6.0

REFERENCES

1. Betz, A., "Energieumsetzungen in Venturidusen," Naturwissenshaften, Vol 10, No. 3, 1929, pp 160-164.

2. Lilley, G. M. and Rainbird, W. J., "A Preliminary Report on the Design and Performance of Ducted Windmills," Rep. 102, April 1956, College of Aeronautics, Cranfield, England. Also available as Tech. Rep. C/T 119, 1957, the Electrical Research Assoc., Leatherhead, England.

3. Kogan, A. and Seginer, A., "Shrouded Aerogenerator Design Study. II. Axisymmetrical Shroud Performance," Israel Journal of Technology. Feb 1963, pp 49-56.

4. Oman, R. A. and Foreman, K.M., "Advantages of the Diffuser Augmented Wind Turbine," NSF/NASA Wind Energy Conversion Systems Workshop Proceedings. NSF/RA/W-73-006, Dec 1973, pp 103-106.

5. Oman, R.A., Foreman, K.M. and Gilbert, B.L., "Investigation of Diffuser-Aumented Wind Turbines, Part I and II, "ERDA Report C00-2616-2, Jan 1977, Grumman Aerospace Corp, Bethpage, NY

6. Igra, 0., "Shrouds for Aerogenerators," Rep. No. 2, March 1975 Dept of Mechanical Engineering, Ben Gurion University of Negev, Beersheba, Israel.

6a. Igra, 0., "The Shrouded Aerogenerator," Energy, Vol 2, 1977, pp 429-439.

7. Foreman, K.M. and Gilbert, B.L. "Further Investigations of Diffuser-Augmented Wind Turbines, Part II - Technical Report," U.S. Dept of Energy Report C00-2616 -2 (Part 2) (Rev 2) July 1979, Grumman Aerospace Corp., Bethpage, NY.

8. L. V. Divone (U.S. Dept. of Energy) private communication to K. M. Foreman (Grumman Aerospace Corp), Nov 1979.

9. Koppes, W., "Design Wind Loads for Building Wall Elements," in Proc NBS Building Science Series 30, Nov 1970, pp 9-18.

10. Zils, J.J., "Designing the Sears Tower for Wind," unpublished paper, Skidmore, Owings and Morrill, Chicago, I11.

10a. Betz, A., "The Theory of Flow Machines," Pergamon Press, Oxford, 1966, pp 239-240.

10b. Abbott, I.H., von Doenhoff, A.E., and Stivers, Jr., L. S., "Summary of Airfoil Data," Report No. 824, 1945, NACA, Washington D.C.

11. Godfrey, R.S. (Editor in chief), "Building Construction Cost Data, 1979, 37th Annual Edition," R. S. Means Co., Inc, Duxbury, Mass. 
12. "Statistics of Privately Owned Electric Utilitites in the U.S., 1973," Publication FPC S-247, Federal Power Commission, Washington, D.C., DeC 1974.

13. "Comprehensive Development Plan, Harper County, Kansas, 1975-1998," Foster and Assoc, Wichita, KA, May 1975.

14. "Principal Electric Facilities, Iowa, Kansas, Missouri, Nebraska, 1979," Map DoE/EIA-0057/7 (79), Energy Information Administration, Dept. of Energy, Washington, DC.

14a. Gates, M. and Scarpa, A., "Learning and Experience Curves," J. Const. Div., Proc ASCE, Vol 98, No. CO-1, March 1972, pp 79-101.

15. Greer, H.C., "Cost Factors in Price Making," Harvard Business Rev., Vol 30, No. 4, (July - Aug 1952) pp 33-45 and BaiTey, E.L. (ed.), "Pricing Practices and Strategies," Report 751, The Conference Board, New York, 1978.

16. "Architectural Fabric Structures," Booklet E-12958, DuPont Company, Wilmington, DE, and Rush, R., "The Era of Swoops and Billows," Progressive Architecture, Vol 61, No. 6 (June 1980) pp 110-123.

17. Loeffler, A.L., "Flow Field Analysis and Performance of Wind Turbines Employing Slotted Diffusers," Research Department Report RE-595, March 1980, Grumman Aerospace Corp, Bethpage, NY.

18. Eldridge, F.R., "Wind Machines," MTR - 6971, NSF-RA-N-75-051, Oct 1975, The Mitre Corporation, McLean, VA.

19. Cliff, W.C., "The Effect of Generalized Wind Characteristics on Annual Power Estimates from Wind Turbine Generators," PNL-2436, 0ct 1977, Battelle Pacific Northwest Labs, Richland, WA.

20. "Wind Energy Mission Analysis," Final Report, Appendix I, ERDA Report C00/2578-1/3, 18 Feb 1977, General Electric Co., Philadelphia, PA.

21. "The 1970 National Power Survey, Part I," Dec 1971, Chapter 19, Federal Power Commission, Washington, DC.

22. Koch, R.N. (Reynolds Metals Co.), private communication to K. M. Foreman, (Grumman Aerospace Corp,), 16 oct 1979. 
APPENDIX A

FERRO-CEMENT DIFFUSER STUDY

for

GRUMMAN AEROSPACE CORPORATION

Bethpage, New York

August 1979

David J. Seymour, Ltd.

Naval Architects \& Marine Consultants

San Francisco, CA

\section{A-1}


$A-2$ 
1. SUMMARY AND CONCLUSIONS

2. INTRODUCTION

3. FERRO-CEMENT - CHARACTERISTICS \& STATE OF THE ART

4. FERRO-CEMENT APPLICATION TO DIFFUSER DESIGN

5. DIFFUSER PRELIMINARY DESIGNS

$9.0 \mathrm{Ft} ., 22.5 \mathrm{Ft}$. , and $36.0 \mathrm{Ft}$. Rotor Dia. Models

6. PRODUCTION TECHNIQUES

7. COST ESTIMATES

Mode1 Costs, Cost Curve, Cost Sensitivity, Cost Effect for Volume Production

8. RECOMMENDATION FOR $R \& D$

a) Establish Maximum Diameter Ferro-Cement Diffuser

b) Prestress - Ferro-Cement System for Large Dia. Diffuser

c) Prototype Ferro-Cement Mode1

APPENDICES

A-I Supporting Calculations

A-II References 


\subsection{SUMMARY \& CONCLUSIONS}

A study has been completed into the feasibility of employing ferro-cement as a material for constructing diffuser shells of proposed wind turbines.

The study was conducted by David J. Seymour, Ltd., Naval Architects \& Marine Consultants of San Francisco, CA., for Grumman Aerospace Corp. of Bethpage, N.Y., developer of the diffuser system.

A diffuser is an augmentation device which increases the efficiency of a wind turbine, and consists of thin shell shrouds down wind from the rotor. The exit diameters of these shrouds may vary from 15 (for $9 \mathrm{ft}$. rotor dia.) to 60 feet (for $36 \mathrm{ft}$. rotor dia.) with lengths of 5 to 20 feet. A key to the overall effectiveness of the diffuser concept is to select a material that not only meets the structural requirement of the system but lends itself to minimum costs through volume production. Results of the study indicate that ferro-cement is a suitable material for wind turbine diffusers. Utilizing current "state of the art" for ferro-cement design and construction this material meets diffuser requirements for structural design, thin shel1 configuration, surface smoothness, resistance to corrosion and adaptability to volume production through re-usable molds. In addition cost estimates made for the study clearly indicate an appreciable economical advantage relative to steel and other materials.

Based on experience with ferro-cement boats the cost for diffuser construction in ferro-cement should be approximately $25 \%$ that of steel. Preliminary structural analysis in the study established a maximum diffuser exit dia. of about 40 feet as the limit for employing ferro-cement design 
and construction techniques. For diameters above 40 feet the need for incorporating a prestress system in combination with ferrocement is suggested.

The following recommendations for further study and analysis beyond the scope of this effort are considered necessary to validate the findings of this study including the concept of combined prestress and ferro-cement.

i) Establish Maximum Diameter for Ferro-cement Diffuser.

ii) Investigate combination prestress/ferro-cement system for large diameter diffusers.

iii) Construct Prototype ferro-cement model for test and evaluation. 


\subsection{INTRODUCTION}

This study presents the results of an investigation into the feasibility of utilizing ferro-cement material and construction methods for the diffuser shells of proposed wind turbines.

The study was conducted under contract with Grumman Aerospace Corporation, P.0. No. 14-74176, dated June 14, 1979, by David J. Seymour, Ltd., Naval Architects and Marine Consultants. The study team was led by Mr. Seymour, Chairman of the Society of Naval Architects and Marine Engineers' Hull Structure Committee PaneT HS-11 on "Ferro-cement and Marine Concrete Structures". Also on the team was Mr. Conroy Betts, an experienced professional builder of ferro-cement marine craft.

The investigation included five main categories:

i) Review of the "state of the art" of Ferro-cement.

ii) Evaluation of Application of Ferro-cement for Wind Turbine Diffusers.

iii) Preliminary Designs in Ferro-cement for Two Typcial Baseline Diffusers.

iv) Production Technique Considerations.

v) Cost Analysis. 


\subsection{FERRO-CEMENT - CHARACTERISTICS \& STATE OF THE ART}

Although ferro-cement is as old as reinforced concrete its employment as a construction material has been somewhat limited. It has received some attention in the last few decades particularly for the building of small boats. The following text summarizes ferro-cement's history, description and current applications.

\subsection{HISTORY}

The first known application of ferro-cement was for small marine craft and was developed by Lambot of France in 1855. Little advance in the art was made until the early 1940's, when the Italian engineer Pier Luigi Nervi concentrated his efforts on relatively large sail and power vessels, as well as some architectural structures employing the principle of thin shell ferro-cement construction.

From 1940 to 1960 most ferro-cement construction development has been on a scale of either small commercial or "amateur" (backyard) efforts concentrated in Canada, New Zealand and the United States. Within the last decade considerable basic research on the engineering properties and application of the use of ferro-cement has been undertaken in Canada, the United States, United Kingdom, Australia and New Zealand. The U.S. Navy and Canadian government have sponsored several research efforts. Also, limited commercial work in the United Kingdom and New Zealand has contributed towards determining the engineering properties of this materiat and $i$ ts practical use as the structural engineering material. See Ref. $1 \& 2$. 


\subsection{USES OF FERRO-CEMENT}

The majority of ferro-cement development and construction has been directed toward marine craft hulls because the naterial is well adaptable for molding into any shape in a monolithic unit.

Its relative high rigidity, compressive and flexural strength, resistance to cracking, non-corrosiveness and resistance to fire contribute to a desirable boat-building material. Not least in this regard are $i$ ts low relative costs to other materials employed in small craft.

Ferro-cement marine craft built have included sail and power vessels for pleasure, commercial fishing or cargo transport mostly ranging in size from 30 to 60 feet in length. Some barges were constructed in Canada having a length of 180 feet although these employed some pre-stressed concrete features in combination with ferro-cement. The Peoples Republic of China is building sampan type barges of ferro-cement.

Pier Nervi has pioneered the use of ferro-cement for building and civil engineering structures such as walls for small buildings and precast units for wide span roofs.

The Indian government has developed low cost ferro-cement silos for storage of grain.

There are definite advantages to ferro-cement in certain types of uses. It is a material that can be engineered to a high degree of precision, however it requires labor ranging from unskilled to semi-skilled utilizing relatively inexpensive materials.

Continuing research should expose a wider range of applications for ferro-cement in many types of 7 and and marine structures. 


\subsection{GENERAL PROPERTIES}

Ferro-cement consists of a thin shell of Portland cement mortar which is heavily reinforced with steel in the form of rods and wire mesh. Typical shell thicknesses are from $3 / 8$ inch to $1 \frac{1}{2}$ inches with steel rods varying from $1 / 8$ inch dia. to $5 / 16$ inch dia. and the steel wire mesh averaging about 19 guage welded $\left(.042^{\prime \prime}\right)$ on about $\frac{1}{2}$ inch centers longitudinally and transversely. For very thin shell construction rods are ommitted and hexagonal (chicken wire) is used.

Figure 1 shows the common types of ferro-cement "lay up" or steel reinforcing. The rods provide the structural shape while the combination of mesh and rods add to the strength of the material. Mortar, usually consisting of Portland cement, sand, pozzalin and additives impregnates the mesh and rod volume with about $1 / 8$ inch cover layer. Ferro-cement demonstrates a synergistic effect during strain and cracking. This is because of the even distribution of steel reinforcing which tends to inhibit cracks from forming in the mortar to a greater extent than in plain mortar or regular reinforced concrete.

The major parameter in analyzing ferro-cement strength (strains and cracking) is the surface area of the steel reinforcement which is rather high relative to its total volume. This is the principal characteristic that differentiates ferro-cement from reinforced concrete. 


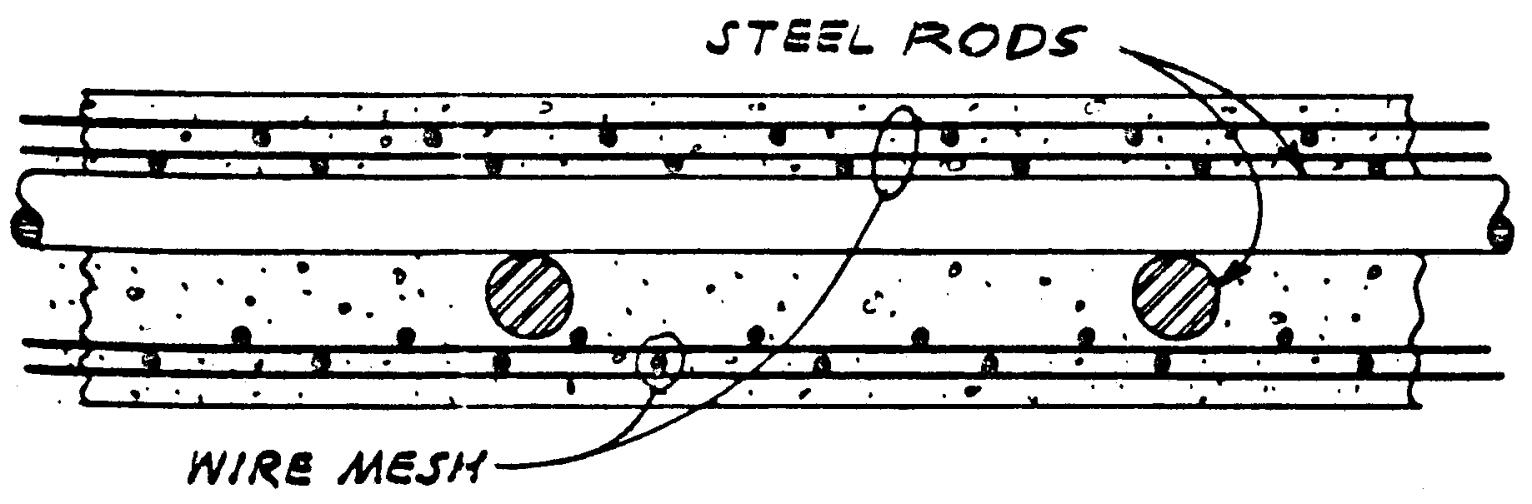

$\frac{\text { SECTION }}{\text { RODS \& WIRE MESH }}$

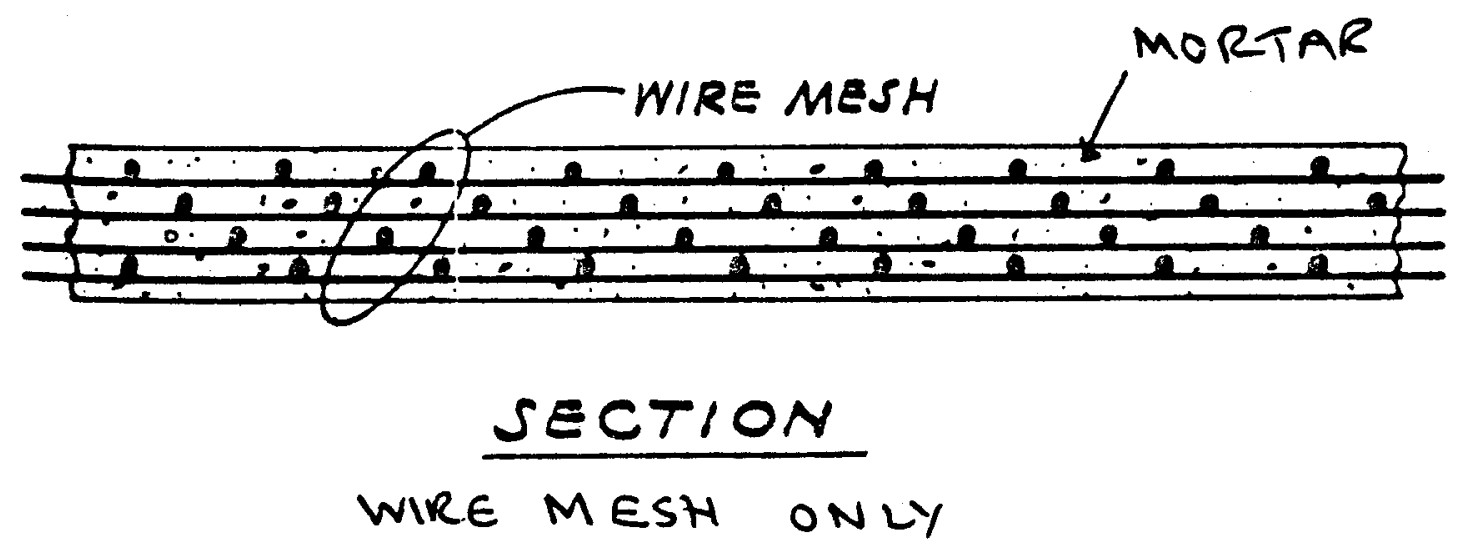

FIGURE 1 - TYPICAL FERRO-CEMENT LAY UP 
Recent research has been done in steel fiber reinforced concrete which is closely related to ferro-cement. It consists of Portland cement mortar reinforced with short (one inch), small diameter wires (.02 inches) evenly mixed and dispersed throughout the concrete. Low cost and adaptability for use with existing reinforced concrete equipment has been its main advantages. However, bond failure and wire pull out have limited its use to concrete highways and airport runway slabs ranging from 4 to 6 inches. It is not recommended for diffuser shells.

The only building codes or standardized design and construction procedures have been those in the marine classifications societies, such as Lloyd's Register of Shipping, the American Bureau of Shipping and Norseke Veritas, the latter being the most complete.

\subsection{STRENGTH PROPERTIES}

a. Compressive Strength of ferro-cement is related directly to the compressive strength of the mortar which for 28 day cure averages 6000 to 10,000 psi. Per Ref. 4 inclusion of steel reinforcement has minimal effect on ultimate mortar compressive strength.

b. Tensile Strength differs from ordinary reinforced concrete in that there are two significant points in its tensile behavior on the stress vs. strain curve. Ferro-cement undergoes elastic elongation prior to first point of cracking, after which the behavior is quasi-elastic with a reduced modulus. See Fig. 2, taken from Ref. 5.

4 The formation of a tensile crack (visible) is the accumulation of micro-cracks which are typical in cementatious materials. In ferro-cement 


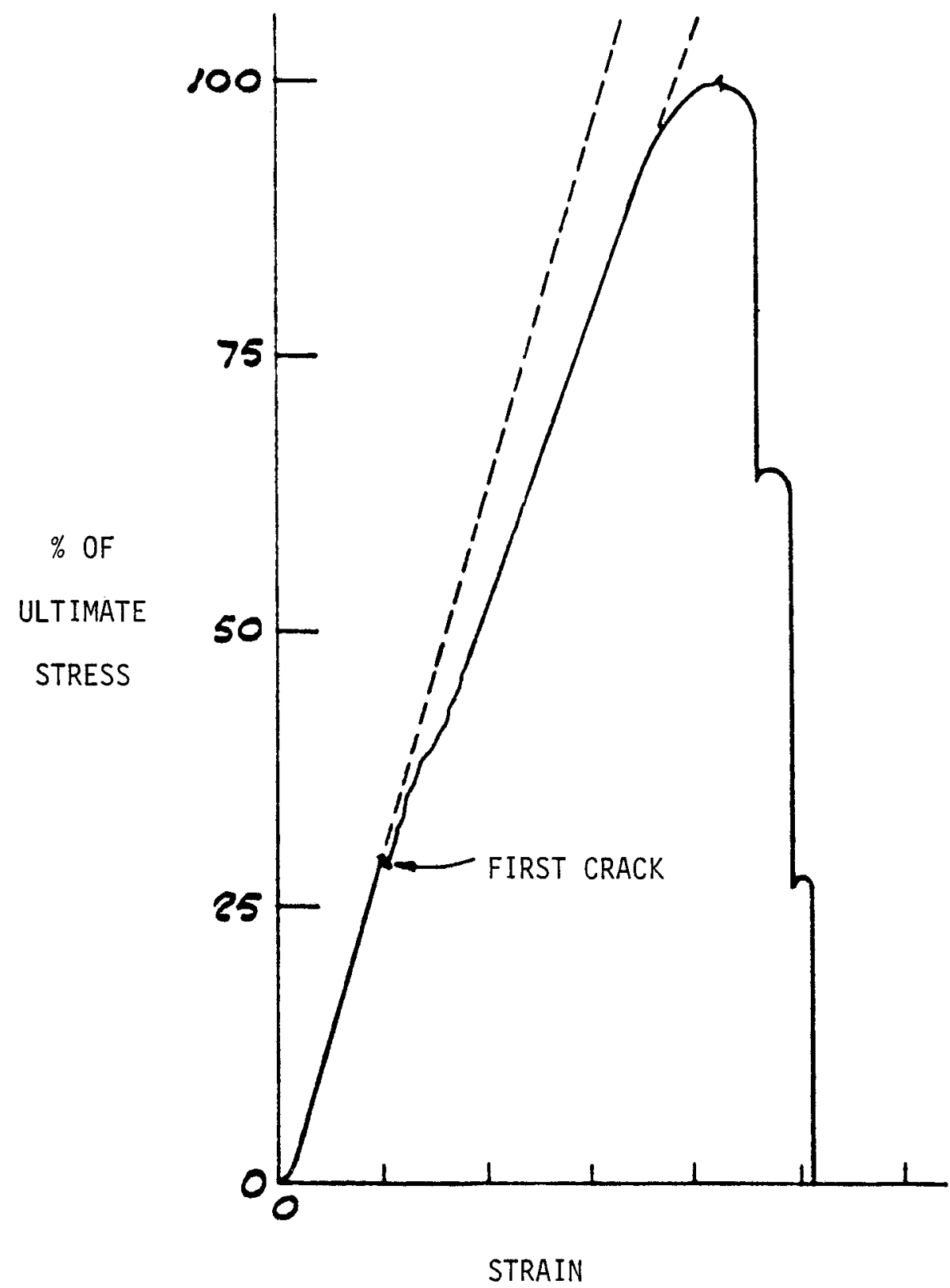

FIGURE 2 - FERRO-CEMENT STRESS VS. STRAIN

A-12 
however, the reinforcement tends to restrict propagation of microcracks in the vicinity of steel reinforcement. The behavior of ferro-cement in tension is shown in Fig. 3 which is the result of work by walkus and Kowalski of Ref. 6.

It has been established (Ref. 5 and 6) that the first crack strength in tension is related to volume percentage of reinforcement and surface area of reinforcement, referred to as "specific surface of reinforcement" which is defined as the surface area of the reinforcement (in direction of load) divided by the total volume of ferro-cement. Fig. 4 shows the relationship of specific surface to tensile stress at first crack.

c. Flexural Strength of ferro-cement in bending exhibits unique properties similar to those in tension. Within the elastic limit (i.e. up to stress at first crack) the relationship of flexural strength to specific surface of reinforcement is significant while at ultimate flexural strength $i$ ts capacity is related to that of the reinforcement. Typical load-deflection curves are shown in Fig. 5, taken from Ref. 7. The normal, form of expressing flexural strength is "Modulus of Rupture", which is defined as load at bending of standard specimen ( $1 \mathrm{~m} \times 0.25 \mathrm{~m})$ divided by section modulus (of total cross section). Stresses of 6000 to 9000 psi for modulus of rupture are normal.

\section{d. Shear Strength}

Available data indicates that shear strength is dependent on volume of reinforcement for shear loading normal to plane of material. See Fig 6. Ref. 8. 


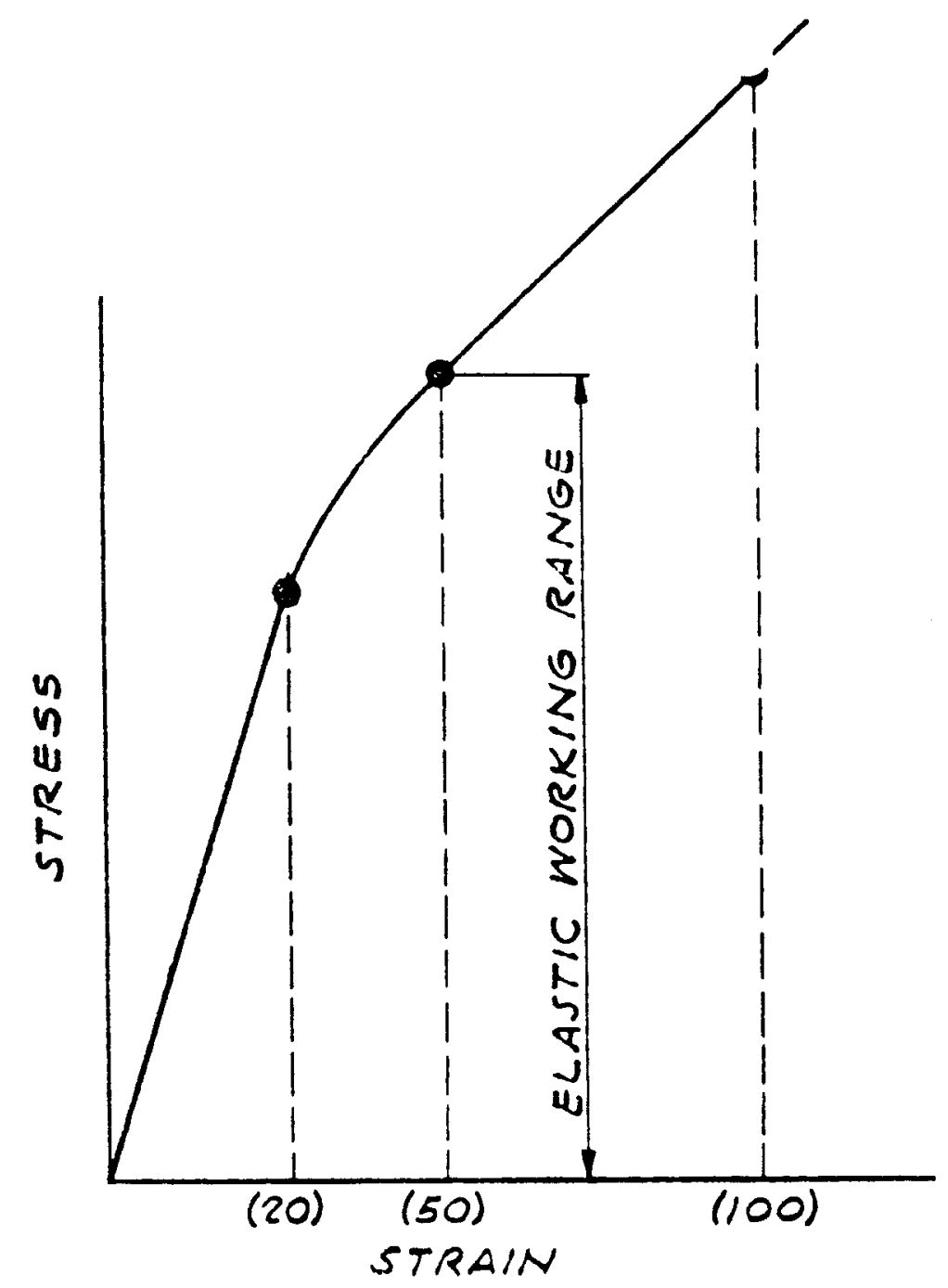

(CRACK WIDTHS IN BRACKETS, MICRONS)

\begin{tabular}{|c|l|c|l|}
\hline STAGE & MATERIAL STATE & $\begin{array}{l}\text { CRACK } \\
\text { WIDTH, } \\
\text { MICRONS }\end{array}$ & TECHNOLOGICAL STATE \\
\hline I & LINEARLY-ELASTIC & 20 & $\begin{array}{l}\text { COMPLETE } \\
\text { WATERTIGHTNESS }\end{array}$ \\
\hline \multirow{2}{*}{$I$} & QUASI-ELASTIC & 50 & NONCORROUIVEI \\
\cline { 2 - 4 } & ELASTO-PLASTIC & 100 & NONCORROSIVEI \\
\hline \multirow{2}{*}{ III } & PLASTIC & $>100$ & CORROSIVE \\
\hline
\end{tabular}

FIGURE 3 WORKING STAGES OF FERRO-CEMENT 


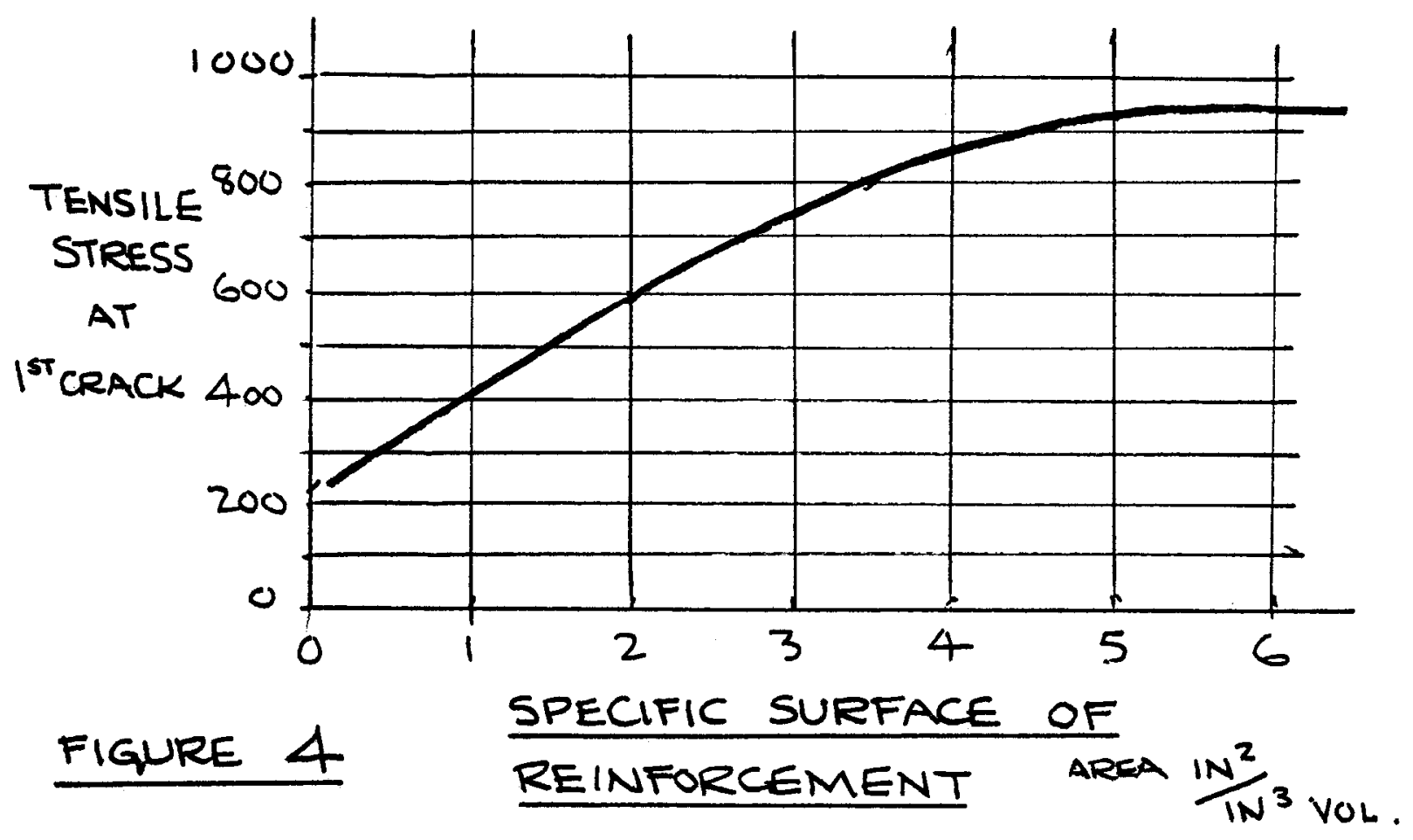






FIGURE 5 TYPICAL LOAD - DEFLECTION CURVE 


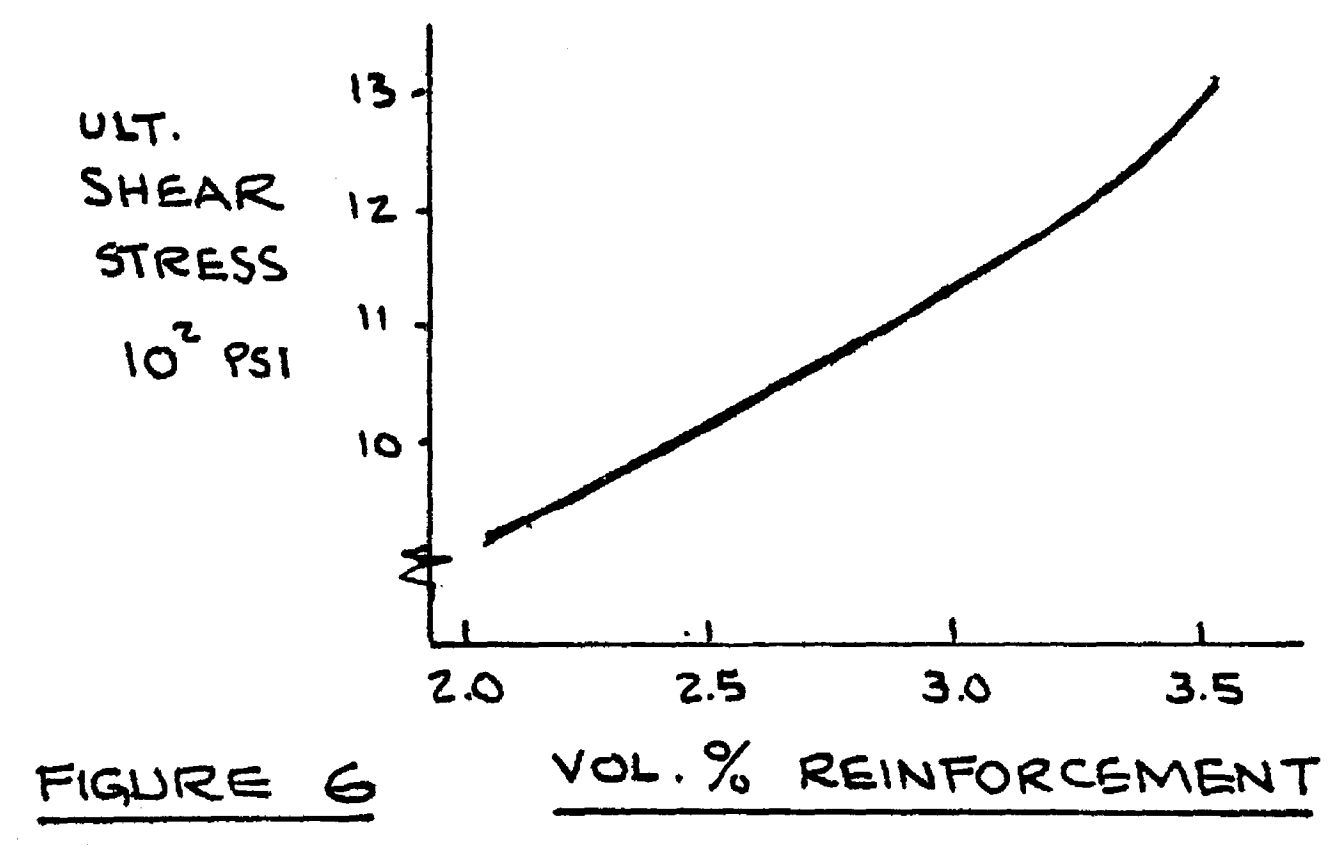

Although design shear stress will be relatively low, flexural or tensile stresses are generally more critical for thin-shell structures.

e. Modulus of Elasticity

Research in modulus of elasticity of ferro-cement shows a relationship between increased volume of percentage of reinforcement in the direction of loading and increased modulus. A definite decrease in modulus after formation of first crack has been noted in all tests. Results of tests in Ref. 7 indicate values of $1 \times 10^{6}$ psi to $4 \times 10^{6}$ psi for ferro-cement.

f. Fatigue Resistance

Limited research shows that fatigue cracks occurred on loaded specimens after 2,000,000 cycles. For highly loaded ferro-cement structures with various loading ranges additional research in fatigue behavior is recommended.

g. Impact Resistance

The behavior of ferro-cement under impact loading is typified by high ductility and energy absorption in the plastic range, excellent localization of damage and easy repair of damaged sections. 
Experiments in Ref. 3 indicate that, by the application of a fiberglass layer with epoxy to the outer sides of a ferro-cement shell in lieu of

a cover layer of morar, the impact strength is inceased by as much as $100 \%$. (Cost data on small boats indicate a cost of about $\$ 4.00$ per square foot for application of fibreglass layer.)

\subsection{PERFORMANCE CHARACTERISTICS}

a. Surface Characteristics of ferro-cement construction are similar to those of reinforced concrete or precast concrete construction. Surface control can be achieved to the desirable level or degree of accuracy such as with precision molds, finishing techniques, mortar additives and surface coating for smoothness and durability. Surface durability depends on the quality of the mortar, finishing and curing all of which are within the scope of normal concrete technology. Epoxy coatings and marine paints have been used on ferro-cement boat hulls for added corrosion protection and surface durability although such methods add appreciably to costs.

Although no data on high velocity air flow on ferro-cement is available considerable research on hydraulic abrasion and cavitation has been accomplished in Portland Cement Association studies. See Ref. 9. No problems should exist for air flow however studies should be conducted to confirm this.

b. Corrosion Resistance

Deterioration of reinforced concrete and ferro-cement in corrosive environments result from chemical attack on the concrete or mortar and corrosion of steel reinforcement. Chemical attack on concrete such as sulfate reactions permits liquids to enter, as do cracks in mortar, to corrode the steel reinforcement. 
Protection against corrosion can be provided by

i) Increase impermeability of mortar

ii) Application of impermeable coatings

iii) Galvanizing of steel reinforcement

iv) Design stress levels to minimize crack widths.

Increased impermeability of mortar has been developed through experimentation using acrylic latex additives. Impermeable protective coatings used in marine ferro-cement construction are normally resin-based coa tings such as polyester, urethane, and epoxy.

c. Freeze-Thaw Characteristics

Studies of Ref 2 and 10 including tests per ASTM C 291-67 (Method of Test for Resistance of Concrete Specimens to Rapid Freezing in Air and Thawing in Water) indicated ferro-cement to have improved freeze-thaw characteristics by increased amount of steel reinforcement. Additional tests are recommended for resistance to freeze-thaw characteristics for diffuser application.

d. Vibration Characteristics

Although no tests have been conducted specifically for vibration and damping it is well known from experience in small boats with combustion engines that ferro-cement has excellent damping characteristics when compared to steel.

e. Fire Resistance

Ferro-cement has high fire resistance due to the incombustible nature of cement mortar which insulates the steel reinforcement. Fire tests at $1700^{8} \mathrm{~F}$ for $1 \frac{1}{2}$ hours had no effect on the material per Ref. 11. 
f. Weight

Unit weight figures (about $13 \mathrm{lbs} / \mathrm{ft} .^{2}$ for 1 inch lay-up with rods) are roughly 10 to $20 \%$ higher than comparable steel structure (plating and stiffeners).

g. Maintenance and Repairability

The low maintenance cost of ferro-cement structures when compared to most metals is due primarily to the corrosion resistant qualities of cementatious materials. A marine problem (not to be considered for diffusers) has been to protect ferro-cement from chemical (sulfate) attack. Good bonding of coating is mandatory. However, even with coating failure well made, applied and cured mortar will resist this attack.

The low impact resistance of ferro-cement relative to figerglass and most metals is compensated by its ease to repair. Considerable experience has been gained with snall craft suffering severe impact damage which was repaired within a few hours at nominal cost.

Tests of repaired panels were conducted per Ref. 2 and found to be 70 to 80 percent of their original strength. Repair materials consist of Portland cement mortar, epoxy grout and commercial patching mixtures. Repair procedures include removing damaged or spalled mortar, straightening or replacing deformed reinforcement, treating broken surfaces with an etching or bonding agert and application of new mortar.

h. Dimensional Stability

The major factors affecting structural dimensions and tolerances are drying shrinkage and creep. Experience on small boat shells has been of the order of $\frac{1}{4}$ of one percent.

Drying shrinkage during curing can be minimized by proper mortar mix specifications or if cast then compensating by casting segments oversize. No data is available on the extent of dimension change with ambient temperature changes and tests on the ferro-cement diffuser prototype are suggested to determine such. 
Creep characteristic studies of ferro-cement indicate that the creep characteristics are those of the metal reinforcement and not those of the composite.

Although not considered a problem area for diffuser element design some research is suggested on creep characteristics of the specific configuration of structures proposed.

\subsection{CONSTRUCTION METHODS}

The most common methods have been developed primarily for marine construction which should be adaptable to fabrication of other types of structures including diffusers for wind turbines.

Two principal ferro-cement construction techniques are currently in use, namely the "open armature" or "open mesh lay-up" method and the "male mold" method.

In the "open mesh lay-up", the structural shape is defined by a network of steel reinforcing rods which is overlain with wire mesh. Mortar application is from both sides and surface control is by hand troweling. This method is labor intensive and achieving close dimensional tolerances is extremely difficult.

The "male mold" method employs a precisely constructed reusable mold to achieve the desired finished shape and surface and appears to be especially compatible with the structural and economic requirements of diffuser wind turbine construction.

Examples in the use of molds in large ferro-cement structure have been:

i) Large $(180 \mathrm{ft})$ ferro-cement cargo barge by Ferrocon Industries of Vancouver, B.C.

ii) Large $55 \mathrm{ft}$ power sailboats by Fibersteel Corp. of West Sacramento, CA.

iii) Prefabricated Folded Plate Roof Elements built in Eastern Europe as described in Ref. 6. 


\subsection{FERRO-CEMENT APPLICATION TO DIFFUSER DESIGN}

\section{1 EVALUATION OF FERRO-CEMENT CHARACTERISTICS}

A general review of ferro-cement characteristics in the preceeding section indicates that the material is generally suitable to meet the structural requirements for wind turbine diffuser design and should be economically competitive against other candidate materials.

\subsection{DESIGN STRESS CRITERIA}

A sumary of ferro-cement design criteria for stress levels has been established for use in preparing preliminary designs of a $9 \mathrm{ft}$. rotor dia. and a $22.5 \mathrm{ft}$. rotor dia. model of diffusers, each having a 2.78 area ratio

$$
\text { PROPOSED FERRO-CEMENT DESIGN STRESS LEVELS }
$$

(exit-to-inlet).

\section{(Based on 1" Mesh Lay-up 2 Layers $\frac{1}{4} " Q$ Rod}

4 Layers $\frac{1}{2} " \times \frac{1}{2} " \times 19$ gauge WWM)

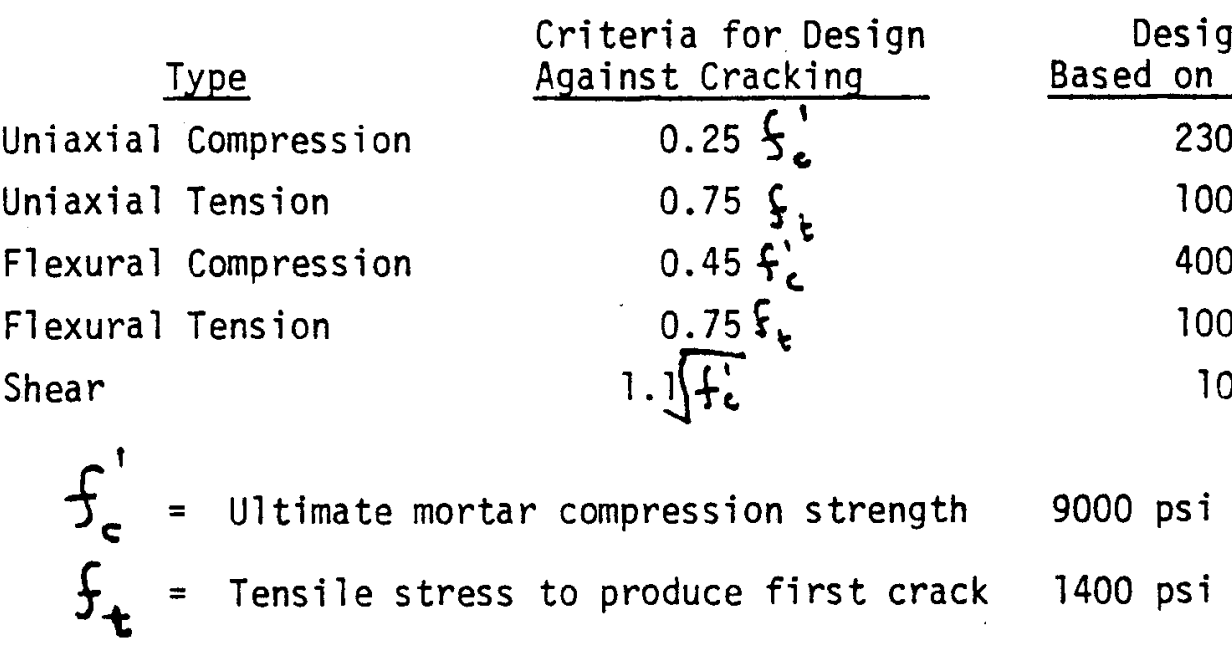

Included in establishing above stress levels the empirical and scientific data of certain regulatory bodies has been incorporated, such as the American Concrete Institute. In addition, due to the similarity of diffuser shells with those of marine craft, the rules for marine ferro-cement construction by American Bureau of Shipping, Lloyds Register of Shipping and Norske Veritas have been used for guidance. 
It is considered that the current "state of the art" in ferro-cement can easily meet above stress levels based on latest mortar mixes and additives together with configuration, distribution and quality of the steel reinforcement.

\subsection{PERFORMANCE CHARACTERISTICS}

The use of ferro-cement for wind turbine diffusers should provide the following advantageous characteristics:
a) Load Capacity - the structural requirements of ferro-cement can easity meet the wind loads as well as the dead load for support of the turbine unit.

b) Dimensional Tolerance - although not critical for wind turbine diffusers, relatively close tolerances in both offset dimensions and deviation from "true curve" can readily be met because of the use of precise molds.

c) Durability of Structure - due to high corrosion resistance qualities of ferrocement it is ideally suited to resist the effects of exposure to a wide range of environmental conditions that a wind turbine diffuser would experience.

d) Diffuser Surface Characteristics - through the use of precise molds and surface preparation with epoxy or similar coatings ferro-cement surfaces should be the equivalent of metals like steel for smoothness of aerodynamic surfaces.

e) Other Characteristics - such as vibration damping, fire resistance, repairability, etc. though not considered as a primary design criteria are nonetheless available as additional advantages.

\subsection{COST EVALUATION}

General cost data available for ferro-cement construction of small boats and marine craft clearly establishes a lower cost level of the magnitude 
of 25 to 50 percent of that for steel construction. Such type construction and costs of course are not directly comparable with subject wind turbine diffusers. However, it appears certain that a definite economic advantage over other materials will be available through the use of ferro-cement.

Cost estimates have been made for ferro-cement type construction, including two diffuser models. See Section 7.0. 


\subsection{DIFFUSER PRELIMINARY DESIGNS}

Preliminary designs were developed for three baseline diffuser configurations name1y:

$$
\begin{aligned}
& \text { Configuration } \#_{1}-9.0 \mathrm{ft} \text { Rotor Diameter } \\
& \text { Configuration } \#_{2}-22.5 \mathrm{ft} \text { Rotor Diameter } \\
& \text { Configuration } \#_{3}-36.0 \mathrm{ft} \text { Rotor Diameter }
\end{aligned}
$$

Basic lines and arrangements for diffuser shrouds, provided by Grumman Aerospace Corp., were based on results of wind tunnel test data.

\subsection{DESIGN CRITERIA}

$\begin{array}{ll}\text { Wind Velocity: } & 120 \mathrm{MPH} \\ \text { Gust Factor: } & 1.21 \text { (U.S. Dept. of Commerce) } \\ \text { Wind Direction: } & \text { Head-On and Lateral } \\ \text { Allowable Design Stress Levels: } & \text { (See Ferro-Cement Stress Levels } \\ & \& \text { Det Norske Veritas Rutles for } \\ & \text { Ferro-Cement Vessels) } \\ \text { Ice/Snow Loads: } & \text { Not Included } \\ \text { Turbine Blade Passage Frequency: } & 12.5 \mathrm{H}_{\mathrm{Z}} \\ \text { Basic Lines: } & \text { By Grumman See Figure } 7 \\ \text { Static Pressure Profiles: } & \text { By Grumman See Figs. } 8 \text { and } 9 \text { in } \\ & \text { main text }\end{array}$

\subsection{FERRO-CEMENT DESIGN CONFIG. \#1 \& \#2 MODELS}

Preliminary designs designated Config. \#1 and 非 2 Models were prepared employing ferro-cement type construction incorporating design criteria furnished by Grumman shown in Fig. 7 and general arrangements as shown in Fig. 8 and 9. Typical details of design are shown by Fig 13 in the main text. 

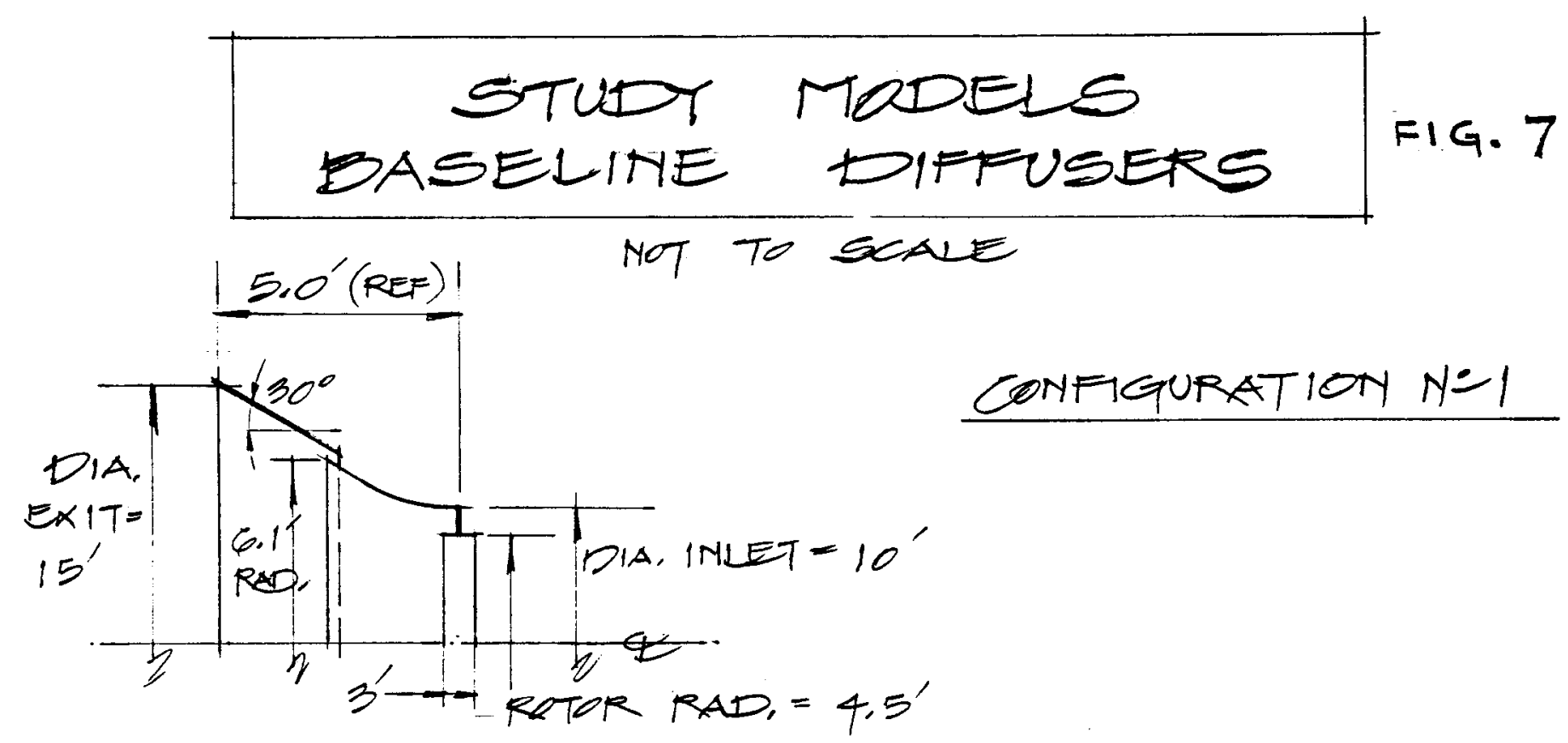

CONFGURATIONY $\mathrm{N}=1$
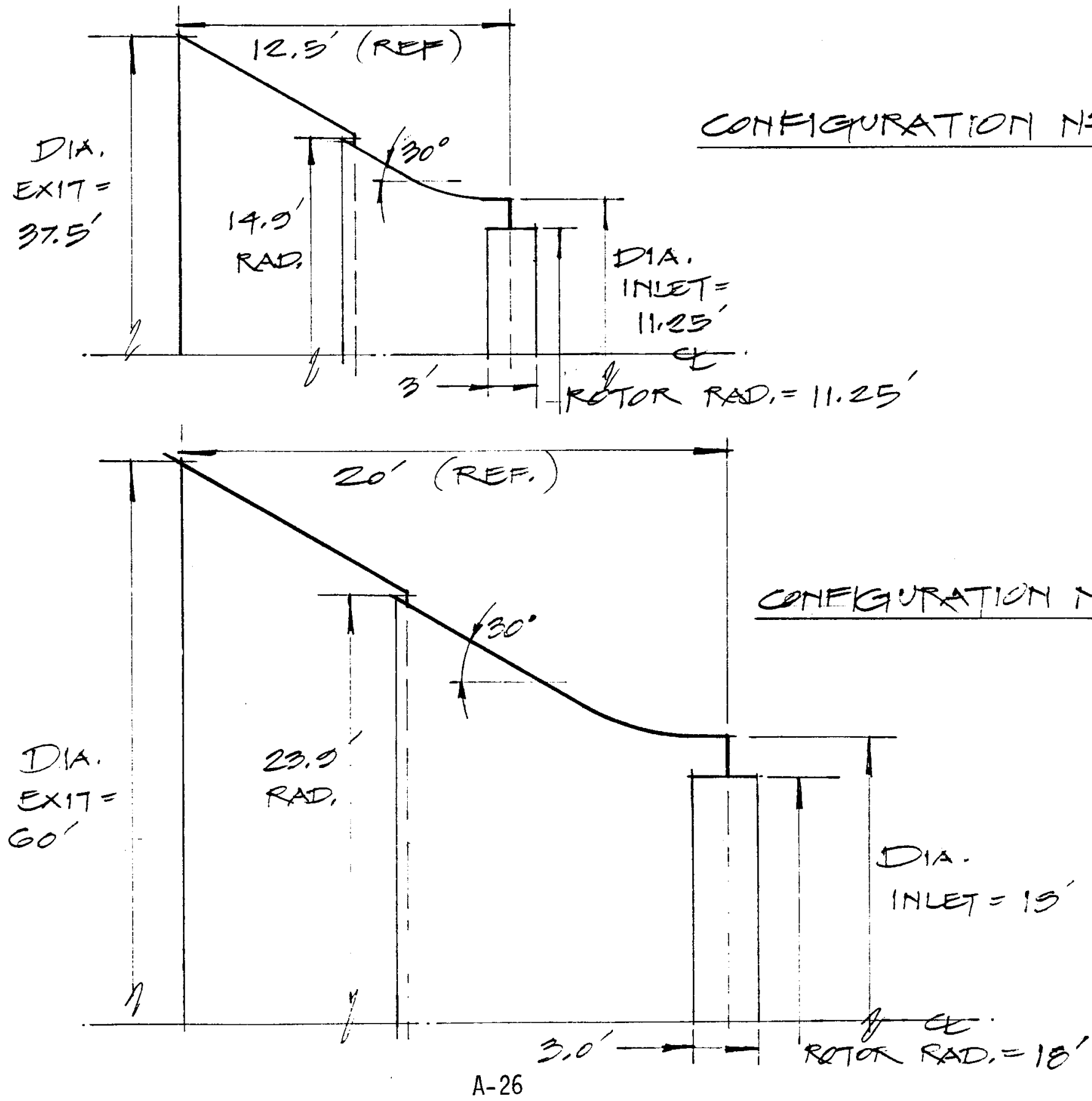
FIG. 8

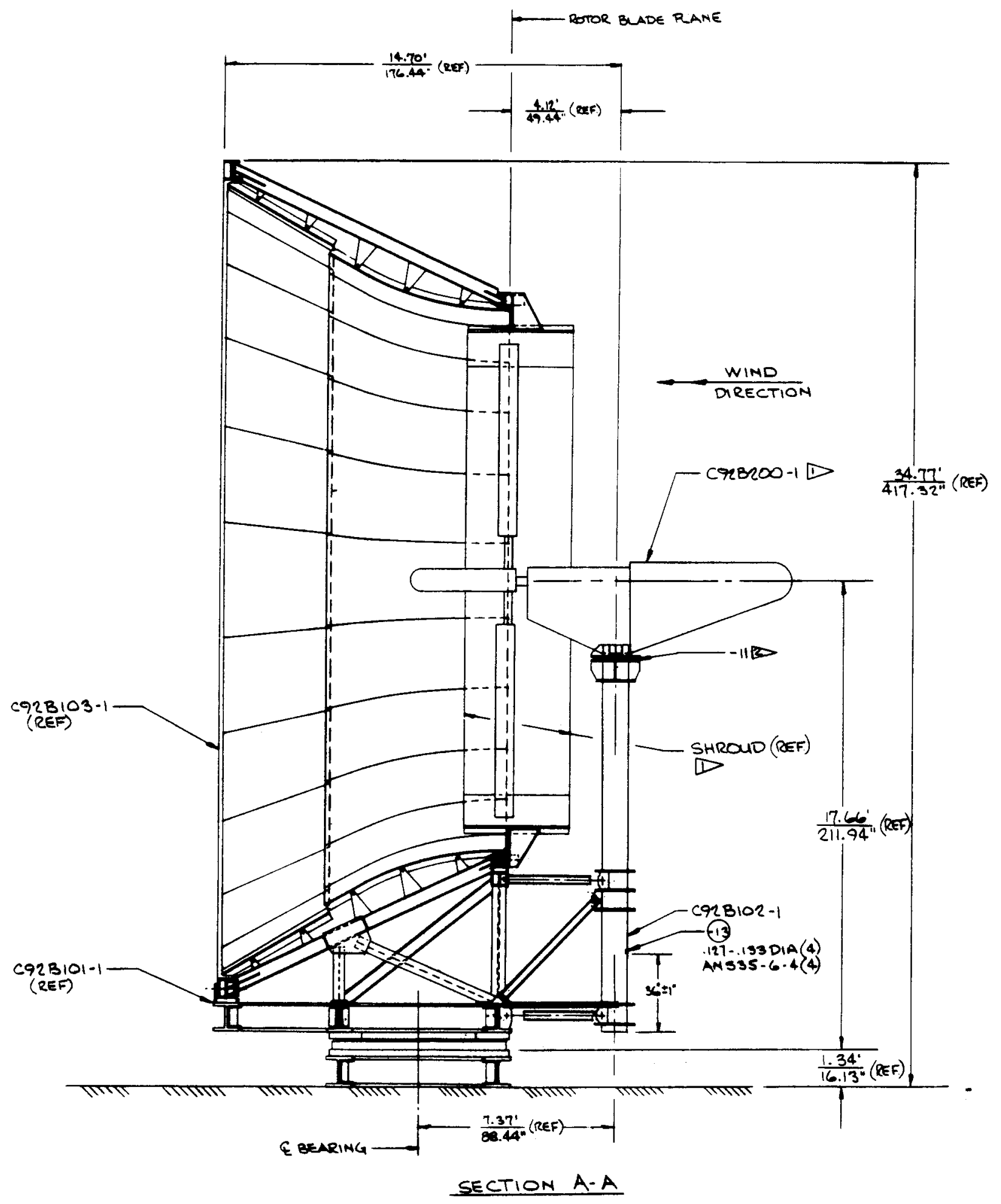

BASIC TURBINE-DIFFUSER

ARRGMT. 
FIG. 9



$$
\begin{gathered}
\text { BASIC TURBINE-DIFFUSER } \\
\text { ARRGMT. }
\end{gathered}
$$




\subsection{CONCEPT DFSIGN OF CONFIG. \#3 MODEL}

Review of the baseline dimensions and arrangements of Configuration \#3 (36 Ft. dia. Rotor - $60 \mathrm{ft}$. dia. exit Diffuser) indicates that it is beyond the feasible size for ferro-cement design and construction as found in the current state of the at for such material. The major reason is that the large spans of the exit diffuser shell will result in excessive tensile stress levels well beyond the capability of ferro-cement to avoid cracking.

To compensate for such high tensile stresses in large concrete structures having similar long spans a prestress system (pre-tensioned or post-tensioned) is provided. Such methods are a departure from the basic principles of ferro-cement design philosophy which derives structural strength through the rigidity of its thin shell panel. Therefore the study team proposes for diffusers with large diameters a system using a combination of prestressed concrete combined with ferro-cement. A concept design was prepared and is shown in Fig. 10 using such a method for Configuration \#3.

Some work has been done in the use of combined prestressed concrete and ferro-cement for large ocean going barges as described in Section 3.6 and Ref. 11.

Since such a method is beyond the scope of this study only a very brief concept design is offerred at this time. From the writers' experience such design and construction appears feasible from both structural design and costs and warrants further research and development as discussed in Section 8. 


\subsection{CONCEPT DESIGN}



REAR VIEW

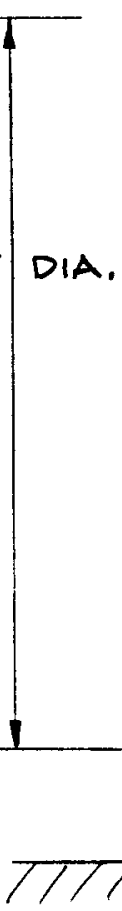

SIDE VIEW

GEN'L ARRANGEMENT


- CONCEPT DESIGN. 60' EXIT DIAMTETER DIFFUSER



FIGURE 10 


\subsection{CONCEPT DESIGN CONFIG NO. 3 (cont.)}

a) Estimated Weight

(short ton)
S.T. $\left(2000^{\#}\right)$

OUTER DIFFUSER $55 \times 8^{\prime} \times .27^{\prime} 0150^{\#} / \mathrm{ft}^{3}=$

21.8

INNER DIFFUSER 45

$45 \times 14^{\prime} \times .21 \times 150^{\#}=$

31.2

ROTOR SHROUD

$36 \times 3^{\prime} \times .25 \div 150^{\#}$

$=$

6.4

LEGS

5.2

RIBS \& MISC.

TOTAL $\quad \underline{3.4} \underline{\underline{68.0} \text { S.T. }}$

b) Pre-Stress-System

A prestress system is proposed with tendon ducts imbedded into diffuser sections which would be separately cast as in the smaller size ferro-cement models.

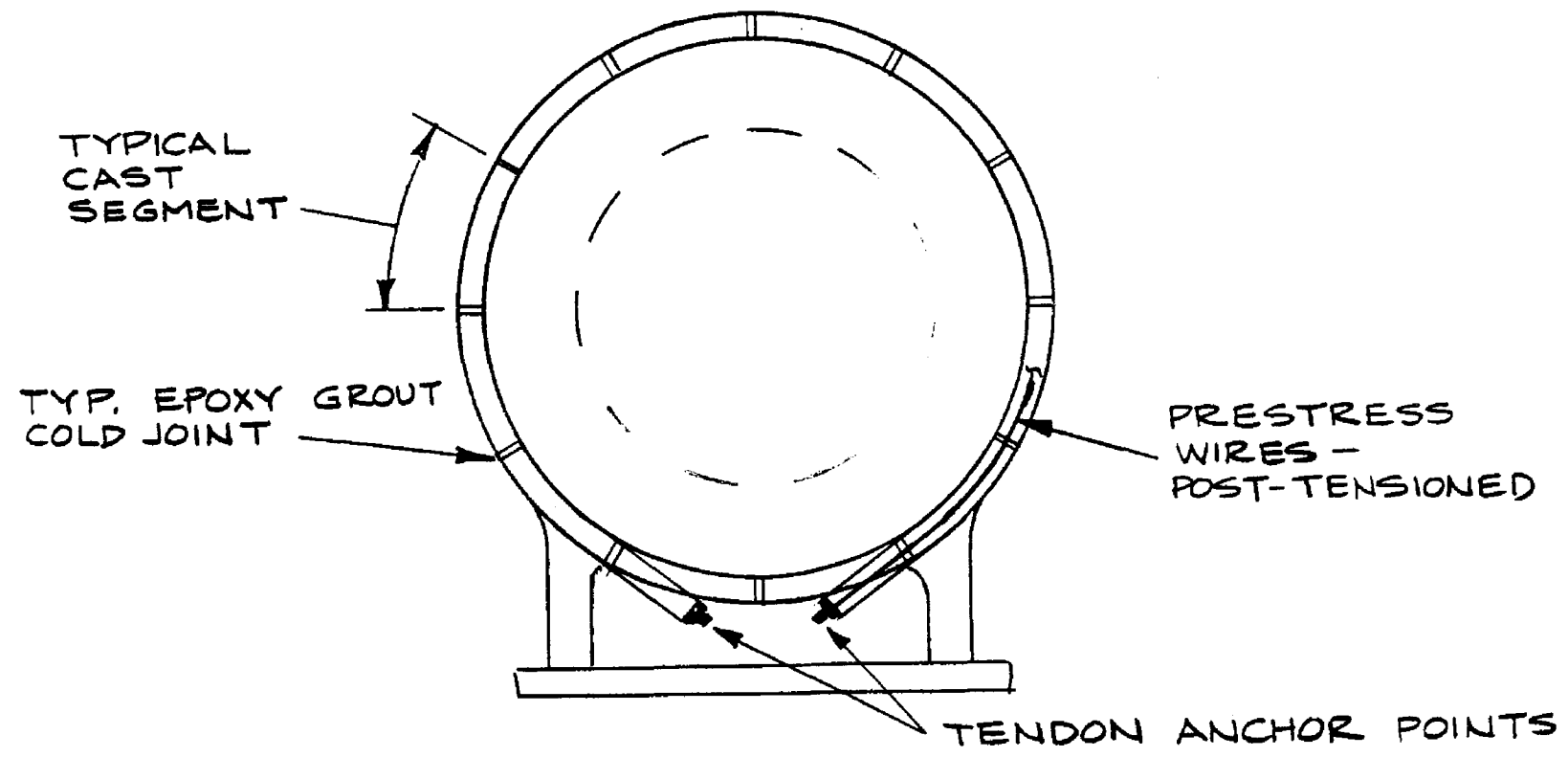

FIGURE 1$]$

A ter assembling and aligning cast segments together on site, "cold Joints" would be made and grouted. Then wire tendons would be inserted in tendon ducts, post tensioned at anchor points and grouted in place. 
c) R.0.M. Costs

Rough Order of Magnitude costs for Conf. No. 3 single prototype

construction is estimated at $\$ 1.50 / 1 b$. giving a total cost of $\$ 200,000$. 


\subsection{PRODUCTION TECHNIQUES}

For configurations $\|_{1}$ and $\#_{2}$ of diffusers it is proposed to employ current fabrication techniques for ferro-cement employing a mold system. Fabrication details are shown in Fig. 19 in the main text.

\subsection{MOLD METHOD}

It is proposed to utilize molds for diffuser fabrication due to accuracy of shape control, smooth surface finish and improved productivity for volume production.

Ferro-cement molds would be used for volumes of up to 10 units. For over 10 units, steel molds are recommended.

Molds would be designed to be dismantable and reusable. They would be sized in segments to meet highway, railroad or barge dimension and weight restrictions to simplify transportation. Fig 20 in the main text shows shipping particulars for mold and/or castings.

\subsection{PRODUCTION SCHEMES}

Dependent on volume of diffuser units and their final site location it is proposed that production centers would be established in close proximity of wind turbine sites. Optimum number and locations of centers would be established in evaluating the total number and size of diffuser units. required, the number and location of wind turbine sites, and the transportation means available in the area.

Other factors in selection of production facilities and their location would be availability of labor, existing suitable buildings, and sources of raw materials. 
Large volume production would probably warrant setting up concrete batch plants adjacent to facilities while small volume would rely on availability of local concrete batch plants.

Also to improve productivity steam curing would be provided which permits higher utilization of molds by reduced curing time. Time for steam curing would be 2 days versus norma 128 day cure to fu11 strength.

\subsection{FACII ITY REQUIREMENTS}

It is suggested that production facilities be situated indoors in a large enough building to accommodate the largest mold segment. 01d warehouses, existing barns or buildings would suit the purposes. Outdoor production is not recommended due to production restrictions from weather and problems with quality control for mortar placement and curing.

Facilities for diffuser production to be accommodated by such a building would include:

i) Floor Area \& Height Clearances to suit largest size diffuser casting segment.

ii) Floor Strength to support diffuser segment weights.

iii) Portable Cranes

iv) Material Storage - Cement/Sand/Additives/reinforced steel

v) Fresh Water Supply

vi) Mortar Mix Equipment (not required if local plant provides mortar) and Tools

viii) Electric Power \& Lighting

viii) Ventilation System

ix) Steam Curing Equipment 

x) Worker's Lockers \& Restrooms
xi) Administrative Offices
xii) Cementatious Waste Material Disposal
xiii) Parking Facilities

\subsection{ASSEMBLY PROCEDURES AT SITE}

Cast ferro-cement diffuser segments would be assembled at site by suitable truck cranes for positioning and securing segments onto wind turbine foundations. 


\subsection{COST ESTIMATES}

\section{a) General}

Cost estimates based on ferro-cement type construction and current price levels have been prepared for two diffuser model configurations. Costs for construction and testing of a single prototype unit for each model employing standard ferro-cement techniques have been estimated. Next volume production cost estimates were made with final analysis of size and shape effects on costs.

b) Labor Rates

A billing rate of $\$ 15.00$ per hour which includes direct labor, indirect, $G \& A$ and profit was used in cost estimates. It is believed that this rate reflects the average for semi to unskilled labor over the general "windy" areas of the U.S. to be employed in ferro-cement construction.

\subsection{COSTS FOR TYPICAL FERRO-CEMENT CONSTRUCTION}

(One Unit - custom fabricated method - no molds) ITEM

a) Material

Mortar a $\$ 70 / y d$

Rod 3/16" \& @ \$.50/7b.

Mesh WWM \& $\$ 0.40 / \mathrm{ft}^{2}$

Concrete o $\$ 40 / y d$.

Reban \#4 o \$.25/ft.

Rod $\frac{1}{4}$ " o $\$ .50 / 1 b$.

Wiggle Rod 3/16" o \$.50/1b.

Bolts, Washers, Nuts

Flat Bar

Epoxy Coating

\begin{tabular}{|r|r|}
\hline$\$$ & $\$$ \\
42 & 231 \\
105 & 1184 \\
480 & 3040 \\
8 & 48 \\
28 & 75 \\
17 & 80 \\
16 & 32 \\
26 & 40 \\
28 & 360 \\
100 & 400 \\
\hline 850 & 5490 \\
\hline
\end{tabular}


b) Labor

\begin{tabular}{|c|c|}
\hline Mesh Lay-Up & $\begin{array}{r}230 \text { MH } @ \$ 15 \\
1500 \text { MH } @ \$ 15\end{array}$ \\
\hline Mortar \& Cure & 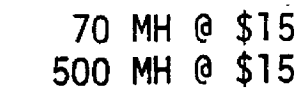 \\
\hline
\end{tabular}

TOTAL LABOR

TOTAL MATERIAL \& LABOR

\begin{tabular}{|l|r|}
\hline 3450 & 22,500 \\
1050 & 7,500 \\
\hline 400 & 2,000 \\
\hline 4900 & 32,000 \\
\hline 5750 & 37,490 \\
\hline
\end{tabular}

c) Unit Costs

Based on estimated weights for typical ferro-cement construction.

WEIGHT

COST/LB.

d) Site Assembly Costs

Transport, Crane Rental, Labor
CONFIG.

No. ?

CONFIG.

No. 2
CONFIG.

No. 2

37,600 1bs.

$\$ 1.00$

$\$ 1000 \$ 2000$


e) Summary of Costs for Prototype Mode1

\begin{tabular}{|c|c|c|}
\hline & $\begin{array}{l}\text { CONFIG. } \\
\text { No. } 1\end{array}$ & $\begin{array}{l}\text { CONFIG. } \\
\text { No. } 2\end{array}$ \\
\hline Engineering \& Development & $\$ 10,000$ & $\$ 15,000$ \\
\hline Materials \& Labor & 5,750 & 37,490 \\
\hline Site Assembly & 1,000 & 2,000 \\
\hline Test \& Evaluation & 5,000 & 10,000 \\
\hline TOTAL & $\$ 21,750$ & $\$ 64,490$ \\
\hline
\end{tabular}

\subsection{COSTS FOR VOLUME PRODUCTION (100 UNITS) DIFFUSER MODELS}

a) Mold Costs

Ferro-cement Mold \& $\$ 1.25 / 7 b$.

\begin{tabular}{c|c}
$\begin{array}{c}\text { CONFIG. } \\
\text { No. } 1\end{array}$ & CONFIG. \\
No. 2 \\
\hline $\begin{array}{c}48001 \mathrm{bs}) \\
\$ 6,000\end{array}$ & $(36,000$ lbs. $)$ \\
$(4000$ 1bs. $)$ & $(28,0001 \mathrm{bs})$. \\
$\$ 12,000$ & $\$ 84,000$ \\
\hline
\end{tabular}

Since ferro-cement molds are limited to only 10 to 20 uses and unit cost differential between ferro-cement and steel mods is not a significant factor, steel molds only recommended.

Steel Mold Cost (Amortized over Per Unit 100 production units)

CONFIG.

No. 2

\begin{tabular}{l|l}
\hline$\$ 120$ & $\$ 840$ \\
\hline
\end{tabular}


b) Summary of Costs for Production Unit (100 Units)

\begin{tabular}{|c|c|c|}
\hline & $\begin{array}{l}\text { CONFIG. } \\
\text { No. } 1\end{array}$ & $\begin{array}{l}\text { CONFIG. } \\
\text { No. } 2\end{array}$ \\
\hline $\begin{array}{l}\text { Cost } \\
\text { Production Unit } \\
\text { See Fig. } 12 \\
\qquad \begin{array}{l}(80 \% \text { of } \$ 5,750) \\
(80 \% \text { of } \$ 37,490)\end{array}\end{array}$ & $\$ 4,600$ & $\$ 30,000$ \\
\hline Steel Mold Costs & 120 & 840 \\
\hline Site Assembly & 1,000 & 2,000 \\
\hline Inspection \& Test & 500 & 1,000 \\
\hline TOTAL COST/UNIT & $\$ 6,220$ & $\$ 33,840$ \\
\hline
\end{tabular}

\subsection{COST SENSITIVITY TO DIFFUSER SIZE \& SHAPE}

a) Effect on Unit costs

From experience in building ferro-cement marine craft huils ranging in length from 20 to 60 feet it has been found that variations in both size and shape have little or no sensitivity to these parameters. Therefore, unit costs $\left(\$ / 1 b_{\text {. }}\right)$ have no effect from these variables.

b) Parameter Affecting Cost

The principal parameter affecting costs of a given diffuser model will be surface area which is related directly to weight and cost.

c) Sensitivity Model Study

To analyse the cost effect of varying surface area of various diffuser configurations the sensitivity models shown in Fig. 12 were selected. Results of the study are shown in Fig. 13 which indicates that increasing the $1 / 2$ angle slope of the Baseline Diffuser to 45 degrees (model A-2) with the same inlet/exit area ratio is the most cost effective. 
SEMSITIVITT MODELS/FIGIL

a) change of sofe $\frac{1}{2}$ avgle same area ratio.
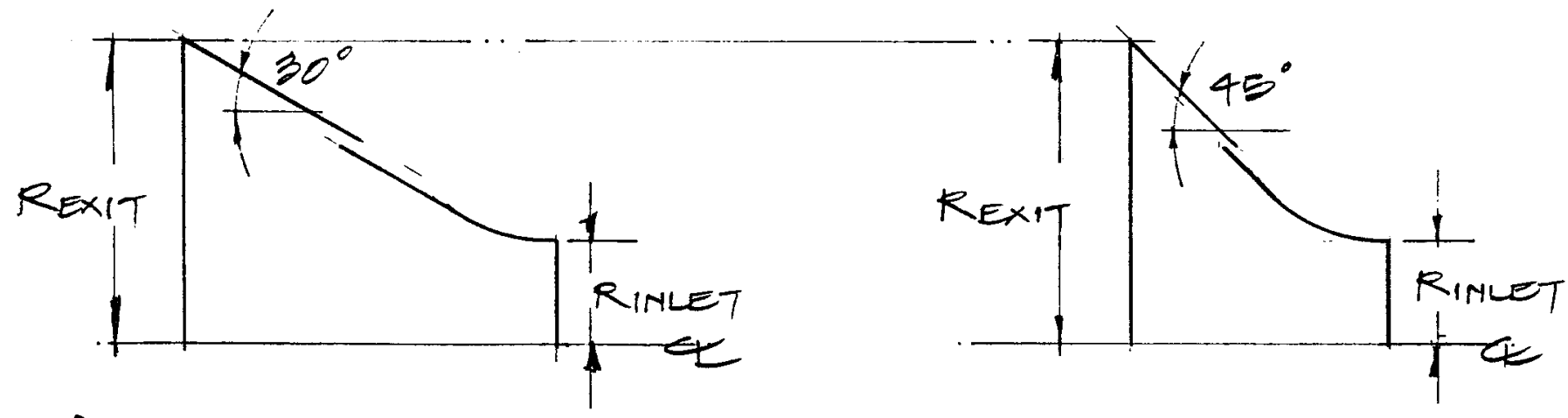

b) chatkge of $\frac{1}{2}$ aigle slofe for same lemett OF DIFFUSER,

$$
\frac{1}{2}<45^{\circ}
$$

$y$.

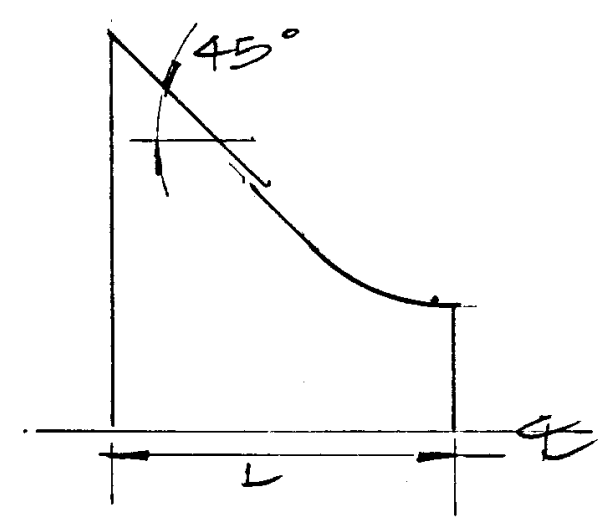

$$
\frac{1}{2}<30^{\circ}
$$

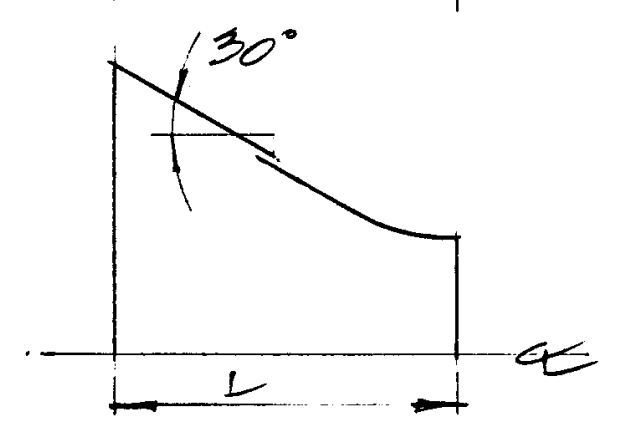

c) Baseline " DUMP DIFTUSER for same BASELITE DUMP


A -40 
SENSITIVITT MODEL STUDY EGURE 13

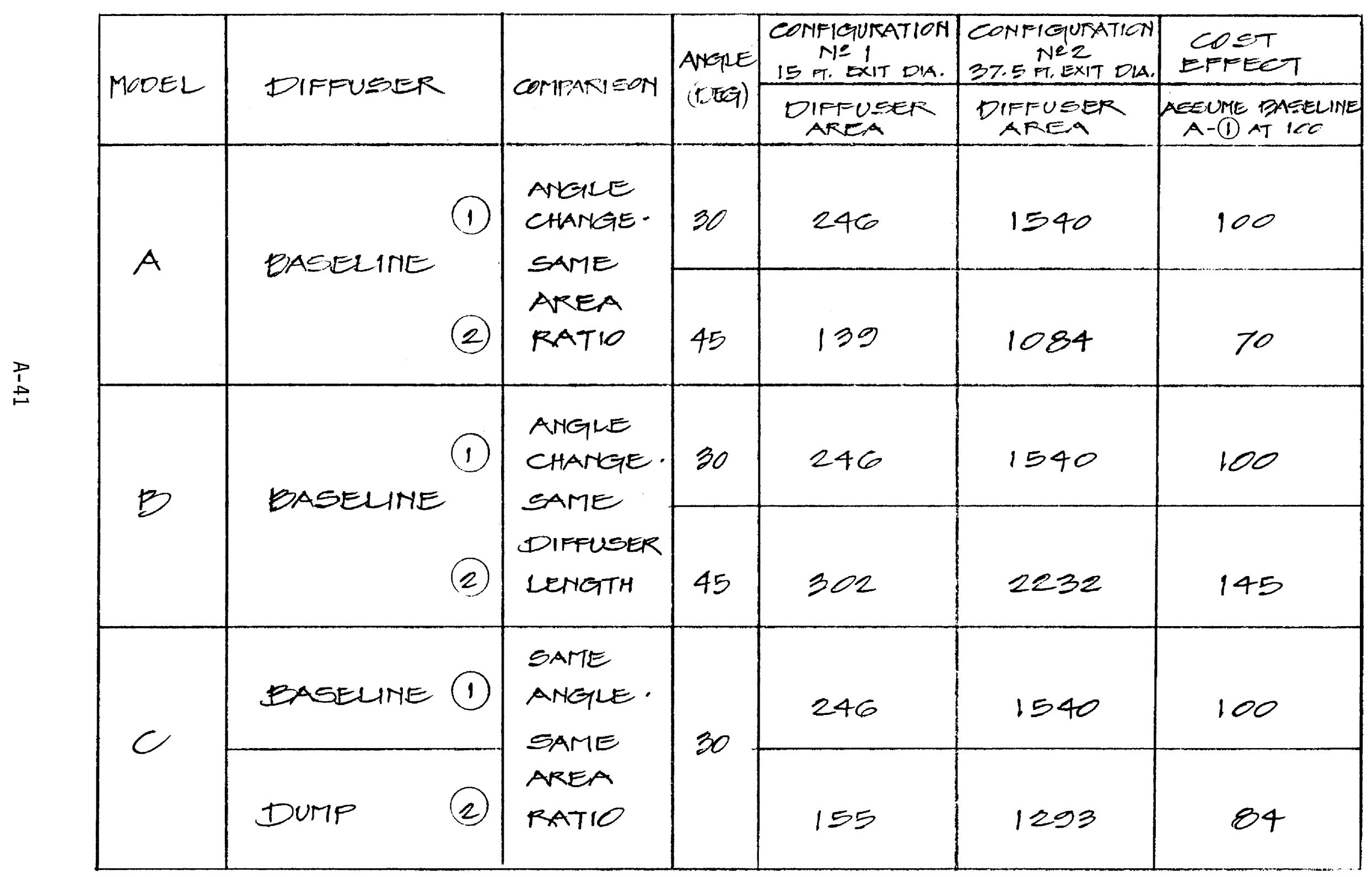


7.4 VOLUME PRODUCTION EFFECT ON COSTS

Estimates on effect of costs by volume production have been made and general curves, indicating the reductions, are given in Fig. 14.

Curves are based on the assumption that material costs (about $15 \%$ of tota1) will appreciable drop for volumes of 100 units due to volume purchasing, particularly of welded wire mesh. The labor costs (about $85 \%$ of total) reduce due to learning experience with molds, mesh lay-up and mortaring up to a volume of 100 units.

\section{FIGURE 14}

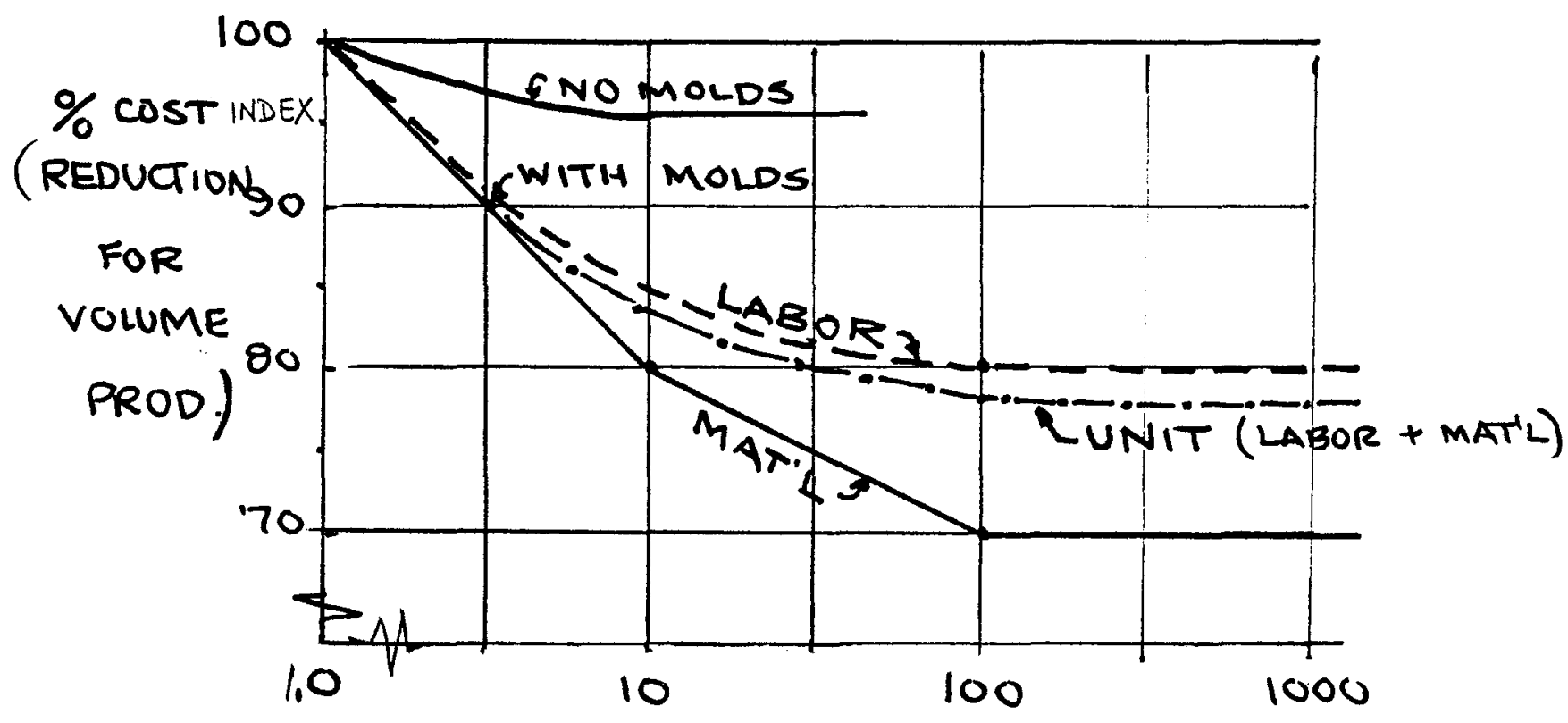

NO. OF UNITS 


\subsection{RECOMMENDAT IONS FOR $R$ \& $D$}

The results of subject study indicate the need for further study and research which authors consider are beyond the scope of this study project, namely:

i) Establish Maximum Diameter Ferro-cement Diffuser

ii) Prestress/Ferro-cement System for Large Diffusers

iii) Prototype Ferro-cement Model

\section{1 ESTABLISH MAXIMUM DIAMETER FERRO-CEMENT DIFFUSER}

As previously established in this study there is a maximum absolute size (approx. that of Configuration \#2 for $22.5 \mathrm{ft}$. dia. Rotor) beyond which the ferro-cement system is not feasible. Further investigation appears warranted to determine this peak limit more accurately since ferro-cement construction is obviously much preferred over prestress system both from weight considerations and economy. Detailed stress analysis and laboratory testing will be required to establish this practical maximum size.

$$
\text { Estimated Cost for Analys is } \$ \$ 800
$$

\subsection{PRESTRESS - FERRO-CEMENT SYSTEM FOR LARGE DIA. DIFFUSERS} According to investigations by Grumman Aerospace on their augmented wind turbine system the largest practical diameter for extruded aluminum type rotor blases is about 36 feet giving a diffuser exit diameter of about 60 feet. In the interest of economy in diffuser construction it has been shown in this study that cementatious materials are most effective in this regard. 
Therefore to continue application of such materials for large size wind turbines beyond the practical range of ferro-cement (both in design and construction techniques) the introduction of prestress concrete is most desirable. The concept design proposed for a $36 \mathrm{ft}$. dia. rotor diffuser in the study indicates the general feasibility of combining prestress concrete technology with that of ferro-cement. Further research appears warranted and is recommended by the authors.

A brief outline of feasibility of a prestress/ferro-cement diffuser system is given below:

i) Establish a study team combining qualified engineers and constructors knowledgeable and experienced in both concrete and ferro-cement.

ii) Undertake structural design analysis of optimum prestress/ferro-cement system utilizing lab tests. Consider high strength light weight concrete.

iii) Undertake construction techniques for automated volume production and site installation.

iv) Prepare cost estimates and economic analysis. Estimated cost for Study $\$ 25,000$

\subsection{PROTOTYPE FERRO-CEMENT MODEL}

The next phase in development of ferro-cement for use in diffuser design and construction, and, to firmly validate it as a practical and feasible material, is to construct a prototype for test and evaluation. It is recommended that a fu11 scale ferro-cement prototype for a $12 \mathrm{ft}$. dia. rotor be constructed and tested. 
Outline of such a prototype program is given below:

i) Establish a team consisting of aerodynamic engineers and ferro-cement specialists for design, construction and testing of diffuser prototype.

ii) Prepare design for ferro-cement prototype diffuser $(12 \mathrm{ft}$. dia. rotor) employing latest version of Grumman Augmenter Diffuser and current ferro-cement design standards .

iii) Construct molds, fabricate,(lay-up) armature,mortar and cure.

iv) Set up prototype - experiment with cold joints, assembly methods, check weights.

v) Conduct Tests - stress analys is under service loads, freeze-thaw, fire, corrosion, surface abrasion, etc.

Estimated cost for project is:

(weight 10,000 ibs.)

Engineering

$\$ 10,000$

Molds

8,000

$\$ 25,000$

Armature

Mortar

7,000

Tests
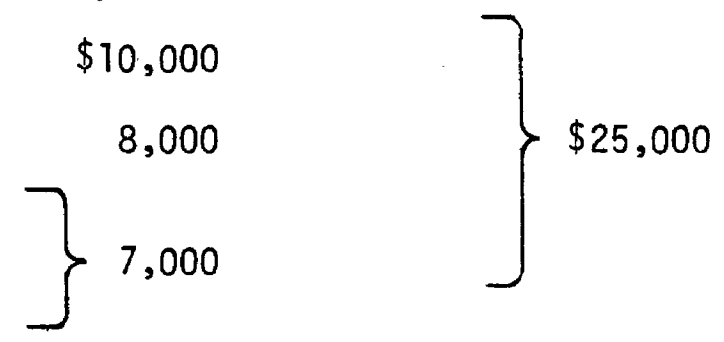

Misc. 
Appendix A-1

\title{
Supporting Calculations
}

\author{
for \\ Ferrocement Design of \\ Baseline and Dump Diffusers
}

Designed for: Gruman Aerospace Corp. Bethpage, N. Y

By: David J. Seymour, Ltd.

San Franciseo, CA.

Oct 15,1979 


\section{SIRUCIVRALCCALEULA T I O N for BASELINEDIFFVSER}

1. LAMINATE PROPORTIONS



$K_{H}=$ SPECIFIC COEFFICIENT OF MESH IN $\frac{C M^{2}}{C M^{3}}$

$$
=59\left[\frac{d}{-a}\right]\left[\frac{n}{t-\left(\eta_{1}+D_{2}\right)}\right]
$$

WHERE $d=$ VIRE DIAMETER IN MM $=.0411(25.4)=1.14 \mathrm{UM}$ $a=M E S H \quad V I D T H \quad N \quad M M=25.4(0,5)=12.7 \mathrm{MM}$ $n=$ NUMBER IF LAYEAS IN LAMINATE = 4 $t=\angle A M I N A T \equiv T H I C K N E S S=25.4(1)=05.4 \mathrm{NH}$ $D_{1}, D_{2}=R O D$ DIAMETER $=25.4\left(\frac{1}{4}\right)=6.35 \min$

\footnotetext{
avid J.Seymour, Ltd. Javal Architects - Marine Consultants Jan Francisco Jalifornia $94105_{A-47}$ Sheet: Job No.: _C 1___ Date: By: _ Check: A-47 Sheet 1 of
} 
THEH:

$$
\begin{aligned}
K_{N} & =59\left[\frac{1.04}{12.7}\right]\left[\frac{4}{25.4-(6.35+6.35)}\right] \\
& =1.524 \frac{C M}{C M}^{2}, N G, 1.8 \leq K_{N} \leq 4.0^{*}
\end{aligned}
$$

TRY 15 GAGE WIRE:

$K_{1}=1.524\left[\frac{172}{041}\right]=2.676 \frac{\mathrm{CM}^{2}}{\mathrm{CM}^{3}}, O K$

$K_{T}=$ TOTAL SPECIFIC ADHESION COEFFICIENT FOR WHOLE LAMINATE IN $\frac{C M^{2}}{C M^{2}}$

$$
\begin{aligned}
& =\frac{31.4}{t}\left[\frac{D_{1}}{\xi_{1}}+\frac{D_{1}}{\xi_{2}}\right]+K_{1}\left[1-\frac{D_{1}+P_{1}}{t}\right] \\
& =\frac{31.4}{25.4}\left[\frac{25}{3}+\frac{.25}{6}\right]+2.676\left[1-\frac{0.15+0.15}{1}\right]
\end{aligned}
$$$$
=0.155+1.338=1.493 \mathrm{CM}^{2}, N G, 1.6 \leq K_{I} \leq 3.0
$$

DECREASE SPACING OF ROPE, SAY 3"X3"

* Nite: permisgible valves taken from dNV rUleg for THE CONSTRICTION OF FERROCEMENT YESSELS

\section{avid J. Seymour, Ltd. Sheet: $_{\text {DESIGN CALCULATION SHEET }}$}

Vaval Architects - Marine Consultants Jan Francisco
Job No: CEf Date:

By:

California 94105 A-48
Check:

Sheet $y$ of 
THEN:

$$
\begin{aligned}
K_{I} & =\frac{31.4}{25.4}\left[\frac{.25}{3}+\frac{.25}{3}\right]+1.338 \\
& =0.216+1.338=1.544 \frac{\mathrm{CM}^{2}}{\mathrm{CM}^{3}}, \text { STILL NG }
\end{aligned}
$$

$$
\begin{aligned}
\text { TRY } & 2 \times q^{\prime \prime} \text { SPACING: } \\
K_{1} & =\frac{31.4}{25.4}\left[\frac{25}{2}+\frac{.25}{2}\right]+1.338 \\
& =0.309+1.338=1.647 \frac{\mathrm{CM}^{2}}{\mathrm{CM}^{3}} \mathrm{OK}
\end{aligned}
$$

$\mu_{\text {H }}=$ REINFORCEMENT COEFFICIENT (q.) FOR CROSSSEEJION OF NETTING LAMINATE

$$
\begin{aligned}
& =1.25(d)\left(K_{H}\right) \\
& =1.25(25.4 \times .0792(2.676)
\end{aligned}
$$

$\mu_{N}=6.117$

$M_{T}=$ TOTAL REINFORCEMENI COEFFICIENT (1.) FOR WHOLE CROQS SECIION

$=78.5 \frac{\nabla^{2}}{2 t}+\mu_{N}\left[1-\frac{D_{1}+\theta^{2}}{t}\right]$

\section{avid J. Sejrmour, Ltd.}

Vaval Architects - Marine Consultants Jan Francisco
California $\left.94105\right|_{\text {A- } 49} ^{\text {By: }}$

\section{DESIGN CALCULATION SHEET}

Sheet:

Job No.: CE/ Date:

Check:

Sheet 3 of 
NOIE, $\mu_{T}$ NILL BE THE SAME IN $X$ AND Y PIRECTIONS SINCE ROD DIAMETERS (DIAND DV) AND SPACINGS

(S1 AND $\left.S_{y}\right)$ ARE EQVAL. THEN:

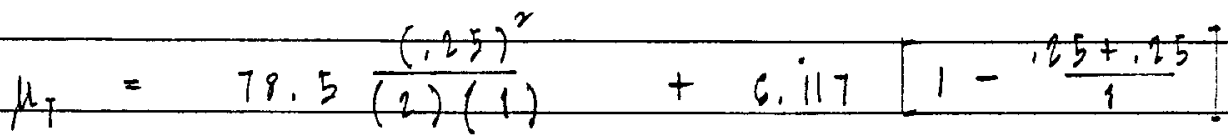

$=5.51,0 k, 2.0 \leq \mu_{1} \leq 6.5^{*}$

$G_{g}=$ SPECIFIE STEEL CONTENT OF FERROCEMENT WATERIAL IN $\frac{K G}{P M^{3}}$

$=\frac{A_{1} G n}{\frac{1}{2}}+\frac{6.18}{t}\left[\frac{D_{1}^{2}}{S_{1}}+\frac{D_{2}^{2}}{S_{2}}\right]$

$\begin{aligned} \text { WHERE GN } & =\text { VEIGHT IN } \frac{K G}{M^{2}} \text { OF ONE NETTING LNYER } \\ & =3.255 \frac{K G}{M^{2}}\end{aligned}$

$=\frac{4(3.255)}{25.4}+\frac{6.18}{25.4}\left[\frac{.25}{2}+\frac{.25}{2}\right]$

$=0.573 \frac{K G}{2 M^{3}}, 0 K, 0.38 \leq G_{3} \leq 0.65^{*}$

THEREFORE PROPORTIONS OF LAMINATE (AS

MODIFIED) ARE SAIISFACTORY

uavid J. Seymour, Ltd. Vaval Architects - Marine Consultants jan Francisco

California 94105 A-50

DESIGN CALCULATION SHEET

Sheet:

Job No: $C+$ Date:

By:

Check:

Sheet 4 of 
1. SETTION MODULUS OF SHELL AND RIB

$$
\begin{aligned}
& \text { (1) (2) } \\
& \text { IIEM } \quad \text { A } \quad y \quad A y \quad A y^{2} \quad I \\
& \text { (1) } \quad \begin{array}{lllll}
64 & 15 & 32 & 16 & 5.33
\end{array} \\
& \text { (2) } 12 \quad 7 \quad 84 \quad 58 \\
& \begin{array}{l|llll}
76 & 1.53 & 17.6 & 604 & 149.33 \\
\hline 1 N A B D L & &
\end{array} \\
& I_{B 1}=I_{N 1}+A y^{2}=753.331 N^{4} \\
& \begin{aligned}
I_{N 1}=I_{B L}-1 \bar{y}^{2} & =753.33-76(1.53)^{2} \\
& =575.421 N^{4}
\end{aligned} \\
& S H=\frac{I_{1}}{4 T}=\frac{575,42}{11.47}=54.961 \mathrm{~N}^{3} \\
& =900.62 \mathrm{CH}^{3}
\end{aligned}
$$

\footnotetext{
Javid J. Seymour, Ltd. Vaval Architects - Marine Consultants Jan Francisco Salifornia $94105 \mid \begin{aligned} & \mathrm{By} \text { : } \\ & \mathrm{A}-51\end{aligned}$

DESIGN CALCULATION SHEET Sheet: Job No.:___ Date: Check: Sheet 2 of
} 
3. REQUIRED SECTION MODULUS

$$
z=45 k_{1} C_{q} l^{2} 5 h
$$

WHERE $K_{1}=1,0$

$$
\begin{aligned}
& C_{v}=1: 0 \\
& l=\operatorname{SPAN}=4.5 \underline{M} \\
& g=R \perp B \operatorname{SPACING}=2,5^{M} \\
& h=\text { DESIGN LOAD }=\text { VIND } \angle O A D+S T A T I C \angle O A D
\end{aligned}
$$

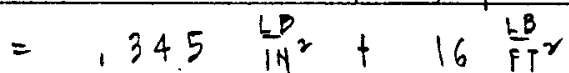

$$
\begin{aligned}
& =0.456 \frac{\mathrm{LB}^{2}}{\mathrm{H}^{2}} \\
& =1.053 \text { FT OF WNTER } \\
& =0.321 \mathrm{M}
\end{aligned}
$$

$$
\begin{aligned}
Z & =45(1.0)(1.0)(4.5)^{2}(2.5)(0.321) \\
& =731.3 \mathrm{CM}^{3}
\end{aligned}
$$

Gavid J. Seymour, Ltd. Vaval Architects - Marine Consultants jan Francisco

California 94105 A-52

\section{DESIGN CALCULATION SHEET}

Sheet:

Job No.: EC

By: Check

Sheet 6 of 


\section{FOUNDA for $D \cup M P D \perp F F V \& E R$}

PROCERIRE:

DEIERMINE DESIGN LOADE:

a. PROJECIED AREAS,

b. DRAG COEFFICIENIS

e. $V I N D$ FORCES (HEAD-ON, LATERAL)

d. VNII VEIGHI

2. DESIGN SUPPORTS

HEAP-OH PROJECIED AREA



\section{Gavid J. Seymour, Ltd. aval Architects - Marine Consultants ian Francisco California $\left.94105\right|_{A-53} ^{B y:}$ \\ DESIGN CALCULATION SHEET \\ Sheet: Job No: $\approx \frac{1}{2}$ Date: Check: Sheet 7 of}




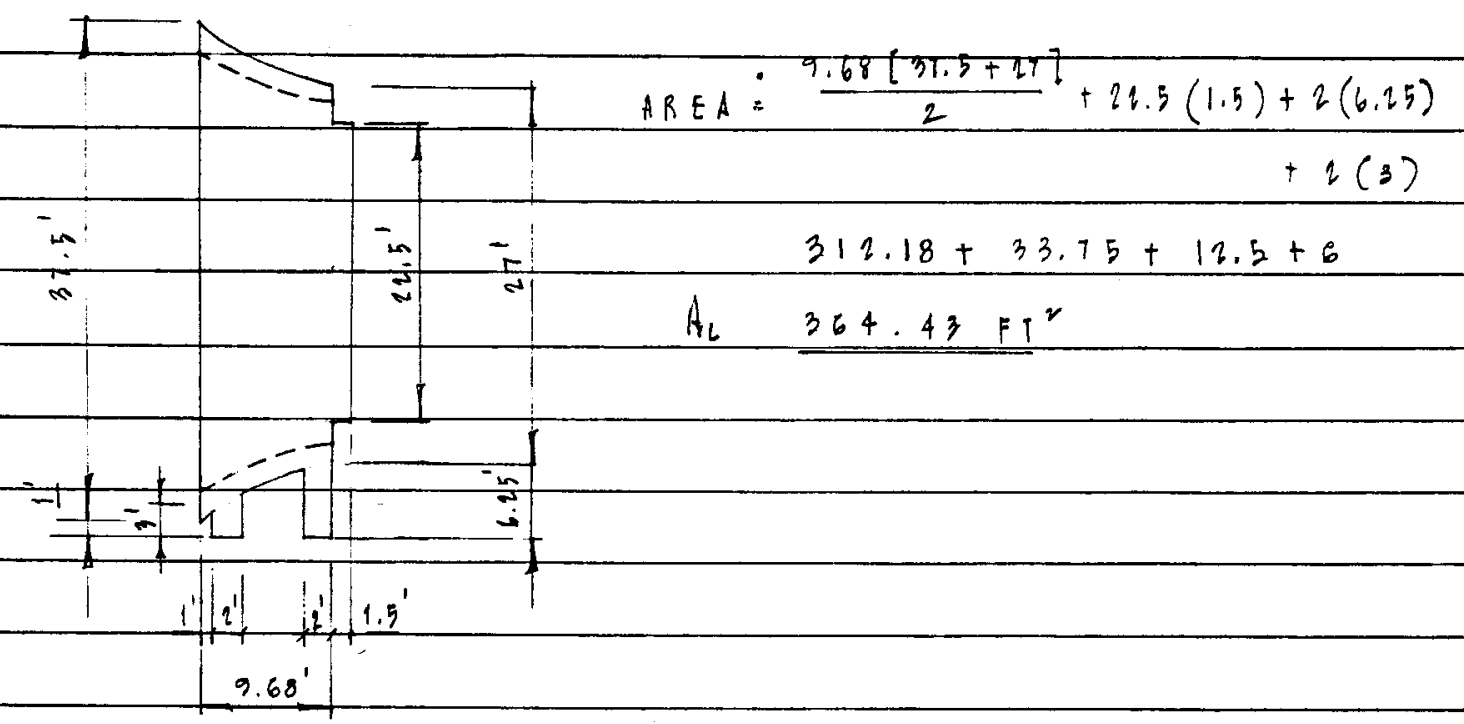

DRAG COEFFICIENIS (CQ):

FROM FOREMAN LETTER DATED 14 JUNE 79:

$$
\begin{aligned}
& C_{P}(\text { HEAD-ON) }=1.10 \\
& C_{P}(\text { LIERAL) }=0.80
\end{aligned}
$$

NOTE: ROTUR SUPPORTED BY SEPARATE STRUCTVRE

Savid J. Seymour, Ltd. laval Architects - Marine Consultants ian Francisco こalifornia 94105
DESIGN CALCULATION SHEET

Sheet:

Job No:_6fi Date:

By:

Check:

Sheet \& of 
VIND CRITERIA:

$$
\begin{aligned}
& Y=120 \mathrm{MPH} \quad V_{\text {MKX }}=121(1.21) \\
& \text { GVGTFACTOR }=1.21=145.2 \mathrm{MPH} \\
& =212.96 \frac{F T}{2 E C}
\end{aligned}
$$

VIND FORCES:

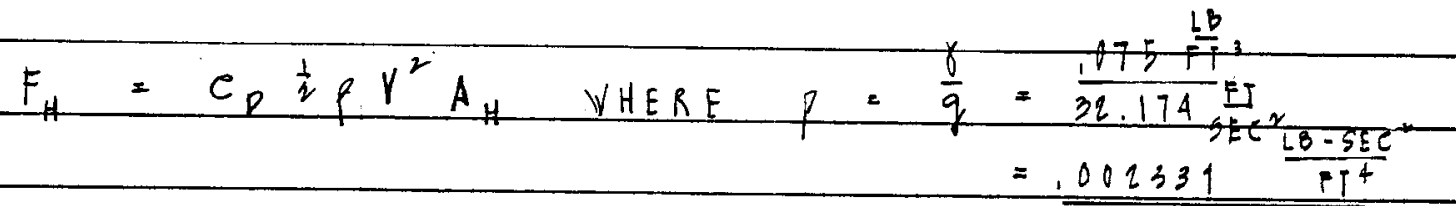

$$
\begin{aligned}
& =1.10\left(\frac{1}{2}\right)(.102331)(212.96)^{2}(714.86) \\
& =41564.45 \mathrm{LB} \quad 53: 1 \\
& F_{1}=C_{p} \frac{1}{2} \rho r^{2} A_{L} \\
& =0.8\left(\frac{1}{2}\right)(.002331)(214.96)^{2}(364.43) \\
& =15410.35 \mathrm{LB}
\end{aligned}
$$

\begin{tabular}{|c|c|}
\hline $\begin{array}{l}\text { avid J. Seymour, Ltd. } \\
\text { laval Architects - Marine Consultants } \\
\text { ian Francisco } \quad \text { California } 94105\end{array}$ & $\begin{array}{ll}\text { Sheet: } & \text { DESIGN CALCULATION SHEET } \\
\text { Job No.: } & \text { Date: } \\
\text { By: } & \text { Sheck: } \\
\text { A-55 } & \text { Sheet } 9 \text { of }\end{array}$ \\
\hline
\end{tabular}

UNIT WEIGHT:

FROM DJS ESTPMAIE, WI $=35720 \mathrm{LB}$

$5 A Y, 4000015$ 
FOUNPATIOA FOBCES:
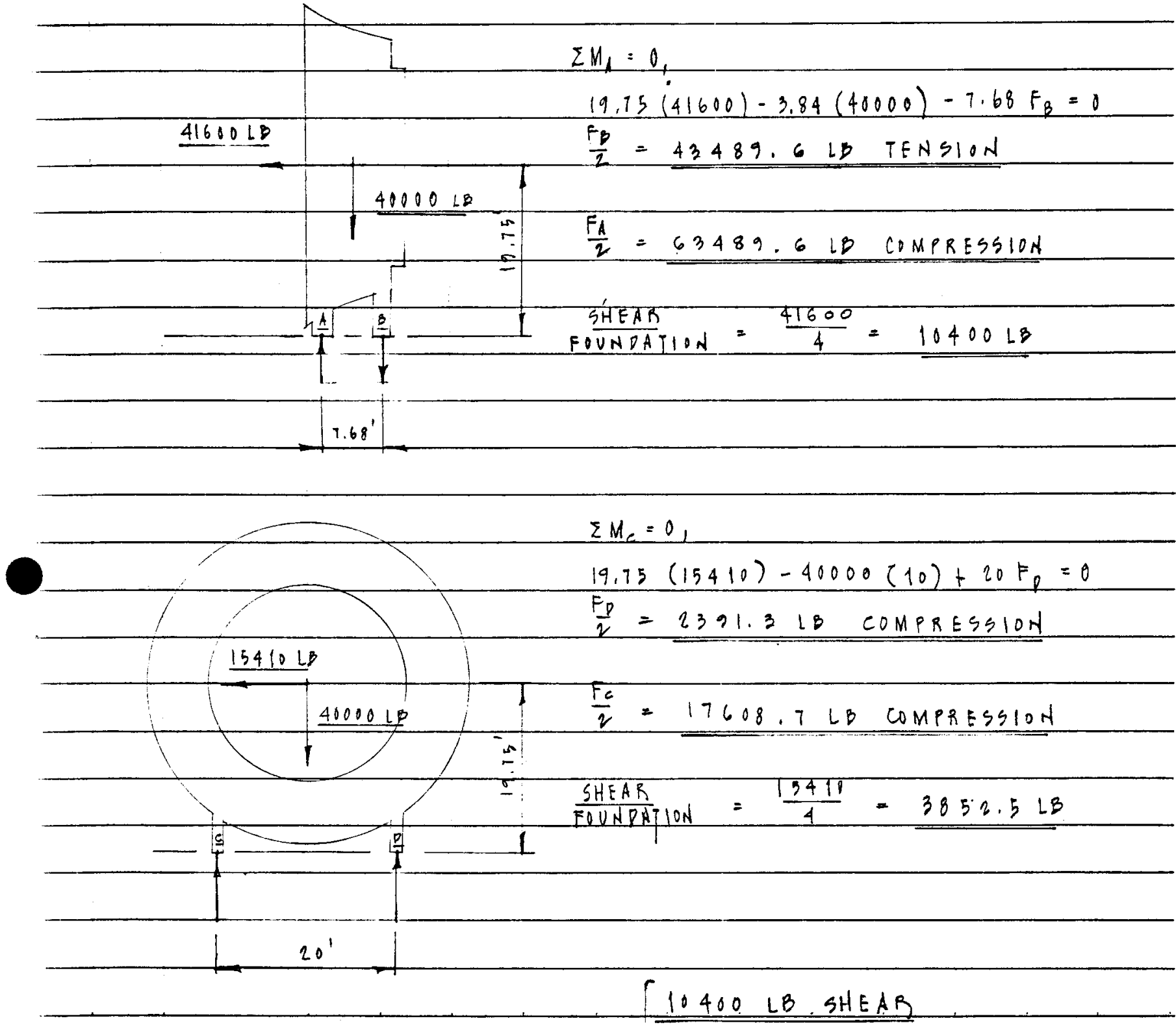

THEN, PESIGH FOUNDAIIONS FOR 43500 LB TENSION

663500 LB COMPRESSION

avid J. Seymour, Ltd. Javal Architects - Marine Consultants ian Francisco California 94105

\section{DESIGN CALCULATION SHEET}

Sheet:

Job No.: Date:

By:

Check:

Sheet 10 of 
PROPOSED COLUMH:

\begin{tabular}{|c|c|c|c|c|c|}
\hline $\begin{array}{llll}0 & 0 & 0 & 0\end{array}$ & & $f^{\prime} e$ & $=$ & 3000 & $P \leq I$ \\
\hline$\theta$ & 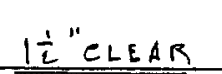 & $\dot{f}_{y}$ & $=$ & 50000 & PSI \\
\hline 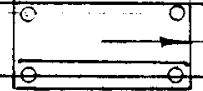 & & 2 & & & \\
\hline b o & \# REBAR & & & & \\
\hline$\theta \quad \div \quad 0$ & & & & & \\
\hline $\begin{array}{lllll}0 & 0 & 0 & 0 & 0\end{array}$ & & & & & \\
\hline
\end{tabular}

$$
\begin{aligned}
p_{1}^{\prime} & =185 f_{c}^{\prime}\left(A_{q}-A_{3 i}\right)+A_{s i} f_{y} \\
& =185(3000)[288-18(.31)]+18(.31)(50000) \\
& =999171 \text { LBg }
\end{aligned}
$$

$$
\begin{aligned}
P_{0} & =\phi P_{1}^{\prime} \\
& =0.70(999171)=699420 \text { LBG (PEPENDABLE VITINAIESIRSNGTH) }
\end{aligned}
$$

$288(.01)=2.88<5.58<23.04=288(.08)$

STEEL SHEAR AREK $=5.58 \mathrm{IN}^{2}=5.58(50000)=179,000133$




APPENDIX A-II

\section{$\underline{\text { References }}$}

1. SNAME Technical Research Report $R-14$ "References on Ferrocement in the Marine Environment."

2. "Ferrocement for Canadian Fishing Vessels" by Greenius and Smith, British Columbia Research Council, Vancouber, Canada. Jan., 1972.

3. Williamson, R.B. Prof. Structures and Materials Research, Dept. of Civil Engineering, Universityof California, Berkeley, CA. 1972.

4. Collins and Claman. "Ferrocement for Marine Applications - An Engineering Evaluation", MIT, March, 1969.

5. Shah, S.P. "Ferrocement as a New Engineering Material" Research Report 70-11, University of Chicago, December, 1970.

6. Walkus, I.R. (Lodz Tech. University, Poland) and T.G. Kowalski (Hong Kong University), "Ferrocement: A Survey", Concrete, London, Vo1. 5. No. 1, Feb., 1971.

7. Tuncreto and Haynes, "Flexural Strength of Ferrocement Panels", Tech Report (MS-359) NCEL, Port Hueneme, CA., 1971.

8. Claman, J.S. "Bending of Ferrocement Plates", M.S. Thesis, M.I.T., May, 1969.

9. Portland Cement Assoc., "State of the Art Report on Wear and Skid Resistance", Concrete Technology Section, Skokie, I11., 1971.

10. Kelly and Mouat, "Ferrocement as a Fishing Vessel.Construction Material", British Columbia Research ounci1, Vąncouver, 1968.

11. Camby, C.D., "Ferrocement with Particular Reference to Marine Applications", Dept. of Naval Architecture \& Marine Engịneering, Univ. of Michigan, 1968.

12. Ferrocon Industries, Vancouver, B.C. "Construction of Thin Shell Ferro-cement Barge", 1971. 


\section{APPENDIX B \\ PRELIMINARY STRESS ANALYSIS OF THREE DAWT \\ DESIGNS USING ALUMINUM CONSTRUCTION}

(Alum. Al loy 5083)

by G. Hudson

$12 / 79$ 
B-2 
CIRCULAR RING IOADS AND DISPILAEDUNS

Ioading Concition



Internal Loeds

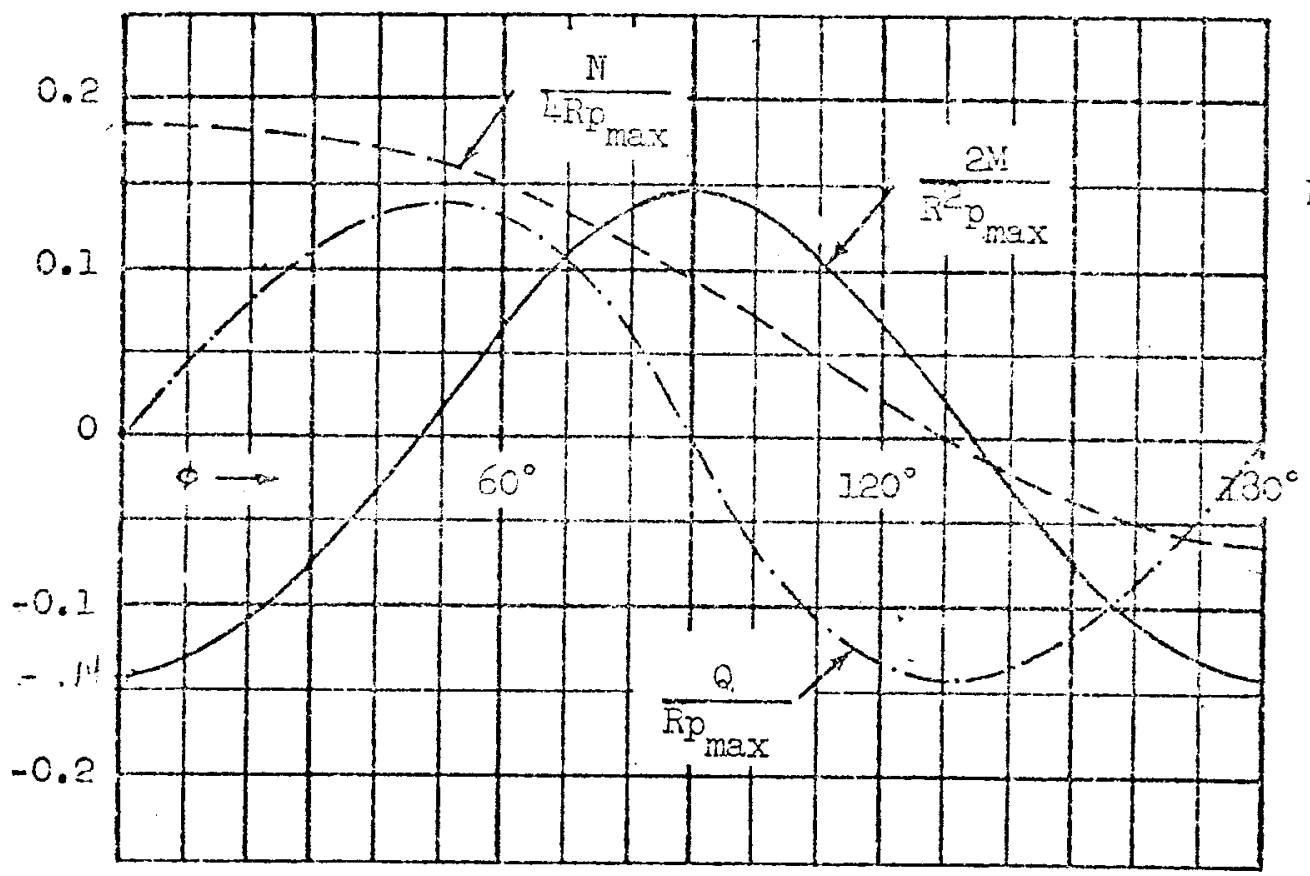

Sign Convention

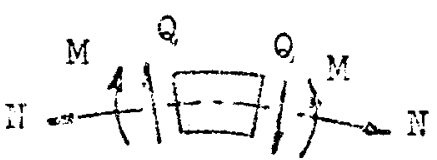

$M(\phi)=M(-\phi)$

$N(\phi)=N(-\phi)$

$Q(\phi)=-Q(-\phi)$

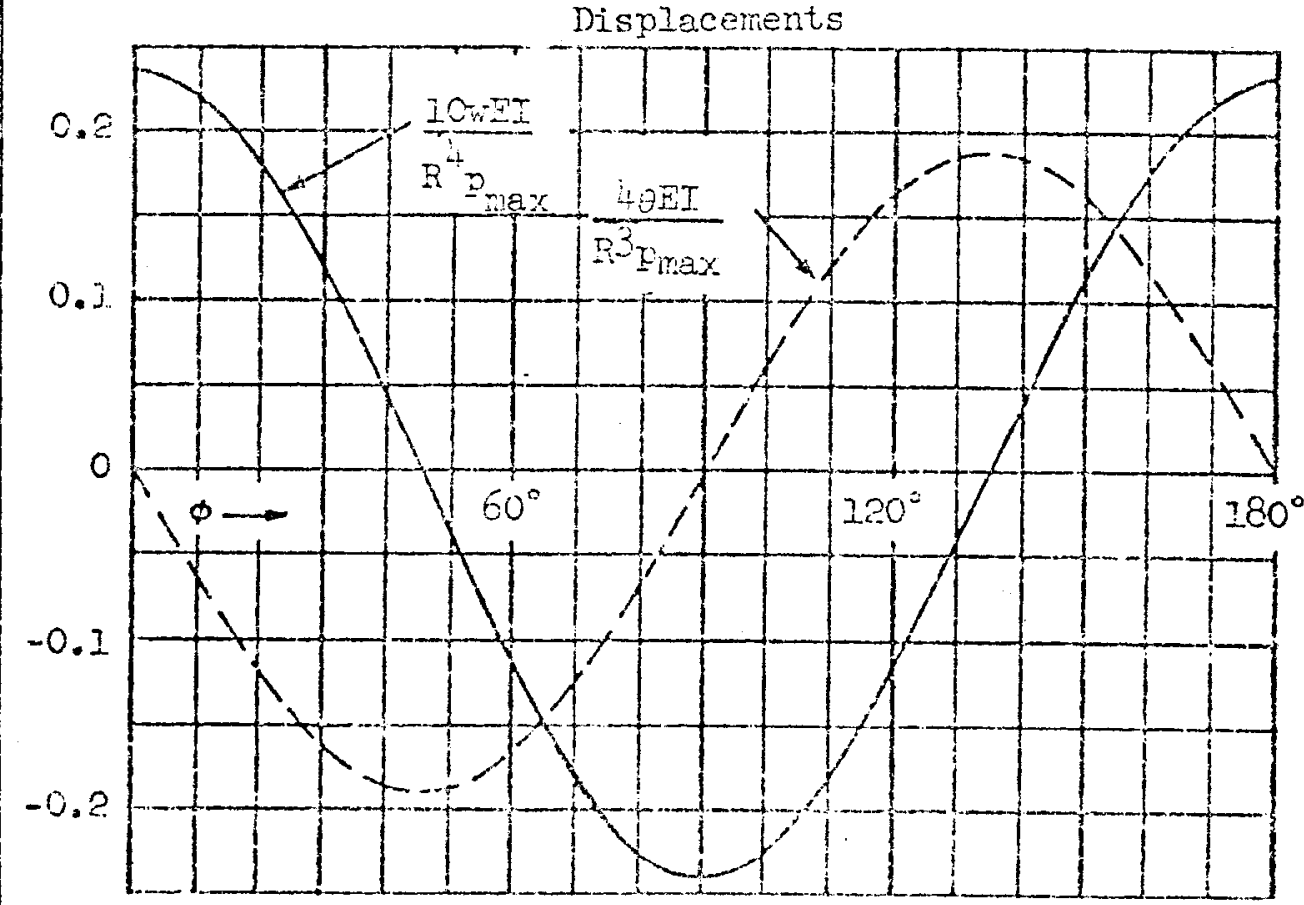

Sign Convention

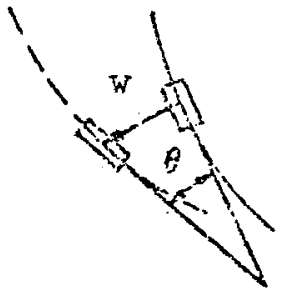

$w=+$ outward

$\theta=+$ counter

alocirwise

$v(\phi)=w(. . \phi)$

$\theta(\phi)=-\partial(-\phi)$ 
CIRCULAR RITIG IOADS AND DISFTACRATITS

Ioading Condition (19)



Internal Ioads



Sign Convention

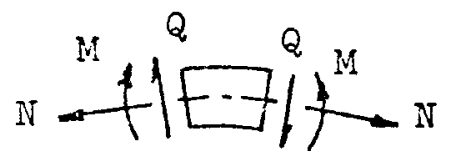
$M(\phi)=M(-\phi)=0$ $H(\phi)=M(-\phi)$ $Q(\phi)=Q(-\phi)=0$

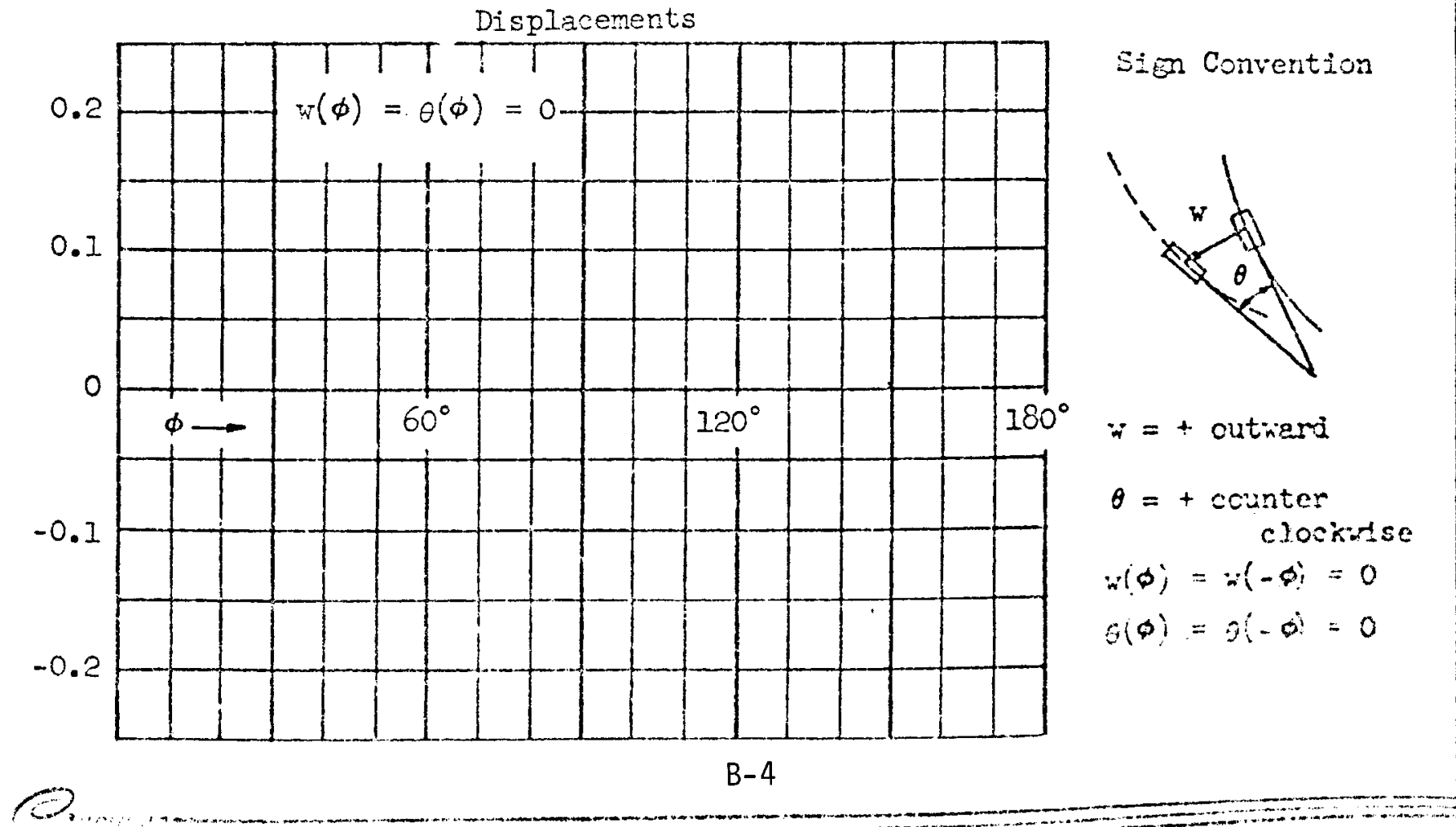




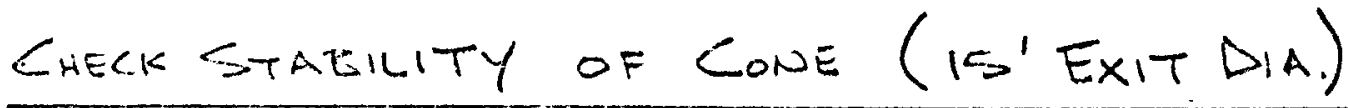

(EXIT DIA.)

$$
\begin{aligned}
t & =\bar{p}\left[\frac{\left(\frac{L}{\bar{P}}\right)\left(P_{c r}\right)}{(0.92)(E)(\gamma)}\right]^{2 / 5} \\
& =81.5\left[\frac{\left(\frac{33.5}{81.5}\right)(.3375)}{(.92)(10.2)\left(10^{6}\right)(.75)}\right]^{2 / 5} \\
& =.067(.075)
\end{aligned}
$$

$$
\begin{aligned}
& L=23.5 " \text { (SLAIT LENGATH) } \\
& F=81.5^{\prime \prime} \\
& P_{C r}=.3375 \text { P.S.1. (P2) } \\
& \gamma=.75 \\
& E=(10.2)\left(10^{\circ}\right) \\
& t=\text { THIKNDESS OF SHELL }
\end{aligned}
$$

(ENTRY DIA.)

$$
\begin{aligned}
t & =63.5\left[\frac{\left(\frac{33.5}{6.5}\right)(.0125)}{(.92)(10.2)\left(10^{6}\right)(.75)}\right]^{2 / 5} \quad \begin{array}{l}
L=33.5^{\prime \prime} \\
P=6.50 \\
p_{c r}=.61250 .11\left(P_{1}\right)
\end{array} \\
& =.0737^{11}(.075)
\end{aligned}
$$

REFERENCE:

MASA Report "Bucklmag of Thin.halled Truncated CONES." (NASA SF-8019), SEPT.1968

SYMBOLS

$$
\begin{aligned}
& \angle=\text { slant length of cone } \\
& \bar{p}=\text { average radius of curvature of cone } \\
& P_{c r}=\text { critical an al lood on cone }
\end{aligned}
$$

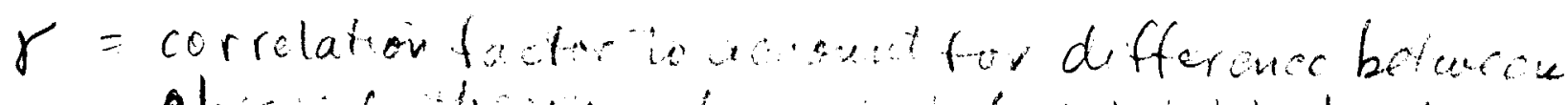

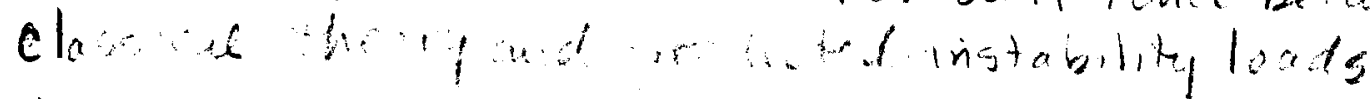

$$
\begin{aligned}
& E=\text { Young's moducis }
\end{aligned}
$$




CHECK IS I WTERHAL DIAMETER FRAME

Page 1

$p=15 \times .28=4.2 \mathrm{HS}$ \% InCH on REAR Frame

$$
P=P_{\max } \cos \phi
$$

$$
R=(7.5)(12)=90 \text { inches }
$$

$P$ is max! when $\phi$ is $0^{\circ}$

$$
\begin{aligned}
P_{\text {max }}= & (A .2) \\
M_{\text {Bending }} & =\frac{\left(R^{2}\right)\left(P_{\text {max }}\right)(.14)}{2} \\
& =\frac{\left(90^{2}\right)(4.2)(.14)}{2} \\
& =\frac{2381 \text { Inch H.S. }}{}
\end{aligned}
$$

For Equal Ami opposite positive pressure on frame,

$$
\begin{aligned}
\text { MAXIMA BENDING MOMENT } & =(2381)(2) \\
& =4762 \mathrm{ln} \angle H \mathrm{HBS}
\end{aligned}
$$

For Equal Ant dp paste pressure the Shear from Shell to frame is cancelled.

axial load on frame, ht $\phi=0^{\circ}$

$$
\begin{aligned}
N & =(.18)(4)(R)\left(P_{\text {MAX }}\right) \\
& =(.18)(4)(90)(4.2) \\
& =272.16168
\end{aligned}
$$

ThIS IS DOUELED For EquAL And OPPOSITE pressures,

$$
\begin{aligned}
& \text { MAXimuM AXIAL LOAD }=(272)(2) \\
&=544148 \\
& \text { B-6 }
\end{aligned}
$$


Axial load on frame At $\phi=180^{\circ}$ :

$$
\begin{aligned}
N & =(.065)(4)(90)(4.2) \\
& =98.28168
\end{aligned}
$$

Resultant Axial LOAd $=544-98=446 \mathrm{lt}-3$.

Load on frame from equal and opposite, positive and Negative Pressures:

ANil LOAD FOR $\phi=90^{\circ}=0$

This Position CoIncIDES WITH $\phi=0^{\circ}$ FOR EquAl AND opposite positive pressures therefore There will Be No Apaitiomal loads To Consider At The point of Maximum Loading:-

Design e loads on frame At $\phi=0^{\circ}$ Are, BIM. $=4762$ INCH LBS (TENSION OUTER FILER) AXIAL LOAD $=446110$. (TENSION)

WIDTH OF FRAME $=.75$ "

SECTION MODULUS $=\frac{b^{2} t}{6}$

Total Stress in frame :-

$$
\begin{aligned}
& =\frac{6 M}{b^{2} t} \pm \frac{P}{A} \\
& =\frac{(6)(4762)}{(2)^{2}(.5)} \pm \frac{446}{(2)(.5)} \\
& =14732 \text { TENSION AND } 13840 \text { COMPRESSION }
\end{aligned}
$$

margin of SAFETY $=\frac{22000}{14732}-1_{\text {B-7 }}= \pm .54$ (AmpLE) 
GHECR $8.91^{\prime}$ DIA. SHROUT

For SEVEN LONGEFONS, $2 \alpha=\frac{360}{7}, \alpha=25.714^{\circ}$

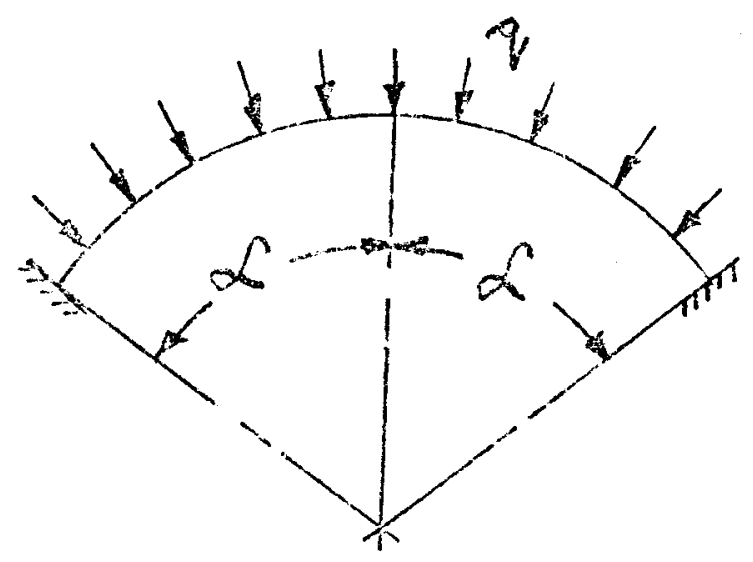

$$
\begin{gathered}
q_{\text {cr }}=\frac{E I}{R^{3}}\left(k^{2}-1\right) \\
k \operatorname{Tan} \alpha \cot k \alpha=1 \\
\text { For } \alpha=25.714^{\circ}, \text { USE } k=8.621
\end{gathered}
$$

OR U UNT HATH:

$$
\begin{aligned}
q, a & =\frac{E I}{R^{2}}\left(K^{2}-1\right) \\
& =\frac{(10.2)\left(10^{6}\right)(.187)^{3}}{(12)(53.46)^{3}}\left(8.621^{2}-1\right) \\
& =2.67 \text { P.5.1. }
\end{aligned}
$$

$$
\begin{aligned}
& \text { APPGE PEESSURE }=.30 \text { P.S.l. } \\
& \text { M.S. }=\frac{2.67}{.30}-1=+7.9 \text { (AMRE) }
\end{aligned}
$$

B-9 
CHECK BENDING STRESS IN 31.0 "DA. SUPPORT COLUMN

$$
\begin{aligned}
I & =\pi R^{3} t \\
& =\pi(15.5)^{3}(.125) \\
& =1462 \text { ACHES }^{4}
\end{aligned}
$$

$$
\begin{aligned}
& t= \text { ThicknesS } \\
& R= \text { RADIUS of } \\
& \text { COLUMN }
\end{aligned}
$$

Bending moment at base of colum i:

$$
\begin{aligned}
& =(5776)(206) \\
& =(1.19)\left(10^{6}\right) 10 \mathrm{LH} 165
\end{aligned}
$$

$$
206^{\prime \prime}=\begin{aligned}
& € \text { Thrust On } \\
& \text { CONE TO SASE }
\end{aligned}
$$

STRESS FROM BENDING:

$$
\begin{aligned}
& =\frac{(1.19)\left(10^{\circ}\right)(15.5)}{1462} \\
& =12632 P .5 .1
\end{aligned}
$$

$$
\begin{aligned}
\text { MAX M } & \text { DEFLECTION: } \\
& =\frac{W L^{3}}{3 E I} \\
& =\frac{(5776)(206)^{3}}{(3)(10.2)\left(10^{6}\right)(1462)} \\
& =1.131 \\
M . S . & =\frac{22000-1}{12632} \\
& =+.74 \text { (AMPLE) }
\end{aligned}
$$

B-10 
Lherk bearing Fressure for 15.0 dia. Cone

DRAL FORLE $=5779 \mathrm{lbS}$.

overturning Moment At Bearing face i-

$$
\begin{aligned}
& =(5779)(867)=501039 \text { INCH } 168 . \\
& \text { DIA. OF EEARING }=33^{11} \\
& \text { CoMPONERTS }=\frac{501039}{33}=\frac{15183168}{} \\
& \text { BEARING AREA }=(1.1)(33)(3.14159)=114.0454 .105 . \\
& \text { AVERAGE BEARING FRESSUEE FROM WEIGRT }=\frac{2400}{114.04} \\
& \text { OF DIFFUSER }
\end{aligned}
$$

For A $42^{\circ}$ center Angle Anas A 16.5" Fadins,

$$
\begin{aligned}
& \text { ChORAAL HEIGHT }=(16.5)(.06642)=1.096 " \\
& \text { EFFECTIVE AREA }=\text { CMORDAL LENGTH x WIBTH }
\end{aligned}
$$
OF BEARIA

$$
13.0 \quad \text { SAP. } \mathrm{N} C H E S
$$

$$
\begin{aligned}
\text { Total Eearing Pressure } & =\frac{15183}{13.0}+21.0 \\
\text { (P.S.1.) } & =1189 \text { F.S.1. }
\end{aligned}
$$

NOTE:- TMS IS MAXIMUM FRESSURE ON BEAFING WHEN TUREINE 15 OPERPTING WITH A WIND VELOCTIY OF TS M.P.H. B-11 
WEIGHT SUMMARY FOR IS' EXIT DIR. CONE

$$
\begin{aligned}
& \text { SURFeR AREA OF CONE }=1.5708 S(D+d) \text { WHERE S = SLANT } \\
& \text { LEngth } \\
& D=\text { LARGE DIs } \\
& \text { WEIGHT OF CONE }=(1.5708)(180+120)(67.5)(.075)(.10) \quad d=\operatorname{SMALL} \text { IA } \\
& =2391 \mathrm{lis} \text {. }
\end{aligned}
$$

WEIGHT OF $15^{\prime}$ DEA. RING $\left(X-\right.$ SECTION $\left.=2.0^{\prime \prime} \times 0.5^{\prime \prime}\right)$

$$
\begin{aligned}
& =.7854\left(184^{2}-180^{2}\right)(.5)(.1) \\
& =57165
\end{aligned}
$$

WEIGH OF MIRING $\left(x-\right.$ SECTION $\left.=4.0^{\prime \prime} \times .5^{\circ}\right)$

$$
\begin{aligned}
& =.7854\left(155^{2}-147^{2}\right)(.5)(.1) \\
& =9516.8 .
\end{aligned}
$$

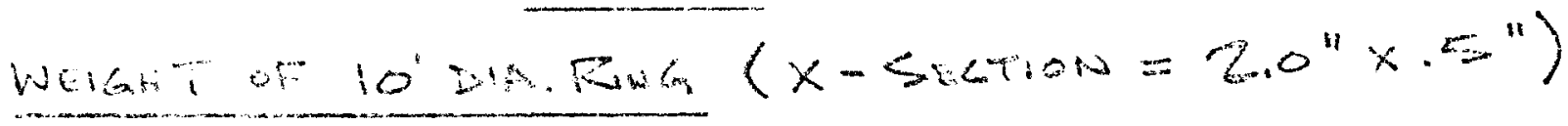

$$
\begin{aligned}
& =.7854\left(124^{2}-120^{2}\right)(.5)(.1) \\
& =38165
\end{aligned}
$$

WEIGHT OF SHROUD (107" "DIA. $\times .187 "$ THICK $) \times 36 "$ WIDE

$$
\begin{aligned}
& =.7854\left(107.38^{2}-107^{2}\right)(36)(.1) \\
& =230115
\end{aligned}
$$

WEIGHT OF TUBES (2.5\% \% $\left.10.125^{\prime \prime} T_{H K K}\right)$

$$
\begin{aligned}
\text { TOTAL LENGTH OF TOES } & =3(63+54+38) \\
& =480^{11} \\
\text { WEIGHT } & =480\left(2.5^{2}-2.25^{2}\right)(.1)(.7854) \\
& =45148 .
\end{aligned}
$$

WEIGHT OF FiTTINGS (ENDS OF TOES)

$$
\begin{aligned}
& =(.7854)(2.25)^{2}(5)(.1)(18) \\
& =36110 .
\end{aligned}
$$

B- 12 
WeIGHT of Column $(-35)$

$$
\begin{aligned}
& =(\pi)(31)(.125)(.1)(21) \\
& =25165 .
\end{aligned}
$$

WEIGHT OF RINGS (STR)

$$
\begin{aligned}
& =(\pi)(31)(2.5)^{2}(.3) \\
& =182.165 .
\end{aligned}
$$

WEIGHT OF BULKHEADS (STR)

$$
\begin{aligned}
& =(2)(.187)(\pi)(15.5)^{2}(.3) \\
& =28 \mathrm{ks} .
\end{aligned}
$$

WEIGHT OF CLAMP (BTL)

$$
\begin{aligned}
& =(\pi)(33)(3.25)(1.5)(.3) \\
& =152105 .
\end{aligned}
$$

Weight of $\operatorname{cotum}(-31)$

$$
\begin{aligned}
& =(.125)(123)(\pi)(31)(.1) \\
& =150 \mathrm{bs}
\end{aligned}
$$

WEIGHT of GUSSETS

$$
\begin{aligned}
& =(.75)(24)(15)(.1) \\
& =27 \mathrm{lbs}
\end{aligned}
$$

WEIGHT OF LONGERON

$$
\begin{aligned}
& =(8)(70)(.5)(.1)(7) \\
& =196 \mathrm{lbs}
\end{aligned}
$$

WEIGHT OF ADAPTORS $(-49)$ STEEL)

$$
\begin{aligned}
& =(\pi)(31)(.125)(.3)(4.0) \\
& =14.6168 . \times 2=29.2168 .
\end{aligned}
$$

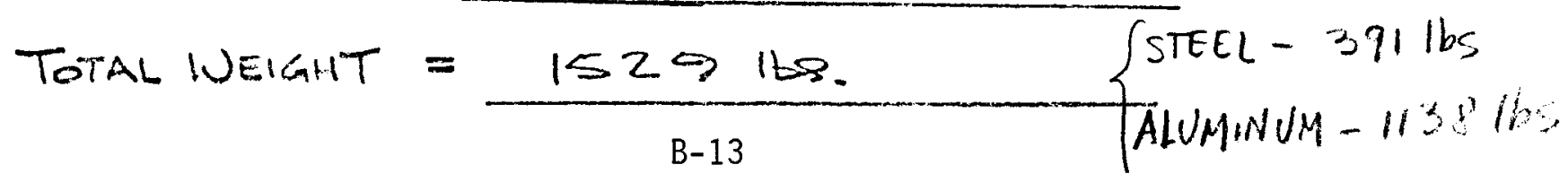


. CHECK STABMTTY of SHELL (37.5' Exit Da.)

REF: BUCKLING OF THWN-WALLED TRUNCATED CONES. (NASA SP-8019

$$
\begin{aligned}
& \text { (EXIT DIs.) } \\
& t=\bar{p}\left[\frac{(\underline{L})(p<r)}{(0.92)(E)(\gamma)}\right]^{2 / 5} \\
& \bar{p}=\text { AVERAGE RADIUS } \\
& L=\text { SLANT LENGTH } \\
& =205\left[\frac{\left(\frac{87}{205}\right)(.3375)}{(.92)(10.2)\left(10^{6}\right)(.75}\right]^{2 / 5} \\
& P_{\angle r}=\text { CRiTical BuCKLINg } \\
& \text { pressure } \\
& \gamma=.75 \\
& E=(10.2)\left(10^{6}\right) \\
& =.77(.180) \\
& t=\text { THICKNESS OF SHELl }
\end{aligned}
$$

ENTRY DEA.

$$
\begin{aligned}
t & =158\left[\frac{\left(\frac{80}{158}\right)(.6125)}{(.92)(10.2)\left(10^{6}\right)(.75)}\right]^{2 / 5} \\
& =.180\left(.190^{11}\right)
\end{aligned}
$$

B-14 
CHECK 37.5 DIR. INSIDE RING.

$p_{\text {MAX }}=(38)(.28)=10.64$ bS/InGH ON REAR Frame.

$$
\begin{aligned}
M & =\frac{(228)^{2}(10.64)(.14)}{2} \\
& =\frac{38718 \mathrm{iNCH} 165}{}
\end{aligned}
$$

$$
R=228^{\prime \prime}
$$

For equal And opposite pressures on frame,

$$
\begin{aligned}
\text { Maximum Bending Moment } & =(38718)(2) \\
& =774361 \mathrm{~W} 24 \text { ib s }
\end{aligned}
$$

Shear from shell to frame is cancelled

Axial loAD ON FRAME:

$$
\begin{aligned}
N & =(.115)(4)(228)(10.64) \\
& =116163 .
\end{aligned}
$$

For equal and opposite positive pressures on frame THIS IS DUELED,

$$
\begin{aligned}
\text { Maximum is } & =(116)(2) \\
& =22321 \mathrm{bs}
\end{aligned}
$$

Total stress in fizame:-

$$
\text { (P.S.I.) }
$$

$$
=\frac{(6)(77436)}{(1)(5)^{2}} \pm \frac{2232}{(1)(5)}
$$

$=19030$ Tension And 18140 COMPRESSION

$$
\text { MARGIN OF SAFETy }=\frac{22000}{19030}-1=+.156 \text { (AMPLE) }
$$


CHELK 23.28'DIA. SHIROUD FOR BUCKLING:-

For seven Longezons, $2 \alpha=\frac{360}{7}, \alpha^{\prime}=25.714^{\circ}$

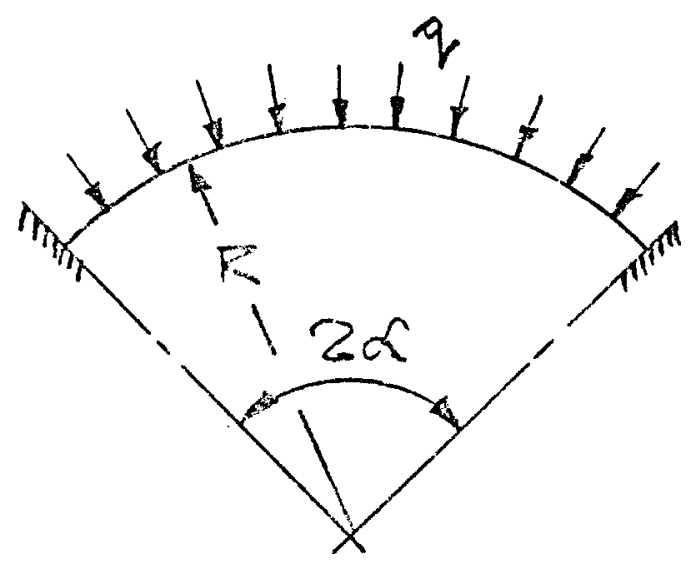

$$
\begin{aligned}
& q_{\text {Cr }}=\frac{E I}{R^{3}}\left(k^{2}-1\right) \\
& U_{S E} K=8.621 \\
& R=133.68^{\prime \prime}
\end{aligned}
$$

FOR UNIT WIDTH:

$$
\begin{aligned}
q_{\text {cr }} & =\frac{E t^{3}}{12 R^{3}}\left(k^{2}-1\right) \\
& =\frac{(10.2)\left(10^{6}\right)(.375)^{3}}{(12)(133.68)^{3}}\left(8.621^{2}-1\right) \\
& =1.375 \text { P.S.1. }
\end{aligned}
$$

APPLIED PEESSURE, $q=.30 F: S .1$.

$$
\begin{aligned}
\text { M.S. } & =\frac{1.375}{.30}-1 \\
& = \pm 3.58 \text { (AMPLE) }
\end{aligned}
$$

B-16 
EHECK EERDING STRESS IN 72.5" DIA. SUPPOET COLUMN

$$
\begin{aligned}
I & =\pi R^{3} t \\
& =\pi(36.3)^{3}(.180) \\
& =27048 \text { NCMES } 4
\end{aligned}
$$

$$
\begin{aligned}
& t=.180^{\prime \prime} \\
& R=36.3 "
\end{aligned}
$$

Bendincm Moment at base of Columa:

$$
\begin{aligned}
& =(36110)(336) \\
& =(12.133)\left(10^{6}\right)
\end{aligned}
$$

STRESS FROM BENDING:

$$
\begin{aligned}
& =\frac{(12.133)\left(10^{6}\right)(36.3)}{27048} \\
& =16283 \text { P. } 5.1 .
\end{aligned}
$$

MAXM. DEFLECTION:

$$
\begin{aligned}
& =\frac{W L^{3}}{3 E I} \\
& =\frac{(36110)(336)^{3}}{(3)(10.2)(27048)\left(10^{6}\right)} \\
& =1.65^{11}
\end{aligned}
$$

$$
\begin{aligned}
\text { M.S. (STRESS) } & \\
= & \frac{22000}{16283}-1 \\
= & \pm .3=\text { (AMPLE) }
\end{aligned}
$$

R- 17 


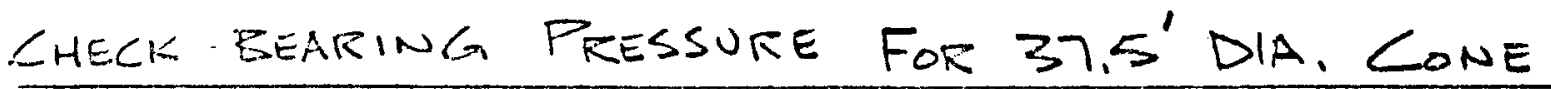

$$
\begin{aligned}
& \text { DRAG FORGE }=36,110 \\
& \text { WEIGHT }=13,500 \text { ILS. } \\
& \text { OVERTURNING MOMENT AT BEARING FACE :- } \\
& \quad=(36,110)(214)=(7.72754)\left(10^{6}\right) \text { INCH HS S. }
\end{aligned}
$$

DA. OF BEARING $=76^{\prime \prime}$

$$
\begin{aligned}
\text { Components } & =\frac{(7.72754)\left(10^{6}\right)}{76}=(.10168)\left(10^{6}\right) \mathrm{HSS} . \\
\text { BeARHO AREA } & =(2.0)(76)(3.14159)=525.27 \text { SQ. INS }
\end{aligned}
$$



$$
\begin{aligned}
& =25.7 \text { P.5.1. }
\end{aligned}
$$

For $A 39^{\circ}$ Center Angle And $A \geq 8.0^{\circ}$ Radius;

$$
\text { ChORDAL HEIGHT }=(38)(.05736)=2.13^{\prime \prime}
$$

EFFEctive AREA = CHORDAL LENGTH $\times$ WIDTH OF SEARING

$$
=2.18 \times 25.37=55.31 \text { Sa. InCHES }
$$

$$
\begin{aligned}
\text { Total Bearing Pressure } & =\frac{(-102)\left(10^{6}\right)}{55.31}+25.7 \\
& =1870 \text { P.5.1. }
\end{aligned}
$$

Note: This is Maximum Pressure on Bearing WHEN TUEBSHE IS OPERATING WITH A WIND VELOCITY OF 75 M.P.H.

B-18 
WEIGHT SUMMIARY FOR 37.5' EXIT DIA. CONE

WEIGHT OF CONE

$$
\begin{aligned}
& =(1.5708)(450+300)(.1)(.185)(85) \\
& =1853 \mathrm{ks}
\end{aligned}
$$

WEIGHT OF $37.5^{\prime}$. DA. RING (X-SECT. ST" $\left.\times 1.0^{\prime \prime}\right)$

$$
\begin{aligned}
& =.7854\left(460^{2}-450^{2}\right)(i)(.1) \\
& =714168 .
\end{aligned}
$$

WEIGHT OF MID RING $\left(x-\right.$ SECT, $\left.11.0^{\prime \prime} \times 1.0^{\prime \prime}\right)$

$$
\begin{aligned}
& =.7854\left(388^{2}-366^{2}\right)(1)(.1) \\
& =1303165
\end{aligned}
$$

WEIGHT OF $2 S^{\prime}$ DIA.RING $\left(X-\right.$ SECT $\left.5.0^{\prime \prime} \times 1.0^{\prime \prime}\right)$

$$
\begin{aligned}
& =.7854\left(310^{2}-300^{2}\right)(1)(.1) \\
& =479165 .
\end{aligned}
$$

WEIGHT OF LONGERON

$$
\begin{aligned}
& =(24)(195)(7)(1)(.1) \\
& =3276 \mathrm{lbs} .
\end{aligned}
$$

WEIGHT OF SHROUD

$$
\begin{aligned}
& =(36)(840)(.375)(.1) \\
& =1134168 .
\end{aligned}
$$

WEIGHT OF CLAMP

$$
\begin{aligned}
& =(80)(\pi)(6.5)(3)(.3) \\
& =1470 \mathrm{lbs} .
\end{aligned}
$$

WEIGHT OF TUBES

$$
\begin{aligned}
& \text { TOTAL LENGTH OF TUbES }=3(104+147+185) \\
& =1308^{\prime \prime} \\
& X \text { - SECT. AREA }=.7854\left(4.0^{2}-3.5^{2}\right) \\
& =2.945 \text { Ser. INS. }
\end{aligned}
$$




$$
\begin{aligned}
\text { WHGHT of TUEES } & =(1308)(2.945)(.1) \\
& =385 \mathbb{E S} .
\end{aligned}
$$

I What of FITTINGS

$$
\begin{gathered}
(.7854)(3.5)^{2}(10)(18)(.1) \\
=173165 .
\end{gathered}
$$

Whlant of Colume $(-35)$

$$
\begin{aligned}
& =(.18)(49)(\pi)(72.4)(.1) \\
& =201165 .
\end{aligned}
$$

Whate of Rincas

$$
\begin{aligned}
& =(\pi)(72.4)(4.75)(4.75)(.3) \\
& =1539.5 .
\end{aligned}
$$

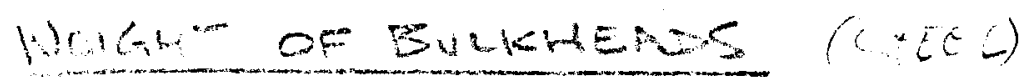

$$
\begin{aligned}
& =(2)(\pi)(34.8)^{2}(.50)(.3) \\
& =1141 \mathrm{bs} .
\end{aligned}
$$

Walat of COLUMN $(-31)$

$$
\begin{aligned}
& =(.18)(132)(\pi)(72.4)(.1) \\
& =54011.5 .
\end{aligned}
$$

WEIG- OF GUSSETS

$$
\begin{aligned}
& =(1.5)(41)(36)(.1) \\
& =221 \mathrm{ks}
\end{aligned}
$$

$$
\begin{aligned}
& \text { WHGH of ADAPTOR }(-49) \text { (2 PRECS) (STIL) } \\
& =(\pi)(72.4)(25)(6.6)(2)(.3) \\
& =225 \mathrm{bs}
\end{aligned}
$$

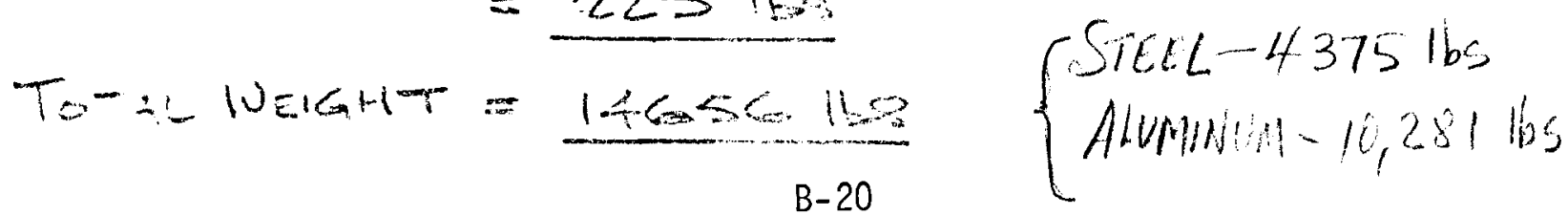


Cheik STAELLITY of CONE (60' EXTT DIA.) (EXT DIA)

$$
\begin{aligned}
t & =\bar{p}\left[\frac{\left(\frac{L}{\bar{P}}\right)\left(p_{c r}\right)}{(0.92)(E)(\gamma)}\right]^{2 / 5} \\
& =328.5\left[\frac{\left(\frac{135}{328.5}\right)(3575)}{(0.92)(10.2)\left(10^{6}\right)(.75)}\right]^{2 / 5} \\
& =.272(.280)
\end{aligned}
$$

$$
\begin{aligned}
& L=135^{\prime \prime} \\
& F=328.5^{\prime \prime} \\
& P_{C r}=.3375 \text { P.S.1. } \\
& \gamma=.75 \\
& E=(10.2)\left(10^{6}\right) \\
& t=T_{\text {HICKNESS OF SHELL }}
\end{aligned}
$$

ENTRY DIA.

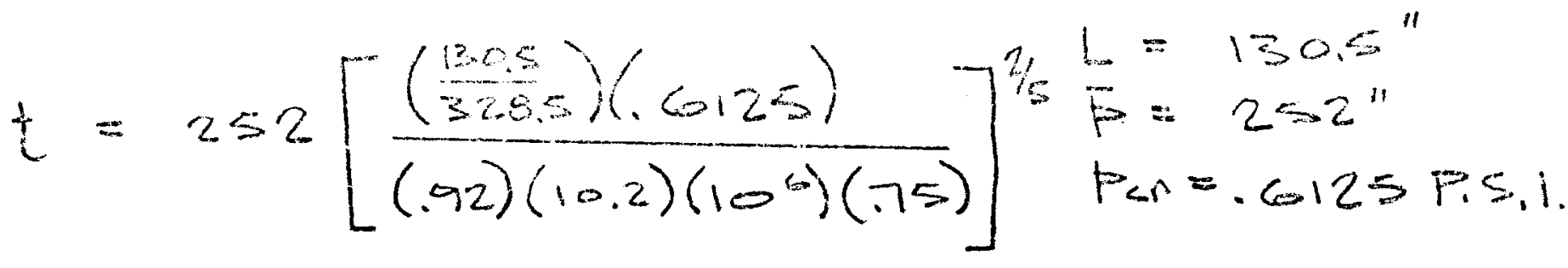

$$
\begin{aligned}
& =.261(.280)
\end{aligned}
$$

B-21 


$$
\begin{aligned}
P_{\text {MAX }} & =(60)(.28)=16.8 \mathrm{lbS} \text { INCH ON REAR FRAME } \\
M & =\frac{(372)^{2}(16.8)(.14)}{2} \quad R=372^{\mathrm{N}} \\
& =162739 \mathrm{lnCH} \mathrm{lbS}
\end{aligned}
$$

For equal and opposite positive pressures on frame,

$$
\begin{aligned}
\text { MAXIMUM LENDINGS MOMENT } & =(162739)(2) \\
& =325478 \text { in } \angle H 1 H S
\end{aligned}
$$

Axial load on frame at $\phi=0^{\circ}$

$$
\begin{aligned}
N & =(.115)(4)(372)(16.8) \\
& =2875145
\end{aligned}
$$

THS Is DOUSLED For Equal And OPPosite Positive pressures

$$
\begin{aligned}
\text { MAXimum AXIAL LOAD } & =(2875)(2) \\
& =5750 \mathrm{BS} .
\end{aligned}
$$

shear from sahel to frame is cancelled.

Total Stress in frame:-

$$
\begin{aligned}
(P .5 .1 .) & =\frac{(6)(325418)}{(1.5)(9)^{2}} \pm \frac{5750}{(1.5)(9)}
\end{aligned}
$$

$=16500$ TENSION AND 15650 COMPRESSION

$$
\begin{aligned}
\text { MARGin of SAFETY } & =\frac{22000}{16500}-1 \\
\text { B-22 } & = \pm .33 \text { (AMPLE) }
\end{aligned}
$$




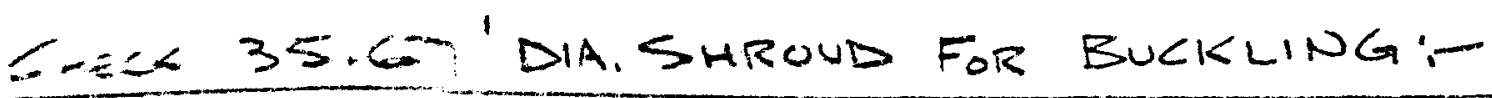

For SEVEN LONGERONS, $2 \alpha=\frac{360}{7}, \alpha=25.714^{\circ}$

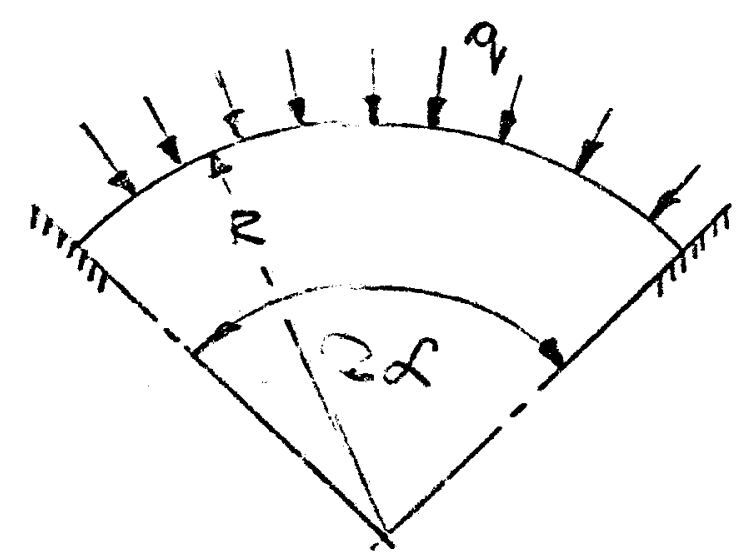

$$
\begin{aligned}
& q_{C R}=\frac{E I}{R^{3}}\left(k^{2}-1\right) \\
& U S E K=8.621 \\
& R=214^{\prime \prime}
\end{aligned}
$$

FOR UNT WIDTH:

$$
\begin{aligned}
q_{c r} & =\frac{E t^{3}}{12 R^{3}}\left(k^{2}-1\right) \\
& =\frac{(10.2)\left(10^{6}\right)(.625)^{3}}{(12)(214)^{3}}\left(8.621^{2}-1\right) \\
& =1.55 \text { P.S.1. }
\end{aligned}
$$

$$
\begin{aligned}
& \text { APPLIED PRESSURE, } q=.30 \text { P.S.1. } \\
& \begin{aligned}
\text { M.S. } & =\frac{1.55}{.30}-1 \\
& =+4.18 \text { (AMPLE) }
\end{aligned}
\end{aligned}
$$

B-23 
CHEK RENEANG STRESS IN $119.4 "$ DIA. SUPPORT COLUMN

$$
\begin{aligned}
I & =\pi R^{3} t \\
& =(\pi)(54.1)^{3}(.280) \\
& =187168 \mathrm{is} 4
\end{aligned}
$$

$$
\begin{aligned}
& t=.280^{\prime \prime} \\
& R=59.7 " \\
& L=469.5^{\prime \prime}
\end{aligned}
$$

BENDIRG MOMENT RT BASE OF COLUMN:

$$
\begin{aligned}
& =(40.5)(0.2442) \\
& =(20.4)(109) \text { iNCH 160. }
\end{aligned}
$$

STRECS FROA1 BENDINAS:

$$
\begin{aligned}
& =\frac{(15.4)\left(10^{6}\right)(-9.7)}{187168} \\
& =\text { Beaspis. } \\
& \text { H.S. }=\frac{22000}{13844}-1 \\
& =+\operatorname{sis}\left(A M P_{6}\right) \\
& \text { MAX MEFLECTION: } \\
& =\frac{W L^{3}}{3 E I} \\
& =\frac{(92442)(469.5)^{3}}{(3)(10.2)\left(10^{6}\right)(187168)} \\
& =1.67 "
\end{aligned}
$$

B-24 


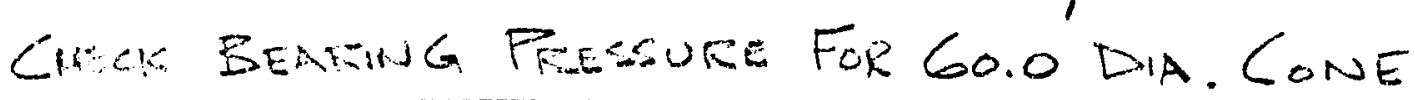

$$
\begin{aligned}
& \text { WM FORcE }=94,4.42112 \text {. } \\
& \text { WEAHT = 60, ora } \mathrm{HS} \text {. }
\end{aligned}
$$

overturning moment at bearing face:-

$$
=(92,442)(332.1)=(3.07)(107) 1 \mathrm{~N} C H \mathrm{~B} P \text {. }
$$

Di. OF BRG, $=100.5^{\prime \prime}$

$$
\begin{aligned}
& \text { Components }=\frac{(3.07)(107)}{100.5}=(.3055)\left(10^{6}\right) \mathrm{lbs} . \\
& \text { EEARAAREA }=(3.4)(3.14159)(100.5)=1073.5<0.105 . \\
& =\frac{60,000}{1075.5} \\
& =56 . \quad 1 \times 5.1
\end{aligned}
$$

For A $42^{\circ}$ included Angle And A $42^{\circ}$ Center Angle:-

$$
\begin{aligned}
& \text { Goral Heat }=(50,25)(.066+2)=3.338^{\circ} \\
& \text { Chordal Length }=(50.25)(.71674)=36.02^{\prime \prime} \\
& \text { EFFECTIVE hEARING AREA }=(36.02) \times(3.4) \\
& =122.4650 .10 .
\end{aligned}
$$

$$
\begin{aligned}
\text { Total Bearing pRessure } & =\frac{(3055)\left(10^{6}\right)}{122.46}+56 . \\
& =2551 \text { F } 1.1 .
\end{aligned}
$$

Note: This Is MaximuM Bearing pressure When TuRenne IS OPERATING WITH A 7STMPH. NINE B-25 
WEGGH SUMMARY FOR 60.0 DIA. EXIT CONE

WeVHT of CONE

$$
\begin{aligned}
& =(1.5708)(276)(720+480)(.1)(.28) \\
& =14567 \quad 1=5 .
\end{aligned}
$$

WEIGHT OF GO' DIA. RING

$$
\begin{aligned}
& =.7854\left(738^{2}-720^{2}\right)(1.5)(.1) \\
& =3002165
\end{aligned}
$$

WuET of Mis Rina

$$
\begin{aligned}
& =.7854\left(622^{2}-588^{2}\right)(1.5)(.1) \\
& =4846 \mathrm{Bs} .
\end{aligned}
$$

WElGHT of $40^{\circ}$ DIA. Fing

$$
\begin{aligned}
& =.7054\left(408^{2}-480^{2}\right)(1.5)(.1) \\
& =2074165 .
\end{aligned}
$$

WEIEHT OF LONGERONS

$$
\begin{aligned}
& =(37.5)(300)(1.5)(.1)(7) \\
& =1181316.5 .
\end{aligned}
$$

WELAHT OF SHPOUD

$$
\begin{aligned}
& =(36)(\pi)(428)(.6)(.1) \\
& =2404 \mathrm{Bs} .
\end{aligned}
$$

WeIGHT of CLAMP (STEL)

$$
\begin{aligned}
& =(129)(\pi)(9.75)(4)(.3) \\
& =4742 \mathrm{lbs} .
\end{aligned}
$$

WEIGHT OF TUEES

$$
\begin{aligned}
\text { TOTAL LENGTH OF TUFES } & =3(170+242+306) \\
& =2154^{11} \\
x \text {-SECT ABEA } & =7854\left(5.0^{2}-4.5^{2}\right) \\
& =3.73 \text { SQ.10.5. B-26 }
\end{aligned}
$$




$$
\begin{aligned}
\text { WEKHT } & =(2154)(3.73)(.1) \\
& =803165 .
\end{aligned}
$$

WEIGHT OF FITTINGS

$$
\begin{aligned}
& =(.7854)\left(4.5^{2}\right)(15)(18)(.1) \\
& =429165 .
\end{aligned}
$$

WEIGHT OF COLUMN (-35)

$$
\begin{aligned}
& =(120)(\pi)(141)(.28)(.1) \\
& =1483 \mathrm{lts} .
\end{aligned}
$$

WEIGHT OF RINGS (STEEC)

$$
\begin{aligned}
& =(\pi)(120)\left(7.15^{2}\right)(.3) \\
& =5781 \mathrm{~b} .
\end{aligned}
$$

WEGHT OF EUKHEADS (ST. $Q$ )

$$
\begin{aligned}
& =(2)(\pi)\left(57.5^{2}\right)(.75)(.3) \\
& =4674145 .
\end{aligned}
$$

WEIGHT OF COLUMN $(-31)$

$$
\begin{aligned}
& =(\pi)(120)(.28)(.1)(75) \\
& =792165 .
\end{aligned}
$$

WGGHT OF GUISETS

$$
\begin{aligned}
& =(2.0)(63)(85.5)(.1) \\
& =1077165
\end{aligned}
$$

WE:GHT OF ALAPTORS $(-49)$ (2PIECES)

$$
\begin{aligned}
& =(\pi)(120)(8.8)(.38)(.3)(2) \\
& =7561158
\end{aligned}
$$






\title{
APPENDIX C
}

\section{INVESTIGATION OF DIFFUSER-AUGMENTED WIND TURBINES* \\ FIBERGLASS REINFORCED PLASTICS FABRICATION}

by

\author{
Bruce R. Collemer \\ Manager, Design \& Engineering Services \\ Design \& Development Department \\ Pearson Yachts Division \\ Grumman Allied Industries, Inc. \\ West Shore Road \\ Portsmouth, Rhode Islaned 02871
}

November 1979

\author{
Prepared for \\ Research Department \\ Grumman Aerospace Corporation \\ Bethpage, New York 11714
}

Approved by: William H. Shaw

Vice President - Marine Products

Grumman Allied Industries, Inc.

*This is a Final Report covering Task 2 thru Task 6 covered under Grumman

Service Request/Authorization \#13982. Reference Purchase Request B 282386

$C-1$ 
C-2 


\section{PREFACE}

Pearson Yachts is a major producer of fiberglass sailing auxiliaries, competing throughout the United States as well as overseas. We've established a reputation of quality throughout our industry that has led to our prominent position in the marine industry. In addition to our sailing auxiliaries, we have produced Industrial Parts for 01son Bodies, Inc. (United Parcel truck parts), Naval Underwater Systems Center - N.U.S.C. (FRP Sonar Nose Cones), and Schlumberger Well Services - Grumman Houston (FRP Modules for offshore oil drilling rigs). In all of the Industrial Parts that we've produced, we have limited ourselves to fabricating the fiberglass portion of the units mentioned.

Our expertise, under our present management structure, available manufacturing facilities, and present available labor market, has allowed us to undertake FRP Industrial Products successfully.

For the purpose of this report, we will focus on the fiberglass manufacturing portion of the Diffuser-Augmented Wind Turbine. As this project progresses through the evolution of design, prototype, testing, and production, this position should be evaluated by Pearson Yachts, Grumman Allied Industries, Grumman Aerospace Corp. and Grumman Corp. as to the potential of Pearson Yachts to participate in what we consider to be a significant project. 


\section{DIFFUSER AUGMENTED WIND TURBINE}

Task 2 - Prepare Preliminary structural designs using FRP for three wind turbine sizes, using general zerodynamic configuration, tolerances, and wind load infornation supplied by Grumman Aerospace Corp., and material guide limits from Task 1. These designs need not include a horizontally rotating base, diffuser, and shroud base supports, or foundation, but should provide means of attaching the FRP-made diffuser and shroud to the structural supports. Also, consideration should be made for atraching or integrating the wind turbine supports structure into the FRP diffuser and shroud components. At the initiation of this contract, GAC will define three rotor diameter sizes to be addressed.

Fig.2-14 in the main text shows the FRP construction design incorporated into the Diffuser-Augmented Wind Turbine, Dump Diffuser.

Based on the current information available, we would propose to use the overlap style joint, shown by Fig.2-15 in the main text. This would allow ease of onsite fabrication, in contrast to using the "butt type" joint, including the inside and outside fairing pieces. A śealant (i.e., silicone, thiokol, etc.) would be used between the overlapping segments to provide some adhesion as well as dampening any vibration between segments.

By using the front and rear flanges of the dump diffuser as well as the longerons that are positioned at the midpoint of each $12^{\prime}-0^{\prime \prime}$ segment, attachment to the base could be easily facilitated. 
Diffusers could be made in any color/colors to minimize visual pollution. This could be a consideration to overcome initial objections by various environmental groups.

Another option available would be to pigment the resin used to layup the entire diffuser and shroud. This would ensure that in the event any of these units become scratched, either in shipment or assembly, it would be undetectable due to the color being all the way through the laminate. This treatment would also have an application, particularly in windy or sandy conditions, where an abrasive type atmosphere exists. A cost for this option is included later in this report.

The fabrication of a D.A.W.T. in Fiberglass Reinforced Plastics also allows for a major advantage of weight savings due to the use of an end grain balsa wood core. This weight savings allows for minimal costs being incurred on the construction site. Also, because of the size of the larger units, this allows individual segments to be relatively rigid compared to thinner materials.

A weight summary follows in this report.

Another area to be considered is the possibility of having to repair any of these units in the field. Fiberglass reinforced plastics can be repaired relatively easy. This could be a major consideration when a unit must be repaired in the field in lieu of disassembling, transporting, and finally repairing at the factory. A simple review of this technique is described within this report. 
DIFFUSER-AUGMENTED WIND TURBINE WEIGHT STUDY*

\begin{tabular}{|c|c|c|c|c|}
\hline & \multicolumn{2}{|c|}{$1 / 8^{\prime \prime}$ Skins } & \multicolumn{2}{|c|}{ 3/16" Skins } \\
\hline & 非/Unit & 非 Segment & 非/Unit & 非/Segment \\
\hline $\begin{array}{l}4^{\prime}-6 \text { " Radius-Diffuser } \\
2 \text { Segments - } 1 \text { Unit }\end{array}$ & 600 & 300 & 810 & 405 \\
\hline Shroud & 240 & 120 & 320 & 160 \\
\hline $\begin{array}{l}11^{\prime}-3^{\prime \prime} \text { Radius -Diffuser } \\
10 \text { Segments - } \frac{1 \text { Unit }}{}\end{array}$ & 3,900 & 390 & 5,120 & 512 \\
\hline Shroud & 620 & 62 & 820 & 82 \\
\hline $\begin{array}{l}11^{\prime}-3^{\prime \prime} \text { Radius -Diffuser } \\
\text { Sensitivity model } \\
10 \text { Segments - } 1 \text { Unit }\end{array}$ & 4,900 & 490 & 6,450 & 645 \\
\hline Shroud & 620 & 62 & 810 & 81 \\
\hline $\begin{array}{l}18^{\prime}-0^{\prime \prime} \text { Radius-Diffuser } \\
16 \text { Segments - } 1 \text { Unit }\end{array}$ & 11,350 & 710 & 14,280 & 893 \\
\hline Shroud & 1,120 & 70 & 1,410 & 88 \\
\hline
\end{tabular}

* These weights do not include any allowance for stiffeners in order to provide a better base for comparison. Stiffener weights would range from approximately 5 非 on the $4^{\prime}-6^{\prime \prime}$ radius unit per segment to 15 非 on the $18^{\prime}-0^{\prime \prime}$ radius unit per segment.

\#=pounds 


\author{
Mr. Bruce Collemer \\ Pearson Yacht Division \\ Grumman Allied \\ West Shore Road \\ Portsmouth, R.I. 02871
}

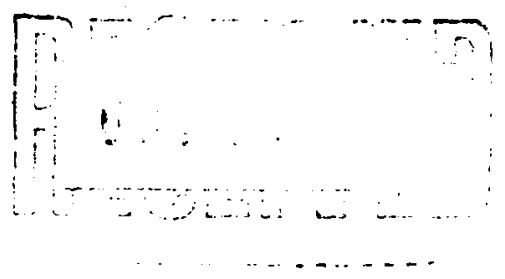

Gentlemen:

Enclosed you will find the printouts for calculating the laminates required to withstand critical buckling pressure on the DAWT shells. The dimensions for the shells were taken off the prints supplied by you. The following information was used for the design:

Modulus of Elasticity - 1 million PSI

Poisson'is Ratio - . 3

Balsa Core Shear Modulus - 26000PSI

Safety Factor - 1.8

In comparing the formula for buckling instability of the truncated cone, as supplied by Ken, with a formula in Military Handbook ANC23, the reduction factor of .75 is not included in the ANC23 formula; therefore, I have included the reduction factor in my calculations for minimum buckling pressure, which was arrived at as follows:

\title{
Design Pressure - 1 PSI \\ Safety Factor - 1.8 \\ Reduction Factor - .75.
}

Therefore, the input PSI buckling pressure into my computer program was 2.4 PSI. I analyzed 2 different skin thicknesses for each of the shells, i.e. .125 and .1875. The enclosed printouts show the results of these calculations.

If you have any questions concerning these analyses, please feel free to contact me.

T. e infermction r.r.ci-ed her: in is bosec' solely en data arcileible to us and en

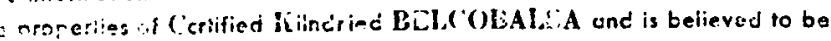

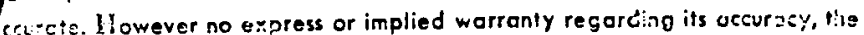
r. sc'ts to be ebtained from the use thereof, or that any such use will not infringe any potent is made.
Very truly yours,

BALTEK CORPORATION

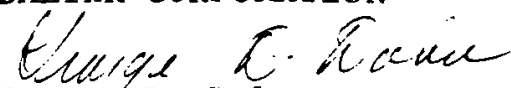

George D. Dohn

Manager, Engineering

Belcobalsa Division 
EALTEK CORFORATION

10 FAIRWAY COURT

NIRTHYALE, NEW JERSEY 07647

TELE: $(201\rangle 767-1400$

CUMPUTER ANALYSIS FOR:

GRIUMMAN REROSFACE COMPANY

PART \#19 (G.A.C.)

4'6" LENGTH ' 5'6" DIAMETER .
The infemation -sntoised hersin is bosod solely on data areilablo to ws and ca the aruanties af Corbified Kindrind EELCOEALGA and is bolleved to bo

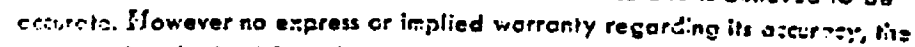
is: is te be ebioined from the use thereof, or tiat any such use will not i. frites cny potent is mode.

EHLTEK PROIRAAM \#1: UHIFURM FAIIAL EXTEFNAL FRESSURE FUR CYLIHDERS

REVISION $5, \quad 27$ APRIL $137 ?$

REFEFEHCES: MIL HAHDEOOK AHE 23 EHAPTER 10

IHFUT ...

MOIULUS OF ELASTIEITY

POISSUN'S RATIO (MIJ)

CQRE SHEAR MODULUS

EYLIHIIER LEHGTH

CYLIHIIER IIIAMETER

CYLIHIER RADIUS

MINIMUM EUEKLIHE FRESSURE

SKIH THICKNESS

COFE THIEKNESS

$\begin{aligned} E(P S I) & =1000000 \\ M & =.3 \\ \text { G(PSI) } & =26000 \\ \text { L(FT) } & =4.5 \\ I I(F T) & =5.5 \\ \text { R2(FT) } & =2.75 \\ \text { P(FSI }) & =2.4 \\ T g(I H) & =.125 \\ \text { I. IN }) & =1.5\end{aligned}$

$E(P S I)=1800000$

G(PSI) $=26001$

$L(F T)=4.5$

$I \perp(F T)=5.5$

T9(IH) $=.125$

. $(I N)=1.5$

GuTPuT...

CRITICAL BUCKLIHI FRESOURE
(PSI)

12.25
LES UF LAMIHATE

(FER SUFT)

2.0

SHIH THILHESS (IH) = .1250

CORE THICKHESS CIHS = .2500

HIMEER IJF FIIES

$=\quad 5$

RIE SFREINE (IN)

$=54.65$ 


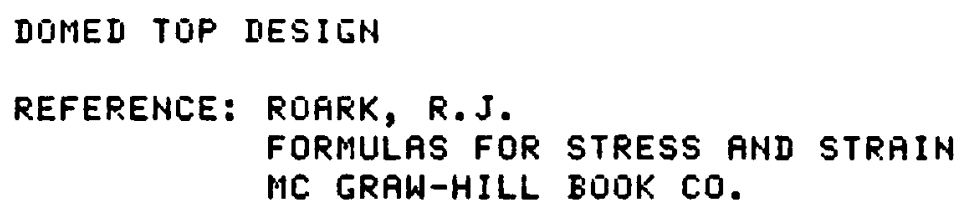

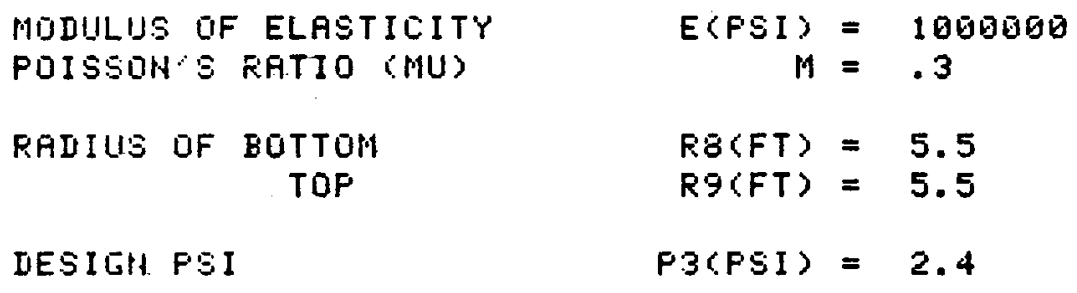

GUTFUT...

COREI STRLICTURE MUST HAVE A CRITICAL BUCKLIHG FRESSURE OF (FSI) = .990978129178

WITH A RIE SPACINL OF (IN) $=54$

CYLINDER RADIUS (FT) $=2.75$ 
BALTEK COFPORATIOH

1B FAIRUA' $'$ COURT

NORTHUALE, HEW JERSEY DJE4?

TELE：(201) 767-1409

COMPUTER ANALYSIS FOR:

GRUMMAN AEROSFACE COMPAHY

PART \# 1 ( $($. A.C.)

4'6" LENGTH > 5'6" DIRMETER.

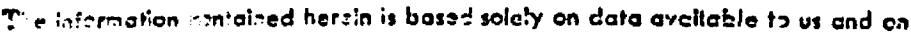

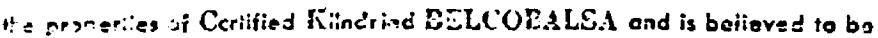


r syis to te cblolned from the use therecf, or that any such use will not iafringe ony patent is made.

EALTEK FROIRAM \#1: UHAFURM RAIIAL ERTERHFL FRESGUFE FOR CULIHIIERS

$$
\text { FEYISIOH 6, } 27 \text { APRIL } 1977
$$

FEFERENCES: MIL HAHIIEODK AHE 23 CHAFTER 10

IHFUT $\ldots$

\begin{tabular}{|c|c|c|c|}
\hline $\begin{array}{l}\text { MOIULUS OF ELASTICITY } \\
\text { POISSOH S RATIO (MU) } \\
\text { CORE SHEAR MODULUS }\end{array}$ & $\begin{array}{l}\text { E(FSI) } \\
\text { G(PSI) }\end{array}$ & $\begin{array}{l}= \\
= \\
=\end{array}$ & $\begin{array}{l}1505650 \\
.3 \\
25506\end{array}$ \\
\hline $\begin{array}{ll}\text { CYLINIER } & \text { LEHSTH } \\
\text { CYLINIER } & \text { IIAMETER } \\
\text { CYLINDER. } & \text { RADIUS }\end{array}$ & $\begin{array}{l}\text { L(FT) } \\
\mathrm{n} 1(\mathrm{FT}) \\
\mathrm{R} 2(\mathrm{FT})\end{array}$ & $\begin{array}{l}= \\
= \\
=\end{array}$ & $\begin{array}{l}4.5 \\
5.5 \\
2.75\end{array}$ \\
\hline $\begin{array}{l}\text { MIHIMUM BIIEKLIHG PRESSURE } \\
\text { SKIH THICKHESS } \\
\text { CORE THICKHESS }\end{array}$ & $\begin{array}{l}F(F S I) \\
\text { T9(IN) } \\
\text { COAH) }\end{array}$ & $\begin{array}{l}= \\
= \\
=\end{array}$ & $\begin{array}{l}2.4 \\
.1875 \\
1.5\end{array}$ \\
\hline
\end{tabular}

DUTFUT...

LRITIEAL EUCKLIHI FFESSIJEE (FOI)

22.75
LES UF LAMIHATE (FER SOFT)

3.0
SHIH THIEKHESS (IH) = .1575

NUWEEF: OF FIES =
COEE THICKHESS (IH) = .2506

RIE SFAEIHE (IH) = $54.5 \overline{0}$ 


\section{IUOMED TOP DESIGN}

REFERENCE: ROARK, R.J.

FORMULAS FOR STRESS AND STRAIN

MC GRAW-HILL BOIK CO.

INFUT $\ldots$

\begin{tabular}{|c|c|c|c|c|}
\hline $\begin{array}{l}\text { MODULUS } \\
\text { FOISSOH. }\end{array}$ & $\begin{array}{l}\text { OF ELASTICITY } \\
5 \text { RATIO (MU) }\end{array}$ & $\begin{array}{r}E(F S I) \\
M\end{array}$ & $=$ & $\begin{array}{l}1000000 \\
.3\end{array}$ \\
\hline RADIUS 0 & $\begin{array}{c}\text { OF BOTTOH } \\
\text { TOP }\end{array}$ & $\begin{array}{l}\text { R.8(FT) } \\
\text { Rg(FT) }\end{array}$ & $=$ & $\begin{array}{l}5.5 \\
5.5\end{array}$ \\
\hline ESIEN F & $P S I$ & $P S(P S I)$ & $=$ & 2.4 \\
\hline
\end{tabular}

UUUTFUT...

CQREG STRUETURE MUST HAVE A CRITIEAL BUEKLINI FRESGUAE OF (FSI) = .996978129178

WITH A RIE SPACING OF (IH) $=54$ CYLINDER RADIUS 
BALTEY CORFORATIOH

1 1G FAIRWRY COURT

NORTHUALE, NEW JERSEY G7647

TELE: (201) 767-1400

CONPUTER FHALYSIS FOR:

GRUMMAN FEROSFACE COMPANY PART \#11 (E.A.C.)

$11^{\prime}$ LENGTH ' 14' DIAMETER


the properiies af Cerified IKindried EELCOBALSA and is betieved to bo ces.rits. However no excress or implied worranty regarting its occurney, his isti:ts to be cbtcined fram the use thereof, or that any such use will not

EALTEK FFIILRAM \#1: UHIFOFM RAIIAL EXTEFHAL FRESSURE FUR CHLIHIIERS

$$
\text { REVISIOH B, } 27 \text { HFPIL } 1977
$$

FEFERENCES: MIL HAHIEIOK RNC 23 CHAFTER 19

$I H|P| I T \ldots$

\begin{tabular}{|c|c|c|c|}
\hline $\begin{array}{l}\text { MOIILUS OF ELASTICITY } \\
\text { FOISSOHS RATIO (MU) } \\
\text { COFE SHEAR MOIULUS }\end{array}$ & $\begin{array}{l}\text { E(PSI) } \\
\text { G(FSI })\end{array}$ & $\begin{array}{l}= \\
= \\
=\end{array}$ & $\begin{array}{l}1000505 \\
.3 \\
26050\end{array}$ \\
\hline $\begin{array}{ll}\text { EYLIHIER } & \text { LEHITH } \\
\text { CHLIHIER } & \text { IIIAHETER } \\
\text { CYLIHIER } & \text { RADIUS }\end{array}$ & $\begin{array}{l}L(F T) \\
I 1(F T) \\
R 2(F T)\end{array}$ & $\begin{array}{l}= \\
= \\
=\end{array}$ & $\begin{array}{l}11 \\
14 \\
7\end{array}$ \\
\hline $\begin{array}{l}\text { MINIMUM EUCKLING FRESSURE } \\
\text { SKIN THICKHESS } \\
\text { CORE THICKHESS }\end{array}$ & $\begin{array}{l}\text { P(PSI) } \\
T g(I N) \\
C(I H)\end{array}$ & $\begin{array}{l}= \\
= \\
=\end{array}$ & $\begin{array}{l}2.4 \\
.125 \\
1.5\end{array}$ \\
\hline
\end{tabular}

GUTPUT...

ERITIEAL EUICKLIHE FRESSUAEE (PSI)

2. 6.5
LES OF LAMINATE r.PER SQRT?

2.0

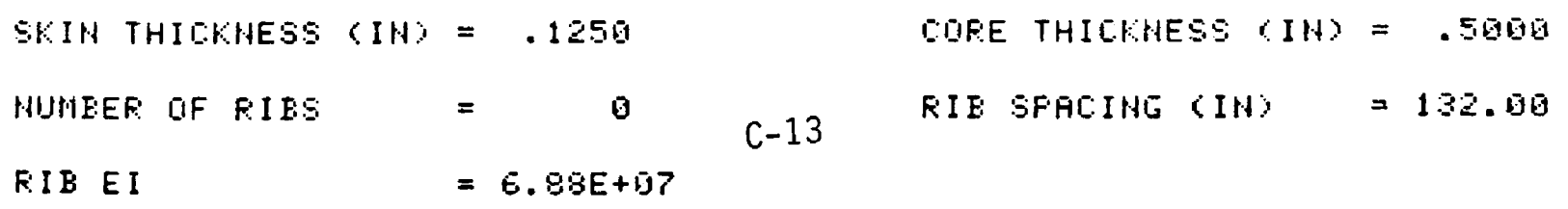




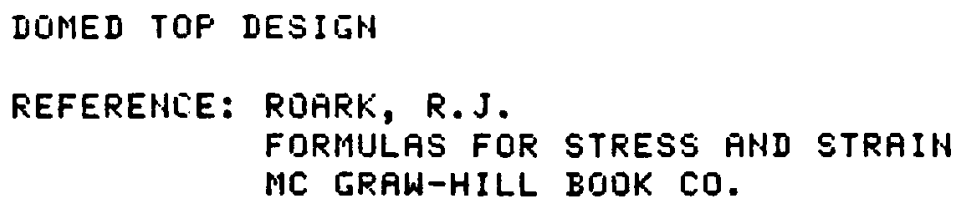

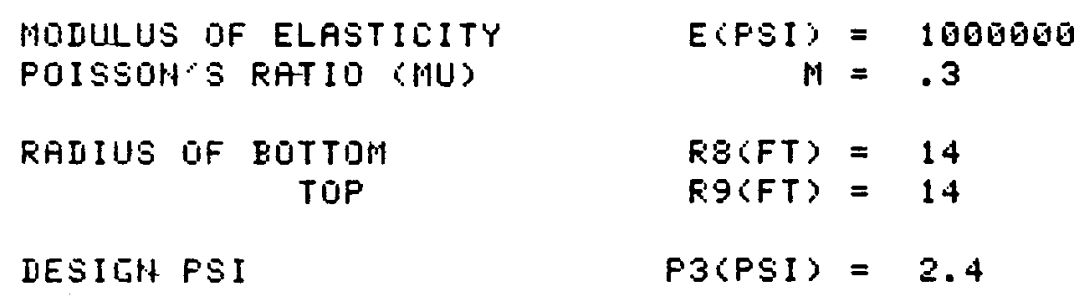

OUTFUT...

COFED STRUCTURE MUST HAUE A ERITICAL BUEKLIHG FFESSURE OF (FSI) = 1.03817597254

$\begin{array}{ll}\text { WITH F EIB SPACIHIS OF } & \text { (IH) }=132 \\ \text { CYLIHIER RADIUS } & \text { (FT) }=7\end{array}$ 


\author{
EALTEK CURPÜRTTIUN \\ 10 FAIRWAY CUIIRT \\ NORTHUHLE, HEW JEPSEY GTE47 \\ TELE: (201) 767-1400
}

COMPUTER FHALYSIS FOR:

GRUMTIAN HERUSFACE COMPANY

PART \#11 (G.A.C.)

11' LenGTH $>$ 14' DIAMETER

\begin{abstract}
The information : snlaised herein ls bosed solaly on dato avellable 10 un and on the rroperties of Ceritied Kindrind BELCORALSA and is balierad to bs cect.rcte. However no express or impliad warrenty regarcing its occur zcy, l.1. $r$-suits to be cbtcined from the use thereof, or that any such use will not intringe any potent is made.
\end{abstract}

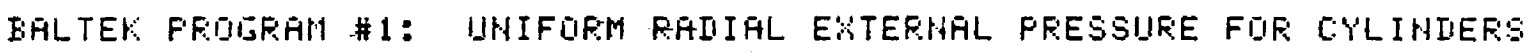

$$
\text { REVISIUN } 6, \quad 27 \text { HFFIL } 1977
$$

REFEREHCES: MIL HAHIEOOK FHL 23 CHAFTER 10

IHPUT ...

\begin{tabular}{|c|c|c|c|}
\hline $\begin{array}{l}\text { MONULUS OF ELASTICITY } \\
\text { POISSONS RATIO SMUS } \\
\text { CORE SHEAR MODULUS }\end{array}$ & $\begin{array}{l}E\langle F S I\rangle \\
G(F S I)\end{array}$ & $\begin{array}{l}= \\
= \\
=\end{array}$ & $\begin{array}{l}1050000 \\
-3 \\
26050\end{array}$ \\
\hline $\begin{array}{l}\text { CYLIHIEE LENGTH } \\
\text { CYLIHDER DIAHETER } \\
\text { CYLIHDER RADIUS }\end{array}$ & $\begin{array}{l}\text { LSFT) } \\
\text { II (FT) } \\
\text { R2(FT) }\end{array}$ & $\begin{array}{l}= \\
= \\
=\end{array}$ & $\begin{array}{l}11 \\
14 \\
7\end{array}$ \\
\hline $\begin{array}{l}\text { MIHIMUM EUIEKLIHI FRESSURE } \\
\text { SKIN THICKHESS } \\
\text { CORE THICKNESS }\end{array}$ & $\begin{array}{l}\text { P(PSI) } \\
\text { TS(IN) } \\
\text { COIN) }\end{array}$ & $\begin{array}{l}= \\
= \\
=\end{array}$ & $\begin{array}{l}2.4 \\
1375 \\
1.5\end{array}$ \\
\hline
\end{tabular}

QUTFIUT...

ERITIEHL EUEKLIHI FRESSUAE (FSI)

$$
3.43
$$

SKIH THICHHES (IH) $=.1875$

HUMEEF: DF FIES

RIE EI

$$
\begin{aligned}
& \text { LES DF LAMINATE } \\
& \text { (FER EOFT) }
\end{aligned}
$$

$$
3.0
$$

EUFE THIEKHESS (IH) = .375

FIE SPACIHG (IH) = 132.010 




GUTFUT...

COFED STRUCTURE MUST HAVE F CRITIEAL EUTELIHG PFESSURE OF (PSI) = 1.03817557254

WITH A RIE SPACING OF

CYLIHIER REIIIUS

$$
\begin{aligned}
& (\text { IH })=1: 32 \\
& (F T)=7
\end{aligned}
$$




\section{BRLTEK CORPOR:ATI INH \\ 19 FAIRWAY COURT \\ NURTHWHLE, NEW JERSEY BPG4? \\ TELE：(201) 767-1400}

COMPUTER FIHALYSIS FOR:

GRUMMAN AEROSPACE COMPAHY

PART \# 12 (G.A.C.)

$19^{\prime}$ LEMGTH ${ }^{\prime} 22^{\prime}$ DIAMETER
The informetion ryntaised herein is based sololy on dota ovelloble to wo and an H. a proserties of Certffied Filndrind BELCOBAISA and ts balioved to bs


r.syits to be ebioined from the use thereof, or that any such use will not intringe cny potent is made.

EALTEK FRIULFAM \#1: UHIFURM RADIAL EXTERNAL PRESSURE FUR CYLIHDERS

REYISION 6, 27 AFRIL 1977

REFEREHCES: MIL HAHIEOOK FHC 23 CHAPTER 10

INFUT $\ldots$

MUIULUUS DF ELASTICITY

FOISSON'S RATIO (MU)

CORE SHEAR MODULUS

EYLINIJER LEHGTH

CYLINIIER DIAMETER

CYLINIER R:AIIUS

MINIMUM BUCKLIHG FRESSURE

SKIN THICKNESS

CORE THICKHESS

$\begin{aligned} E(P S I) & =1000000 \\ M & =.3 \\ G(P S I) & =26050 \\ \mathrm{~L}(\mathrm{FT}) & =19 \\ \mathrm{I} 1(\mathrm{FT}) & =22 \\ \mathrm{R} 2(\mathrm{FT}) & =11 \\ \mathrm{P}(\mathrm{FSI}) & =2.4 \\ \mathrm{~T}(\mathrm{IN}) & =.125 \\ \mathrm{C}(\mathrm{IN}) & =1.5\end{aligned}$

$E(P S I)=1000060$

$\mu=.3$

$G(P S I)=26050$

$L(F T)=19$

II $1(F T)=22$

T $G(I N)=.125$

$C(I N)=1.5$

DITFUT...

CRITIEAL EUEKLIHG FRESSUFE (PSI)

$$
\text { 2. ED }
$$

SKIH THIEKHESS (IH) = .1256

HUMEEF OF RIES

RIB EI

\section{LES OF LAMIHATE (FER SQFT)}

$$
2.6
$$

CORE THICKNESS (IH) = 1.2505

RIE SFREIHG (IH) = 228.00

$$
\begin{aligned}
& = \\
& =4.61 E+05
\end{aligned}
$$




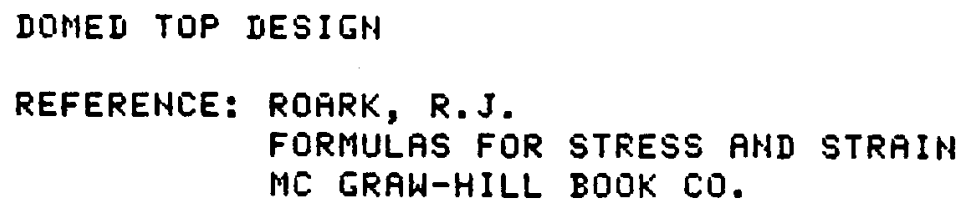

DESIGH PSI

P3(PSI) $=2.4$

OUTFUT...

GOFET STFULTUFE MUST HAVE A CRITICAL EUCKLIHE PRESSURE OF (PSI) = .944505590063

WITH A RIB SFACING DF $\quad$ (IN) $=228$

CYLIHUER RAIIUS

$(F T)=11$ 
EALTEK CORPDRATIOH

16 FAIRLAY COIJRT

NORTHYHLE, NEW JERSEY B7E47

TELE: (201) $767-1400$

EOMFUTER AHALYSIS FOR:

GRUMMAN AEROSPACE COMPAHY PART \#12 (G.A.C.)

$19^{\circ}$ LENGTH $2^{\circ}$ DIAMETER

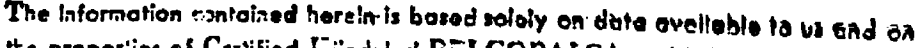

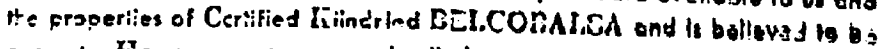


$r$ asis to be ebtcined from the use therest, or that any aush use will nat isiringe any patent is mado.

EALTEK FROGFAM \#1: UHIFORM RADIAL ERTERHAL PRESSURE FUR CYLIHUERS

REVISION $6, \quad 27$ AFRIL 1977

REFEREHCES: MIL HANDEOOUK FHC 23 CHAFTER 10

IHFIIT $\ldots$

MODULUS OF ELFSTICITY

POISSON'S RRTIO (MU)

CORE SHEAR MODULUS

CYLIHIEE: LEHITTH

CYLINDER IIAHETER

CYLIHDER RADIUS

MINIMUM BUCKLING PRESSURE

SKIN THICKNESS

CORE THICKHESS

$\begin{aligned} E(F S I) & =1000000 \\ H & =.3 \\ G(F S I) & =26000 \\ L(F T) & =19 \\ D 1(F T) & =22 \\ R 2(F T) & =11 \\ P(P S I) & =2.4 \\ T P(I H) & =.1875 \\ C(I N) & =1.5\end{aligned}$

$E(P S I)=1000000$

$G(F S I)=2600 \overline{0}$

$L(F T)=19$

$\mathrm{D} 1(\mathrm{FT})=22$

$T P(I N)=.1875$
$C(I N)=1.5$

QUTFUT. . .

CPITIEAL EUCKLIHG FRESSURE (PSI)

$$
3.04
$$

\section{LES UF L.AMINATE \\ (FER SUFT)}

3.5
SKIH THICKHESS (IH) $=.1275$

HUHEER OF RIES

RIB EI
$=5$

$=4.61 \mathrm{E}+5 \mathrm{~s}$
CORE THICKHESS (IH) $=1.0000$

RIE SFAEIHG (IH) $=228.00$ 




IHPUT $\ldots$



OUTFUT...

CUREI STRUETURE MUST HAVE A CRITICAL BUCKLIHG PRESSURE OF (PSI) = .944505596063

WITH A RIB SPACIHE OF $\quad$ (IH) $=228$

CYLINDER RADIUS $\quad$ (FT) $=11$ 


\section{EALTEK CORFOFATION \\ 10 FAIRWAY COURT \\ NORTHUALE, NEW JERSEY OTE47}

TELE: (201) 767-1400

COMFUTER AHALLISIS FOR:

GRUMMAN FEROSPACE COMPANY

PART \# 13 (G.A.C.)

$13^{\prime} 6^{\prime \prime}$ LENGTH $/ 15^{\prime}$ DIAMETER



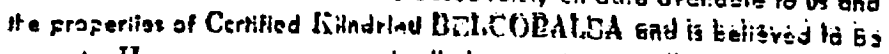


$r$ suits 10 be cbieined from the use therod, af hal any ligh wa will nial infringe eny patent is mado.

EALTEK FRÜGRAM \# 1: UNIFIRM FAIIAL EXTERHAL FRESSIIRE FOR CYLINIERS

$$
\text { REVISIOW E, } 27 \text { HFRIL } 1977
$$

REFERENCES: MIL HAHIEOOK ANC 23 CHAPTER 1 G

IHFIT $\ldots$

\begin{tabular}{|c|c|c|c|}
\hline $\begin{array}{l}\text { MOIILUS OF ELASTICITY } \\
\text { FOISSOH'S RATIO (MUS } \\
\text { CORE SHEAR MODULUS }\end{array}$ & $\begin{array}{l}E(F B I) \\
G(P S I)\end{array}$ & $\begin{array}{l}= \\
= \\
=\end{array}$ & $\begin{array}{l}1000600 \\
23 \\
26000\end{array}$ \\
\hline $\begin{array}{ll}\text { CYLINDER } & \text { LEHGTH } \\
\text { CYLINIIER } & \text { DIAHETER } \\
\text { CYLIHDER } & \text { RHDIUS }\end{array}$ & $\begin{array}{l}\text { LCFT) } \\
\text { II } 1(F T) \\
\text { R2(FT) }\end{array}$ & $\begin{array}{l}= \\
= \\
=\end{array}$ & $\begin{array}{l}13.5 \\
15 \\
7.5\end{array}$ \\
\hline $\begin{array}{l}\text { MIHIMUM EUCKLIHE FRESSURE } \\
\text { SKIH THICKNESS } \\
\text { COFE THICKHESS }\end{array}$ & $\begin{array}{l}F(F S I) \\
T 9(I H) \\
E(I H)\end{array}$ & $\begin{array}{l}= \\
= \\
=\end{array}$ & $\begin{array}{l}2.4 \\
0125 \\
1.5\end{array}$ \\
\hline
\end{tabular}

OUTFUT...

ERITICAL BUCKLIHE FRESSURE (FSI)

$$
2.54
$$

SKIH THICKHESS (IH) $=.125 \bar{B}$

HUMEEF OF FIES

$=0$

F. I B E I
$=1.04 E+58 \quad C-21$

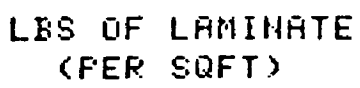

2. 9

RIE SFACIHE (IN) = $162.0 B$ 


\section{EALTEK CORPOEATION \\ 1] FAIRUAY CQURT \\ HORTHYALE, NEW JERSEY GTE47 \\ TELE：(201) 767-1400}

COMPUTER ANAFLYSIS FOR:

GRUMMAN AERBSPRCE COMPAHY

PART \# 13 (G.A.C.)

$13: 6^{\prime \prime}$ LENCTH / 15'DIAMETER
The information aniai-ed herein is based sololy en dala avellablo to us and on the fraperites of Cerified Kïindrind RELCORALCA end is believed to bs

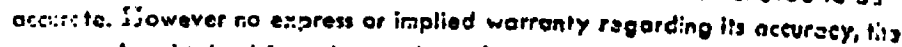
$r$ ist: $1 \mathrm{~s}$ to be cbtcined from the use thereof, or that any such use will not infrirge eny potent is made.

BFLTEK FROGRAM \# 1: UHIFUFT RAIIAL EXTERHAL FRESSURE FUR. CILINIIERS

REVISIUN $5, \quad 27$ AFRIL 1977

REFEFEHCES: MIL HAHIEOIIK AHC 23 CHAPTER 10

IHFUT $\ldots$

MOIULUS OF ELASTICITY

FOISSONS RATIO (NU)

CORE SHEAR MODULUS

EULIHIIER LENTTH

CYLIHDER IIAHETER

CYLIHDER RADIUS

MINIMUM BUCKLINE PRESSUFE

SKIH THICKNESS

CORE THILKHESS

$\begin{aligned} E(P S I) & =1000050 \\ H(P S I) & =3 \\ L(F T) & =13.5 \\ D I(F T) & =15 \\ R Z(F T) & =7.5 \\ P(P S I) & =2.4 \\ T P(I N) & =1875 \\ C(I H) & =1.5\end{aligned}$

$E(P S I)=1000050$

$M=.3$

$G(P S I)=26000$

15

OUTFIJT...

CRITIEAL EUCKLIHT FRESSUFE (FSI)

$$
2.45
$$

EKIH THIEKHESS (IH) = .1875

HUMEEP DF FIIES =

F.IB EI

$=1.64 E+15 \overline{5}$
LES OF LAMIHATE

(FER SUFT)

3.0

COFE THICKHESS (IH) = .3750

RIE SFAEIHE (IH) = 162.06 


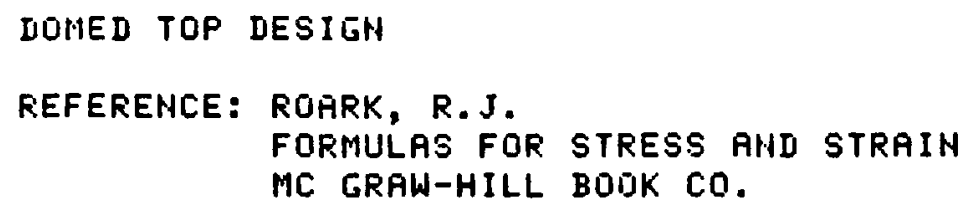

UUTFUT...

CDRED STRUCTURE MUST HAVE A CRITICAL BUCKLIHI FRESSURE OF 〈FSI〉 = .96394375398

WITH F RIE SPACING OF (IN) $=1 E ?$

CYLINDER RADIUS $\quad\langle F T\rangle=7.5$ 
D.A.W.T. - estiMate of PANEL conNection loADING zased ON HOCP STRESS DERVED FROM PERRENTICULAR FLN PRESSURE RISTRBOUTON.

MAXIMUM PERPEUDICULAR FLOW PRESSURE $=0.345$ PSI $@$ WIND VELOKIM OF $120 \mathrm{MPH}$ (FROM U.M. PLST OF "D.A.W.T. STATIC PRESSURE PROFILE" DATED 6-13-79)

GUSTING" CORRECTION $=\frac{535}{36.1}(0.345)=.571$ PSI

(TAKEN FrOM K.F. CALCS DATED $5-1-78$ )

FORCE $(P)$ ON CYLINDER WAL DUE TO STATC PRESSURE : $P=p 2 r L$

WHERE $p=$ STATIC PRESSUEE

$r=$ CYLINDER RADIUS

$L=$ CYLINDER LENGTH

TENSION $(Q)$ IN CYLINDER WALL DUE TO FORCE $(P)$ : $Q=\frac{P}{2}$

cALCULATE Q FOR DIFFERENT D.A.W.T. SIZES:

\begin{tabular}{|c|c|c|c|c|}
\hline $\begin{array}{l}\text { ROTOR } \\
\text { RADIUS }\end{array}$ & $\begin{array}{l}\text { MEANA } \\
\text { DEEWSER } \\
\text { RADIUS }\end{array}$ & $\begin{array}{l}\text { DIFFUSER } \\
\text { LENGINt }\end{array}$ & $P=2 p r L$ & $Q=\frac{P}{2}$ \\
\hline $4-6 "$ & $5.92^{\prime}$ & $4.0^{1}$ & 3485 LIS. & 1742 LBS. \\
\hline $111-3 "$ & $14.75^{1}$ & $10.0^{1}$ & 21707 LBS. & 10854 LBS. \\
\hline $18^{\prime}-0^{\prime \prime}$ & $23.59^{\circ}$ & $16.0^{1}$ & 55547 LBS. & 27774 LBS. \\
\hline
\end{tabular}


calculate nuMBer of $3 / 8$ " DIA. FAsteneres NEeded to JOIN SECTIONS:

PEARSON YACHTS MATERLAL STREUGTH VALUES: SHEAR, 304 STAINLESS STEEL $=30000$ PSI BEARING, FIBERGLASS $=21000$ PS

\begin{tabular}{|c|c|c|c|c|c|c|c|}
\hline & ROTOR & Total (1) & \multirow{2}{*}{$\begin{array}{l}\text { TOTAL (1) } \\
\text { THtCKItESS } \\
(t)\end{array}$} & \multirow{2}{*}{$\begin{array}{l}\text { FASTENER } \\
\text { SHEAR AREA } \\
\text { REQID } \\
\text { R/30000 }\end{array}$} & \multirow{2}{*}{$\begin{array}{l}\text { NO. OF } 3 / 8^{\prime \prime} \\
\text { DA. FASTENA } \\
\text { (BASED ON (2) } \\
\text { SHEAR) }\end{array}$} & \multirow{2}{*}{\multicolumn{2}{|c|}{ 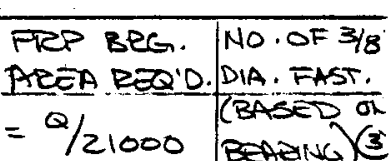 }} \\
\hline & RADIUS & THICKNESS & & & & & \\
\hline & $4^{\prime}-6^{\prime \prime}$ & $.25^{\prime \prime}$ & $.50^{\prime \prime}$ & $.050 \mathrm{~N}^{2}$ & 1 & $.08310^{2}$ & 1 \\
\hline & $4^{\prime}-6^{\prime \prime}$ & $.375^{\circ}$ & $.625^{\prime \prime}$ & $"$ & 1 & $"$ & $1^{\prime}$ \\
\hline \multirow[t]{4}{*}{-} & $11-3 \cdot$ & $.25^{\prime \prime}$ & $.750^{\prime \prime}$ & $.362 \mathrm{~N}^{2}$ & 6 & $.517 \quad \mathrm{NN}^{2}$ & 4 \\
\hline & $111-3 "$ & $.375^{\prime \prime}$ & $.750^{\prime \prime}$ & $"$ & 6 & " & 4 \\
\hline & $18^{\prime}-0^{\prime \prime}$ & $.25 "$ & $1.50 "$ & $.926 \mathrm{in}^{2}$ & 14 & $1.32310^{2}$ & 5 \\
\hline & $18^{\prime}-0^{\prime \prime}$ & $.375^{\prime \prime}$ & $1.375 "$ & $"$ & 14 & $"$ & 5 \\
\hline
\end{tabular}

(1) From BALTEK STRUCTURAL cALCULATIONS

(2) SHEAR AREA OF 3/8" DIA- BOLT (AT THE RDOT) $=.068 \mathrm{in}$ (3) No. OF $3 / 8^{\prime \prime}$ DIA. FASTENERS $=\frac{\text { BEARING AREA }}{.375(t / 2)}$ 
D.A.W.T. - ESTMNAE OF STIFENER DESIGN:

MAXMUM PRESSURE FROM STATC PRESSURE PROFILE =.345 PSI

ASSUME UNIFOCMLY DISTRBUTED LOAD, ONE END FIXED: OTHER END SIMPLY SUPPOTTED:

$$
M_{\text {min }}=\frac{\omega L^{2}}{8}
$$

WHERE: MUAK = MAXIMUM BENDING MOMENT

$\omega=$ UNT UNIFORM LOAD

$S M=\frac{M_{M A x}}{S}$

$L=$ SPAN

WHERE: $S M=$ REQUIRED SECTON MODULUS

$\sigma=$ ALLOWABLE BENDING STRESS : 15000 PSI (P.Y. MATEEIAL STENGTH VALUE)

CALCULATE LOADED AREAS:

4'-6"R. ROTOR:

ENTRANCE CIRCUMFERENCE, Cars $=2 \pi\left(5.0^{\prime}\right)=34.16^{\circ}$

EXT CIRCUMFERENCE, $C_{\text {EXIT }}=2 \pi\left(6.83^{\prime}\right)=42.91^{\prime}$

ARP OF ONE PANEL, $A_{1}=\frac{1}{4}\left(\frac{34.16+42.91}{2}\right)(4.0)=38.54 \mathrm{FI}$

$11^{\prime}-3^{\prime \prime}$ R. ROTOR:

$\cos =2 \pi(12.5)=78.54^{\prime}$

$C_{\text {axt }}=2 \pi(17.0)=106.81^{\prime}$

$A_{1}=\frac{1}{10}\left(\frac{100.81+78.54}{2}\right)(10.0)=92.68 \mathrm{~F}^{2}$

$18^{\prime}-0^{\prime \prime}$ R. ROTOR:

$C_{\text {art }}=2 \pi(20.0)=125.66^{\prime}$

$C_{\text {exiT }}=2 \pi(27.25)=171.22^{\prime}$

$A_{1}=\frac{1}{16}\left(\frac{125,66+171.22}{2}\right)(16.0)=148.44 \mathrm{FT}_{2}$ 


\begin{tabular}{|c|c|c|c|c|c|c|}
\hline ROTOR & $\begin{array}{l}\text { AREA SUPPORTEI } \\
\text { BY STIFENER }\end{array}$ & $\begin{array}{l}\text { DTAR LAAD- } \\
\text { PANE ACEA }\end{array}$ & $\begin{array}{l}\text { UNT LOAD } \\
\text { PER EDOT OE }\end{array}$ & $A A+0$ & $S M$ & \\
\hline RADIUS & (SINGLE PANEL) & X PRESSURE & SIFFENER & 10 & & \\
\hline $4-6 "$ & $3852 F^{2}$ & 1915235. & $478.7^{105} / \mathrm{FT}$ & 1957 FT-LBS & $.064 \mathrm{IN}^{3}$ & \\
\hline $111-3^{\prime \prime}$ & $92.68 F^{2}$ & 4604 LBS & $460.4^{\mathrm{BS}} / \mathrm{FT}$ & S755 FI-LBS. & $.384 \mathrm{IN}^{3}$ & \\
\hline $18^{\prime}-0^{\prime \prime}$ & $148.44 \quad F T 2$ & $7375 \mathrm{LBS}$ & $460.9^{\mathrm{LBS} / \mathrm{FT}}$ & $14749 F-\angle B S$ & $.983 \mathrm{in} 3$ & \\
\hline
\end{tabular}




$$
\begin{aligned}
& 4^{\prime}-6^{\prime \prime} \text { R. ROTOR } \\
& S M=.064 \mathrm{NN}^{3} \\
& \text { STIFENER HESHI }=5^{1 / 2} \text { " } \\
& I=\frac{b h^{3}}{12} \text { FOR A RECTANGULAR sECTION } \\
& \therefore \quad S M=\frac{I}{h / 2}=\frac{b h^{3}(2)}{12 h}=\frac{b h^{2}}{6} \\
& b=\frac{.064(6)}{(5.5)^{2}} \\
& b=.013^{\prime \prime} \Rightarrow \text { USE } 1 M+1 R
\end{aligned}
$$

$11-3 " R$. ROTOR

$$
\begin{aligned}
& S M \rightarrow B O=.384 \mathrm{~N}^{3} \\
& \text { STIEFENER HEVHT }=15^{\prime \prime} \\
& b=\frac{6 S M}{h^{2}}=\frac{6(.384)}{(15)^{2}}=.010^{\prime \prime} \Rightarrow \text { USE } 1 M+1 R
\end{aligned}
$$

$$
\begin{aligned}
& 18^{\prime}-0^{\prime \prime} \text { R. Roter: } \\
& S M_{R=010}=.983 \mathrm{in}^{3} \\
& \text { STFEONER HEGHT = 24" } \\
& b=\frac{65 M}{h^{2}}=\frac{6(-985)}{(24)^{2}}=.010^{\circ} \Rightarrow \text { USE } 1 M+1 R
\end{aligned}
$$


IRY SHALLWER SECTIONS BASED ON $M+1 R\left(t=.107^{\prime \prime}\right.$, FroM P.Y. STANDARDS)

4'-6"R. ROTOR:

$S M=.0641 N^{3}$
$h=\sqrt{\frac{65 M}{b}}=\sqrt{\frac{6(.064)}{.107}}=1.894^{\prime \prime}$

11'-3"R. ROTOR:

$S M=\frac{3841 N^{3}}{h=\sqrt{\frac{6(.384)}{.107}}=4.64^{11}}$

18'-0"R. ROTOR:

$$
\begin{aligned}
& S M=.983 \mathrm{NO}^{3} \\
& h=\sqrt{\frac{6(.983)}{.107}}=7.42^{11}
\end{aligned}
$$

USE THIS FOR ESTMATING, PROBASLY USE HAT SECTIONS ON ACUAS UNITS. 
D.A.W.T. - Comparison of Physical Properties of FRP for Mat/Woven roving composite :

\begin{tabular}{llc} 
Property & $\begin{array}{c}\text { Gruman } \\
\text { Values }\end{array}$ & $\begin{array}{c}\text { Pearson Yachts } \\
\text { Values }\end{array}$ \\
\cline { 2 - 2 } Density 非/ft & 94 & 100 \\
Flexural Ultimate KSI & 30 & 1.1 \\
Modules of Elasticity K10 & 1.3 & 15 \\
Tensile Ultimate KSI & 15 & \\
Compression KSI & 22 & 10 \\
*Interlamikar Shear KSI & 1.2 & 21 \\
Perpendicular Shear KSI & 12 & \\
Bearing KSI & 18 & \\
Endurance Limit $\%$ of U1t. & 20 & \\
K Factor BTU/in/ft $/ \mathrm{hr}$ & 3.6 &
\end{tabular}

*Note: Gruman values indicate a higher interlaminar shear value $(1.3 \mathrm{kSI})$ for an all woven roving laminate 
Task 3 - Establish and describe fabrication techniques for the three designs resulting from Task 2. Because production lot quantities may vary from only a single prototype to larger quantities of 50 to 100 units per year, the production methods may differ with lot size; establish techniques for prototype and larger lot sizes. Also, consideration is to be given to shipping and erection requirements at a field installation site.

The fabrication technique for the prototype D.A.W.T. would be fabricated by a hand layup process common throughout the FRP field. This procedure would be done on a One-off process involving formica covered plywood molds. It may be necessary to substitute an Airex PVC foam core in lieu of the proposed balsa wood core intended for the production pieces. This is a common practice in OneOff type construction. Provided all segments of the diffuser and shroud are the same, this would mean that relatively low costs would be involved in the prototype tooling. Another advantage of this method is that any unforeseen changes that should become necessary, at a later date, could also be accommodated at a minimum of expense. These units could have either a preapplied gel coat surface of a post applied paint finish (i.e., Awlgrip, Imron). The texture of both sides would be in accordance with samples supplied with this report.

Once the prototype design and installation have been approved for production, we would then propose to commit to FRP tooling. This tooling would be fabricated from constructing a plug/plugs (plugs are wooden parts reproducing the actual finish parts desired) over which FRP mold/molds would be layed up using tooling resins and gel coats to insure longer production life versus conventional general purpose resins and gelcoats.

In the mold would be markings, on the mold side, for locating fittings, holes to be drilled on site, or attachment of miscellaneous fittings. 
Any individual piece will not exceed a measurement of $12^{\prime}-0^{\prime \prime}$ in at least one direction to facilitate shipment over the road. 
Task 4 - Devise a preliminary production plan for the designs of Task 2 and fabrication methods of Task 3 including facilities, personnel requirements and training, and special equipment or tooling. Provide a written description of these production plans including schematics of production line arrangements, manpower assignments, and job descriptions.

We have included a diagram showing the general arrangement of a plant that would be needed to produce diffusers and shrouds in any major quantity. This arrangement doesn't include any provisions for offices, cafeteria, wash rooms, lockers, or lunch room. It is intended to demonstrate the type of material flow that would be necessary. Also, we've included a page on the plant facility it would take to produce 100 units/yr. of each size for a total plant output of 300 units/yr.

The following three graphs (one for each size diffuser) show the number of mold segments necessary to produce from zero to one thousand units per year, actual square footage for molds only, actual square footage for molds and trimming, and manpower requirements for the appropriate number of units. It becomes apparent from these graphs that on the $11^{\prime}-3^{\prime \prime}$ radius and the $18^{\prime}-0^{\prime \prime}$ radius units that as the quantities increase above 200-300 units per year, it becomes somewhat prohibitive to produce this amount in one facility because of labor pools and facilities.

There are at least two alternatives to this situation; an alternate method of fabrication (discussed at the end of this section), or to produce these units at various locations throughout the country. This latter alternative would obviously depend on "geographical demand". 




TYPICAL FACILITY 







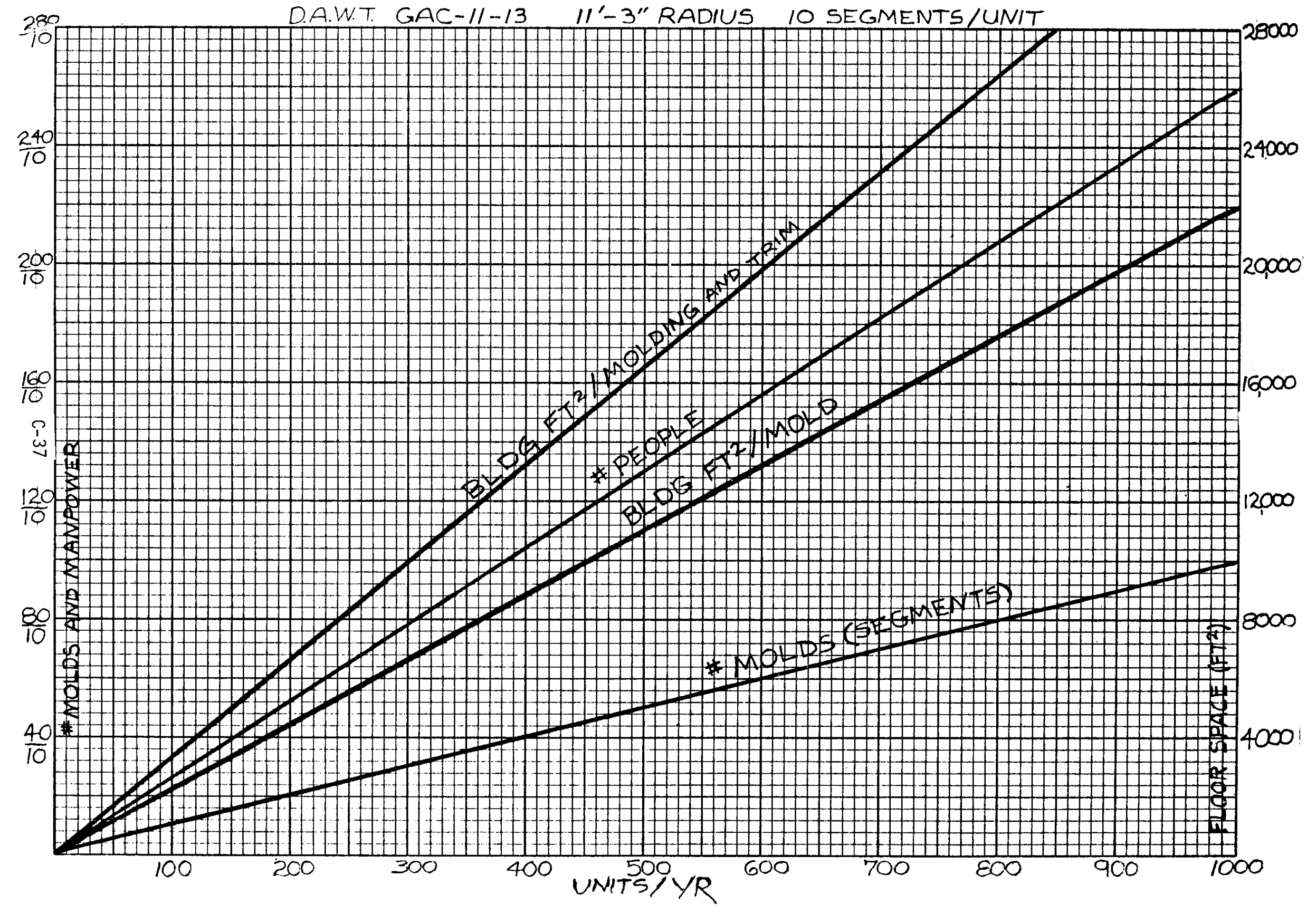







PLANT FACILITY TO PRODUCE 100 UNITS OF EACH SIZE

PLANT:

35,000 square feet

$16^{\prime}-0$ " high overhead

Mold Room with adequate ventilation for styrene removal

Grinding Room adequate air and dust removal system

Stockroom

Office, Lunch Room, Locker Rooms/ showers

EQUI PMENT :

2 - Gelcoat guns

$\$ 15,000$

2 - Chopper guns

15,000

3 - Resin wet out guns

15,000

1 - Acetone tank

15,000

1 - Overhead bridge crane

22,000

1 - Hyster fork truck 15 ton

35,000

1 - Sma11 fork truck 3-5 tons

17,000

2 - Resin tanks 4500 - 5,000 gal./ea.

30,000

Miscellaneous hand tools, etc.

$\frac{20,000}{18400}$

MANPOWER:

Direct labor - 90 people

Indirect labor - 12 people

MOLDS :

Diffuser - 28 molds

Shroud - 28 molds. This quantity may be reduced at a later date if each segment could be made longer. However, it will not change any other requirements. 


\section{MANUFACTURING PROCESS}

\section{Hand Layup Process}

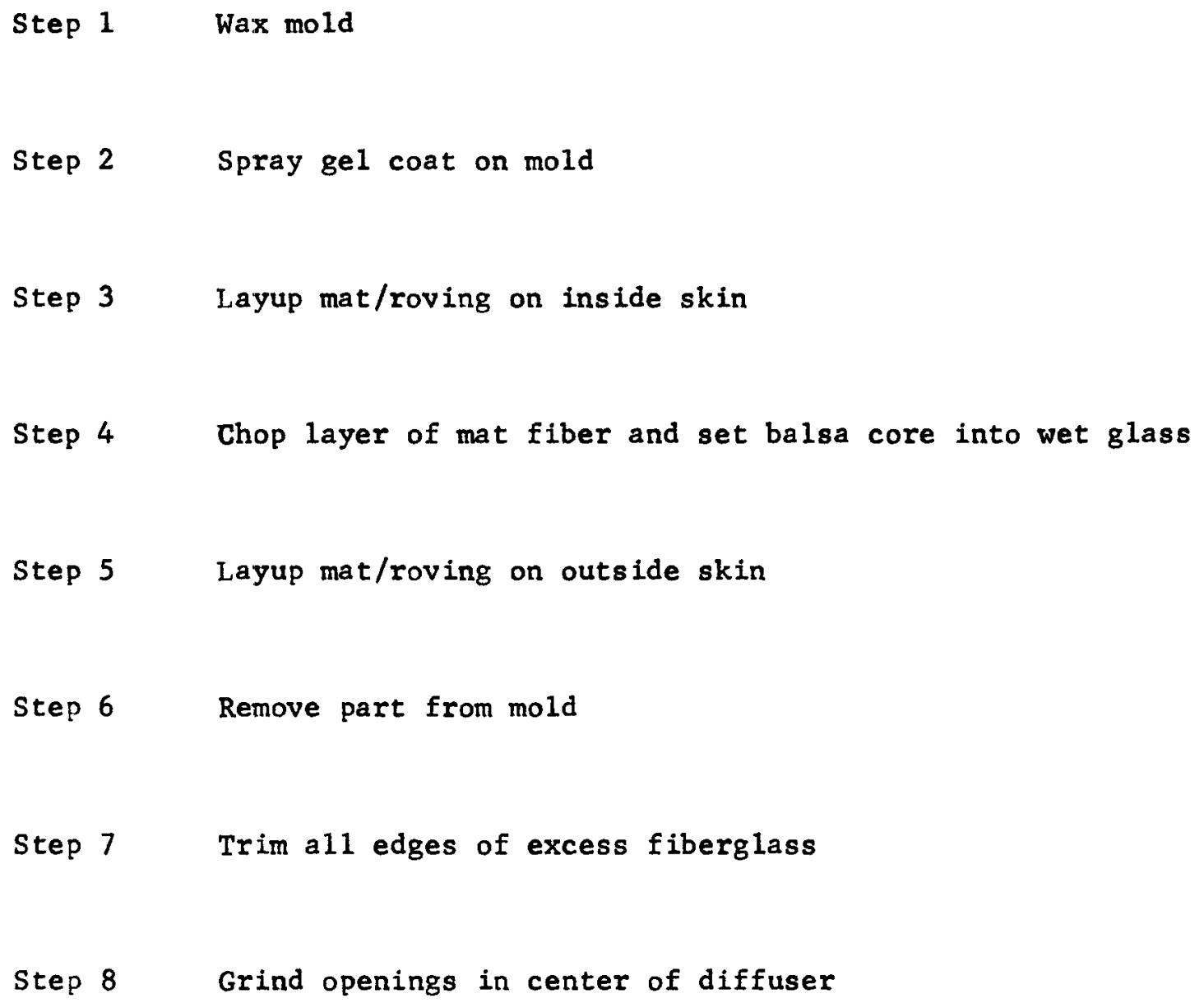




\section{ALTERNATE MANUFACTURING PROCESS}

Resin Transfer Method - RTM

This is a fairly new process being used by several FRP manufacturers in an attempt to produce greater quantities than allowed by using conventional hand layup or spray layup. A brochure is included which describes this process as well as show a comparison between the two processes.

Although not shown in the literature enclosed, there are European manufacturers making $30^{\prime}$ and $34^{\prime}$ sailboat hulls and decks. These people are using a vacuum assist in conjunction with RTM because of the size of the part.

This process is also known as Resin Injection Molding. 
Task 5 - Prepare cost estimates for the Designs of Task 2 and fabrication methods and production plans of Task 3 and 4. Costs are to be detailed so that individual facets of the final program can be identified. These facets shall include engineering, direct unit production (for prototype and 50-100/yr. lot sizes), special tooling or fixtures or other facilities, and shipping and installation costs. The rationale and sources for arriving at these cost estimates sha11 be given to provide confidence in their accuracy and validity.

A11 costs used within are our present day costs and represent bulk purchases (i.e., truckload, tankwagon, etc.) This would mean that initial production lots would be priced with this advantage, versus someone just starting to build up to these quantities.

THE PRICES INCLUDED IN THIS REPORT ARE NOT TO BE CONSTRUED AS ANY TYPE OF QUOTATION. THESE NUMBERS ARE TO BE CONSIDERED ONLY FOR COMPARISON BASIS. 
D.A.W.T. Material Cost Per. Sq.Ft Based On Diffuser Radius

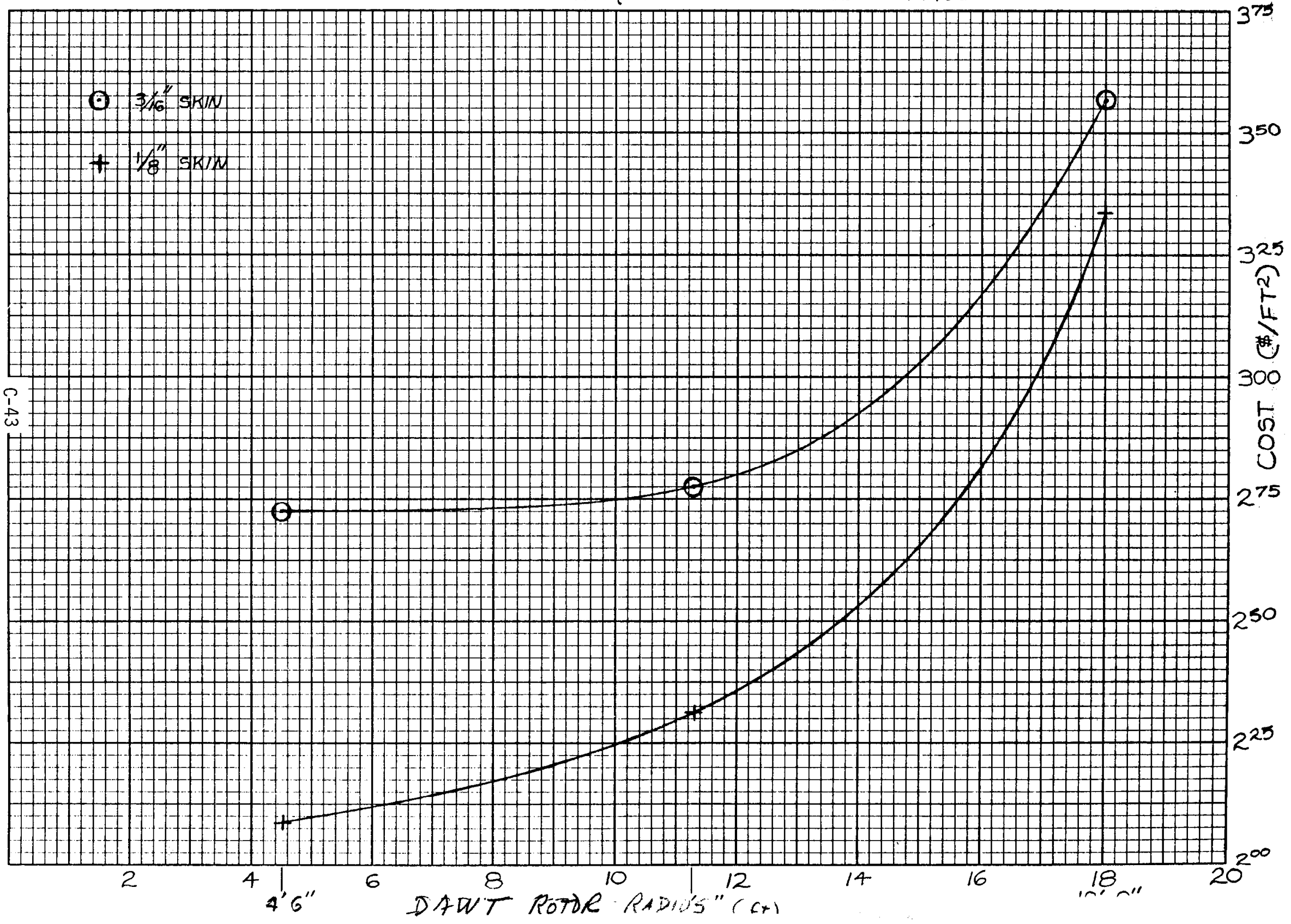




\section{DIFFUSER-AUGMENTED WIND TURBINE}

The tooling used to make one-off parts due to its construction has a very limited life.

On the 4'-6" radius diffuser we would propose to make a one-off mold that would encompass $\frac{1}{2}$ of the total unit. It is highly probable that two fiberglass pieces would be molded off of this $\frac{1}{2}$ mold.

The one-off mold for the $11^{\prime}-3^{\prime \prime}$ radius diffuser would encompass $1 / 10$ of the total unit. This mold would have to be carried to a further degree of sophistication, in order tc fabricate 10 molded pieces off a oné-off mold. The $18^{\prime}-0^{\prime \prime}$ radius diffuser mold would encompass $1 / 16$ of a total unit. A higher degree of sophistication would also be obtained on this part in order to mold 16 pieces off of this one-off mold.

$$
4^{\prime}-6^{\prime \prime}
$$

One-off Mold Costs Ea. $\quad \$ 14,048$

\section{$11^{\prime}-3^{\prime \prime}$}

$\$ 8,508$

$\underline{18^{\prime}-0^{\prime \prime}}$ Sensitivity

$\$ 8,607$ $\$ 14,526$

One-Off Diffuser/Shroud/Set

(From one-off mold)

$1 / 8$ " skins

$\$ 4,482$

$\$ 16,402$

$\$ 17,442$

$\$ 38,618$

3/16" skins

$\$ 4,716$

$\$ 17,316$

$\$ 18,560$

$\$ 39,818$ 


\section{PRODUCTION TOOLING COSTS}

These would be FRP molds intended to be used for continuing production. The life of these molds depends greatly on the production rate the molds are used at. A reasonable rate has been shown on the graphs on pages $20,21,22$. One production mold produces the following portion of the Diffuser/Shroud:
$4^{\prime}-6^{\prime \prime}$
$11^{\prime}-3^{\prime \prime}$
$11^{\prime}-3^{\prime \prime}$
$18^{\prime}-0^{\prime \prime}$
$\frac{1}{2}$
$1 / 10$
Sensitivity
$1 / 10$
$1 / 16$

Once the initial piece of tooling has been fabricated, there is a cost reduction involved in making further sets of tooling.

These costs are reflected below:

$$
\underline{4^{\prime}-6^{\prime \prime}} \quad \underline{11^{\prime}-3^{\prime \prime}} \quad \underline{11^{\prime}-3^{\prime \prime}} \quad \underline{18^{\prime}-0^{\prime \prime}}
$$

Initial Production

Tooling-1 Mold

$\begin{array}{llll}\$ 14,930 & \$ 14,915 & \$ 15,213 & \$ 18,979 \\ \$ 14,356 & \$ 14,303 & \$ 14,464 & \$ 17,777\end{array}$

A11 costs FOB Portsmouth, Rhode Island 


\section{DIFFUSER/SHROUD PER PART COSTS}

The following is a breakdown of the material and labor breakdown for each individual size diffuser/shroud. ( $30^{\circ}$ half-angle)

$1 / 8^{\prime \prime}$ Skins

$\frac{4^{\prime}-6^{\prime \prime}}{\frac{648.33}{112}}$
Materia1 \$

Labor Hours

$$
\frac{11^{\prime}-3^{\prime \prime}}{\$ 3,721.81}
$$

$3 / 16^{\prime \prime}$ Skins

Material \$

Labor Hours

Diffuser Lrai, fT.

Diffuger Arrerts

$\therefore 76$

\$ 835.47

112

4

2.79

If these numbers were used to calculate a selling results would be the following: $\underline{11^{\prime}-3^{\prime \prime}}$

$\$ 12,290$

$\$ 13,204$

\begin{tabular}{|c|}
\hline$\frac{11^{\prime}-3^{\prime \prime}}{4,553.26}$ \\
\hline
\end{tabular}

\section{Sensitivity}

Sensitivity

$\begin{array}{cc}\$ 5,447.79 & \$ 13,994.75 \\ 570 & 1,152 \\ 12.5 & 16 \\ 3.05 & 2.78\end{array}$

$1 / 8^{\prime \prime}$ Skins

$\$ 2,455$

$11^{\prime}-3^{\prime \prime}$

$18^{\prime}-0^{\prime \prime}$

3/16" Skins

$\$ 2,689$

$\$ 14,063$

$\$ 33,213$

$\$ 15,182$

$\$ 34,413$ 


\begin{tabular}{|c|c|c|c|c|}
\hline & $4^{\prime}-6^{\prime \prime}$ & $\underline{11^{\prime}-3^{\prime \prime} *}$ & $11^{\prime}-3^{\prime \prime} *$ & $18^{\prime}-0^{\prime \prime} *$ \\
\hline Segments/Truckload & 9 Segments & 11 Segments & 11 Segments & 11 Segments \\
\hline Denver, Colorado & $\$ 2,800$ & $\$ 3,240$ & $\$ 3,240$ & $\$ 3,240$ \\
\hline Houston, Texas & 2,400 & 2,800 & 2,800 & 2,800 \\
\hline Los Angeles, California & 4,200 & 4,760 & 4,760 & 4,760 \\
\hline Bethpage, New York & 475 & 635 & 635 & 635 \\
\hline Miami, Florida & 2,175 & 2,630 & 2,630 & 2,630 \\
\hline
\end{tabular}

* Indicates it would be a permit load for width 
$4^{\prime}-6^{\prime \prime}$ RADIUS GAC-10

$11-8-79$

8'-O" WIDE LOAD

11,000 \#OAD

9 COMPLETE SETS

SCALE: $1 / 4^{\prime \prime}-1^{\prime}-O^{\prime \prime}$

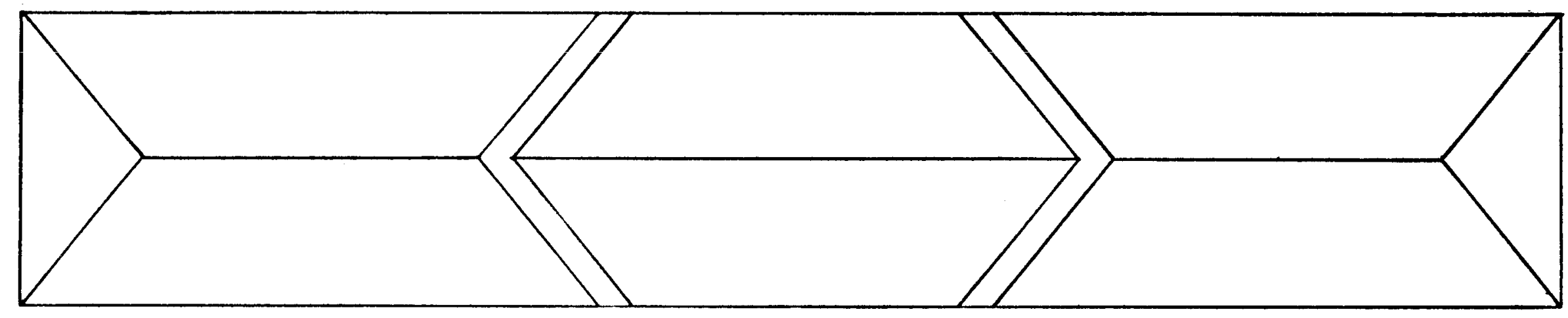

$\stackrel{?}{\infty}$
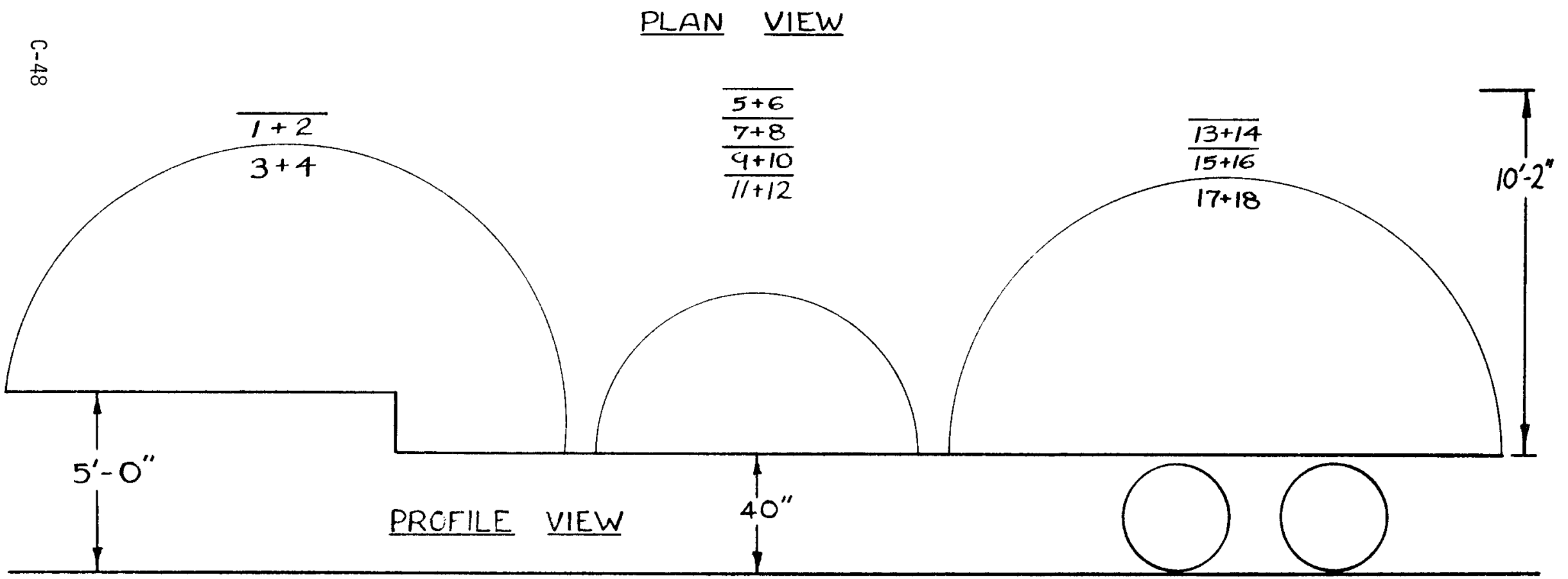
11 -3" RADIUS GAC - 11

$11-8-79$

10'-O" WIDE LOAD

7300 LOAD

I COMPLETE SET

SCALE: $1 / 4^{\prime \prime}=1^{\prime}-O^{\prime \prime}$

1
1
0

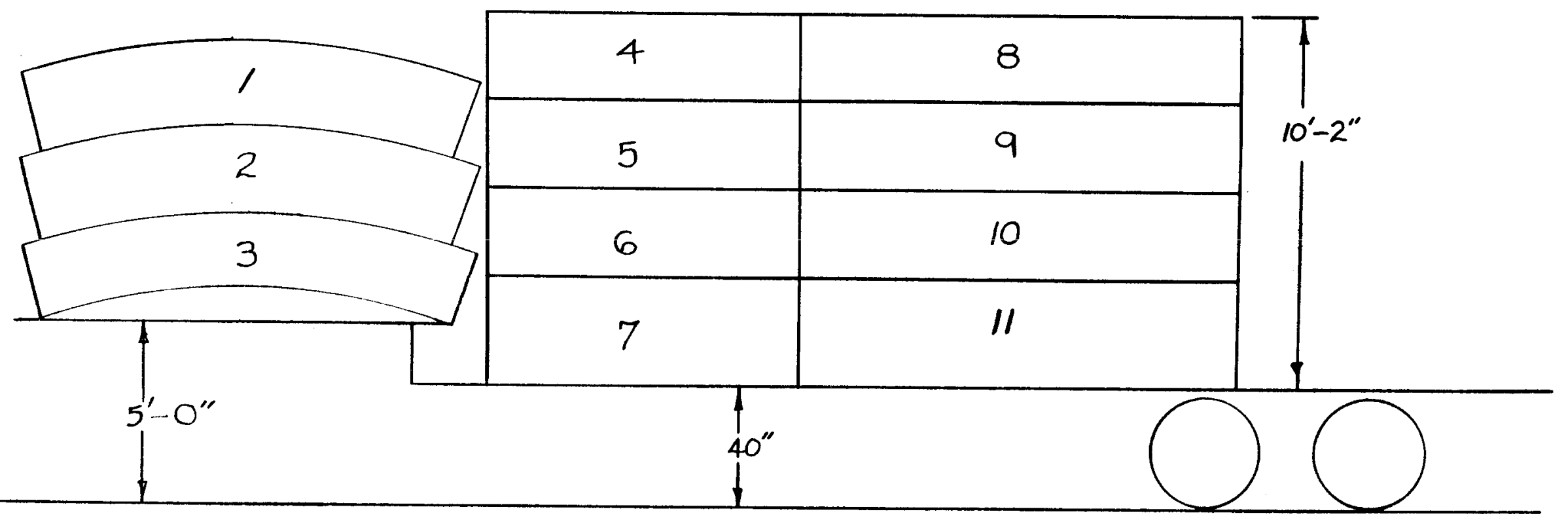


18'-O"RADIUS GAC-12

$11-8-79$

$12^{\prime}-O^{\prime \prime}$ WIDE LOAD

11000 \# $\angle O A D$

$\|$ SECTIONS $=" \mathrm{~K}$

SCALE: $1 / 4 "=1 "-O^{\prime \prime}$

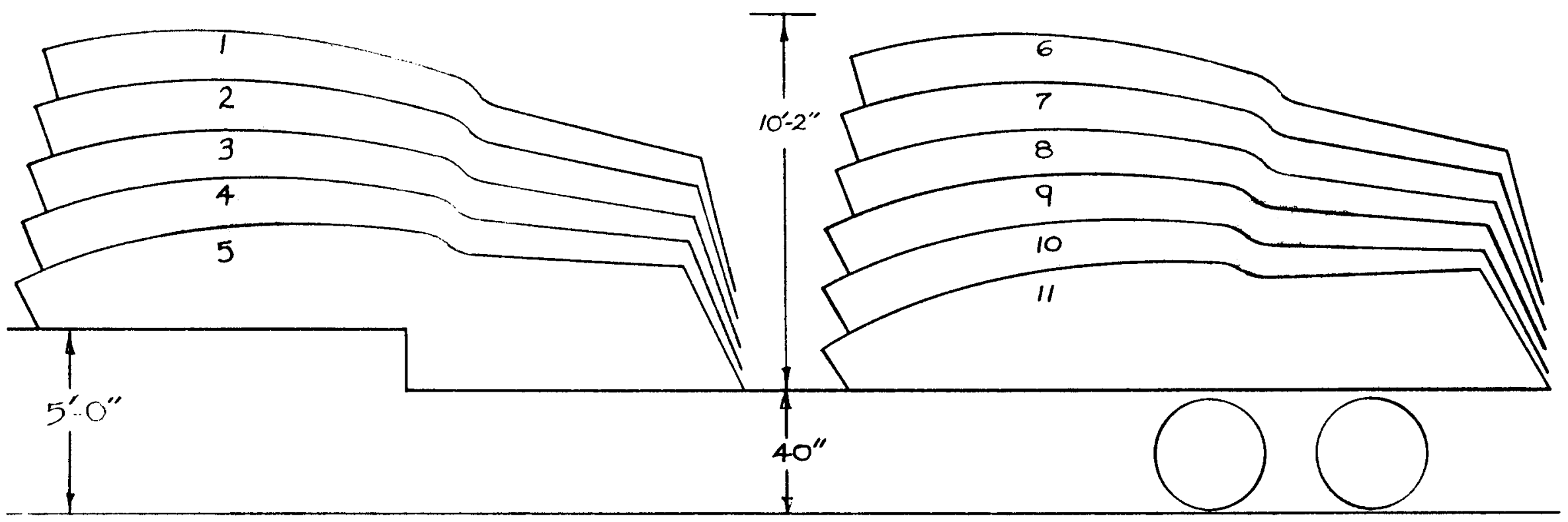




\section{SOURCES}

Owens-Corning Fiberglass

Bean Fiberglass

Henry \& Frick Fiberglass Dist.

United States Steel, Chemical Division

Koppers Chemical

Reichold Chemical

Glidden Coatinge \& Chemicals
Cleveland, Ohio

Jaffrey, New Hampshire

Dedham, Massachusetts

Linden, New Jersey

Pittsburgh, Pennsylvania

Detroit, Michigan

Reading, Pennsylvania 
Task 6 - Prepare a final report describing all work done under Task 1 to Task 5. The report is to include design sketches, drawings, design data, reference sources, production plan and fabrication descriptions and cost estimate results. Basic data developed and used in this investigation may be included in appendixes to the report. A summary of the investigation and its results is to be included in the report.

As this Task is being submitted concurrently with Tasks 2-5, much of the data requested above will not be repeated within this Task, as it is included within this overall report. However, it is appropriate to review this investigation and its findings.

During the initial study of the design it became apparent that with the cooperation of Grumman Aerospace Corporation working with Pearson Yachts an item with the magnitude of the Diffuser-Augmented Wind Turbine could be conceived and manufactured with existing state-of-the-art processes that are readily available with a large producer of fiberglass reinforced plastics capability. At this juncture, it doesn't appear that there would be any major obstacles (manpower, talent, or manufacturing processes) that would have to be overcome to produce this item.

It is felt that the FRP D.A.W.T. would be a viable product because of its relatively low weight, low cost, and proven durability of material. All of these advantages are reflected from production to freight costs to site fabrication to visual environmental acceptance.

The availability of material, in this day and age, must be considered on a project of this magnitude. The sources that Pearson Yachts uses for our resins and fiberglass have proven over the years to be reliable and consistent. Our prime supplier 
of fiberglass is owens-Corning Fiberglass. They are the largest supplier of fiberglass in the country producing approximately 520 million pounds of the 800 million pounds produced nationwide. Recently they built a facility in Amarillo, Texas, which has the capability to produce 200 million pounds of fiberglass per year. This plant was located in Amarillo because it is situated over a very large gas field giving them a very distinct advantage of fuel availability. All other plants have dual fuel sources. We also use fiberglass from Pittsburgh plate Glass (PPG), Certainteed Fiberglass, and Bean Fiberglass. Certainteed also has recently completed building a facility in Texas for the same reasons as owensCorning.

Our prime supplier of polyester resin is United States Steel, Chemical Division. We also use resin supplied by Koppers Chemical and Reichold Chemical. These suppliers represent the three largest producers of polyester resins in the United States. Pearson Yachts has carefully selected its suppliers over the years to be able to support, supply, and stand behind the products we manufacture. To date, inspite of oil embargoes, trucking strikes, and allocations, Pearson Yachts has never altered a Production Schedule due to the inability of these suppliers to deliver material at the agreed upon price and on time.

Based on weight, cost, flexibility, endurance, and visual color acceptance, it appears that fiberglass reinforced plastics is a viable material with which to manufacture Diffuser-Augmented Wind Turbines. 


\section{APPENDIX D \\ DETAILS OF FOUNDATION DESIGNS AND COSTING FOR THREE SIZES OF DAWTS}

$D-1$ 
D-2 


\section{General Descriptions:}

Foundation Design No. 1

The circular shaft of the windmill tower is anchored to a circular concrete footing. The diameter and depth of footing depends on the vertical and horizontal forces transmitted to the footing by the shaft and on soil conditions; the dimensions shown in Fig. D-1 are based on forces generated by a $9 \mathrm{ft}$ rotor and a soil friction angle of $30^{\circ}$. For the footing, loading conditions are critical when the horizontal wind force is a maximum. The overturning moment generated by this force is resisted by passive earth pressures acting on the side of the footing and by an unequal ground pressure distribution at the base of the footing.

This type of foundation is economical for the smaller DAWTs when soil conditions permit excavation for the footing without bracing, and mobilization of pile driving equipment is costly.

Foundation Design No. 2

An alternative to Design \# 1 is a reinforced concrete circular slab foundation at a shallow depth. The overturning moment imposed by wind forces on the slab is resisted by a shift in the distribution of ground pressures. Reinforcment of the slab is necessary because of the moments and shear induced in the slab by the ground pressures. The diameter of the slab is determined on the condition that negative (tensile) ground pressures are not allowed.

This type of foundation may be used practically under any soil conditions but the reinforcing required for the relatively large diameter slab makes it uneconomical where piling (shown for a $36 \mathrm{ft}$ diameter rotor) is feasible.

Foundation Design No. 3

This type of foundation consists of piles and a reinforced concrete pile cap in which the shaft of the DAWT tower is anchored (shown by Fig. D-3). The overturning moment imposed on the pile cape by wind forces is resisted by downward and upward directed pile forces. These are highest in the piles farthest from the center in the direction of the wind. The magnitude of the downward and upward directed pile forces because of the overturning moment is equal in piles symmetrical to the axis perpendicular to the wind direction. The downward pile force from the weight of the structure and pile cap is distributed equaliy among the piles.

Timber piles are most economical and provide good uplift capacity under most conditions. If ground water level is below the pile cap, the piles have to be treated. 


\section{Design Details and Costing:}

Foundation Design No. 1 - For DAWT 9

Ref. Fig. D-1

p $3000 \mathrm{lbs}$

$w=x(3)^{2} \times 12 \times 1251 \mathrm{bs} / \mathrm{ft}^{3}=42000 \mathrm{lbs}$

Avg. pressure $=45000 / 28.27=1590 \mathrm{lbs} / \mathrm{ft}^{2}$

$=2 \times 1590=31801 \mathrm{bs} / \mathrm{ft}^{2}$

which is $0 . K$. for average soil conditions

Anchor bolt design:

Total X-section area $=(31 / 42) \times 31^{\prime \prime} \times \quad \times 1 / 4=18 \mathrm{in}^{2}$

$=24,1$ in diam., anchor bolts

Structural steel plate and collar:

$42 \times \times 12 \times 1 / 4=396 \mathrm{in}^{3}$

$32 \times \times 4 \times 1 / 4=106$ in $^{3}$

$500 \mathrm{in}^{3}$ is equivalent to $140 \mathrm{lbs}$.

Passive Resistances:

$F_{2}=1320 \mathrm{lbs} / \mathrm{ft}^{2} \times 2 / 3 \times 8 \times 6=42240 \mathrm{lbs}$

$F_{1}=F_{2}-H=42240-5800=364401 \mathrm{bs}$

$\mathrm{p} \max =3040 \mathrm{lbs} / \mathrm{ft}^{2} 110 \times 3 \times 12=3960 \mathrm{lbs} / \mathrm{ft}^{2}$

which is $0 . K$.

Moments about " $\mathrm{C}$ "

Overturning: $5780 \times(25 \times 8)=190,700 \mathrm{ft}-1 \mathrm{~b}$ 


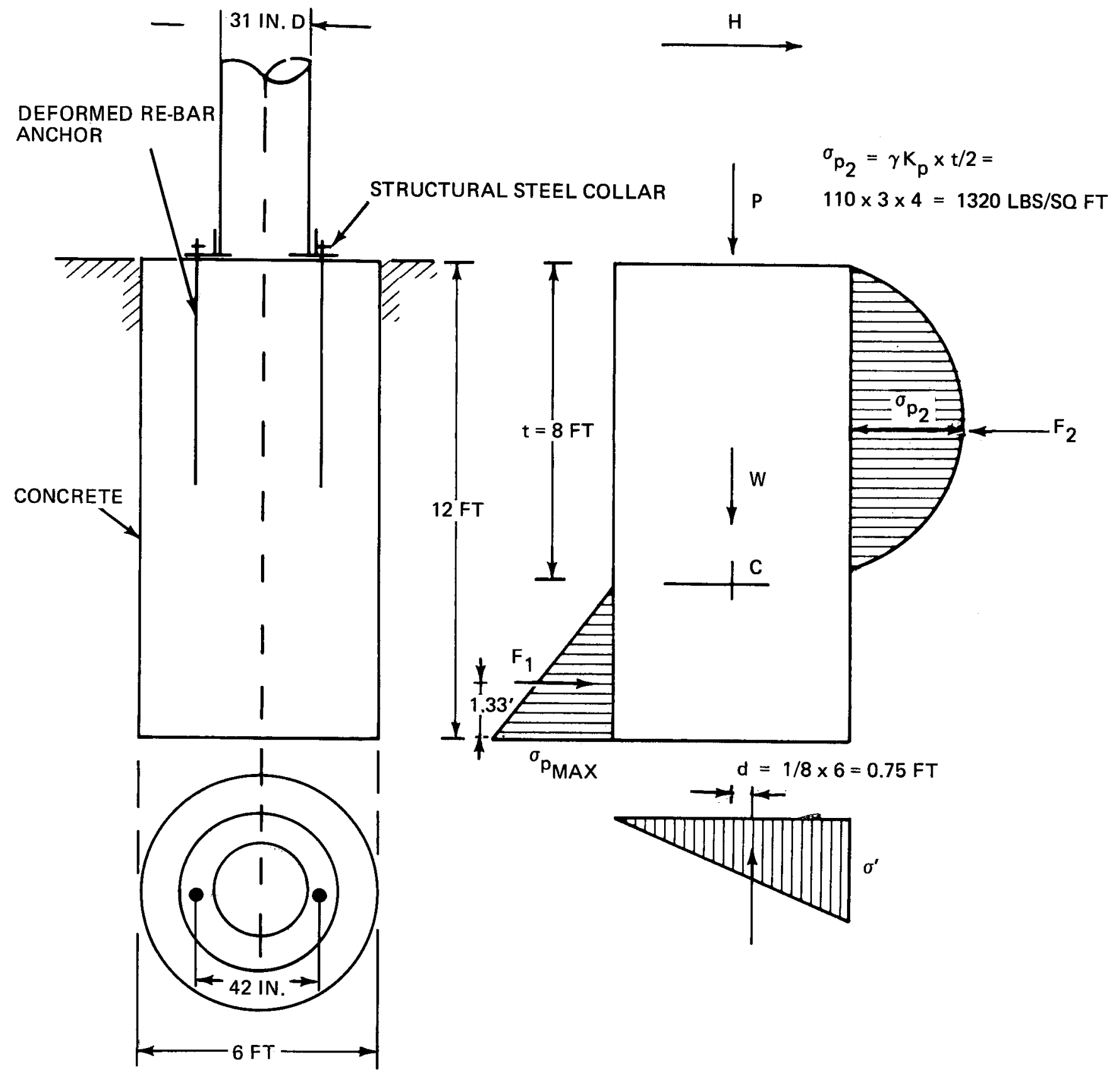

0647-028W

Fig. D-1 Foundation Design No. 1 for DAWT with 9 Ft Dia Rotor 
Foundation Design No. 1 (continued)

Resisting:

$42240 \times 4=168,900$

$45000 \times .75=33,700$

$36440 \times 2.67=97,300$

$300,000 \mathrm{ft}-1 \mathrm{~b}$

$\mathrm{F} . \mathrm{S}=300,000 / 190,700 \quad 1.5$ which is $0 . \mathrm{K}$.

Cost Estimate (using Ref 11)

(Excluding soil exploration, design, and transportation over 15 miles)

Mobilization

$\$ 500$

Common excavation incl. overbreak

$15 \mathrm{cu}$. yd $@ \$ 3.10$

Shoring

200

Concrete, redi-mix, 3000 psi

$15 \mathrm{cu}$. yd $\mathrm{e} \$ 31.65$

475

Anchor bolts, 36" ing.,

$24 \$ 23$

552

Structural St1. 140 1bs @ $\$ .51$

71

Sub total $\$ 1845$

Round-off $\quad 155$

Total $\$ 2000$ 
Foundation Design No. 2 (For DAWT 22.5)

Slab design of reinforced concrete without piles.

$D=28 \mathrm{ft}$, slab thickness $=5 \mathrm{ft}$.

0verturning moment about bottom :

$$
(28.75+5) \times 36110=1,220,000 \mathrm{ft}-1 \mathrm{~b}
$$

Weight of superstructure 15,000 lbs

Weight of slab

$$
\begin{aligned}
(14)^{2} \times \times 5= & 3080 \mathrm{ft}^{3} \\
& \frac{\times 125 \mathrm{lbs} / \mathrm{ft}^{3}}{385,600 \mathrm{lbs}}
\end{aligned}
$$$$
\text { Total weight }=400,000 \mathrm{lbs}
$$

$S 7 a b$ area $=616 \mathrm{ft}^{2}$

Avg. pressure $=400,000 / 616=650$ psf $\quad\left(\right.$ which are $\left.0 . k_{\text {. }}\right)$

Max. edge pressure $=2 \times 650=1300$ psf

Ref. to Fig. D-2

$\underline{\text { Resisting Moment }}$

$400,000 \times 28 / 8=1,400,000 \mathrm{ft}-1 \mathrm{~b}$ (which is $0 . \mathrm{K}_{\text {.) }}$ )

Anchor bolts:

Total $x$ - sectional area

$72 \times \times 1 / 2=113 \mathrm{in}^{2}$

$11 / 2$ in. anchor bolts $=113 / 1.17=96$ (36 "long)

Structural steel:

$$
\begin{aligned}
& \text { Plate: } 80 \times \quad \times 10 \times 1 / 4=630 \mathrm{in}^{3} \\
& \text { Collar: } 72 \times \quad \times 6 \times 1 / 2=680 \mathrm{in}^{3}
\end{aligned}
$$

$$
\text { Total }=1310 \mathrm{in}^{3} \text { equiv. to } 370 \mathrm{lbs} \text {. }
$$






Fig. D-2 Foundation Design No. 2 for DAWT with 22.5 Ft Dia Rotor 
Foundation Design No. 2 (continued)

Cost Estimate (using Ref 11)

Mobilization

$\$ 1000$

Common excavation (120 cu yd e \$3.10) 372

Reinf. Concrete slab (114 cu yd @ \$82.) 9348

Anchor bolts, 1 1/2 "diam., 36 " long,

96 ? $\$ 34$

3264

Structural steel, 3701 bs $\$ .51$

190

Rivets, mylar, etc.

200

Sub total $\$ 14,374$

Round of $f$ and Contingency

$\underline{1,626}$

Total

$\$ 16,000$

(Excludes exploratory drilling (not essential for slab foundation), design, and transportation over 15 miles) 
Foundation Design No. 3 (for DAWT 36)

Ref Fig. D-3

Weight of Superstructure

$52,5001 \mathrm{bs}$

Pile Cap: $(12.5)^{2} \times 1 \times 4=1960 \mathrm{ft}^{3}$

$$
\begin{aligned}
\times 125 \mathrm{lb} / \mathrm{ft} & =\frac{254,000 \mathrm{lbs}}{306,000 \mathrm{lbs}} \\
\text { Total } &
\end{aligned}
$$

Overturning moment about point $A$ :

$$
(40+4) \times 92,400=4,066,000 \mathrm{ft}-1 \mathrm{~b}
$$

If $P=$ pile pull capacity

Moment :

$$
\begin{aligned}
2 \mathrm{P} \times 11 & =22 \mathrm{P} \\
4 \mathrm{P} \times 11 \cos 18^{\circ} & =41.8 \mathrm{P} \\
4 \mathrm{P} \times 11 \cos 36^{\circ} & =35.6 \mathrm{P} \\
4 \mathrm{P} \times 11 \cos 54^{\circ} & =25.9 \mathrm{P} \\
4 \mathrm{P} \times 11 \cos 72^{\circ} \quad & =13.6 \mathrm{P} \\
\text { Total } & =138.9 \mathrm{P}
\end{aligned}
$$

where:

$$
\begin{aligned}
& P=4,066,000 / 138.9=29,270 \mathrm{lbs} \\
& \text { Compressive load }=306,000 / 20=15,300 \text { lbs } \\
& \text { Total compressive load }=45,000 \mathrm{lbs}=22.5 \mathrm{ton} / \mathrm{pile} \\
& \text { which is 0.K. (safe load) } \\
& \text { Pul1 }=14,000 \mathrm{lbs}=7 \text { ton } / \mathrm{pile} \\
& \text { which is } 0 . K \text {. for } 12^{\prime \prime} \text { dia., } 30 \mathrm{ft} \text { long } \\
& \text { timber pile }
\end{aligned}
$$




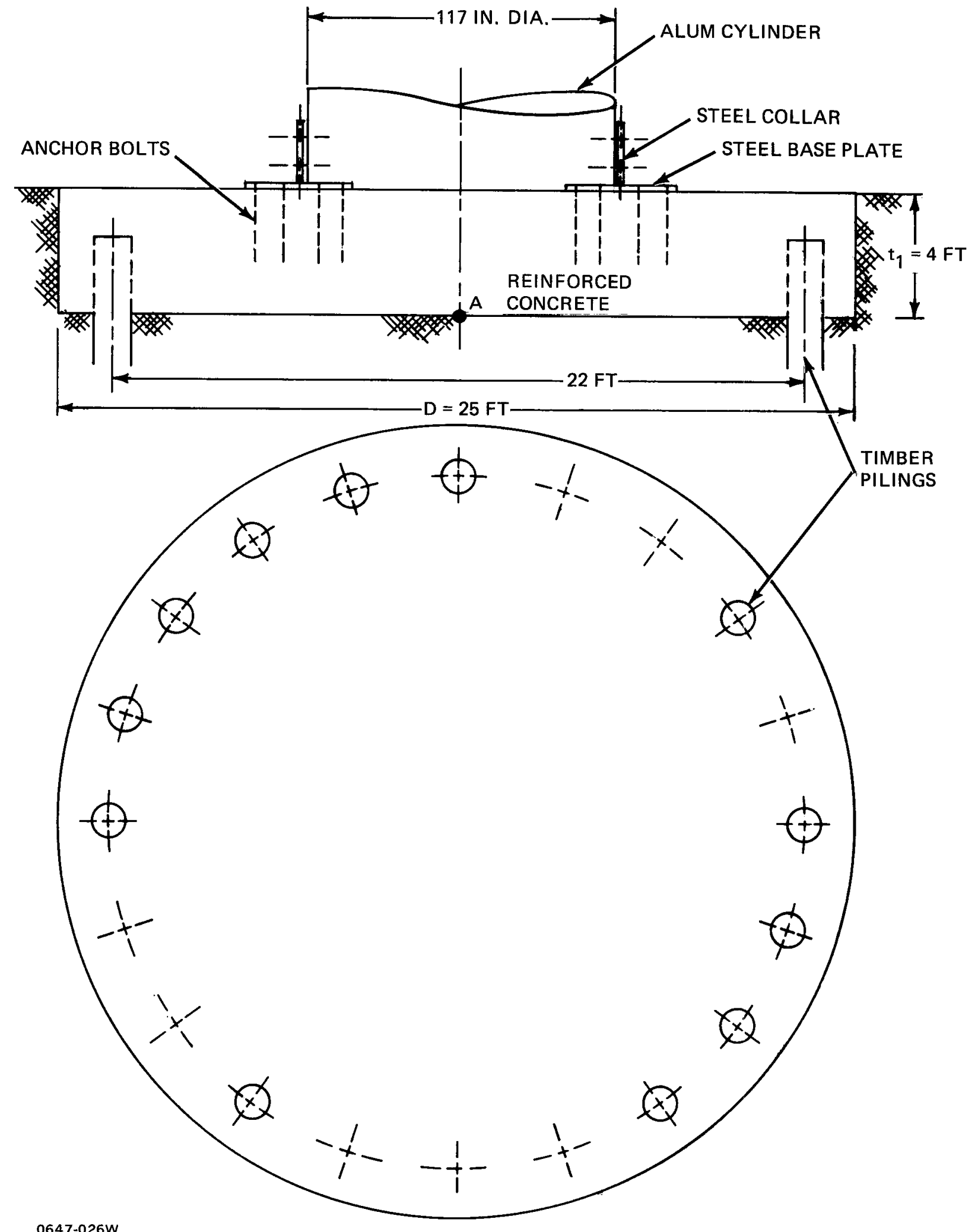

0647-026W

Fig. D-3 Foundation Design No. 3 for DAWT with 36 Ft Dia Rotor 
Foundation Design No. 3 (continued)

\section{Anchor bolts:}

$$
\begin{aligned}
& \text { Cross sectional area } \\
& =117 \times \times 3 / 4=276 \mathrm{in}^{2} \\
& 11 / 2 \text { in diam. }=1.17 \mathrm{in}^{2} \\
& \text { No. of bolts }=234 \\
& \text { Base plate }=120 \times \times 18 \times 1 / 2=3400 \mathrm{in}^{3} \\
& \text { Collar }=120 \times \quad \times 10 \times 3 / 4=2827 \mathrm{in}^{3} \\
& \text { Total }=6227 \mathrm{in}^{3} \quad 1750 \mathrm{lbs}
\end{aligned}
$$

Cost estimate (using Ref 11)

Mobilization

Excavation, (80 cu yds o $\$ 3.10$ )

Pile Driving, $600 \mathrm{ft}, 12 \mathrm{in.}$ dia. treated

$$
\text { timber piles } 0 \$ 6.85
$$

Encasement with wire mesh and tube

Reinforced concrete slab, 73 cu yd $0 \$ 82$

Anchor bolts, 18 in. diam, 36 in. long,

$$
234 \text { @ } \$ 34
$$

Structural steel, 1750 lbs @ $\$ .51$

Rivets, mylar, etc. to join alum. and stl.

Sub total

Round off and contingencies

Total

(Excludes exploratory drilling, design and transportation over 15 miles)
7956

$\$ 3000$

892

500

$\$ 22,870$

$\underline{1,130}$

$\$ 24,000$ 


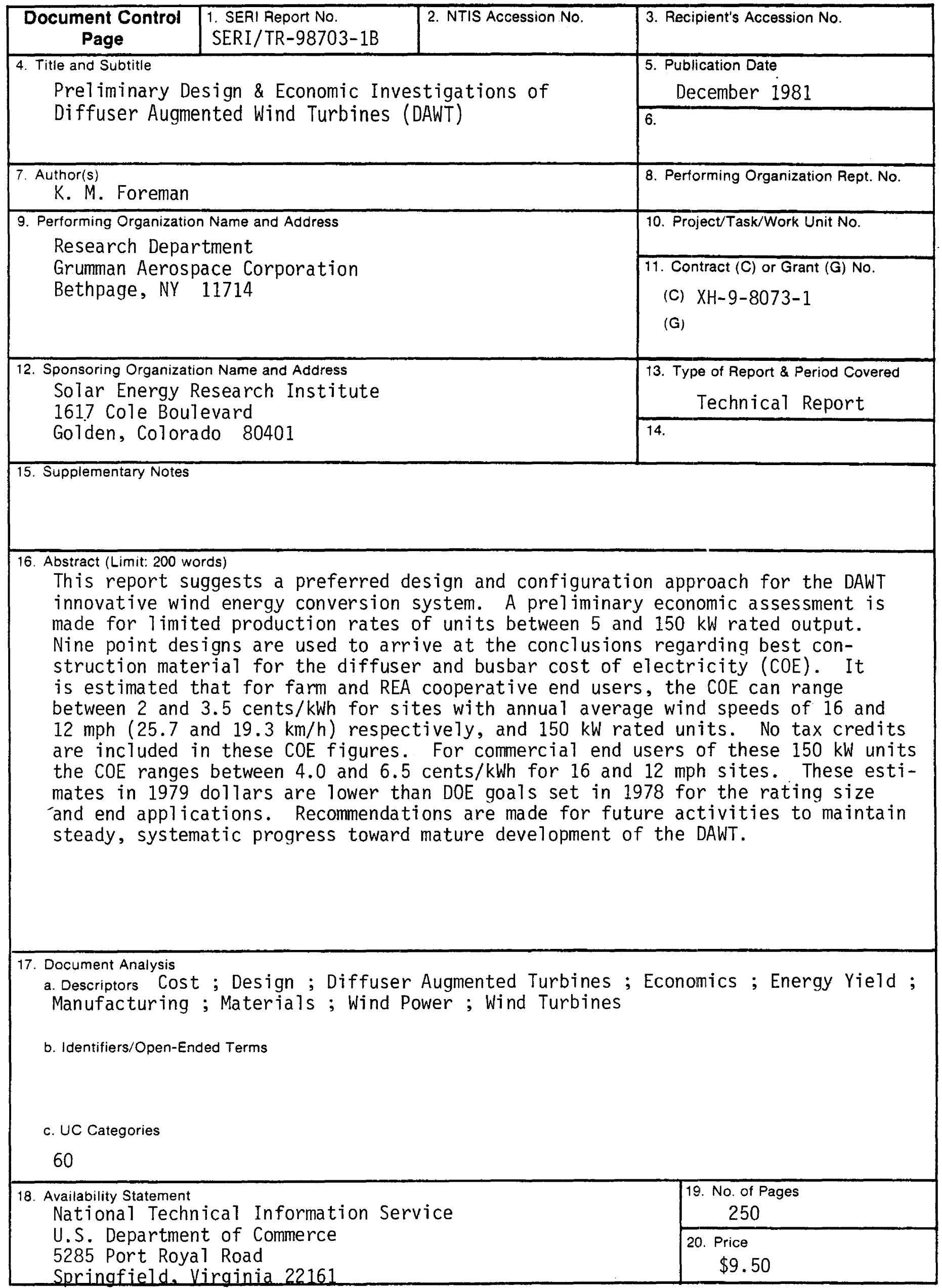

